\title{
Myeloperoxidase in immune mediated vascular disorders
}

Citation for published version (APA):

Rutgers, A. (2004). Myeloperoxidase in immune mediated vascular disorders. [Doctoral Thesis, Maastricht University]. Universitaire Pers Maastricht. https://doi.org/10.26481/dis.20041001ar

Document status and date:

Published: 01/01/2004

DOI:

10.26481/dis.20041001ar

Document Version:

Publisher's PDF, also known as Version of record

\section{Please check the document version of this publication:}

- A submitted manuscript is the version of the article upon submission and before peer-review. There can be important differences between the submitted version and the official published version of record.

People interested in the research are advised to contact the author for the final version of the publication, or visit the DOI to the publisher's website.

- The final author version and the galley proof are versions of the publication after peer review.

- The final published version features the final layout of the paper including the volume, issue and page numbers.

Link to publication

\footnotetext{
General rights rights.

- You may freely distribute the URL identifying the publication in the public portal. please follow below link for the End User Agreement:

www.umlib.nl/taverne-license

Take down policy

If you believe that this document breaches copyright please contact us at:

repository@maastrichtuniversity.nl

providing details and we will investigate your claim.
}

Copyright and moral rights for the publications made accessible in the public portal are retained by the authors and/or other copyright owners and it is a condition of accessing publications that users recognise and abide by the legal requirements associated with these

- Users may download and print one copy of any publication from the public portal for the purpose of private study or research.

- You may not further distribute the material or use it for any profit-making activity or commercial gain

If the publication is distributed under the terms of Article $25 \mathrm{fa}$ of the Dutch Copyright Act, indicated by the "Taverne" license above, 
Myeloperoxidase in immune mediated vascular disorders 
(C) A. Rutgers, Maastricht 2004

ISBN 90-9018534-8

Vormgeving en druk: Datawyse / Universitaire Pers Maastricht 


\section{Myeloperoxidase in immune mediated vascular disorders}

\section{Proefschrift}

ter verkrijging van de graad van doctor

aan de Universiteit Maastricht,

op gezag van de Rector Magnificus,

Prof. mr. G.P.M.F. Mols

volgens het besluit van het College van Decanen,

in het openbaar te verdedigen

op vrijdag 1 oktober 2004 om 14:00 uur

door
Abraham Rutgers
geboren op 29 augustus 1975
te Hellendoorn 


\section{Promotor}

Prof. dr. J.W. Cohen Tervaert

\section{Copromotor}

Dr. P. Heeringa

\section{Beoordelingscommissie}

Prof. dr. K.M.L. Leunissen (voorzitter)

Prof. dr. M.J.A.P. Daemen

Prof. dr. C. Kallenberg (Rijksuniversiteit Groningen)

Dr. N. Moguilevsky (Université Libre de Bruxelles, Belgium)

Prof. dr. E.F.M. Wouters 
aan mijn ouders en Maartje 


\section{Contents}

CHAPTER 1

General introduction

Myeloperoxidase in immune mediated vascular disorders

CHAPTER 2

ANCA and anti-GBM antibodies in diagnosis and follow-up of vasculitic disease

CHAPTER 3

ANCA-GBM Dot-Blot: Evaluation of an assay in the differential diagnosis of patients presenting with rapidly progressive glomerulonephritis

CHAPTER 4

High affinity of anti-GBM antibodies from Goodpasture and transplanted Alport patients to $\alpha 3$ (IV)NC 1 collagen

CHAPTER 5

Coexistence of anti-GBM antibodies and MPO-ANCA in crescentic glomerulonephritis

CHAPTER 6

Neutrophil myeloperoxidase activity and the influence of two single nucleotide promoter polymorphisms.

CHAPTER 7

The myeloperoxidase 463 promoter polymorphism is related to the pulse wave velocity in subjects with hypertension

CHAPTER 8

Intra-neutrophil myeloperoxidase activity in ANCA associated vasculitis

CHAPTER 9

Review: The role of myeloperoxidase in the pathogenesis of systemic vasculitis

CHAPTER 10

Summary, conclusions and general discussion

NEDERLANDSE SAMENVATTING

DANKWOORD

CURRICULUM VITAE

PUBLICATIES 


\section{CHAPTER 1}

\section{General introduction}

Myeloperoxidase in immune mediated vascular disorders 


\section{Introduction}

Myeloperoxidase (MPO; EC 1.11.1.7) is a heme containing peroxidase expressed and stored in monocyte and neutrophil granulocyte precursors. With the production of hypochlorous acid (bleach) and other toxic intermediates it is part of the host defense system of neutrophils and monocytes'. However, recent evidence indicates that MPO also plays an important pathophysiological role in other, non-infectious diseases, such as immune mediated vascular disorders. Immune mediated vascular disorders comprise a large group of vascular diseases in which the immune system plays an important role and can be roughly divided into two groups. the vasculitides and atherosclerotic diseases. In atherosclerotic disease cumulating evidence suggests that the enzymatic functions of MPO are vital in pathogenesis, whereas in certain types of vasculitides MPO plays an additional pathogenic role as antigenic target.

This chapter will give a brief overview of the different vasculitides, atherosclerotic disease, MPO, and the role of MPO in these diseases. Subsequently, the aim of this thesis will be described.

\section{The vasculitides}

Vasculitis is a condition characterized by acute inflammation of blood vessels. This can lead to microscopic as well as macroscopic damage to the vascular wall and ischemic damage to the organs supplied by these vessels. Vessel aneurysm, stenosis or occlusion with thrombosis can be macroscopic characteristics. Microscopically, there is evidence of immune cell infiltration, intima proliferation, fibrinoid necrosis, and loss of vessel wall integrity leading to erythrocyte and fibrin extravasation. Clinical manifestations depend on the localization, magnitude and type of vessels involved 2,3 .

Vasculitis can be a primary or secondary disease. Secondary causes include infectious disease, connective tissue disease and drug reactions. In many of these secondary disorders immune complexes, either deposited from the circulation or formed in situ are involved in pathogenesis. When no secondary cause can be found, the vasculitis is primary. The primary vasculitides (figure 1 and table 1) are idiopathic systemic diseases with a variable clinical expression (for clinical characteristics see chapter 2, table 2).

Within the group of the primary vasculitides the antibody mediated or associated vasculitides are of particular interest. These vasculitides primarily affect the small vessels and are characterized by the presence of specific autoantibodies like anti-neutrophil cytoplasmic antibodies (ANCA) and anti-glomerular basement membrane (anti-GBM) antibodies (table 1).

ANCA have first been described in 1982 by Davies et al in patients with renal vasculitis ${ }^{4}$. In the years thereafter ANCA have been specifically associated with Wegener's granulomatosis, microscopic polyangiitis, Churg-Strauss syndrome and with idiopathic pauci-immune necrotizing glomerulonephritis. Basically, two distinct patterns can be distinguished when ANCA are detected by indirect immunofluorescence on ethanol fixed neutrophils, i.e. a granular cytoplasmic neutrophil fluorescence with central interlobular accentuation (C-ANCA) and a perinuclear pattern ( $p$-ANCA) often with nuclear extension (see figure 2$)^{5}$. The $c-$ and p-ANCA found in vasculitis patients are mostly directed against the neutrophil azurophilic 
Small-Vessel Vasculitis

(e.g. microscopic polyangiitis, Wegener's granulomatosis)

Medium-Sized-Vessel Vasculitis

(e.g., polyarteritis nodoso, Kawasaki's disease)

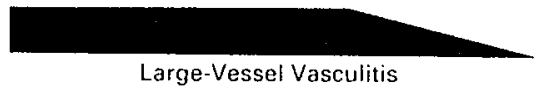

(e.g. giant-cell arteritis, Takayasu's arteritis)

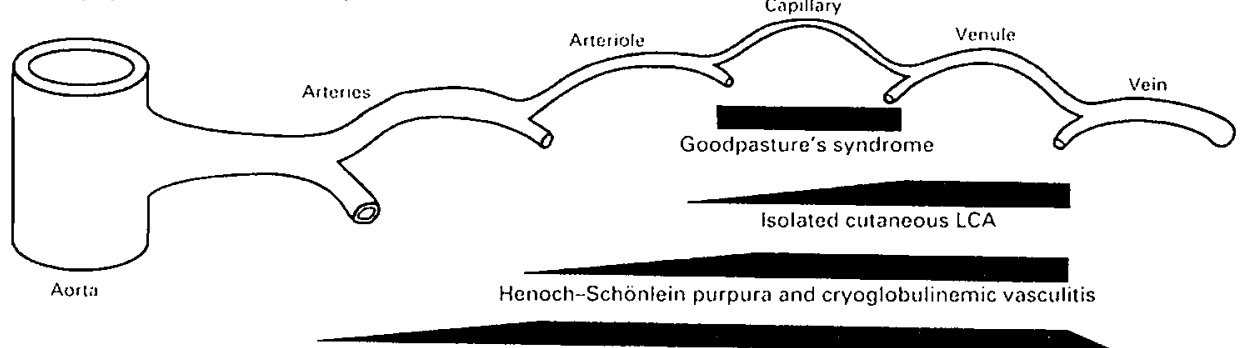

Microscopic polyangiitis, Wegener's granulomatosis, and Churg-Strauss syndrome

Figure 1. Primary vasculitides ${ }^{3}$

Table 1. Primary vasculitides (adapted from ${ }^{2}$ )

\begin{tabular}{ll}
\hline Type of vessels (primarily) involved & Diseases \\
\hline Large vessels & Giant cell arteriitis \\
Medium-sized vessels & Takayasu's arteritis \\
& $\begin{array}{l}\text { Polyarteritis nodosa } \\
\text { Kawasaki disease }\end{array}$ \\
Small vessels (often antibody associated) & \\
Not ANCA associated & Henoch-Schönlein purpura \\
& Essential Cryoglobulinemic vasculitis \\
& Cutaneous leukocytoclastic angiitis \\
ANCA associated & Wegener's granulomatosis \\
& Churg Strauss syndrome \\
& Microscopic polyangiitis \\
Anti-GBM mediated & Goodpasture disease \\
& Anti-GBM nephritis \\
& Anti-GBM alveolitis \\
\hline
\end{tabular}

ANCA, Anti-neutrophil cytoplasmic antibodies; GBM, glomerular basement membrane. 


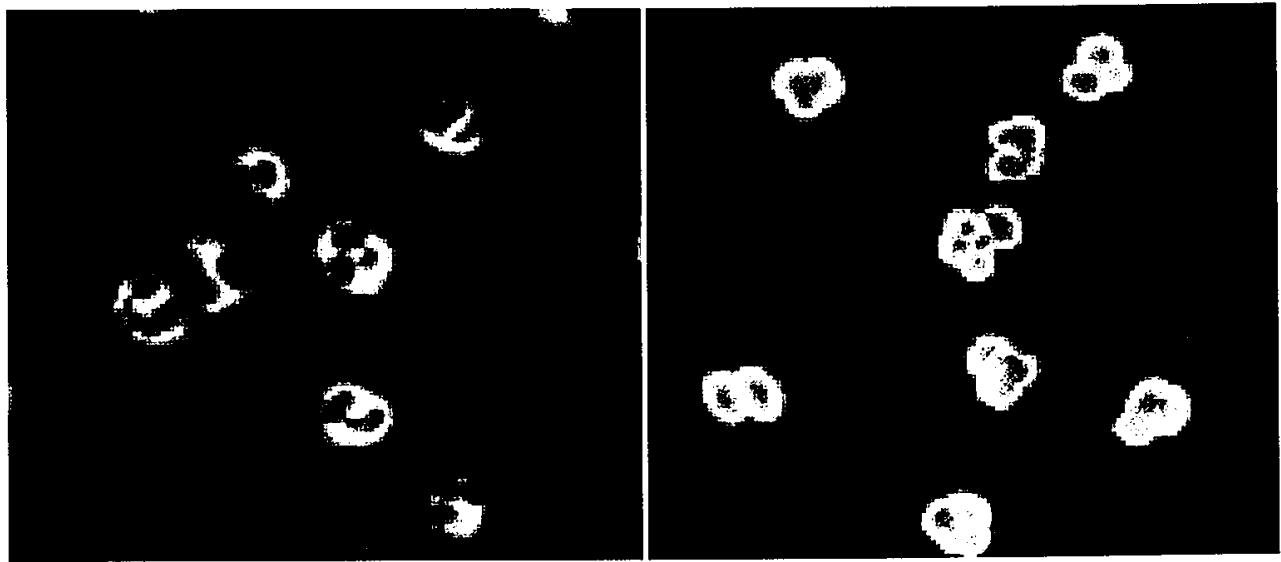

Figure 2. Anti-neutrophil cytoplasmic antibodies (ANCA) detection by indirect immunofluorescence on ethanol fixed neutrophil granulocytes. The left picture shows a cytoplasmic neutrophil fluorescence with central interlobular accentuation, i.e. C-ANCA. The right picture shows a perinuclear staining pattern with nuclear extension, i.e. p-ANCA.

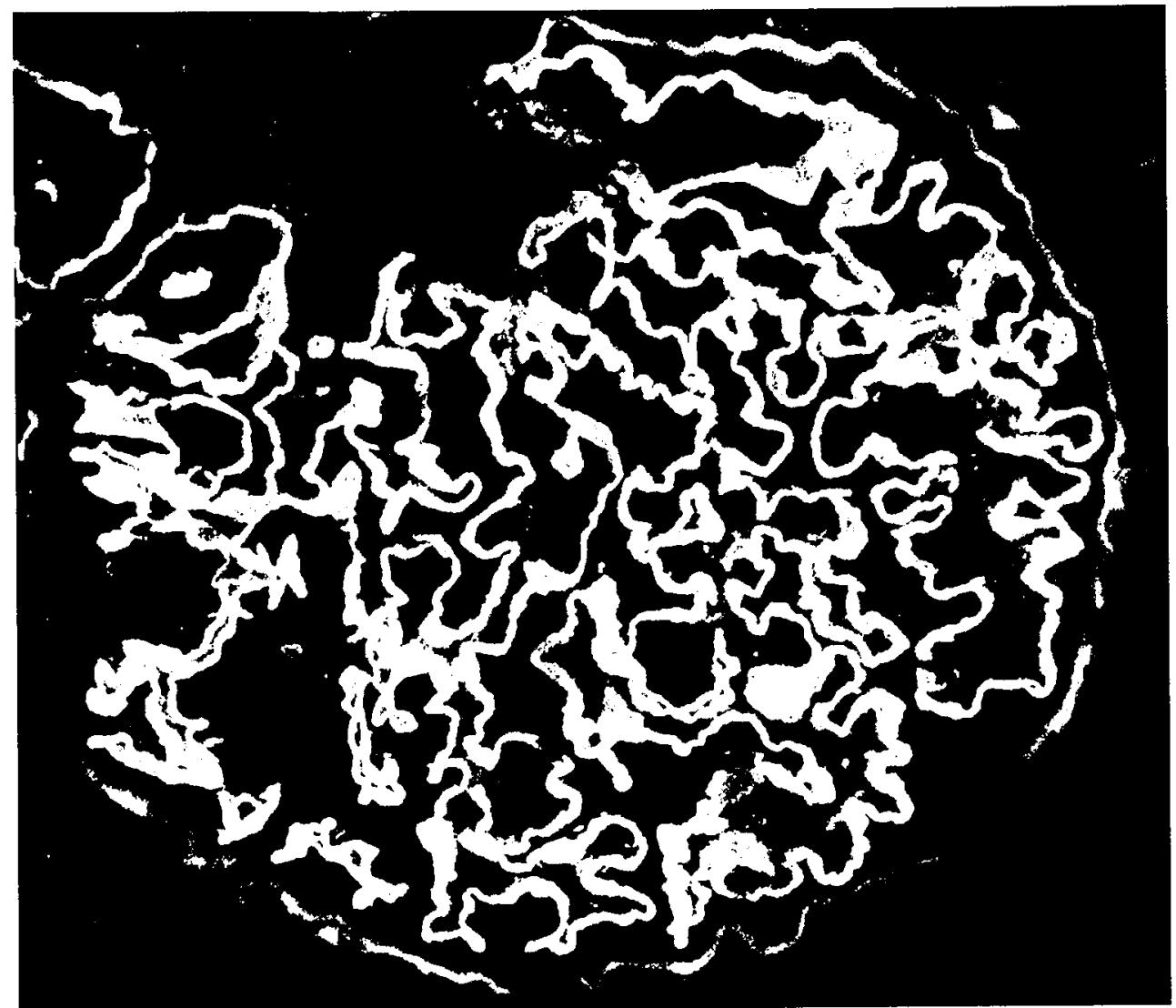

Figure 3. Direct immunofluorescence of glomerulus in a kidney biopsy showing linear staining of glomerular basement membrane (GBM) by patients' anti-GBM antibodies. 
granule proteins proteinase 3 (PR3) and myeloperoxidase (MPO) respectively, as can be detected by antigen specific assays like enzyme linked immuno sorbent assays (ELISAs), or dot-blot 3,6 .

Anti-GBM antibodies (see figure 3) have first been described in 1967 by Lerner et al and are specifically associated with anti-GBM crescentic nephritis, anti-GBM alveolitis, or pulmonary hemorrhage combined with crescentic glomerulonephritis (i.e. Goodpasture disease) ${ }^{7}$. Interestingly, about $30 \%$ of patients with anti-GBM mediated disease are positive for (MPO-) ANCA as well 8 .

These antibody mediated small vessel vasculitides occur in every age group and can have a devastating disease outcome. Treatment often save lives and organ function when commenced at an early stage and the ability to test for the serologic presence of the auto-antibodies facilitates diagnosis and patient follow-up (chapter 2). Auto-antibody titers often correlate with disease activity and appropriate treatment usually results in decreased or undetectable auto-antibody titers. Moreover, persistently elevated levels of auto-antibodies are associated with adverse outcome or relapse of disease (chapter 9). The presence of antigen (e.g. MPO) to which antibodies can react is crucial in disease development 9.10 .

\section{Atherosclerosis}

Atherosclerosis is the underlying cause for heart attacks, strokes, and peripheral vascular disease and is the major cause of death in western society. It is a vascular disease involving primarily the large- and medium-sized vessels ( $>3 \mathrm{~mm}$ external diameter) ${ }^{11}$. One of the major theories to explain the pathogenesis of atherosclerosis is the response to injury hypothesis ${ }^{12}$. Herein, different sources of injury (e.g. oxidized low density lipoprotein (LDL), shear stress from hypertension, diabetes mellitus, smoke and other toxins, micro-organisms, and immunological) to the endothelium result in endothelial cell dysfunction. This causes increased adherence of monocytes and T cells to the endothelium and increases LDL entrapment in the subendothelial space, either through damaged endothelium or by transcytosis through intact endothelial cells. $L D L$ is then minimally modified by oxidants, inducing endothelial cells to release macrophage colony stimulating factor (M-CSF) and monocyte chemoattractant protein 1 (MCP-1). M-CSF and MCP-1 attract additional monocytes and induce monocyte to macrophage differentiation within the subendothelial space. Subsequently, highly oxidized LDL particles are formed due to the increased production of oxidants by activated macrophages and endothelial cells. Highly oxidized LDL can be taken up by the macrophage scavenging receptor resulting in large lipid laden macrophages, the so called foam cells. Foam cells, together with $T$ cells and smooth muscle cells, form a fatty streak, the earliest lesion observed in atherosclerosis. With ongoing disease, the fatty streak develops into a progressive atherosclerotic lesion which forms the basis for clinically manifest disease such as myocardial infarction, stroke and peripheral vascular disease ${ }^{11,12}$.

The finding of active immunological processes in atherosclerotic plaques together with the observation that circulating markers of inflammation like C-reactive protein, serum fibrinogen, and elevated levels of leukocytes, are consistently associated with atherosclerotic 
disease, has strongly supported the recognition of atherosclerosis as a chronic inflammatory disease $12-17$

\section{Vasculitis and atherosclerosis}

Both vasculitis and atherosclerosis are characterized by an immune mediated vessel directed inflammatory process. Although there are basic differences between these two types of vascular inflammation (e.g. the rate of lesions development and the dominant role of oxidized LDL in atherosclerosis), similarities exist. It has for instance been proposed that low-grade vasculitis caused by Chlamydia pneumonia results in endothelial dysfunction which can lead to atherosclerosis ${ }^{18,19}$. Also, in patients with systemic vasculitis, endothelial dysfunction was found to be increased compared to controls ${ }^{20,21}$. Moreover, vasculitic disease as well as atherosclerosis are characterized by an influx of MPO containing myeloid cells, and in both diseases the pathogenic effects of MPO and its oxidative products have been suggested to play an important pathophysiological role.

\section{MPO}

MPO is encoded on chromosome 17 (17q23.1) next to the peroxidase genes eosinophil peroxidase and lactoperoxidase (see figure 4). The similarities in gene organization and sequence among these three peroxidases indicate that their genes may have evolved from a common ancestor ${ }^{22}$. MPO, however, is unique in the capacity to utilize chloride in generating halogeneting oxidants. MPO transcription products are primarily detected in myeloblasts (i.e. the first recognizable myeloid precursor) and promyelocytes, whereas in the later stages of granulopoiesis (myelocytes, metamyelocytes, band cells and mature neutrophils) transcription subsides 23,24 . Monocytes and monocyte precursors synthesize MPO as well, however, after monocyte to macrophage transformation MPO synthesis stops. Interestingly, recent papers suggest that certain types of tissue macrophages may still contain 25,26 or even produce MPO ${ }^{27}$. The transcription factors AML-1, c-myb, PU.1, and C/EBP $\alpha$ have all been linked to MPO transcription. PU. 1 is most likely not necessary for induction of expression, but only for full MPO expression ${ }^{28}$. Recently, areas in the MPO promoter have been identified that are essential for limiting the expression of MPO to haematopoietic tissues, although the repressing factor for myeloid restriction has not been identified yet ${ }^{29}$. Also, two single nucleotide promoter polymorphisms have been described that influence MPO levels, the MPO463 and MPO129 polymorphisms 30,31 .

Once synthesized, the primary MPO translation product undergoes $N$-linked glycosylation generating a 90-kDa heme-free inactive precursor, apopro-MPO. After heme insertion an enzymatically active precursor is created, pro-MPO. Subsequently, pro-MPO undergoes proteolytic maturation, whereby the 125-amino acid pro-sequence is removed, the remaining peptide is cleaved into heavy and light subunits, the heavy-light protomers are paired into the dimeric mature MPO (see figure 5), and the mature protein is targeted to the lysosome ${ }^{32}$.

Myeloperoxidase deficiency is relatively common, with an incidence of 1 in 2000 to $4000^{33-35}$. To date, 4 mutations responsible for MPO deficiency have been registered in the Online Men- 


"IIIIYY!

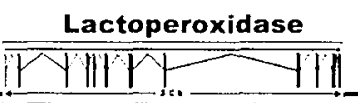

56.7 Mb

\section{Myeloperoxidase}

Figure 4. Figure showing the relative position of the myeloperoxidase (MPO) gene to the lactoperoxidase (LPO) and eosinophil peroxidase (EPX) gene on chromosome 17. The location of the chromosome markers D17S1975 and D16S1716 is indicated by two black arrowheads

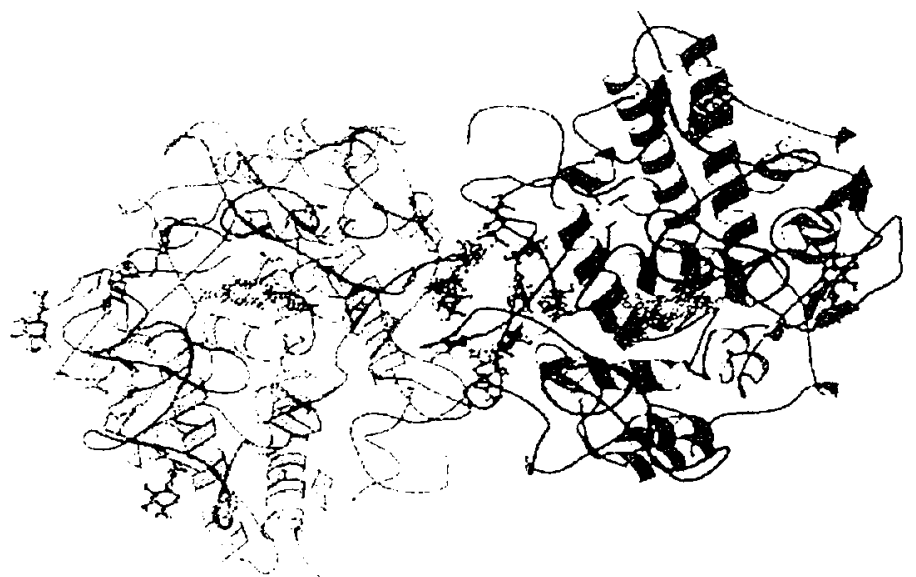

Figure 5. Figure showing myeloperoxidase (MPO) projected from a 3-dimensional computerized image. MPO is a homo-dimer consisting of two heavy and two light chains. Both monomers contain one heme-group (round structure)

delian Inheritance in Man (OMIM) database ${ }^{36}$ and recently 3 additional mutations have been identified ${ }^{9}$. MPO deficiency has been associated with disseminated candidiasis in vivo ${ }^{37-39}$ and in vitro to a diminished capacity to kill Staphylococcus Aureus as well ${ }^{40}$. Nevertheless, surprisingly few MPO deficient people have been described with a clinically increased susceptibility to infections. The occurrence of malignancies was found to be increased by some ${ }^{35}$, although others were not able to find this association ${ }^{41}$.

MPO constitutes approximately $5 \%$ of human neutrophil protein and about $1 \%$ of monocyte protein ${ }^{42,43}$. Upon neutrophil activation MPO is readily released into phagocytic vacuoles as well as in the extracellular space where it catalyses the formation of hypochlorous acid (bleach; $\mathrm{HOCl}$ ) and other reactive oxidants out of hydrogen peroxide $\left(\mathrm{H}_{2} \mathrm{O}_{2}\right)^{1,44}$. $\mathrm{HOCl}$ can react with a variety of cellular substrates including thiols, nucleotides and amines and, as such, it contributes to innate immunity against bacteria and fungi by neutrophils ${ }^{1,44}$. Growing evidence indicates that the MPO-HOCl system may also play a potential pathophysiological role in non-infectious diseases such as vasculitis and atherosclerosis (see next paragraphs). 


\section{MPO and its role in vasculitis}

The role of MPO in vasculitis is two-sided. On the one hand, MPO is a major immunological target in patients with ANCA associated vasculitides and also in a subset of patients with anti-GBM mediated disease. On the other hand, the enzymatic functions of MPO can play an important direct pathogenic role.

Although it still remains to be determined what the exact pathological mechanisms are, experimental animal models strongly support the hypothesis that binding of MPO-ANCA to MPO directly cause disease ${ }^{10,45}$. Many in vitro studies have tried to unravel the pathologic mechanisms involved in MPO-ANCA associated disease (reviewed in ${ }^{46}$ ). In short, priming of neutrophils by TNF $\alpha$ (e.g. as a result of an upper respiratory tract infection) results in mitogen-activated protein kinase (MAPK) dependent translocation of MPO to the cell surface (see also figure 6$)^{47}$. Stimulation of these primed neutrophils with MPO-ANCA results in neutrophil activation, with reactive oxygen species generation (including superoxide and hydrogen peroxide), degranulation, adhesion to and killing of endothelial cells $\mathrm{s}^{46}$. Also, degranulated MPO can bind to unprimed neutrophils making them directly vulnerable to activation by MPO-ANCA ${ }^{48}$. Monocytes can be activated as well, resulting in enhanced cytokine and chemokine production (e.g. IL-8, II-6, TNF and MCP-1) 46 . Most of these processes are thought to be FC and Fcy-receptor dependent ${ }^{46}$.

Circulating MPO has been detected in patients with MPO-ANCA associated vasculitis in higher concentrations than in healthy controls ${ }^{49}$. Endothelial cells can bind and take up this degranulated MPO resulting in an increased intracellular oxidant radical formation ${ }^{50}$. MPO can also form complexes with circulating MPO-ANCA that bind and dimerize Fc $\gamma$-receptors on neutrophils resulting in activation ${ }^{46}$. MPO present outside inflammatory sites is normally cleared and inactivated by ceruloplasmin ${ }^{51}$. The presence of MPO-ANCA however, interferes with these mechanisms, leaving a circulating highly reactive enzyme ${ }^{52}$.

This circulating and deposited active enzyme can add to the oxidative damage to the vessel wall by locally producing $\mathrm{HOCl}$ and other reactive oxidants. $\mathrm{HOCl}$ is directly cytotoxic in high concentrations, whereas in lower concentrations it is able to activate MAPK pathways and can cause growth arrest and apoptosis ${ }^{53}$. Also, MPO can increase protease activity at inflammatory sites by inactivating protease inhibitors and by acting as a detoxicant for $\mathrm{H}_{2} \mathrm{O}_{2}$ thereby protecting proteolytic enzymes from inactivation ${ }^{54-56}$. Especially in ANCA associated vasculitis, the protease/anti-protease imbalance has been proposed to play a role in vasculitic lesion development ${ }^{57}$. MPO can also act as a leukocyte-derived vascular nitric oxide (NO) oxidase, thereby reducing NO bioavailability and contributing to endothelial dysfunction ${ }^{58-60}$ (see also figure 6). Endothelial dysfunction has been shown to be an important characteristic of ANCA associated disease, especially during active disease 20,21 .

\section{MPO and its role in atherosclerosis}

Also in atherosclerosis, MPO has been implicated in damaging host tissue. In atherosclerotic lesions MPO and hypochlorite modified proteins are found ${ }^{6 i}$. In addition, compelling evi- 


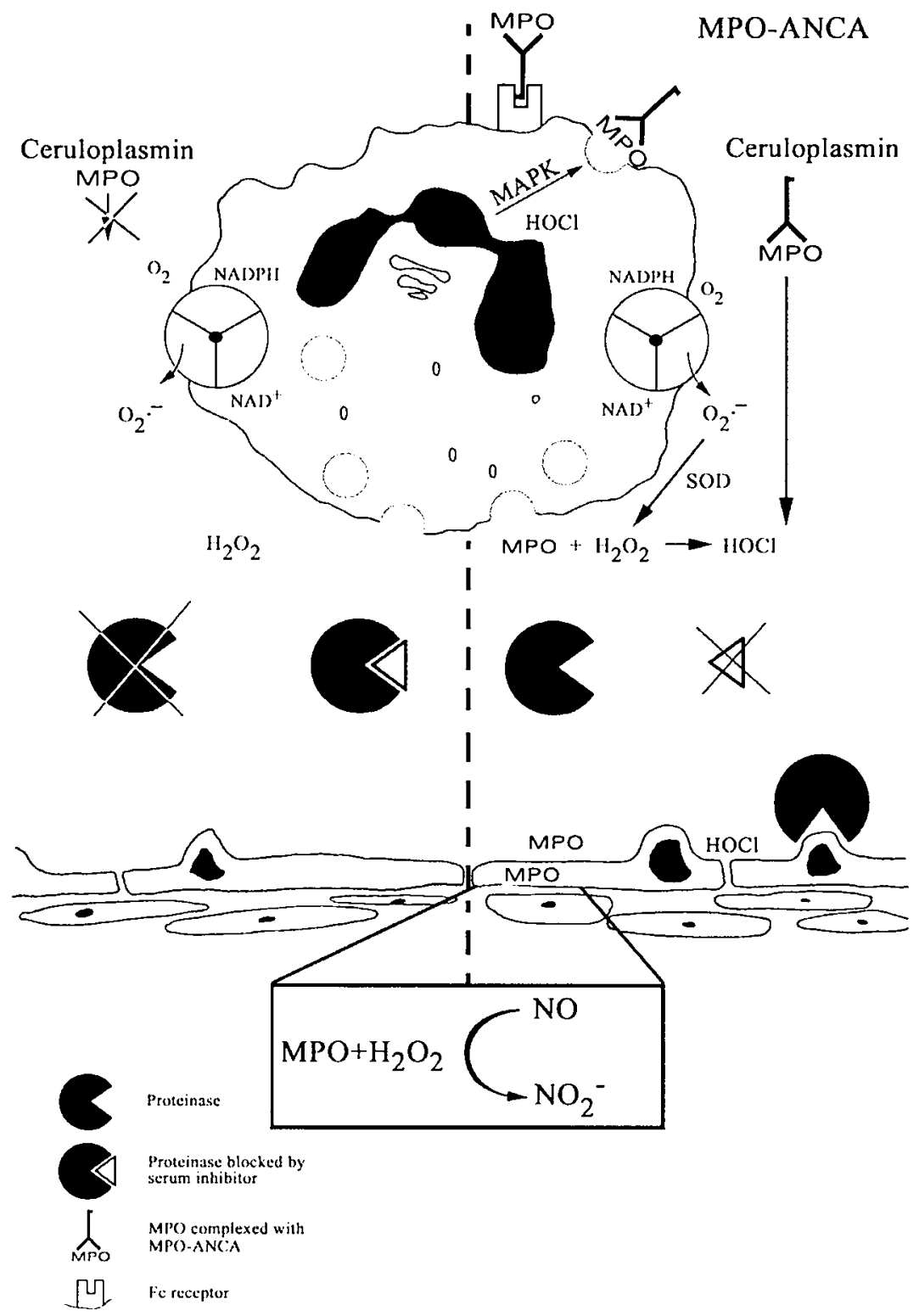

Figure 6. Schematic presentation of the functions of MPO. Left-side of the figure represents the situation without ANCA, right-side figure represents the situation where MPO-ANCA can activate primed neutrophils directly or via the $\mathrm{Fc}-\gamma$ receptor and prevent inhibition of MPO by ceruloplasmin 
dence suggests that the MPO-HOCl system has an important role in the oxidative conversion of LDL into a high-uptake form for macrophages, leading to foam cell formation and thus contributing to the atherosclerotic plaque formation 62.63 . Moreover, recent studies have shown that MPO can use nitric oxide (NO) as a substrate in the presence of $\mathrm{H}_{2} \mathrm{O}_{2}$ leading to reduced $\mathrm{NO}$ bioavailability 58,60 . Such an effect would be especially relevant at sites of inflammation where MPO, $\mathrm{NO}$ and $\mathrm{H}_{2} \mathrm{O}_{2}$ are present. In addition, it has been demonstrated that coronary atherosclerosis is associated with an increased neutrophil MPO content suggesting a link between MPO protein levels and atherosclerosis ${ }^{59}$ and MPO promoter polymorphisms influencing MPO levels have been associated with risk for atherosclerosis ${ }^{64-66}$. Buffon et a/ recently demonstrated that circulating neutrophils release MPO while passing over an atherosclerotic vasculature $^{67}$. Finally, it has recently been suggested that MPO deficient individuals possibly have a decreased risk of atherosclerosis 41,68 . In contrast, MPO deficient mice develop more severe atherosclerosis than MPO sufficient mice. On the other hand, mice that were genetically modified to over-express human MPO in their monocytes developed more severe atherosclerosis compared to wild-type mice ${ }^{69}$. The latter data could suggest that differences between mouse and human MPO or their expression patterns are responsible for the differences in atherosclerotic disease development between human MPO deficient individuals and mouse MPO knockouts ${ }^{70}$.

\section{Aim of this thesis}

The general aim of this thesis was to further characterize the role of MPO and MPO-ANCA in immune mediated vascular disorders.

Chapter 2 to 5 focus on the role of auto-antibodies (like MPO-ANCA) in small vessel vasculitides.

In Chapter 2 we give a current review of the importance of the determination of MPO- and PR3-ANCA and anti-GBM antibodies for diagnosing and evaluating follow-up of patients with a small vessel vasculitis. Chapter 3 describes the employability of a rapid screening assay, the ANCA-GBM dot-blot, for the determination of MPO- and PR3-ANCA and anti-GBM antibodies in patients with crescentic glomerulonephritis. In Chapter 4 we measure the affinity of anti-GBM antibodies to the GBM as a possible explanation for both the fulminant nature and the resistance to therapy of anti-GBM mediated crescentic glomerulonephritis. A substantial proportion of patients with anti-GBM antibody mediated crescentic glomerulonephritis are positive for MPO-ANCA as well. In Chapter 5 we reviewed this frequency in the Limburg renal biopsy registry and evaluated the influence of the respective autoantibodies on renal biopsy features. Chapter 6 to 8 focus on functional MPO levels in health and disease, in Chapter 6 we measured neutrophil MPO activity in a large group of healthy individuals and investigated whether this is linked to differential promoter activity due to two single nucleotide promoter polymorphisms, MPO463 and MPO129. In Chapter 7 we measured the effect of these polymorphisms on the pulse wave velocity, as a measurement for atherosclerosis, in a patient group with hypertension. Patients with small vessel vasculitis often have evidence of neutrophil activation with release of MPO. In Chapter 8 we investigated the neutrophil MPO activity in a small group of patients with a small vessel vasculitis in remission as well as during 
disease relapse. Chapter 9 reviews the current knowledge on the role of myeloperoxidase in the pathogenesis of systemic vasculitis. Finally, in Chapter 10, the results of the studies described in this thesis are summarized and some perspectives for future studies are given.

\section{References}

1. Winterbourn CC, Vissers MC, Kettle AJ: Myeloperoxidase. Curr Opin Hematol 7:53-58., 2000

2. Jennette JC, Falk RJ, Andrassy K, Bacon PA, Churg J, Gross WL, Hagen EC, Hoffman GS, Hunder GG, Kallenberg $C G$, et al: Nomenclature of systemic vasculitides. Proposal of an international consensus conference. Arthritis Rheum 37:187-192, 1994

3. Jennette JC, Falk RJ: Smali-vessel vasculitis. N Engl I Med 337:1512-1523, 1997

4. Davies DJ, Moran JE, Niall JF, Ryan GB: Segmental necrotising glomerulonephritis with antineutrophil antibody: possible arbovirus aetiology? Br Med J (Clin Res Ed) 285:606, 1982

5. Savige J, Davies D, Falk RJ, Jennette JC. Wiik A: Antineutrophil cytoplasmic antibodies and associated diseases: a review of the clinical and laboratory features. Kidney Int 57:846-862, 2000

6. Cohen Tervaert JW, Limburg PC. Elema JD, Huitema MG, Horst G, The TH, Kallenberg CG: Detection of autoantibodies against myeloid lysosomal enzymes: a useful adjunct to classification of patients with biopsy-proven necrotizing arteritis. Am J Med 91:59-66, 1991

7. Lerner RA, Glassock RJ, Dixon FJ: The role of anti-glomerular basement membrane antibody in the pathogenesis of human glomerulonephritis. J Exp Med 126:989-1004, 1967

8. Short AK, Esnault VL, Lockwood CM: Anti-neutrophil cytoplasm antibodies and anti-glomerular basement membrane antibodies: two coexisting distinct autoreactivities detectable in patients with rapidly progressive glomerulonephritis. Am J Kidney Dis 26:439-445, 1995

9. Reumaux D, de Boer M, Meijer AB, Duthilleul P, Roos D: Expression of myeloperoxidase (MPO) by neutrophils is necessary for their activation by anti-neutrophil cytoplasm autoantibodies (ANCA) against MPO. $J$ Leukoc Biol 73:841-849, 2003

10. Xiao H, Heeringa P, Hu P, Liu Z, Zhao M, Aratani Y, Maeda N, Falk RJ, Jennette JC: Antineutrophil cytoplasmic autoantibodies specific for myeloperoxidase cause glomerulonephritis and vasculitis in mice. JClin Invest 110:955-963, 2002

11. Naoumova RP, Scott J: The pathogenesis of atherosclerosis, in Oxford textbook of medicine ( $v 0 l$ 2), edited by Warell DA, Cox TM, Firth JD, Benz Jr EJ, 4 ed, Oxford university press, 2003

12. Ross R: The pathogenesis of atherosclerosis: a perspective for the 1990s. Nature 362:801-809, 1993

13. Ridker PM, Cushman M, Stampfer MJ, Tracy RP, Hennekens CH: Inflammation, aspirin, and the risk of cardiovascular disease in apparently healthy men. N Engl I Med 336:973-979, 1997

14. Ridker PM, Hennekens CH, Buring JE, Rifai N: C-reactive protein and other markers of inflammation in the prediction of cardiovascular disease in women. NEng/ / Med 342:836-843, 2000

15. Ross R: Atherosclerosis-an inflammatory disease. N Eng/ J Med 340:115-126, 1999

16. Hansson GK, Libby P, Schonbeck U, Yan ZQ: Innate and adaptive immunity in the pathogenesis of atherosclerosis. Circ Res 91:281-291, 2002

17. Lind L: Circulating markers of inflammation and atherosclerosis. Atherosclerosis 169:203-214, 2003

18. Juvonen T, Juvonen J, Savolainen MJ: Is vasculitis a significant component of atherosclerosis? Curr Opin Rheumatol 11:3-10, 1999

19. Libby P, Egan D, Skarlatos S: Roles of infectious agents in atherosclerosis and restenosis: an assessment of the evidence and need for future research. Circulation 96:4095-4103, 1997

20. Filer AD, Gardner-Medwin JM, Thambyrajah J, Raza K, CarruthersDM, Stevens RJ, Liu L, Lowe SE, Townend JN, Bacon PA: Diffuse endothelial dysfunction is common to ANCA associated systemic vasculitis and polyarteritis nodosa. Ann Rheum Dis 62:162-167, 2003

21. Raza K, Thambyrajah J, Townend JN, Exley AR, Hortas C, Filer A, Carruthers DM, Bacon PA: Suppression of inflammation in primary systemic vasculitis restores vascular endothelial function: lessons for atherosclerotic disease? Circulation 102:1470-1472, 2000

22. SakamakiK, Kanda N, Ueda T, Aikawa E, Nagata S: The eosinophil peroxidase gene forms a cluster with the genes for myeloperoxidase and lactoperoxidase on human chromosome 17. Cytogenet Cell Genet $88: 246-248,2000$ 
23. Bjerregaard MD, Jurlander J, Klausen P, Borregaard N, Cowland 38 : The in vivo profile of transcription factors during neutrophil differentiation in human bone marrow. Blood 101:4322-4332, 2003

24. Cowland JB, Borregaard N: The individual regulation of granule protein mRNA levels during neutrophil maturation explains the heterogeneity of neutrophil granules. J Leukoc Biol 66:989-995, 1999

25. Sugiyama S, Okada Y, Sukhova GK, Virmani R, Heinecke JW, Libby P: Macrophage myeloperoxidase regulation by granulocyte macrophage colony-stimulating factor in human atherosclerosis and implications in acute coronary syndromes. Am I Pathol 158:879-891, 2001

26. Brown KE, Brunt EM, Heinecke JW: Immunohistochemical detection of myeloperoxidase and its oxidation products in Kupffer cells of human liver. Am J Pathol 159:2081-2088, 2001

27. Nagra RM, Becher B, Tourtellotte WW. Antel JP. Gold D, Paladino T, Smith RA, Nelson JR, Reynolds WF: Immunohistochemical and genetic evidence of myeloperoxidase involvement in multiple sclerosis. $J$ Neuroimmunol 78:97-107, 1997

28. Borregaard N, Theilgaard-Monch K, Sorensen OE, Cowland JB: Regulation of human neutrophil granule protein expression. Curr Opin Hematol 8:23-27, 2001

29. Chumakov AM, Chumakova EA, Chih D, Koeffler HP: Molecular analysis of the human myeloperoxidase promoter region. Int J Oncol 16:401-411, 2000

30. Reynolds WF, Chang E, Douer D, Ball ED, Kanda V: An allelic association implicates myeloperoxidase in the etiology of acute promyelocytic leukemia. Blood 90:2730-2737, 1997

31. Hoy $A$, Tregouet $D$, Leininger-Muller $B$, Poirier $O$, Maurice M, Sass C, Siest G, Tiret L, Visvikis S: Serum myeloperoxidase concentration in a healthy population: biological variations, familial resemblance and new genetic polymorphisms. Eur I Hum Genet 9:780-786, 2001

32. Nauseef WM, MCCormick SJ, Clark RA: Calreticulin functions as a molecular chaperone in the biosynthesis of myeloperoxidase. J Biol Chem 270:4741-4747, 1995

33. Parry MF, Root RK, Metcalf JA, Delaney KK, Kaplow LS, Richar WJ: Myeloperoxidase deficiency: prevalence and clinical significance. Ann Intern Med 95:293-301, 1981

34. Kutter D: Prevalence of myeloperoxidase deficiency: population studies using Bayer-Technicon automated hematology. I Mol Med 76:669-675, 1998

35. Lanza F, Fietta A, Spisani S, Castoldi GL, Traniello S: Does a relationship exist between neutrophil myeloperoxidase deficiency and the occurrence of neoplasms? I Clin Lab Immunol 22:175-180. 1987

36. Online Mendelian Inheritance in Man, OMIM (TM). Johns Hopkins University, Baltimore, MD, USA. http://www3.ncbi.n/m.nih.gov/omim/ accessed 24 August 2003, MIM nr 254600

37. Cech P. Stalder H, Widmann J), Rohner A, Miescher PA: Leukocyte myeloperoxidase deficiency and diabetes mellitus associated with Candida albicans liver abscess. Am J Med 66:149-153, 1979

38. Lehrer RI, Cline MJ: Leukocyte myeloperoxidase deficiency and disseminated candidiasis: the role of myeloperoxidase in resistance to Candida infection. J Clin Invest 48:1478-1488, 1969

39. Chiang AK, Chan GC, Ma SK, Ng YK, Ha SY, Lau YL: Disseminated fungal infection associated with myeloperoxidase deficiency in a premature neonate. Pediatr infect Dis J 19:1027-1029, 2000

40. Cech P, Papathanassiou A, Boreux G, Roth P. Miescher PA: Hereditary myeloperoxidase deficiency. Blood 53:403-411, 1979

41. Kutter D, Devaquet P, Vanderstocken G, Paulus JM, Marchal V, Gothot A: Consequences of total and subtotal myeloperoxidase deficiency: risk or benefit? Acta Haematol 104:10-15, 2000

42. Shultz J, Kaminker K: Myeloperoxidase of the leucocyte of normal human blood. Arch Biochem Biophys $96: 465-467,1962$

43. Bos $A$, Wever $R$, Roos D: Characterization and quantification of the peroxidase in human monocytes. Biochim Biophys Acta 525:37-44, 1978

44. Klebanoff SJ: Iodination of bacteria: a bactericidal mechanism. J Exp Med 126:1063-1078, 1967

45. Smyth CL, Smith H, Cook T, Haskard DO, Pusey CD: Immunisation with MPO directly induces small vessel vasculitis with pauci-immune focal segmental glomerulonephritis and alveolar haemorrhage in WKY rats, in American Society of Nephrology, Philadelphia, 2002

46. Hewins P, Savage C: Anti-neutrophil cytoplasm antibody associated vasculitis. Int / Biochem Cell Biol $35: 277-282,2003$

47. Kettritz R, Schreiber A, Luft FC, Haller $\mathrm{H}$ : Role of mitogen-activated protein kinases in activation of human neutrophils by antineutrophil cytoplasmic antibodies. J Am Soc Nephrol 12:37-46, 2001

48. Hess C, Sadaliah S, Schifferli JA: Induction of neutrophil responsiveness to myeloperoxidase antibodies by their exposure to supernatant of degranulated autologous neutrophils. Blood 96:2822-2827, 2000 
49. Minota S, Horie S, Yamada A, Iwamoto M, Yoshio T, Mimori A, Masuyama J, Kano S: Circulating myeloperoxidase and anti-myeloperoxidase antibody in patients with vasculitis. Scand J Rheumatol 28:94-99, 1999

50. Luqmani RA, Robinson $\mathrm{H}$ : Introduction to, and classification of, the systemic vasculitides. Best Pract Res Clin Rheumatol 15:187-202, 2001

51. Segelmark M, Persson $B$, Helimark $T$, Wieslander J: Binding and inhibition of myeloperoxidase (MPO): a major function of ceruloplasmin? Clin Exp Immunol 108:167-174, 1997

52. Griffin SV, Chapman PT, Lianos EA, Lockwood CM: The inhibition of myeloperoxidase by ceruloplasmin can be reversed by anti-myeloperoxidase antibodies. Kidney int 55:917-925, 1999

53. Winterbourn CC: Biological reactivity and biomarkers of the neutrophil oxidant, hypochlorous acid. Toxicology 181-182:223-227, 2002

54. Roos D. Winterbourn CC: IMMUNOLOGY: Enhanced: Lethal Weapons. Science 296:669-671, 2002

55. Reeves EP, Lu H, Jacobs HL, Messina CG, Bolsover S, Gabella G, Potma EO, Warley A, Roes J, Segal AW: Killing activity of neutrophils is mediated through activation of proteases by $K+$ flux. Nature 416:291-297. 2002

56. Matheson NR, Wong PS, Travis J: Enzymatic inactivation of human alpha-1-proteinase inhibitor by neutrophil myeloperoxidase. Biochem Biophys Res Commun 88:402-409, 1979

57. Esnault VL, Audrain MA, Sesboue R: Alpha-1-antitrypsin phenotyping in ANCA-associated diseases: one of several arguments for protease/antiprotease imbalance in systemic vasculitis. Exp Clin Immunogenet 14:206-213, 1997

58. Eiserich JP. Baldus S, Brennan ML, Ma W. Zhang C, Tousson A, Castro L, Lusis AJ, Nauseef WM, White CR, Freeman BA: Myeloperoxidase, a leukocyte-derived vascular NO oxidase. Science 296:2391-2394, 2002

59. Zhang R, Brennan ML, Fu X, Aviles RJ, Pearce GL, Penn MS, Topol EJ, Sprecher DL, Hazen SL: Association between myeloperoxidase levels and risk of coronary artery disease. JAMA 286:2136-2142, 2001

60. Abu-Soud HM, Hazen SL: Nitric oxide is a physiological substrate for mammalian peroxidases. $\mathrm{B} B \mathrm{ol} / \mathrm{Chem}$ 275:37524-37532, 2000

61. Malle E, Waeg G, Schreiber R, Grone EF, Sattler W. Grone HJ: Immunohistochemical evidence for the myeloperoxidase $/ \mathrm{H}_{2} \mathrm{O}_{2}$ /halide system in human atherosclerotic lesions: colocalization of myeloperoxidase and hypochlorite-modified proteins. Eur J Biochem 267:4495-4503, 2000

62. Zhang R, Brennan ML, Shen Z, MacPherson JC, Schmitt D, Molenda CE, Hazen SL: Myeloperoxidase functions as a major enzymatic catalyst for initiation of lipid peroxidation at sites of inflammation. $\mathrm{SBiol}$ Chem 277:46116-46122, 2002

63. Podrez EA, Schmitt D, Hoff HF, Hazen SL: Myeloperoxidase-generated reactive nitrogen species convert LDL into an atherogenic form in vitro. J Clin Invest 103:1547-1560, 1999

64. Hoy A, Leininger-Muller B, Poirier O, Siest G, Gautier M, Elbaz A, Amarenco P, Visvikis S: Myeloperoxidase polymorphisms in brain infarction. Association with infarct size and functional outcome. Atherosclerosis $167: 223-230,2003$

65. Nikpoor B, Turecki G, Fournier C, Theroux P, Rouleau GA: A functional myeloperoxidase polymorphic variant is associated with coronary artery disease in French-Canadians. Am Heart /142:336-339., 2001

66. Pecoits-Filho R, Stenvinkel P, Marchlewska A, Heimburger O, Barany P, Hoff CM, Holmes CJ, Suliman M, Lindholm B, Schalling M, Nordfors L: A functional variant of the myeloperoxidase gene is associated with cardiovascular disease in end-stage renal disease patients. Kidney Int Suppl:172-176, 2003

67. Buffon A, Biasucci LM, Liuzzo G, D'Onofrio G, Crea F, Maseri A: Widespread coronary inflammation in unstable angina. N Engl I Med 347:5-12, 2002

68. Brennan ML, Hazen SL: Emerging role of myeloperoxidase and oxidant stress markers in cardiovascular risk assessment. Curr Opin Lipidol 14:353-359, 2003

69. MCMillen TS, Heinecke JW, LeBoeuf RC: Abstract: Accelerated atherosclerosis in myeloperoxidase transgenic mice. 4th Conference on Arteriosclerosis, Thrombosis and Vascular Biology, 2003

70. Nauseef WM: The proper study of mankind. J Clin Invest 107:401-403, 2001 

CHAPTER 2

\section{ANCA and anti-GBM antibodies in diagnosis and follow-up of vasculitic disease}

A. Rutgers, P. Heeringa, J.G. Damoiseaux, and J.W. Cohen Tervaert Clinical and experimental immunology, University hospital Maastricht, The Netherlands

Eur J Intern Med. 2003 Aug; 14(5): 287-295. 


\section{ABSTRACT}

In the last decade serologic detection of anti-neutrophil cytoplasmic antibodies (ANCA) and anti-glomerular basement membrane (GBM) antibodies has facilitated the diagnostic process of small vessel vasculitides tremendously. Once diagnosed these diseases have proven to be treatable. However, in contrast to anti-GBM disease, ANCA associated vasculitides are chronic diseases with a high relapse rate. Since morbidity in ANCA associated vasculitides is dictated by the frequency and severity of relapses, much health benefit would be achieved if a relapse could be prevented or when early treatment could be commenced. ANCA titer rises and persistent high ANCA levels indicate a high risk of relapse and warrant the clinical evaluation of the patient for signs of relapse.

This editorial review will focus on the value of ANCA and anti-GBM antibody testing in diagnosis and on the importance of these tests in follow-up of disease. 


\section{Introduction}

Primary or idiopathic vasculitis is a condition characterized by inflammation of blood vessels. Clinical presentation largely depends on the type and size of vessels involved. Primary vasculitides can be subdivided according to the 1993 Chapel Hill Consensus Conference definitions in large vessel vasculitides, medium-sized vessel vasculitides, small vessel vasculitides not associated with anti-neutrophil cytoplasmic antibodies (ANCA), and small vessel vasculitides associated with ANCA (see also table 1)' . Not defined by the 1993 consensus conference are the vasculitides that are associated with antibodies to the glomerular basement membrane (GBM), rare types of small vessel vasculitis confined to the small capillaries of the lung and kidney often mimicking ANCA associated vasculitis.

A distinction between large and small vessel vasculitides can often be made based on the clinical presentation. For example glomerulonephritis, i.e. inflammation of the smallest capillaries, is by definition part of the small vessel vasculitides ${ }^{2}$. Differentiating between the different forms of small vessel vasculitis is more difficult. Fortunately, in the last decade serological (auto)antibody testing has become increasingly available and these tests have facilitated the diagnostic process enormously. Testing can be quick, non-invasive and relatively cheap compared to other diagnostic procedures. Also, sequential (auto)antibody testing is an attractive parameter in disease follow-up.

This editorial review will focus on the value of ANCA and anti-GBM antibody testing in diagnosis and on the importance of these tests in follow-up of disease.

Table 1. Primary vasculitides'

\begin{tabular}{ll}
\hline Type of vessels (primarily) involved & Diseases \\
\hline Large vessels & Giant cell arteriitis \\
Medium-sized vessels & Takayasu's arteritis \\
Small vessels & Polyarteritis nodosa \\
Not ANCA associated & Kawasaki disease \\
& \\
& Henoch-Schönlein purpura \\
ANCA associated & Essential cryoglobulinemic vasculitis \\
& Cutaneous leukocytoclastic angiitis \\
& Wegener's granulomatosis (WG) \\
Anti-GBM mediated & Churg Strauss syndrome (CSS) \\
& Microscopic polyangiitis (MPA) \\
& Goodpasture disease \\
& Anti-GBM nephritis \\
& Anti-GBM alveolitis
\end{tabular}

ANCA = Anti-neutrophil cytoplasmic antibodies; GBM = glomerular basement membrane. 


\section{ANCA}

ANCA have first been described in 1982 by Davies et a/ in patients with renal vasculitis ${ }^{3}$. In the years thereafter ANCA have been specifically associated with Wegener's granulomatosis (WG), microscopic polyangiitis (MPA), Churg-Strauss syndrome (CSS) and with idiopathic pauci-immune necrotizing glomerulonephritis (iNCGN). Clinical characteristics are summarized in table 2 .

Basically, two distinct (immuno fluorescent ANCA) patterns can be distinguished when ANCA are detected by indirect immunofluorescence, i.e. a granular cytoplasmic neutrophil fluorescence with central interlobular accentuation (c-ANCA) and a perinuclear pattern ( $p$-ANCA) often with nuclear extension (figure 1$)^{4}$.

Table 2. Clinical characteristics of anti neutrophil cytoplasmic antibody (ANCA) associated or anti-glomerular basement membrane (GBM) mediated small vessel vasculitides

\begin{tabular}{|c|c|c|c|c|}
\hline Disease & Pathologic definition & $\begin{array}{l}\text { Clinical } \\
\text { hallmarks }\end{array}$ & $\begin{array}{l}\text { PR3- } \\
\text { ANCA }\end{array}$ & $\begin{array}{l}\text { MPO- } \\
\text { ANCA }\end{array}$ \\
\hline $\begin{array}{l}\text {-Wegener's } \\
\text { granulomatosis }(W G)^{*}\end{array}$ & $\begin{array}{l}\text { Granulomatous inflammation } \\
\text { involving the respiratory } \\
\text { tract. Necrotizing vasculitis } \\
\text { affecting small to medium-sized } \\
\text { vessels }\end{array}$ & $\begin{array}{l}\text { Nose bleeds, } \\
\text { nephritis, lung } \\
\text { infiltrates, } \\
\text { hemoptysis }\end{array}$ & $>70 \%$ & $10-30 \%$ \\
\hline $\begin{array}{l}\text {-Churg-Strauss syndrome } \\
(\mathrm{CSS})^{\star}\end{array}$ & $\begin{array}{l}\text { Eosinophil-rich and } \\
\text { granulomatous inflammation } \\
\text { involving the respiratory tract. } \\
\text { Necrotizing vasculitis affecting } \\
\text { small to medium-sized vessels. }\end{array}$ & $\begin{array}{l}\text { Asthma, } \\
\text { eosinophilia, } \\
\text { neuropathy }\end{array}$ & $3-10 \%$ & $30-70 \%$ \\
\hline $\begin{array}{l}\text {-Microscopic polyangiitis } \\
(\text { MPA })^{\star}\end{array}$ & $\begin{array}{l}\text { Necrotizing vasculitis affecting } \\
\text { small vessels with absence of } \\
\text { granulomatous inflammation of } \\
\text { the respiratory tract. }\end{array}$ & $\begin{array}{l}\text { Nephritis, } \\
\text { purpura, } \\
\text { hemoptysis }\end{array}$ & $30-70 \%$ & $30-70 \%$ \\
\hline $\begin{array}{l}\text {-Idiopathic pauci-immune } \\
\text { necrotizingcrescentic } \\
\text { glomerulonephritis } \\
\text { (iNCGN) }\end{array}$ & $\begin{array}{l}\text { Crescentic glomerulonephritis, } \\
\text { with few or no immune } \\
\text { deposits. Absence of small vessel } \\
\text { vasculitis in other organs. }\end{array}$ & $\begin{array}{l}\text { Nephritis, } \\
\text { malaise }\end{array}$ & $10-30 \%$ & $30-70 \%$ \\
\hline $\begin{array}{l}\text {-Goodpasture disease } \\
\text {-Isolated anti-GBM } \\
\text { nephritis } \\
\text {-Isolated anti-GBM } \\
\text { alveolitis }\end{array}$ & $\begin{array}{l}\text { Crescentic glomerulonephritis } \\
\text { and/or alveolitis. With linear } \\
\text { imunofluorescence of the GBM. }\end{array}$ & $\begin{array}{l}\text { Hemoptysis, } \\
\text { nephritis }\end{array}$ & $<10 \%$ & $20-25 \%$ \\
\hline
\end{tabular}

\footnotetext{
*(necrotizing) Arteritis involving medium-sized or larger arteries may be occasionally found. Adapted from references ${ }^{1,22,23,64}$ PR3-ANCA $=$ anti proteinase 3 neutrophil cytoplasmic antibodies; MPO-ANCA = anti myeloperoxiase neutrophil cytoplasmic antibodies; $G B M=$ glomerular basement membrane.
} 


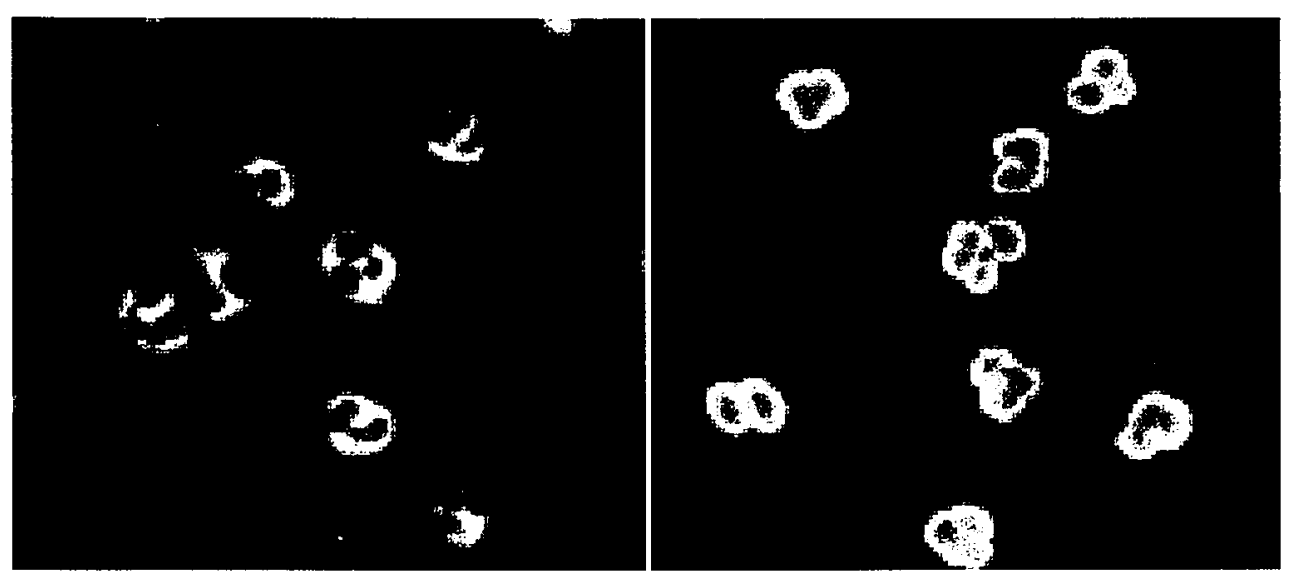

Figure 1. Anti-neutrophil cytoplasmic antibodies (ANCA) detection by indirect immunofluorescence on ethanol fixed neutrophil granulocytes. The left picture shows a cytoplasmic neutrophil fluorescence with central interlobular accentuation, i.e. c-ANCA. The right picture shows a perinuclear staining pattern with nuclear extension, i.e. $\mathrm{p}$-ANCA.

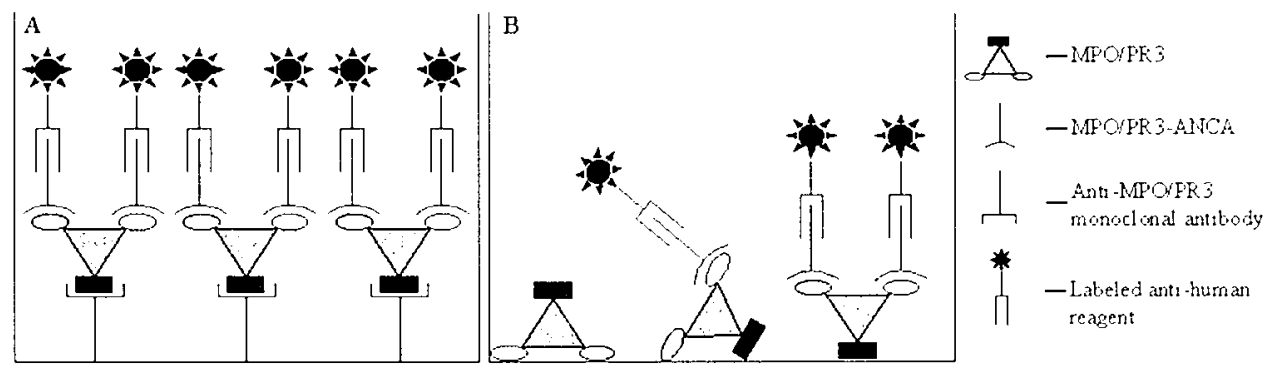

Figure 2. Schematic representation of a capture (A) and a direct (B) enzyme linked immunosorbent assay (ELISA). Circles represent immunodominant epitopes on the proteinase 3 (PR3) or myeloperoxidase (MPO) molecules. Squares represent immunologic irrelevant sites. Monoclonal antibodies to these irrelevant sites (A) can help better position immunological important sites (circles) for binding by MPO/PR3-anti-neutrophil cytoplasmic antibodies (ANCA). Dotblot assays are basically comparable with the direct ELISA (B) using a membrane as coating surface in stead of a plastic ELISA plate. Binding ANCA are detected by a labeled anti-human reagent.

The $c-$ and $p$-ANCA found in vasculitis patients are mostly directed against the neutrophil azurophilic granule proteins proteinase $3(P R 3)$ and myeloperoxidase (MPO) respectively, as can be detected by direct and capture antigen specific assays like enzyme linked immuno sorbent assays (ELISAS), or dot blot (see figure 2) ${ }^{2,5}$. Importantly, the perinuclear staining of the p-ANCA is an artificial result due to binding of highly positively charged proteins, including $\mathrm{MPO}$, to the negatively charged nucleus during ethanol fixation of neutrophils. Antibodies against other positively charged proteins, e.g. elastase and lactoferrin, give also rise to a 


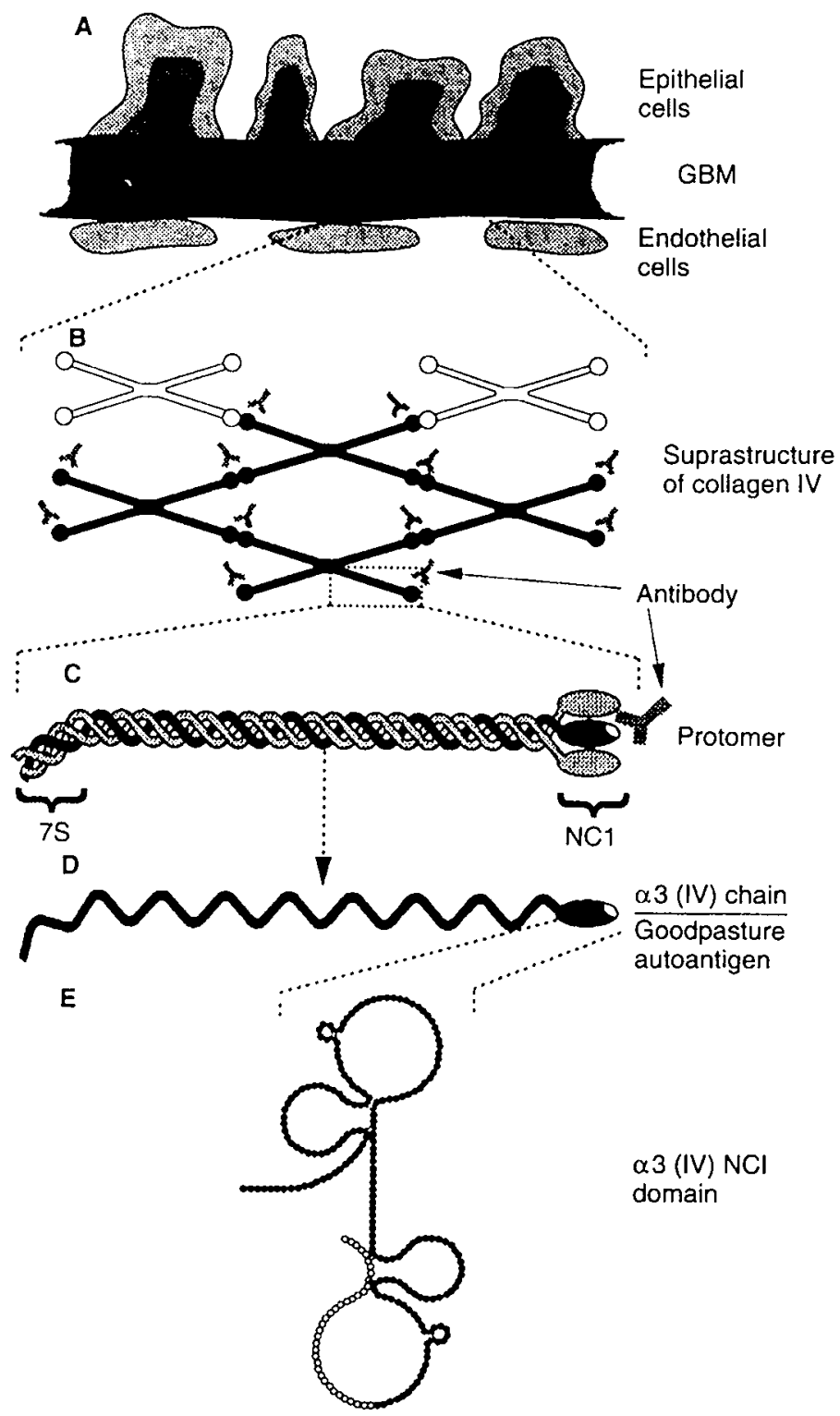

Figure 4. Figure showing schematically the molecular structure of type IV collagen and the Goodpasture autoantigen of glomerular basement membrane. Reprinted from ${ }^{13}$ with permission. (A) The glomerular basement membrane (GBM) is positioned between epithelial and endothelial cells. (B) Type IV collagen, the major constituent of GBM exists as a supramolecular network. The dark area denotes collagen triple helical molecules containing the $\alpha .3$ (IV) chain, the Goodpasture autoantigen, in contrast to the light areas. (C) Three $\alpha$-chains in a triple helical conformation, including an $\alpha .3$ chain (black) containing the Goodpasture autoantigen. (D) $\alpha .3$ (IV) chain with the Goodpasture epitope on the non-collageneous (NC1) or globular domain shown in white. (E) The detailed molecular structure of the NC1 domain with disulfide pairings and the primary interaction site for the autoantibodies (white area). Each dot represents an amino acid residue. 
superior to direct ELISAs, with higher sensitivity (74\% versus $22-70 \%$ ) and comparable specificity $(100 \% \text { versus } 93-100)^{9}$.

\section{Anti-GBM antibodies}

During the 1919 influenza epidemic, Goodpasture described a disease association between pulmonary hemorrhage and rapidly progressive glomerulonephritis (RPGN) ${ }^{10}$. This pulmonary-renal vasculitic syndrome is now known as "Goodpasture syndrome". In 1977, Lerner et a/ discovered that sera and/or kidneys of some patients with this syndrome contained antibodies against the GBM (see figure 3 ).

The current definition of anti-GBM mediated disease includes any patient with circulating or deposited anti-GBM antibodies and includes patients with isolated pulmonary involvement, combined pulmonary and renal vasculitic diseases (i.e. Goodpasture disease) and individuals with RPGN who lack hemoptysis (RPGN type I) ${ }^{11,12}$. In the last couple of years the auto-antigen for the anti-GBM antibodies has been identified as the non-collageneous part of the $\alpha 3$ chain of type IV collagen (only present in the glomerular and alveolar basement membrane and the cochlear membrane) and conformational epitopes have been identified on amino acid level (see figure 4$)^{13,14}$.

\section{Prevalence and incidence}

The estimated point prevalence of primary systemic vasculitides (included are the small vessel vasculitides WG, MPA, CSS and the medium sized vessel vasculitis polyarteriitis nodosa) in Norwich (England) was 144.5 per million on December 31, 1997 15.16. The annual incidence of overall ANCA-associated disease in East England was 17.4 per million between 1988-1992 and 23.8 per million between 1993-1998. This apparent increase has also been found in Norwegian populations of WG between 1992-1994 and 1995-1998 ${ }^{17}$. Whether this reflects an increased awareness of these diseases with the introduction of ANCA testing or an actual increased incidence is not known. Furthermore, there seem to be geographical differences in the incidence of ANCA-associated vasculitis throughout Europe, with an inverse relation between WG and MPA, the former being more common in higher latitude countries ${ }^{18}$. However, no differences could be observed between north and south Germany, where ANCA-associated vasculitis occurred in about 9.5 per million annually ${ }^{19}$.

Anti-GBM mediated disease is very rare and its incidence is unknown. However, the combined analysis of two studies with a total of 128 patients with evidence of pulmonary hemorrhage and nephritis show that $17 \%$ was anti-GBM mediated 20,21 . Interestingly, in about $20-30 \%$ of anti-GBM mediated disease ANCA (predominantly MPO-ANCA) are detected as wel122-24. It is at present unclear what strikes first, anti-GBM antibodies or MPO-ANCA ${ }^{23}$. The remaining patients with pulmonary renal syndrome were either single ANCA positive $(60 \%)$ and the rest (23\%) had neither ANCA nor anti-GBM antibodies 20,21 . 


\section{Diagnostic value ANCA}

Large multicenter studies combining immunofluorescence and ELISA ANCA testing (c-ANCAVPR3-ANCA positive, p-ANCAMPO-ANCA positive) reach a specificity of $99 \%$ for WG, MPA or iNCGN ${ }^{8,25}$. In general, the combination of immunofluorescence-ANCA testing with the antigen specific ELISA's results in a very high specificity for ANCA associated vasculitis, as was also shown in a large study of over 400 patients with connective tissue disease (specificity for vasculitis was $99.5 \%)^{26}$.

ANCA have also been detected in broncho-alveolar lavage fluids ${ }^{27}$ and cerebro-spinal fluids ${ }^{28}$ of patients with active vasculitis. No data are available on the sensitivity or specificity of ANCA testing in these body fluids.

Only rarely are MPO-ANCA or PR3-ANCA detected outside the vasculitic diseases. However, p-ANCA detected by indirect immunofluorescence can be found in many other inflammatory diseases, like chronic active auto-immune hepatitis, primary biliary sclerosis, primary sclerosing cholangitis, and inflammatory bowel disease (reviewed in ${ }^{29}$ ). In some of these diseases, i.e. inflammatory bowel disease and autoimmune hepatitis, direct MPO-ANCA ELISA's may reveal false positive results. MPO-ANCA capture ELISAs should always be performed to confirm positivity in these cases?

Noteworthy are reports of ANCA positivity in diseases that can present with the same clinical symptoms as the ANCA-associated diseases. Pudifin et al found that $75 \%$ of patients with invasive amoebiasis were PR3-ANCA positive by direct ELISA ${ }^{30}$. Also in subacute bacterial endocarditis PR3-ANCA have been described ${ }^{31}$. Interestingly, Choi et a/ report that $43 \%$ of their highest titered MPO-ANCA positive patients with small vessel vasculitis received either hydralazine or propylthiouracil suggesting a drug-induced vasculitis ${ }^{32}$. Patients with this drug-induced vasculitis often not only have MPO-ANCA but also anti-elastase and/or anti-lactoferrin antibodies ${ }^{32}$. Finally, patients with anti-DNA antibodies sometimes exhibit anti-MPO activity due to binding of DNA-antibody complexes to the highly cationic MPO coated on the ELISA plate 33 .

\section{Diagnostic value of anti-GBM antibodies}

The detection of anti-GBM antibodies is highly specific for anti-GBM mediated disease. Antibodies can be detected in situ by direct immuno fluorescence staining of a kidney biopsy (see figure 3) Circulating antibodies are detected by indirect immunofluorescence or by direct ELISA. In a case report, a patient with hemoptysis and pulmonary carcinoma is described in which circulating anti-GBM antibodies were detected by ELISA. In this patient antibodies were not directed against the Goodpasture antigen but against the $\alpha .1$ chain of type IV collagen ${ }^{34}$. Furthermore, entactin, a basement membrane constituent, has been suggested as a possible antigen in patients with non-Goodpasture anti-GBM disease, however larger analyses have shown poor association between these anti-entactin antibodies and pulmonary renal syndrome 21.35 
There are few data on sensitivity of anti-GBM antibodies. However, there are case reports of patients having overt clinical and histopathological proof of anti-GBM antibody mediated disease without detectable circulating anti-GBM antibodies. Possibly antibodies are rapidly cleared through high affinity binding to the GBM and alveolar basement membrane thus diminishing levels in peripheral blood ${ }^{36,37}$. Therefore, negative serology should be interpreted cautiously ${ }^{38}$.

\section{Pathogenic relevance}

The pathologic relevance of ANCA associated disease has been much debated in the past and many studies have shown pathogenic relevance for ANCA in vitro (reviewed in ${ }^{39}$ ). In vivo experiments revealed that MPO-ANCA can severely aggravate subclinical anti-GBM glomerular disease in rats ${ }^{40}$. Recently, Xiao et a/ have been able to show that MPO-ANCA IgG alone was capable of causing pauci-immune glomerulonephritis with crescent formation, vasculitis and pulmonary involvement in naive mice 41 . Others have also shown disease induction in certain rat strains, i.e. WKY rats that were immunized with human MPO ${ }^{42}$. Thus, ANCA can now be considered truly pathogenic ${ }^{43}$.

The pathologic significance of anti-GBM antibodies has been well established. Passive transfer of anti-GBM antibodies to naive animals induces disease ${ }^{44}$. Furthermore, immunization with the Goodpasture antigen, the $\alpha .3$ chain of type IV collagen, can induce Goodpasture-like disease in animal models. For this it is necessary to disrupt the hexameric $\alpha 3$ chain into mono- and di-mers for unmasking of the Goodpasture epitope ${ }^{45}$.

\section{Therapy}

Depending on extent of organ involvement and severity of disease the current "standard" consensus therapy for ANCA associated vasculitides consists of an induction therapy of daily oral cyclophosphamide $(2-3 \mathrm{mg} / \mathrm{kg} /$ day) in combination with slowly tapered doses of prednisolone (starting $1 \mathrm{mg} / \mathrm{kg} /$ day). In cases of severe extrarenal involvement such as pulmonary hemorrhage pulsed intravenous methylprednisolone with or without plasma exchange should be added. Three months after remission induction cyclophosphamide is replaced with the less toxic azathioprine ${ }^{46}$. Recent evidence suggests improved renal survival with the use of plasma exchange compared to the use of methylprednisolone in addition to cytotoxic induction therapy in patients with severe renal involvement ${ }^{47}$.

Currently, many other promising (novel) treatment strategies are being tested for therapeutic use in ANCA associated vasculitides, these include mycophenolate mofetil, 15-deoxyspergualin, intravenous immunoglobulins, tumor necrosis factor- $\alpha$ directed therapy, anti-thymocyte globulin, anti-CD52/anti-CD4 therapy, and immunoablation with or without stem cell rescue ${ }^{48}$. Direct immunoglobulin clearing using protein $A$ columns have also been used successfully in combination with cytotoxic therapy 49 and the usefulness of antigen specific immunoabsorption clearing only pathogenic antibodies is under investigation 50 . 
Table 3. Yearly relapse rate of anti-neutrophil cytoplasmic antibody-associated diseases

\begin{tabular}{lrllll}
\hline Reference & $n$ & $\begin{array}{l}\text { Patients with (a) } \\
\text { relapse(s) }\end{array}$ & $\begin{array}{l}\text { Number of } \\
\text { relapses }\end{array}$ & $\begin{array}{l}\text { Median follow-up } \\
\text { in years (range) }\end{array}$ & $\begin{array}{l}\text { Relapses/ } \\
\text { years }\end{array}$ \\
\hline Cohen Tervaert 198954 & 35 & $12(34 \%)$ & 17 & $1.3(1.3)$ & 0.26 \\
Stegeman 1994 & 57 & $23(40 \%)$ & 32 & $3.5(1.2-3.5)$ & 0.18 \\
Boomsma 2000 & 100 & $37(37 \%)$ & 48 & $2.9(1.1-3.0)$ & 0.18 \\
\hline
\end{tabular}

In anti-GBM mediated disease therapy is similar to the therapy in severe ANCA associated disease. As in ANCA associated vasculitis with severe extrarenal involvement, a two-week course of plasmapheresis to remove pathogenic anti-GBM antibodies is always added ${ }^{51}$.

\section{ANCA and anti-GBM antibodies in follow-up}

\section{ANCA associated disease relapse}

ANCA associated vasculitides are chronic diseases with a high relapse rate. After achieving complete remission, between $25-81 \%$ of patients suffered from one or more relapses during follow-up in different studies (reviewed $\mathrm{in}^{52}$ ). In the largest observational study by Hoffman et al $66 \%$ had a relapse within 5 and $80 \%$ within 10 years after disease remission. In this study patients were treated with cyclophosphamide for at least one year ${ }^{53}$. Another way to look at the relapse rate is to estimate the amount of relapses per year (see table 3) ${ }^{54-56}$.

Nowadays the amount and severity of relapses a patient suffers dictate the morbidity rate of ANCA associated vasculitides 57,58 . Much health benefit would be achieved if a relapse could be prevented or when early treatment could be commenced. In a small study it was shown that when patients were treated with cyclophosphamide after an ANCA titer rise, relapse could be prevented and cumulative cyclophosphamide dosage was lower than in a control group of patients with a rise in titer and an expectative policy ${ }^{5}$. However, the later recognized severity of cyclophosphamide toxicity makes it impossible to preventively treat patients with such a regimen and new treatment strategies are developed to safely prevent relapse ${ }^{60}$. One such a strategy is treatment of patients with WG in remission with co-trimoxazole; this reduced relapses with $55 \%$ over a two year period ${ }^{61}$.

\section{ANCA titer rise as risk factor for relapse}

The correlation between active disease and ANCA titer has long been recognized. Most available data are for PR3-ANCA associated vasculitis and less studies have been performed in MPO-ANCA associated vasculitis.

Most PR3-ANCA positive patients become negative when remission is achieved and a positive titer at remission carries an increased risk for relapse (see figure 5; reviewed in ${ }^{62}$ ). In addition, switching patients from cyclophosphamide to azathioprine therapy, usually 3 months after induction of remission, while patients are still PR3-ANCA positive is associated with a high risk of developing relapses ${ }^{63}$. 


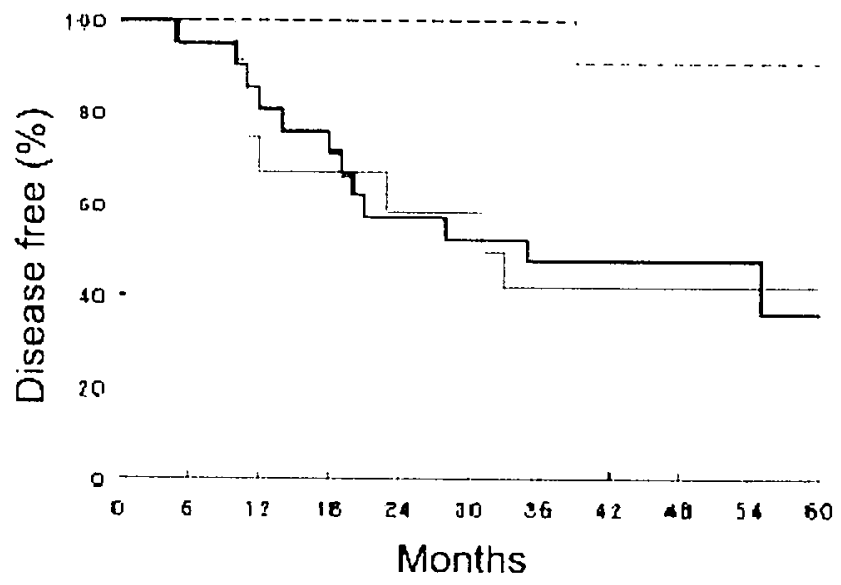

Figure 5. Disease-free interval according to the course of cytoplasmic anti-neutrophil cytoplasmic antibodies ( $c$-ANCA) during the study $(n=54)$. Dashed line $=c$-ANCA-negative $(n=21)$; broad line $=$ intermittently c-ANCA positive $(n=21)$; thin line $=$ persistently c-ANCA-positive $(n=12)$. Reprinted from Stegeman et al (1994) with permission of the publisher ${ }^{\text {s's }}$

Table 4. Serial anti-neutrophil cytoplasmic antibodies (ANCA) measurements and relapse

\begin{tabular}{|c|c|c|c|c|}
\hline$\overline{A N C A}$ & Reference & $\mathrm{n} /$ relapse & $\begin{array}{l}\text { Relapse preceded } \\
\text { by a rise in ANCA }\end{array}$ & $\begin{array}{l}\text { Rise in ANCA } \\
\text { followed by a } \\
\text { relapse }\end{array}$ \\
\hline \multirow[t]{6}{*}{ C-ANCA } & Cohen Tervaert $1989^{54}$ & $35 / 17$ & $100 \%$ & $77 \%$ \\
\hline & Egner \& Chapel $1990^{71}$ & $10 / 6$ & $100 \%$ & $75 \%$ \\
\hline & Cohen Tervaert $1990^{59}$ & $58 / 9$ & $90 \%$ & $82 \%$ \\
\hline & Kerr $1993^{72}$ & $68 / 45$ & $24 \%$ & $56 \%$ \\
\hline & Kyndt $1999^{73}$ & $19 / 13$ & N.R. & $57 \%$ \\
\hline & Boomsma $2000^{56}$ & $85 / 33$ & $52 \%$ & $57 \%$ \\
\hline \multirow[t]{2}{*}{ PR3-ANCA } & Kyndt $1999^{73}$ & $17 /$ N.R. & $33 \%$ & $59 \%$ \\
\hline & Boomsma $2000^{56}$ & $85 / 33$ & $82 \%$ & $71 \%$ \\
\hline Combination of & Davenport $1995^{74}$ & $37 / N . R$. & $43 \%$ & $23 \%$ \\
\hline \multirow[t]{2}{*}{ Ip-ANCAOr N.R. } & D'Oliviera $1995^{75}$ & $56 / 27$ & $41 \%$ & $62 \%$ \\
\hline & Jayne $1995^{76}$ & $60 / 23$ & $74 \%$ & $79 \%$ \\
\hline \multirow[t]{2}{*}{ MPO-ANCA } & Kyndt $1999^{73}$ & 19/N.R. & $73 \%$ & $79 \%$ \\
\hline & Boomsma $2000^{56}$ & $15 / 4$ & $75 \%$ & $100 \%$ \\
\hline
\end{tabular}

c-ANCA = cytoplasmic ANCA; PR3-ANCA = proteinase 3 ANCA; $p$-ANCA = perinuclear ANCA; MPO-ANCA $=$ myeloperoxidase $A N C A ; N . R .=$ not reported; $n=$ patients included in study; relapse = relapses observed during study period 
Thus ANCA positivity is a risk factor for relapse, but can a rise in ANCA titer also be used as a predictor of relapse?

In 1989. Cohen Tervaert et al observed that 17 relapses in 35 patients were all preceded by a rise in C-ANCA titer and that out of 22 C-ANCA rises $17(77 \%)$ were followed by a relapse ${ }^{54}$. This suggested that serial c-ANCA measurement can be a useful tool to identify patients at risk for relapse. Others have also addressed this question (see table 4) and a pooled analysis of data in 1996 showed that only $48 \%$ (range $24-100 \%$ ) of rises in C-ANCA titers as measured by indirect immunofluorescence were followed by a relapse, and only $51 \%$ (range $23-100 \%$ ) of relapses were preceded by rising titers ${ }^{64}$. The clinical usefulness of serial measurements of C-ANCA in monitoring disease activity therefore remains controversial. However, very few prospective studies have been performed.

A recent prospective study by Boomsma et al showed a rise in ANCA titer measured by immuno fluorescence or ELISA in $92 \%$ of patients with a relapse. In this study the positive predictive value of an increase in ANCA titers for relapse was $57 \%$ for C-ANCA, $71 \%$ for PR3-ANCA and 100\% (only 3 patients) for MPO-ANCA. The ELISA detection of PR3 or MPO is more sensitive in predicting relapse free intervals than immuno fluorescence detection ${ }^{56}$.

Only few and small studies have evaluated the use of the recently developed capture ELISAs in patient follow-up. Gisslen et al find that in 10 patients with a long follow-up increases in PR3-ANCA as detected by capture ELISA is more sensitive than by direct ELISA in identifying patients with a relapse ( 29 versus 23 detected relapses of 29 relapses respectively). However, at the cost of loss of specificity ${ }^{65}$. Arranz et al retrospectively conclude that only the capture ELISA was able to predict relapse in 11 patients during follow-up ${ }^{66}$. Boomsma et al have compared the use of capture ELISAS, direct ELISAs, immuno fluorescence-ANCA and image analysis of immuno fluorescence-ANCA for the prediction of relapse in WG patients based on C-ANCAVPR3-ANCA titer rise. The overall positive predictive value and negative predictive value was around $70 \%$ with no significant differences between the techniques ${ }^{67}$.

\section{Anti-GBM disease relapse}

Anti-GBM mediated disease is considered a monophasic disease where auto-antibodies disappear within 12-18 months ${ }^{68}$. However, case reports exist describing recurrent disease ${ }^{69}$. In most of these studies anti-GBM titers are positive during disease, but data during remission are often lacking. Levy et a/ have been able to nicely show that in a single patient 3 relapses were associated with the presence of high anti-GBM titers, whereas these antibodies were absent during remission 70 .

\section{Conclusion}

The detection of ANCA and anti-GBM antibodies plays a very important role in the diagnosis of vasculitic disease. Small vessel vasculitis can be diagnosed and treated earlier potentially limiting the extent of organ involvement and/or damage. In contrast to anti-GBM disease, 
ANCA associated vasculitides are chronic diseases with a high relapse rate and the amount and severity of relapses a patient suffers dictates morbidity in these patients. Much health benefit would be achieved if a relapse could be prevented. ANCA titer rises and persistent high ANCA levels indicate a high risk of relapse and warrant clinical evaluation of the patient for signs of relapse. Thus monitoring ANCA levels in patients with vasculitis can provide important information for the clinician.

\section{Acknowledgements}

We would like to thank H. van Rie (Dept of Clinical and Experimental Immunology, University Hospital of Maastricht) for providing figure 3.

\section{References}

1. Jennette JC, Falk RJ, Andrassy K, Bacon PA, Churg J. Gross WL, Hagen EC, Hoffman GS, Hunder GG, Kallenberg CG, et al:: Nomenclature of systemic vasculitides. Proposal of an international consensus conference. Arthritis Rheum 37:187-192, 1994

2. Jennette JC, Falk RJ: Small-vessel vasculitis. N Engl I Med 337:1512-1523, 1997

3. Davies DJ, Moran JE, Niall JF, Ryan GB: Segmental necrotising glomerulonephritis with antineutrophil antibody: possible arbovirus aetiology? Br Med J (Clin Res Ed) 285:606, 1982

4. Savige J, Davies D, Falk RJ, Jennette JC, Wiik A: Antineutrophil cytoplasmic antibodies and associated diseases: a review of the clinical and laboratory features. Kidney Int 57:846-862, 2000

5. Cohen Tervaert JW, Limburg PC. Elema JD, Huitema MG, Horst G, The TH, Kallenberg CG: Detection of autoantibodies against myeloid lysosomal enzymes: a useful adjunct to classification of patients with biopsy-proven necrotizing arteritis. Am J Med 91:59-66, 1991

6. Cohen Tervaert JW, Goldschmeding R, Elema JD, van der Giessen M, Huitema MG, van der Hem GK, The $\mathrm{TH}$, von dem Borne $A E$, Kallenberg CG: Autoantibodies against myeloid lysosomal enzymes in crescentic glomerulonephritis. Kidney Int 37:799-806, 1990

7. Boomsma MM, Stegeman CA, Oost-Kort WW, Kallenberg CG, Moguilevsky N, Limburg PC, Cohen Tervaert JW: Native and recombinant proteins to analyze auto-antibodies to myeloperoxidase in pauci-immune crescentic glomerulonephritis. J Immunol Methods 254:47-58, 2001

8. Westman KW, Selga D, Bygren P, Segelmark M, Baslund B, Wiik A, Wieslander J: Clinical evaluation of a capture ELISA for detection of proteinase-3 antineutrophil cytoplasmic antibody. Kidney int 53:1230-1236, 1998

9. Csernok E, Ahlquist D, Ullrich S, Gross WL: A critical evaluation of commercial immunoassays for antineutrophil cytoplasmic antibodies directed against proteinase 3 and myeloperoxidase in Wegener's granulomatosis and microscopic polyangiitis. Rheumatology (Oxford) 41:1313-1317, 2002

10. Goodpasture E: The significance of certain pulmonary lesions in relation to the etiology of influenza. Amer J Med Sci 158:863-870, 1919

11. Harrity P, Gilbert-Barness E, Cabalka A, Hong R, Zimmerman J: Isolated pulmonary Goodpasture syndrome. Pediatr Pathol 11:635-646, 1991

12. Jones DA, Jennette JC, Falk RJ: Goodpasture's syndrome revisited. A new perspective on glomerulonephritis and alveolar hemorrhage. NCMed J 51:411-415, 1990

13. Hudson BG, Kalluri R, Gunwar S, Noelken ME, Mariyama M, Reeders ST: Molecular characteristics of the Goodpasture autoantigen. Kidney int 43:135-139, 1993

14. Netzer KO, Leinonen A, Boutaud A, Borza DB, Todd P, Gunwar S, Langeveld JP, Hudson BG: The goodpasture autoantigen. Mapping the major conformational epitope(s) of alpha3(IV) collagen to residues 17-31 and 127-141 of the NC1 domain. J Biol Chem 274:11267-11274, 1999

15. Watts RA, Lane SE, Bentham G, Scott DG: Epidemiology of systemic vasculitis: a ten-year study in the United Kingdom. Arthritis Rheum 43:414-419, 2000 
16. Watts RA, Scott DG, Lane SE: Epidemiology of Wegener's granulomatosis, microscopic polyangiitis, and Churg-Strauss syndrome. Cleve Clin I Med 69 Suppl 2:S1184-86, 2002

17. Koldingsnes W, Nossent H: Epidemiology of Wegener's granulomatosis in northern Norway. Arthritis Rheum 43:2481-2487, 2000

18. Watts RA, Lane SE, Scott DG, Koldingsnes W, Nossent H, Gonzalez-Gay MA, Garcia-Poorua C, Bentham GA: Epidemiology of vasculitis in Europe. Ann Rheum Dis 60:1156-1157, 2001

19. Reinhold-Keller E, Herlyn K, Wagner-Bastmeyer R, Gutfleisch J, Peter HH, Raspe HH, Gross WL: No difference in the incidences of vasculitides between north and south Germany: first results of the German vasculitis register. Rheumatology (Oxford) 41:540-549, 2002

20. Niles J, Bottinger EP, Saurina GR, Kelly KJ, Pan G, Collins AB, MCCluskey RT: The syndrome of lung hemorrhage and nephritis is usually an ANCA-associated condition. Arch Intern Med 156:440-445, 1996

21. Saxena R, Bygren $P$, Arvastson $B$, Wieslander J: Circulating autoantibodies as serological markers in the differential diagnosis of pulmonary renal syndrome. J Intern Med 238:143-152, 1995

22. Short AK, Esnault VL, Lockwood CM: Anti-neutrophil cytoplasm antibodies and anti-glomerular basement membrane antibodies: two coexisting distinct autoreactivities detectable in patients with rapidly progressive glomerulonephritis. Am J Kidney Dis 26:439-445, 1995

23. Verburgh CA, Bruijn JA, Daha MR, van Es LA: Sequential development of anti-GBM nephritis and ANCA-associated Pauci-immune glomerulonephritis. Am J Kidney Dis 34:344-348, 1999

24. Hellmark T, Niles JL, Collins AB, MCCluskey RT, Brunmark C: Comparison of anti-GBM antibodies in sera with or without ANCA. I Am Soc Nephrol 8:376-385, 1997

25. Hagen EC, Daha MR, Hermans J, Andrassy K, Csernok E, Gaskin G, Lesavre P, Ludemann J, Rasmussen N, Sinico RA, Wiik A, van der Woude FJ: Diagnostic value of standardized assays for anti-neutrophil cytoplasmic antibodies in idiopathic systemic vasculitis. EC/BCR Project for ANCA Assay Standardization. Kidney Int 53:743-753, 1998

26. Merkel PA, Polisson RP. Chang Y, Skates SJ, Niles JL: Prevalence of antineutrophil cytoplasmic antibodies in a large inception cohort of patients with connective tissue disease. Ann Intern Med 126:866-873, 1997

27. Hoffman GS, Sechler JM, Gallin Jl, Shelhamer JH, Suffredini A, Ognibene FP, Baltaro RJ, Fleisher TA, Leavitt RY, Travis WD, et al.: Bronchoalveolar lavage analysis in Wegener's granulomatosis. A method to study disease pathogenesis. Am Rev Respir Dis 143:401-407, 1991

28. Faust J, Visbeck A, Fitzek S, Fitzek C. Orth T, Wandel E, Mayet WJ: Vasculitic wallenberg syndrome with detection of anti-proteinase 3 antibodies in the cerebrospinal fluid of a patient with severe Wegener's granulomatosis and only mild kidney involvement. Nephrol Dial Transplant 15:893-896, 2000

29. Kallenberg CG, Mulder AH, Cohen Tervaert JW: Antineutrophil cytoplasmic antibodies: a still-growing class of autoantibodies in inflammatory disorders. Am J Med 93:675-682, 1992

30. Pudifin DJ, Duursma J, Gathiram V, Jackson TF: Invasive amoebiasis is associated with the development of anti-neutrophil cytoplasmic antibody. Clin Exp Immunol 97:48-51, 1994

31. Choi HK, Lamprecht P. Niles JL, Gross WL, Merkel PA: Subacute bacterial endocarditis with positive cytoplasmic antineutrophil cytoplasmic antibodies and anti-proteinase 3 antibodies. Arthritis Rheum 43:226-231, 2000

32. Choi HK, Merkel PA, Walker AM, Niles JL: Drug-associated antineutrophil cytoplasmic antibody-positive vasculitis: prevalence among patients with high titers of antimyeloperoxidase antibodies. Arthritis Rheum 43:405-413, 2000

33. Jethwa HS, Nachman PH, Falk RJ, Jennette $J$ : False-positive myeloperoxidase binding activity due to DNAanti-DNA antibody complexes: a source for analytical error in serologic evaluation of anti-neutrophil cytoplasmic autoantibodies. Clin Exp Immunol 121:544-550, 2000

34. Kalluri R, Petrides S, Wilson CB, Tomaszewski JE, Palevsky HI, Grippi MA, Madaio MP, Neilson EG: Anti-alpha1(IV) collagen autoantibodies associated with lung adenocarcinoma presenting as the Goodpasture syndrome. Ann intern Med 124:651-653, 1996

35. Saxena R, Bygren P, Butkowski R, Wieslander J: Entactin: a possible auto-antigen in the pathogenesis of non-Goodpasture anti-GBM nephritis. Kidney Int 38:263-272, 1990

36. Rutgers A, Meyers KE, Canziani G, Kalluri R, Lin J, Madaio MP: High affinity of anti-GBM antibodies from Goodpasture and transplanted Alport patients to alpha3(IV)NC 1 collagen. Kidney Int 58:115-122, 2000

37. Dougan T, Levy JB, Salama A, George AJ, Pusey CD: Characterization of autoantibodies from patients with Goodpasture's disease using a resonant mirror biosensor. Clin Exp /mmunol 128:555-561، 2002 
38. Salama AD, Dougan T, Levy JB, Cook HT, Morgan SH, Naudeer S, Maidment G, George AJ, Evans D, Lightstone L, Pusey CD: Goodpasture's disease in the absence of circulating anti-glomerular basement membrane antibodies as detected by standard techniques. Am J Kidney Dis 39:1162-1167, 2002

39. Savage CO, Harper L, Holland M: New findings in pathogenesis of antineutrophil cytoplasm antibody-associated vasculitis. Curr Opin Rheumatol 14:15-22, 2002

40. Heeringa P. Brouwer E, Klok PA. Huitema MG, van den Born J, Weening JJ, Kallenberg CG: Autoantibodies to myeloperoxidase aggravate mild anti-glomerular-basement-membrane-mediated glomerular injury in the rat. Am J Pathol 149:1695-1706, 1996

41. Xiao H, Heeringa P, Hu P, Liu Z, Zhao M, Aratani Y, Maeda N, Falk RJ, Jennette JC: Antineutrophil cytoplasmic autoantibodies specific for myeloperoxidase cause glomerulonephritis and vasculitis in mice. J Clin Invest 110:955-963, 2002

42. Smyth CL, Smith H, Cook T. Haskard DO, Pusey CD: Immunisation with MPO directly induces small vessel vasculitis with pauci-immune focal segmental glomerulonephritis and alveolar haemorrhage in WKY rats, in ASN, Philadelphia, 2002

43. Falk RJ, Jennette JC: ANCA Are Pathogenic-Oh Yes They Are! J Am Soc Nephrol 13:1977-1979, 2002

44. Lerner RA, Glassock RJ, Dixon FJ: The role of anti-glomerular basement membrane antibody in the pathogenesis of human glomerulonephritis. J Exp Med 126:989-1004, 1967

45. Kalluri R, Gattone VH, 2nd, Noelken ME, Hudson BG: The alpha 3 chain of type IV collagen induces autoimmune Goodpasture syndrome. Proc Natl Acad Sci U S A 91:6201-6205, 1994

46. Cohen Tervaert JW, Stegeman CA, Kallenberg CG: Standard therapeutic regimens for vasculitis, in Disease-modifying Therapy in Vasculitides, edited by Kallenberg CG, Cohen Tervaert JW, Basel, Birkhauser Verlag. 2001, pp 21-41

47. Gaskin G, Jayne DR: Adjunctive plasma exchange is superior to methylprednisolone in acute renal failure due to ANCA-associated glomerulonephritis. J Am Soc Nephrol 13:F-FC010, 2002

48. Cohen Tervaert JW. Stegeman CA, Kallenberg CG: Novel therapies for anti-neutrophil cytoplasmic antibody-associated vasculitis. Curr Opin Nephrol Hypertens 10:211-217, 2001

49. Esnault VL, Testa A, Jayne DR, Soulillou JP, Guenel J: Influence of immunoadsorption on the removal of immunoglobulin $G$ autoantibodies in crescentic glomerulonephritis. Nephron 65:180-184, 1993

50. Yorioka N, Taniguchi Y, Amimoto D, Katsutani M, Kumagai J, Yamakido M: Plasmapheresis for removal of myeloperoxidase antineutrophil cytoplasmic antibodies: a case report. Ther Apher 2:314-316, 1998

51. Jindal KK: Management of idiopathic crescentic and diffuse proliferative glomerulonephritis: evidence-based recommendations. Kidney Int Supp/ 70:533-40, 1999

52. Boomsma MM, Stegeman CA, Kallenberg CG, Cohen Tervaert JW: Prevention of relapsing disease in anti-neutrophil cytoplasmic antibody related necrotizing small-vessel vasculitis: the role for autoantibody guided and anti-bacterial treatment, in Disease-modifying Therapy in Vasculitides, edited by Kallenberg CG, Cohen Tervaert JW, Basel, Birkhauser Verlag, 2001, pp 181-201

53. Hoffman GS, Kerr GS, Leavitt RY, Hallahan CW, Lebovics RS, Travis WD, Rottem M, Fauci AS: Wegener granulomatosis: an analysis of 158 patients. Ann Intern Med 116:488-498, 1992

54. Cohen Tervaert JW, van der Woude FJ, Fauci AS, Ambrus JL, Velosa J, Keane WF, Meijer S, van der Giessen $M$, van der Hem GK, The TH, et al.: Association between active Wegener's granulomatosis and anticytoplasmic antibodies. Arch Intern Med 149:2461-2465, 1989

55. Stegeman CA, Cohen Tervaert JW, Sluiter WJ, Manson WL, de Jong PE, Kallenberg CG: Association of chronic nasal carriage of Staphylococcus aureus and higher relapse rates in Wegener granulomatosis. Ann Intern Med 120:12-17, 1994

56. Boomsma MM, Stegeman CA, van der Leij MJ, Oost W, Hermans J, Kallenberg CG, Limburg PC, Cohen Tervaert JW: Prediction of relapses in Wegener's granulomatosis by measurement of antineutrophil cytoplasmic antibody levels: a prospective study. Arthritis Rheum 43:2025-2033, 2000

57. Exley AR, Carruthers DM, Luqmani RA, Kitas GD, Gordon C, Janssen BA, Savage CO, Bacon PA: Damage occurs early in systemic vasculitis and is an index of outcome. Qjm 90:391-399, 1997

58. Slot MC. Cohen Tervaert JW. Franssen CF, Stegeman CA: Renal survival and prognostic factors in patients with PR3-ANCA associated vasculitis with renal involvement. Kidney Int 63:670-677, 2003

59. Cohen Tervaert JW. Huitema MG, Hene RJ, Sluiter WJ, The TH, van der Hem GK, Kallenberg CG: Prevention of relapses in Wegener's granulomatosis by treatment based on antineutrophil cytoplasmic antibody titre. Lancet 336:709-711, 1990 
60. Jayne DR, Rasmussen N: Treatment of antineutrophil cytoplasm autoantibody-associated systemic vasculitis: initiatives of the European Community Systemic Vasculitis Clinical Trials Study Group. Mayo Clin Proc 72:737-747, 1997

61. Stegeman CA, Cohen Tervaert JW, de Jong PE, Kallenberg CG: Trimethoprim-sulfamethoxazole (co-trimoxazole) for the prevention of relapses of Wegener's granulomatosis. Dutch Co-Trimoxazole Wegener Study Group. N Engl I Med 335:16-20, 1996

62. Cohen Tervaert IW: The value of serial ANCA testing during follow-up studies in patients with ANCA-associated vasculitides. A review. I Nephrol 9:232-240, 1996

63. Slot MC, Cohen Tervaert JW, Boomsma MM, Stegeman CA: A positive C-anca titer at switch to azathioprine therapy is associated with a disquieting relapse rate in pr3-anca-related vasculitis. Arthritis Care Res In press, 2003

64. Cohen Tervaert JW, Stegeman CA, Kallenberg CG: Serial ANCA testing is useful in monitoring disease activity of patients with ANCA-associated vasculitides. Sarcoidosis Vasc Diffuse Lung Dis 13:241-245, 1996

65. Gisslen K, Wieslander J, Westberg G. Herlitz H: Relationship between anti-neutrophil cytoplasmic antibody determined with conventional binding and the capture assay, and long-term clinical course in vasculitis. I Intern Med 251:129-135, 2002

66. Arranz O, Ara J, Rodriguez R, Quinto L, Font J, Mirapeix E, Darnell A: Comparison of anti-PR3 capture and anti-PR3 direct ELISA for detection of antineutrophil cytoplasmic antibodies (ANCA) in long-term clinical follow-up of PR3-ANCA-associated vasculitis patients. Clin Nephrol 56:295-301, 2001

67. Boomsma MM, Damoiseaux JGMC, Stegeman CA, Kallenberg CG, Meeta P, Peter JB, Cohen Tervaert JW: Image analysis: a novel approach for the quantification of antineutrophil cytoplasmic antibody (ANCA) levels in patients with Wegener's Granulomatosis. J Immunol Methods In press, 2003

68. Flores JC. Taube D, Savage CO, Cameron JS, Lockwood CM, Williams DG, Ogg CS: Clinical and immunological evolution of oligoanuric anti-GBM nephritis treated by haemodialysis. Lancet 1:5-8, 1986

69. Mehler PS, Brunvand MW. Hutt MP, Anderson RJ: Chronic recurrent Goodpasture's syndrome. Am J Med 82:833-835, 1987

70. Levy JB, Lachmann RH, Pusey CD: Recurrent Goodpasture's disease. Am JKidney Dis 27:573-578, 1996

71. Egner W, Chapel HM: Titration of antibodies against neutrophil cytoplasmic antigens is useful in monitoring disease activity in systemic vasculitides. Clin Exp Immunol 82:244-249, 1990

72. Kerr GS, Fleisher TA, Hallahan CW, Leavitt RY, Fauci AS, Hoffman GS: Limited prognostic value of changes in antineutrophil cytoplasmic antibody titer in patients with Wegener's granulomatosis. Arthritis Rheum 36:365-371, 1993

73. Kyndt X, Reumaux D, Bridoux F, Tribout B, Bataille P, Hachulla E, Hatron PY, Duthilleul P, Vanhille P: Serial measurements of antineutrophil cytoplasmic autoantibodies in patients with systemic vasculitis. Am JMed 106:527-533, 1999

74. Davenport A, Lock RJ, Wallington T: Clinical significance of the serial measurement of autoantibodies to neutrophil cytoplasm using a standard indirect immunofluorescence test. Am J Nephro/ 15:201-207, 1995

75. De'Oliviera J, Gaskin G, Dash A, Rees AJ, Pusey CD: Relationship between disease activity and anti-neutrophil cytoplasmic antibody concentration in long-term management of systemic vasculitis. Am J Kidney Dis 25:380-389, 1995

76. Jayne DR, Gaskin G, Pusey CD, Lockwood CM: ANCA and predicting relapse in systemic vasculitis. Qjm $88: 127-133,1995$ 



\section{CHAPTER 3}

\section{ANCA-GBM Dot-Blot}

Evaluation of an assay in the differential diagnosis of patients presenting with rapidly progressive glomerulonephritis

Abraham Rutgers', Jan Damoiseaux' ${ }^{1}$, Caroline Roozendaal², Pieter C. Limburg?', Coen A. Stegeman ${ }^{3}$, and Jan Willem Cohen Tervaert ${ }^{1}$

Department of Internal Medicine, Division of Clinical Immunology',

University Hospital Maastricht, and Division of Clinical Immunology ${ }^{2}$ and Nephrology ${ }^{3}$, University Hospital Groningen, The Netherlands. 
Rapidly progressive glomerulonephritis (RPGN) is characterized by rapid and progressive loss of renal function and the presence of crescentic glomerulonephritis (CGN). Early diagnosis and appropriate treatment is mandatory to prevent death and/or renal failure. We have evaluated an ANCA-GBM dot-blot diagnostic test in terms of sensitivity, specificity, and inter-observer effect in consecutive patients with RPGN $(n=82)$. Control sera $(n=34)$ included healthy and relevant disease controls. Dot-blots were independently evaluated by 9 observers. Proteinase 3 (PR3)-ANCA, myeloperoxidase (MPO)-ANCA, and both were detected by ELISA in 36, 32 and 3 samples of 71 patients with pauci-immune CGN, respectively. Two additional samples were ANCA negative. The dot-blot revealed a sensitivity of $92-95 \%$ for PR3-ANCA and $80-86 \%$ for MPO-ANCA. The specificity of the dot-blot for PR3- and MPO-ANCA was 100\%. In the patients with anti-GBM nephritis $(n=9)$ anti-GBM was detected by both ELISA and dot-blot (sensitivity: 100\%). The specificity of the anti-GBM dot-blot was 91-94\%. However, the inter-observer effect was relatively high for detection of anti-GBM antibodies (24\%). In conclusion, the ANCA-GBM dot-blot is a useful screening tool in situations were conventional ANCA testing is not readily available with excellent performance for PR3-ANCA detection, but less optimal sensitivity for MPO-ANCA and specificity for anti-GBM detection. Therefore, it is recommended to include the following advises in the report to the physicians: 1 . patients with a high clinical suspicion for MPO-ANCA associated RPGN and negative dot-blot must have conventional analysis for MPO-ANCA, and 2. negative anti-GBM dot-blot makes anti-GBM disease very unlikely, but positive samples should be confirmed by conventional anti-GBM tests. 


\section{Introduction}

Rapidly progressive glomerulonephritis (RPGN) is characterized by a rapid decline of renal function that can lead to end-stage renal failure within days or a few weeks. Histopathologically, RPGN is characterized by a vasculitis of the glomerular capillaries resulting in the formation of cellular crescents within most glomeruli ${ }^{1}$. RPGN can be primary or secondary to any form of glomerulonephritis, e.g. membranoproliferative GN, IgA nephropathy, post-infectious GN and systemic lupus erythematosus (SLE). Primary RPGN is an autoimmune disease caused by anti-glomerular basement membrane antibody mediated GN (anti-GBM nephritis; type I RPGN), immune-complex induced GN (type \| RPGN), or by anti-neutrophil cytoplasmic antibody (ANCA) associated crescentic glomerulonephritis (CGN) (pauci-immune GN or type II! RPGN). It is mandatory to start immunosuppressive therapy in patients with RPGN as soon as a diagnosis is made. Treatment can prevent further deterioration of kidney function as well as partially reverse renal damage 2,3 . The best predictors of disease outcome in these patients are serum creatinine, dialysis dependency and percentage of non-crescentic glomeruli at diagnosis ${ }^{4-6}$. The early serologic detection of auto-antibodies associated with these diseases (i.e. anti-GBM antibodies and ANCA) can facilitate and speed up the diagnostic process tremendously and eventually prevent end-stage renal disease.

The presence of ANCA can be tested by indirect immunofluorescence (IIF) on ethanol fixed neutrophils. Two distinct patterns can be distinguished, i.e. a granular cytoplasmic neutrophil fluorescence with central interlobular accentuation (C-ANCA) and a perinuclear pattern ( $p$-ANCA) often with nuclear extension? ${ }^{7}$. The $c-$ and $p$-ANCA found in vasculitis patients are mostly directed against the azurophilic granule proteins proteinase 3 (PR3) and myeloperoxidase (MPO), respectively. However, in less selected patients detection of a c-and especially a p-ANCA by IIF is not equivalent to the presence of PR3-and MPO-ANCA. Therefore, it is recommended to detect ANCA by an antigen specific ELISA 7.8. Both direct and capture ELISAs for detecting MPO- and PR3-ANCA have been used ${ }^{9,10}$. The serologic presence of anti-GBM antibodies, directed to the non-collageneous part of the $\alpha .3$ chain of type IV collagen, can also be evaluated by both IIF and ELISA.

ELISA and IIF testing requires the presence of an immunological equipped laboratory with skilled and experienced personnel. A recently developed combined dot-blot strip assay for detection of anti-GBM, MPO-ANCA and PR3-ANCA has advantage over ELISA and IIF since the use of a fluorescence microscope or an optical density meter is unnecessary and experienced personnel is not needed. Furthermore, results are obtained in one single assay. The current study was set up to validate and evaluate sensitivity, specificity, and inter-observer effect of the dot-blot assay in a well defined, i.e. based on renal biopsy, patient population with pauci-immune crescentic glomerulonephritis $(n=73)$ and anti-GBM nephritis $(n=9)$. 


\section{Patients \& Methods}

\section{Patients}

Eighty-two patients with biopsy-proven RPGN were included for the present retrospective study (table 1). Samples of consecutive patients that presented with pauci-immune CGN $(n=57)$ at the University Hospital Groningen were included. In order to have sufficient samples of patients with MPO-ANCA associated CGN, these samples were supplemented with consecutive samples from patients that presented with MPO-ANCA associated CGN $(n=16)$ at the University Hospital Maastricht. The diagnosis of pauci-immune CGN was based on a renal biopsy showing focal or diffuse segmental crescentic glomerulonephritis and a paucity of immune deposits by immunofluorescence studies ${ }^{1-13}$. In addition, samples from consecutive patients with anti-GBM nephritis $(n=9)$ were included from both centers. Anti-GBM mediated CGN was diagnosed based on evidence of anti-GBM antibody formation. This was demonstrated by the presence of linear fluorescence of IgG along the GBM in the renal biopsy and/or by the presence of specific circulating anti-GBM antibodies ${ }^{14}$. All 82 samples were obtained at the time of kidney biopsy and before treatment was installed.

In addition, 34 control samples of patients who did not have ANCA associated vasculitis were included in this study. These samples came from healthy controls $(n=5)$, or from patients with (auto)antibodies that are known to interfere with ANCA-assays. Ten sera from patients with SLE-nephritis (7 out of 10 were positive for anti-dsDNA), 11 sera with high IgM rheumatoid factor (range $72-350 \mathrm{IU} / \mathrm{ml}$ ), and 8 sera with hyper-lgG (not monoclonal; range 20.4-30.9 $\mathrm{g} /$ ) were included.

\section{Classification of PR3- and MPO-ANCA}

All samples were tested at the time of diagnosis by a combination of IIF and direct or capture ELISA for MPO and PR3. Results obtained by direct ELISA were confirmed by capture ELISA. Assays were performed as previously described 10,15 .

\section{Detection of anti-GBM antibodies by direct ELISA}

Anti-GBM antibodies were measured using a commercially available direct anti-GBM antibody ELISA kit (Euro-diagnostica, Malmö, Sweden). The assay was performed according to the manufacturer's instructions. Samples were diluted 1:50 and measured in duplicate. Using 4 calibrators of 10,50,100, and 300 arbitrary units (AU) a calibration curve was prepared. The reference range was supplied by the manufacturer: values below the calibrator of $10 \mathrm{AU}$ were reported as negative, values of 10-20 AU were considered borderline positive, and values of more than 20 AU were considered positive. 


\section{Detection of ANCA and anti-GBM antibodies by ANCA-GBM dot-blot}

The ANCA-GBM dot-blot (Biomedical Diagnostics, Brugge, Belgium) is a qualitative assay that uses nitrocellulose strips on which purified antigens are blotted at preset spots. MPO and PR3 antigens that are used in this test are produced from human leukocytes. GBM preparations were produced from bovine kidney and contained the NC 1 domain of type IV collagen. Purity was $95 \%$ or above as checked by SDS-PAGE analysis. The test procedure was performed according to the directions of the manufacturer. The assay strip was incubated for 45 minutes with patient serum diluted 1:50. After washing with a standardized wash buffer, bound antibody was visualized by incubation of the strips with an alkaline phosphatase-protein A conjugate for 20 minutes and subsequently with the substrate 5-bromo-4-chloro-3-indolyl phosphate/nitro blue tetrazolium for 10 minutes. Finally, the strip was allowed to dry completely during 30 minutes before reading the results. All reagents were provided with the dot-blot kit. Positive results were noted when a grayish colorization was observed. The total duration of the test procedure was less than 2 hours.

All dot-blots were independently evaluated by 9 observers. A positive score by 8 or 9 observers was considered positive, a positive score by 3 to 7 observers was considered equivocal, and a positive score by 0 to 2 observers was considered negative. The inter-observer effect was defined as the percentage of sera not revealing unanimous results.

\section{Results}

Presence of ANCA and/or anti-GBM antibodies as determined by ELISA All samples of the 82 patients (table 1) that presented with RPGN were analyzed for the presence of MPO-ANCA and PR3-ANCA by ELISA at the time of presentation. Within the population with pauci-immune CGN ( $n=73)$, MPO-ANCA and PR3-ANCA were detected in 35 and 39 samples, respectively. This reactivity was present in 71 samples because 3 samples were positive for both MPO- and PR3-ANCA. Samples of 2 additional patients with pauci-immune CGN appeared negative for both MPO- and PR3-ANCA. Nine patients were diagnosed as having anti-GBM nephritis. All patients tested positive for anti-GBM antibodies by ELISA; 5 of these were additionally positive for MPO-ANCA.

\section{GBM-ANCA dot-blot results in patients with pauci-immune CGN}

Table 2 shows the results of the GBM-ANCA dot-blot upon incubation with the 73 samples of patients with pauci-immune CGN. MPO-ANCA were unequivocally detected in 28 of 35 samples known to be MPO-ANCA positive as determined by ELISA. Two additional samples were equivocal positive for MPO-ANCA. All samples being negative $(n=5)$ or equivocal $(n=2)$ for MPO-ANCA on dot-blot were re-analyzed in the MPO-ANCA ELISA and were found positive. The sensitivity of the MPO-ANCA dot-blot therefore is between $80-86 \%$, depending on whether equivocal results are considered to be negative or positive. PR3-ANCA were unequivocally detected in 36 of 39 samples known to be PR3-ANCA positive and 1 additional sample was equivocal positive. Again, both negative samples and the equivocal sample were 
Table 1. Presence of ANCA and/or anti-GBM antibodies as determined by ELISA

\begin{tabular}{lllll}
\hline & $\begin{array}{l}\text { antibody } \\
\text { reactivity }\end{array}$ & \multicolumn{3}{l}{ Center of diagnosis } \\
\hline \multirow{2}{*}{ Pauci-immune crescentic } & MPO & Groningen & Maastricht & total \\
glomerulonephritis $(n=73)$ & PR3 & 17 & 15 & 32 \\
& MPO and PR3 & 2 & - & 36 \\
& negative & 2 & 1 & 3 \\
Anti-GBM nepritis $(n=9)$ & GBM & 2 & 2 & 2 \\
& GBM/MPO & - & 5 & 4 \\
& & & & 5 \\
\hline
\end{tabular}

Table 2. GBM-ANCA dot-blot results in patients with pauci-immune CGN

\begin{tabular}{lcccl}
\hline ELISA: & $\begin{array}{c}\text { MPO-ANCA } \\
(n=35)^{*}\end{array}$ & $\begin{array}{c}\text { PR3-ANCA } \\
(n=39)^{\star}\end{array}$ & $\begin{array}{l}\text { MPO \& PR3-ANCA } \\
(n=3)^{\star}\end{array}$ & $\begin{array}{l}\text { ANCA negative } \\
(n=2)\end{array}$ \\
\hline Dot-Blot: & $28(2)$ & $2(0)$ & $2(0)$ & $0(0)$ \\
PRO-ANCA & $2(1)$ & $36(1)$ & $1(1)$ & $0(0)$ \\
Anti-GBMCA & $2(1)$ & $0(3)$ & $0(0)$ & $0(0)$ \\
\hline
\end{tabular}

Table 3. GBM-ANCA dot-blot results in patients with anti-GBM nephritis

\begin{tabular}{lll}
\hline \multicolumn{1}{c}{ ELISA: } & $\begin{array}{l}\text { Anti-GBM antibodies } \\
(n=9)^{*}\end{array}$ & $\begin{array}{l}\text { Anti-GBM/MPO-ANCA } \\
(n=5)\end{array}$ \\
Dot-Blot: & $9(0)$ & $5(0)$ \\
\hline Anti-GBM antibodies & $4(1)$ & $4(1)$ \\
MPO-ANCA & $0(0)$ & $0(0)$ \\
PR3-ANCA & &
\end{tabular}

Numbers represent unequivocal positive results in the dot-blot assay; numbers between brackets represent equivocal results. * Anti-GBM antibodies include anti-GBM single-positive sera $(n=4)$ and anti-GBM/MPO-ANCA double-positive sera $(n=5)$.

re-tested and found to be positive in the PR3-ANCA ELISA. The sensitivity of the PR3-ANCA dot-blot therefore varies between $92-95 \%$. When evaluating the dot-blot assay in terms of overall sensitivity and specificity for pauci-immune CGN, it appeared that 63 of 73 samples were unequivocal positive for MPO and/or PR3-ANCA. Three additional samples were equivocal positive, revealing a sensitivity between $86-90 \%$. The specificity of the ANCA dot-blot for pauci-immune CGN was $100 \%$.

The GBM-ANCA dot-blot assay also revealed reactivities that had not been detected by ELISA. Firstly, 1 sample that was only positive for MPO-ANCA by ELISA revealed unequivocal positive results for both PR3- and MPO-ANCA in the dot-blot assay. Secondly, 2 samples from patients with MPO-ANCA associated CGN appeared to be unequivocal positive for anti-GBM antibodies. This reactivity was confirmed by anti-GBM ELISA and therefore was considered as 
true-positive. Four additional patients had equivocal results with respect to anti-GBM antibodies. This reactivity could not be confirmed by anti-GBM ELISA or IIF.

Finally, two patients that presented with pauci-immune CGN had negative results for ANCA as tested by MPO- and PR3-ANCA ELISA, and these were negative by dot-blot assay as well.

\section{GBM-ANCA dot-blot results in patients with anti-GBM nephritis}

Nine patients with anti-GBM nephritis were included. Anti-GBM antibodies were detected by dot-blot analysis in all these patients (table 3). Five of these samples also contained MPO-ANCA as determined by ELISA. The MPO-ANCA were detected in the dot-blot assay unequivocally in 4 of these samples, whereas the fifth sample revealed an equivocal result (sensitivity $80-100 \%$ ). PR3-ANCA were not detected in these samples by dot-blot.

\section{Specificity of the GBM-ANCA dot-blot assay}

In order to determine the specificity of the GBM-ANCA dot-blot assay we tested control samples from both healthy $(n=5)$ and disease controls $(n=29)$. For MPO- and PR3-ANCA the specificity was excellent (100\%) since no positivity was observed in any of the control samples. For anti-GBM antibodies, however, 2 unequivocal reactions (1 SLE nephritis and 1 rheumatoid factor control) and 1 equivocal reaction (hyper-lgG control) were observed. The presence of anti-GBM antibodies could not be confirmed in these samples by direct ELISA. The specificity of the anti-GBM antibody dot-blot assay therefore varies between 91 - $94 \%$ (table 4).

\section{Inter-observer effect of the GBM-ANCA dot-blot}

The GBM-ANCA dot-blot assay did reveal unanimous results for MPO-ANCA in 110 of the 116 tested samples (95\%). Non-unanimous results were only obtained in samples known to be positive for MPO-ANCA as determined by ELISA. These 6 samples were scored positive by 1,4 , $4,6,8$, and 8 observers, respectively, revealing 1 negative, 3 equivocal, and 2 positive overall results and an inter-observer effect of $5 \%$ (table 4). The inter-observer effect for PR3-ANCA was only $1 \%$ (table 4), because only 1 sample, being positive for PR3-ANCA by ELISA, was not scored unanimously positive. Only 7 observers detected PR3-ANCA positivity in this sample revealing an equivocal overall result. All samples from patients with anti-GBM nephritis were unanimous positive in the dot-blot. However, many non-unanimous results were obtained in the other samples (table 5). The inter-observer effect appeared to be $24 \%$. Importantly, 2 observers appeared responsible for the majority (61\%) of these non-unanimous results. Exclusion of these 2 observers reduced the inter-observer effect to $8 \%$ (table 4 ).

\section{Discussion}

The occurrence of RPGN constitutes a medical emergency. After correct diagnosis, early treatment can prevent adverse outcome like end-stage renal disease or death. Causes of RPGN include ANCA-associated CGN and anti-GBM nephritis. In order to quickly identify patients with these forms of RPGN antibody testing is of great importance. In this context, rapid 
48 Chapter 3

Table 4. Characteristics of the GBM-ANCA dot-blot assay

\begin{tabular}{llll}
\hline & MPO-ANCA & PR3-ANCA & Anti-GBM antibodies \\
\hline Sensitivity & $80-86 \%{ }^{*}$ & $92-95 \%^{*}$ & $100 \%$ \\
Specificity & $100 \%$ & $100 \%$ & $91-94 \%$ * \\
Inter-observer effect & $5 \%$ & $1 \%$ & $8-24 \%$ * \\
\hline
\end{tabular}

*Sensitivity and Specificity vary depending on whether equivocal results are considered negative or positive.

**Inter-observer effect for anti-GBM antibodies varies depending on whether 2 observers, being responsible for $61 \%$ of the non-unanimous results are included $(24 \%)$ or excluded $(8 \%)$.

Table 5. Inter-observer effect for detection of anti-GBM antibodies by dot-blot analysis

\begin{tabular}{lllllllllll}
\multicolumn{1}{l}{} & \multicolumn{1}{l}{ Negative } & \multicolumn{1}{l}{ Equivocal } & \multicolumn{1}{c}{ Positive } \\
\hline & 0 & 1 & 2 & 3 & 4 & 5 & 6 & 7 & 8 & 9 \\
Anti-GBM antibodies & - & - & - & - & - & - & - & - & - & 9 \\
Anti-GBM neg. CGN & 49 & $14^{*}$ & $4^{*}$ & 2 & - & - & 2 & - & - & 2 \\
Controls & 28 & $2^{\star}$ & $1^{*}$ & 1 & - & - & - & - & 2 & - \\
\hline
\end{tabular}

* Two observers were responsible for a positive score in 17 of these samples.

ANCA-GBM dot-blot assays that can be performed without the need for a well equipped laboratory may facilitate this serological testing, especially in situations where conventional ANCA testing is not available.

The ANCA-GBM dot-blot has advantage over standard ANCA and anti-GBM tests in terms of costs, time, and easiness ( 1 assay versus 3 assays).

Previously, the performance of the MPO- PR3-ANCA dot-blot was studied in samples that were positive for ANCA as tested by ELISA. The dot-blot was found to have a high sensitivity and specificity for PR3-ANCA ( $100 \%$ and $98 \%$ respectively), but a low sensitivity and high specificity for detecting MPO-ANCA ( $53 \%$ and $97 \%$, respectively) ${ }^{16}$. In this study, however, serum samples were selected by being positive in an ELISA and not based on clinical diagnosis. To further study this dot-blot assay, we performed an extended study and included serum samples from consecutive patients with biopsy proven CGN. The performance of the dot-blot is excellent for detection of PR3-ANCA, with a high sensitivity and specificity. MPO-ANCA are detected with a high specificity as well, but a reduced sensitivity was observed: between 14 $20 \%$ of patients were missed. In case of a negative dot-blot result in patients with a high clinical suspicion for MPO-ANCA associated RPGN it should be advised that conventional analysis for MPO-ANCA is subsequently performed. Specificity in our studies was $100 \%$, i.e. no patients were wrongfully diagnosed as having MPO-ANCA associated vasculitis.

We detected anti-MPO positivity in about half of our anti-GBM positive samples. In the literature about $30 \%$ of patients with anti-GBM disease have serum positivity for MPO-ANCA ${ }^{17.18}$. These double positive patients are suggested to have a different prognosis and response to therapy ${ }^{19,20}$. 
We also found that the sensitivity of the anti-GBM dot-blot was excellent. False positive results were, however, observed in a substantial portion of serum samples. Moreover, we observed a high inter-observer effect for the detection of anti-GBM antibodies. Thus a negative anti-GBM dot blot makes anti-GBM disease very unlikely, but positive samples should be re-evaluated by conventional anti-GBM tests. This policy has the advantage that only a few samples need to be tested additionally, which often requires sending of the sample to an external laboratory.

ANCA are often used in clinical follow-up as well. A rise in ANCA levels indicates a high risk of disease relapse and warrant clinical evaluation of the patient for signs of relapse ${ }^{21-23}$. The dot-blot method is not capable of indicating antibody titers, it is either positive or negative, and is thus of limited value during follow-up of disease.

In conclusion, the ANCA-GBM dot-blot has advantage over standard ANCA and anti-GBM tests in terms of costs, time, and simplicity. The performance of the dot-blot is excellent for detection of PR3-ANCA, but the assay has reduced sensitivity for MPO-ANCA. Also, the specificity of the anti-GBM dot-blot is hampered by a high inter-observer effect. Knowing these restrictions, the ANCA-GBM dot-blot is a useful screening tool in situations were conventional ANCA testing is not available.

\section{Acknowledgements}

J. Austen, J. Barron-Houben, R. Brandts, J. Giessen, Y. Knapen, L. Musson, and M. Vaessen of the Clinical Immunology laboratory in Maastricht are gratefully acknowledged for excellent technical assistance. We also like to thank Biomedical Diagnostics for supplying the dot-blots; no further financial support was obtained for this study. None of the authors has received any kind of consulting fees from Biomedical Diagnostics.

\section{References}

1. Hricik DE, Chung-Park M, Sedor JR: Glomerulonephritis. N Engl / Med 339:888-899, 1998

2. Couser WG: Glomerulonephritis. Lancet 353:1509-1515, 1999

3. Johnson JP: Rapidly progressive glomerulonephritis, in Primer on kidney disease, edited by Greenberg A, San Diego, Academic Press, 1994, pp 94-99

4. Levy JB, Turner AN, Rees AJ, Pusey CD: Long-term outcome of anti-glomerular basement membrane antibody disease treated with plasma exchange and immunosuppression. Ann Intern Med 134:1033-1042. 2001

5. Bajema IM, Hagen EC, Hermans J, Noel LH, Waldherr R, Ferrario F, Van Der Woude FJ, Bruijn JA: Kidney biopsy as a predictor for renal outcome in ANCA-associated necrotizing glomerulonephritis. Kidney Int $56: 1751-1758,1999$

6. Slot MC, Cohen Tervaert JW, Franssen CF, Stegeman CA: Renal survival and prognostic factors in patients with PR3-ANCA associated vasculitis with renal involvement. Kidney Int 63:670-677, 2003

7. Savige J, Davies D, Falk RJ, Jennette JC, Wiik A: Antineutrophil cytoplasmic antibodies and associated diseases: a review of the clinical and laboratory features. Kidney int 57:846-862, 2000

8. Cohen Tervaert JW, Limburg PC, Elema JD, Huitema MG, Horst G, The TH, Kallenberg CG: Detection of autoantibodies against myeloid lysosomal enzymes: a useful adjunct to classification of patients with biopsy-proven necrotizing arteritis. Am J Med 91:59-66, 1991 
9. Csernok E, Ahlquist D, Ullrich $S$, Gross WL: A critical evaluation of commercial immunoassays for antineutrophil cytoplasmic antibodies directed against proteinase 3 and myeloperoxidase in Wegener's granulomatosis and microscopic polyangitis. Rheumatology (Oxford) 41:1313-1317, 2002

10. Boomsma MM, Stegeman CA, Oost-Kort WW, Kallenberg CG, Moguilevsky N, Limburg PC, Cohen Tervaert JW: Native and recombinant proteins to analyze auto-antibodies to myeloperoxidase in pauci-immune crescentic glomerulonephritis. IImmunol Methods 254:47-58, 2001

11. Jennette JC, Wilkman AS, Falk RJ: Anti-neutrophil cytoplasmic autoantibody-associated glomerulonephritis and vasculitis. Am I Patho/ 135:921-930, 1989

12. Hogan SL, Nachman PH, Wilkman AS, Jennette JC, Falk RJ: Prognostic markers in patients with antineutrophil cytoplasmic autoantibody-associated microscopic polyangiitis and glomerulonephritis. J Am Soc Nephrol 7:23-32, 1996

13. Cohen Tervaert JW, Goldschmeding R, Elema JD, van der Giessen M. Huitema MG, van der Hem GK, The $T H$, von dem Borne AE, Kallenberg CG: Autoantibodies against myeloid lysosomal enzymes in crescentic glomerulonephritis. Kidney Int 37:799-806, 1990

14. Glassock RJ. Adler SG, Cohen AH: Primary Glomerular Diseases, in The Kidney (vol 1), edited by Brenner BM, Rector FC, 4 ed, Philadelphia, W.B. Saunders Company, 1991, pp 1182-1279

15. Boomsma MM, Damoiseaux JG, Stegeman CA, Kallenberg CG, Patnaik M, Peter JB, Cohen Tervaert JW: Image analysis: a novel approach for the quantification of antineutrophil cytoplasmic antibody levels in patients with Wegener's granulomatosis. J Immunol Methods 274:27-35, 2003

16. Ermens AA, Bayens AJ, Crooymans A, Broekman-Van Hout AA, van Duijnhoven HL: Evaluation of a simple dot-blot method for the detection of anti-neutrophil cytoplasmic antibodies directed against proteinase 3 and myeloperoxidase. Clin Chem 46:1717-1719, 2000

17. Short AK, Esnault VL, Lockwood CM: Anti-neutrophil cytoplasm antibodies and anti-glomerular basement membrane antibodies: two coexisting distinct autoreactivities detectable in patients with rapidly progressive glomerulonephritis. Am J Kidney Dis 26:439-445, 1995

18. Hellmark T, Niles U., Collins AB, MCCluskey RT, Brunmark C: Comparison of anti-GBM antibodies in sera with or without ANCA. I Am Soc Nephrol 8:376-385, 1997

19. Bosch X, Mirapeix E, Font J, Borrellas X, Rodriguez R, Lopez-Soto A, Ingelmo M, Revert L: Prognostic implication of anti-neutrophil cytoplasmic autoantibodies with myeloperoxidase specificity in anti-glomerular basement membrane disease. Clin Nephrol 36:107-113, 1991

20. Hudson BG, Tryggvason K, Sundaramoorthy M, Neilson EG: Alport's syndrome, Goodpasture's syndrome, and type IV collagen. N Engl I Med 348:2543-2556, 2003

21. Rutgers A, Heeringa P, Damoiseaux J, Cohen Tervaert JW: ANCA and anti-GBM antibodies in diagnosis and follow-up of vasculitic disease. Eur J Intern Med 14:287-295, 2003

22. Han WK, Choi HK, Roth RM, MCCluskey RT, Niles JL: Serial ANCA titers: Useful tool for prevention of relapses in ANCA-associated vasculitis. Kidney int 63:1079-1085, 2003

23. Stegeman CA: Anti-neutrophil cytoplasmic antibody (ANCA) levels directed against proteinase-3 and myeloperoxidase are helpful in predicting disease relapse in ANCA-associated small-vessel vasculitis. Nephrol Dial Transplant 17:2077-2080, 2002 
CHAPTER 4

\section{High affinity of anti-GBM antibodies from Goodpasture and transplanted Alport patients to $\alpha 3$ (IV)NC1 collagen}

Abraham Rutgers, Kevin E.C. Meyers, Gabriela Canziani, Raghuram Kalluri, Julie Lin, and Michael P. Madaio

The PENN Center for Molecular Studies of Kidney Diseases, Department of Medicine, University of Pennsylvania, Philadelphia, Pennsylvania, and Nephrology Division, Department of Medicine, Beth Israel Deaconess Medical Center and Harvard Medical school, Boston, Massachusetts, USA

Kidney Int 2000 Jul; 58(1): 115-22. 


\section{ABSTRACT}

Background. Anti-glomerular basement membrane (anti-GBM)antibody-mediated diseases are characterized by rapidly progressive glomerulonephritis (RPGN) that often results in irreversible loss of renal function and renal failure. Although many factors contribute to the fulminant nature and treatment resistance of this disease, we questioned whether high affinity auto-antibody- $\alpha 3$ (IV) collagen interactions lead to persistent antibody deposition, thereby perpetuating inflammation. To address this hypothesis, the binding kinetics of human anti-GBM antibodies (Ab) to $\alpha 3$ (IV)NC1 were evaluated using an optical biosensor interaction analysis.

Methods. Polyclonal anti-GBM Abs were purified by $\alpha 3$ (IV)NC 1 affinity chromatography from the sera of patients with anti-GBM AB-mediated diseases, including individuals with Goodpasture syndrome (GS), idiopathic RPGN $(n=7)$, and Alport syndrome $(A L)$ following kidney transplantation $(n=4)$. The affinity-binding characteristics of the auto-antibodies were determined using a biosensor analysis system, with immobilized bovine $\alpha 3$ (IV)NC1 dimers.

Results. All of the auto-antibody preparations bound to $\alpha 3$ (IV)NC1, whereas none bound to $\alpha 1$ (IV)NC1 (control). Purified, normal serum IgG did not bind to either antigen. Estimated dissociation constants $(\mathrm{Kd})$ for the purified auto-antibodies were 1.39E-04 $\pm 7.30 \mathrm{E}-05 \mathrm{~s}^{-1}$ (GS) and 8.90E-05 $\pm 2.80 \mathrm{E}-05$ $\mathrm{S}^{-1}(\mathrm{AL})$. Their estimated association constants $(\mathrm{Ka})$ were $2.67 \mathrm{E}+04 \pm 1.8+04$ (M-Is-I) and 2.76E+04 $\pm 1.70 E+04$ (M-Is-I) for GS and AL patients, respectively. By comparison with other Ab interactions, these Abs demonstrated high affinity, with relatively high on (binding) rates and slow off (dissociation) rates.

Conclusions. The results suggest that anti-GBM Abs bind rapidly and remain tightly bound to the GBM in vivo. This property likely contributes to both the fulminant nature of this disease and its resistance to therapy, because persistent glomerular $\mathrm{Ab}$ deposition has the potential to produce continuous inflammation, despite removal of circulating $\mathrm{Abs}$ and adequate immuno suppression. 


\section{Introduction}

Spontaneous production and deposition of anti-GBM antibodies characterize anti-GBM antibody-mediated diseases. The disease spectrum includes patients with glomerulonephritis and pulmonary hemorrhage [Goodpasture syndrome (GS)], rapidly progressive glomerulonephritis (RPGN) without clinical evidence of lung involvement (type I), and isolated pulmonary hemorrhage ${ }^{1,2}$. The mortality in patients with GS is high $(11 \%)$, and 40 to $70 \%$ of patients with anti-GBM antibody mediated nephritis develop end-stage renal disease ${ }^{3-6}$. Of potential pathogenic relevance, anti-GBM antibodies are frequently produced in patients with Alport's syndrome following renal transplantation, and a significant fraction of these patients develops crescentic glomerulonephritis that results in the loss of graft function 7,8 .

In the spontaneous form of the disease, the factors leading to auto-antibody production are unclear, however exposure of "hidden" basement membrane antigens and molecular mimicry have been postulated to be involved in disease induction ${ }^{9}$. Nevertheless, it has been conclusively demonstrated that the NC 1 domain of $\alpha .3$ chain of type IV collagen [ $\alpha 3$ (IV)NC 1$]$ is the major auto-antigenic target ${ }^{9-12}$. Similarly, in patients with Alport syndrome (AL) who develop anti-GBM disease following kidney transplantation, most studies find that the auto-antibodies are directed at $\alpha 3$ (IV)NC1, despite a lack of expression of $\alpha 5$ (IV)NC 1 in the native kidneys ${ }^{13}$. Presumably novel $\alpha 3$ (IV)NC1 epitopes are expressed in the transplanted kidney. Anti- $\alpha 5$ (IV)NC 1 antibody serum activity has also been described, although the pathogenecity of the latter is less certain (Kalluri, unpublished observations) $)^{14}$.

A particularly striking feature of these diseases is their resistance to therapy. Despite treatment with plasmapheresis to remove circulating antibodies, glucocorticoids to suppress inflammation, and cyclophosphamide for immuno suppression to reduce auto-antibody production and suppress B- and T-cell activity, irreversible renal failure is common 3,5,15,16. This is especially evident in patients with a significant reduction of GFR at the time treatment is initiated. Of potential clinical relevance, these therapies are directed at either removing circulating antibodies, suppressing auto-antibody production, or reducing ongoing inflammation. They do not, however, deal with the possibility that glomerular-bound antibody may linger within the glomerulus, with the potential for continuous perpetuation of inflammation and fibrosis, despite the aforementioned aggressive, therapies to remove circulating auto-antibodies and decrease their production. In this regard, deposited anti-GBM antibodies tightly bound to $\alpha 3$ (IV)NC 1 within the glomerulus could perpetuate inflammation, prolong injury, and limit recovery. To address this possibility, we examined the kinetics of anti-GBM antibody- $\alpha 3$ (IV)NC 1 interactions using auto-antibodies derived from nephritic patients. Analysis of binding and dissociation as a function of time indicated that anti-GBM antibodies bind rapidly and tightly to $\alpha 3$ (IV)NC 1 . Once bound, they remain complexed, with slow dissociation rates. Thus, the results suggest that securely bound anti-GBM antibodies linger within the glomerulus, in vivo, and that their continued presence may perpetuate inflammation, despite the removal of circulating auto-antibodies and suppression of auto-reactive $B$ cells. This phenomenon may contribute to the accelerated and progressive nature of disease in these patients. 


\section{Methods}

\section{Sera}

Alport syndrome and GS sera were obtained from patients with active nephritis who had circulating anti- GBM antibodies and linear deposits of $\mathrm{IgG}$ along the GBM. Anti- $\alpha 1$ serum was obtained from a patient who developed anti- $\alpha .1$ auto-antibodies in the setting of lung carcinoma ${ }^{17}$.

Expression and purification of the recombinant $\alpha 3$ (IV)NC 1 antigen and purification of sera from GS and AL patients

Recombinant $\alpha 3$ (IV)NC1 antigen was prepared as previously described ${ }^{10,18}$. Briefly, sera from GS and AL patients were purified over a recombinant $\alpha 3$ (IV)NC 1 affinity column; the concentration and purity of the anti-bodies were determined by sodium dodecyl sulfate-polyacrylamide gel electrophoresis (SDS-PAGE). Enzyme- linked immunosorbent assays (ELISA) and dot blot assays were used to confirm anti- $\alpha 3$ (IV)NC1 activity of the purified anti-GBM antibodies, using previously described methods ${ }^{18}$. As described later in this article, the recombinant $\alpha 3$ (IV)NC 1 was used only for antibody purification and to test for post-purification antibody reactivity.

\section{Production of bovine $\alpha .1$ (IV)NC 1 and $\alpha 3$ (IV)NC 1 dimers}

Bovine $\alpha 1(\mathrm{IV}) \mathrm{NC} 1$ and $\alpha 3(\mathrm{IV}) \mathrm{NC} 1$ dimers were isolated from bovine testis, as previously described ${ }^{19}$. The isolated dimers were characterized by type IV collagen chain-specific antibodies by ELISA and Western blot, and were shown to be pure before use ${ }^{19}$. These bovine $\alpha 1$ (IV)NC1 and $\alpha .3$ (IV)NC1 dimers were used in the optical biosensor interaction analysis.

\section{Optical biosensor interaction analysis}

Surface plasmon resonance (SPR) was used to determine antibody-antigen interactions in a BIAcore 2000 instrument (BIAcore AB, Uppsala, Sweden). The principles by which optical biosensors operate are described in detail elsewhere ${ }^{20,21}$. Briefly, SPR occurs when light at an angle equal to or higher than the critical angle is directed at the base of a prism onto which a semitransparent gold film is coupled. This results in total internal reflection (TIR) at which an evanescent field is formed. The evanescent field couples with an electromagnetic surface wave at the gold/liquid interface called surface plasmon. The plasmon is a propagating electrode mode in a metal at a metal/dielectric interface, which is maximal at the interface and decays exponentially in intensity in a direction perpendicular to the surface 22,23 . The SPR angle at which this coupling occurs is sensitive to the refractive index close to the gold film. By linking the gold film with a single chain (non-cross-linked) carboxymethylated dextran, it is possible to register changes in the evanescent field profile resulting from the binding of a protein to the dextran layer, where resonance angle shifts toward higher values as the refractive index of the aqueous solution in the neighborhood of the gold surface $(100 \mathrm{~nm})$ increases ${ }^{21}$. In the BIA-core, an integrated microfluidic cartridge (IFC) controls the continuous flow of buffer or injection of sample over the dextran surfaces ${ }^{20}$. Different chemical coupling reac- 
tions are used to couple the antigen to the dextran matrix. By using the negative charge of the matrix and the positive charge of the antigen, below its $\mathrm{pl}$, it is possible to concentrate the antigen in the dextran layer; a covalent bond is then formed by previously activating the surface with N-hydrosuccinimide (NHS), N-ethyl-N9-(3-diethyl-aminopropyl)-carbodiimide (EDC), and ethanolamine-hydrochloride.

The bovine $\alpha 1$ (IV)NC1 and $\alpha 3$ (IV)NC1 antigens (purified from bovine testis) were coupled to the sensor surface (carboxymethyl-dextran, sensor chips CM5; Research Grade, BIAcore AB, Uppsala, Sweden) at a flow of $10 \mathrm{uL} / \mathrm{min}$, as previously described ${ }^{22}$. Spare amine-coupling sites were blocked with $1 \mathrm{~mol} / \mathrm{L}$ ethanolamine, $\mathrm{pH}$ 8.0, at a surface density of approximately $1000 \mathrm{RU}$ per sample per surface; however, the maximum auto-antibody binding capacity of these surfaces was found to be around $200 \mathrm{RU}$ after repeated immobilization assays. The surfactant Tween P-20, phosphate buffered saline, NHS, EDC, and ethanolamine-hydrochloride were obtained from Sigma (St. Louis, MO, USA). The purified bovine $\alpha 1$ (IV)NC1 and $\alpha 3$ (IV)NC 1 were immobilized to a carboxymethylated dextran hydrogel layer using EDC/NHS chemistry. At a pH of 4.5, the interaction between the $\alpha 3$ (IV)NC1 and the negatively charged carboxyl groups was optimal. Approximately 1000 RUs were coupled to the sensor matrix. Adequate coupling of the bovine $\alpha 3$ (IV)NC 1 and of bovine $\alpha 1$ (as a negative control) to the cell surface was achieved (data not shown). It was not possible to immobilize recombinant $\alpha 3$ (IV)NC 1 to the carboxymethylated dextran hydrogel layer, as the E. coli expressed protein precipitated from solution despite vigorous attempts to solubilize it prior to coupling. A blank, activated and blocked under the same protocol without antigen, was used as an additional control. The three surfaces (blank, $\alpha 3$ antigen, and $\alpha 1$ antigen) were conditioned twice with $\mathrm{HCl} 20 \mathrm{mmol} / \mathrm{L}$ injections at a flow of $30 \mathrm{uL} / \mathrm{min}$ for one minute to purge unbound antigen and to test for stability of the baseline and regeneration. Affinity-purified active serum antibodies were then passed over the three flow cells in series using different concentrations (200 to 6.25 $\mathrm{nmol} / \mathrm{L}$, twofold dilutions) in this order: activated blank, $\alpha 3$, and $\alpha 1$. The $\alpha 1$ antigen was used as an additional control surface, and it was further tested for specificity by exposure to affinity purified anti- $\alpha 1$-specific $\lg G^{17}$. Normal human serum Ig $G$ was also passed over the three surfaces; however, binding by the normal human IgG antibody fraction was never detected. The kinetics of binding are initially evaluated assuming the ligand (analyte) is in solution. The analyte, auto-antibody $[A]$ interacts with the immobilized antigen [B] (in this case the antigens $\alpha 3$ and $\alpha 1$ ), to form complex [AB]). The net rate of complex formation depends on the free concentration of $A$, the $R_{\text {max }}$ in RU or maximum binding capacity of the surface, $B$, and the stability of the formed complex $A B$. Kinetics data are evaluated using relationships described previously ${ }^{24}$. For a bimolecular interaction, the signal change with time is given by $d R / d t=k$ on $[A]$ $\left(R_{\max }-R\right)-$ koffR

At equilibrium, the amount of complex formed is equal to the amount of complex dissociated. Under those conditions, $\mathrm{dR} / \mathrm{dt}=0$ so that redistributing

$\operatorname{Req}=\operatorname{kon}[A] R_{\max } / k o n[A]+\operatorname{koffR}$ 
Based on these equations, plots of $d R / d t$ versus $R$, In $d R / d t$ versus $t$ will be linear, with negative slope ks = kon $[A]+$ koff. The extrapolated intercept of the linear portion of the derivative of the binding signal would correspond to the expected signal in RU at steady state. The parameters obtained from the linear transformations of the raw data were compared with the BIA evaluations 3.0 estimates of independent analysis of association and dissociation ${ }^{24}$. Global fit of parameters using the two-compartment model to account for the effect of mass transfer (diffusion limited kinetics) was evaluated using 3.0.1 BIAevaluation software.

\section{Results}

All of the patients' purified anti-GBM auto-antibodies bound to the $\alpha$ (IV)NC1 coupled to the biosensor surface. Figure $1 \mathrm{~A}$ shows the binding of anti- $\alpha 3$ (IV)NC 1 auto-antibodies to immobilized antigen. The injection of antibody to the sensor surface at a flow of $30 \mathrm{~L} / \mathrm{min}$ resulted in a rapid increase in binding (initial part of the curve) to the coupled $\alpha .3$ (IV)NC1 (seen as increasing RUs as a function of time). At the end of the injection, unbound antibody was washed from the $\alpha 3$ (IV)NC 1 surface with phosphate-buffered saline (PBS)/Tween. The dissociation rate, visualized as an almost horizontal line, indicates that the antigen-antibody complex formed was very stable. All of the patient's anti-GBM antibodies, including GS and AL, had slow dissociation rates. The GS and AL patient's auto-antibodies bound only to the $\alpha 3$ (IV)NC1 surface. The anti-GBM antibodies did not bind to the $\alpha 1$ cell, proving their selectivity for the $\alpha 3$ (IV)NC 1. By contrast, the anti- $\alpha 1$ auto-antibodies (derived from a patient with lung carcinoma without disease) bound only to the $\alpha 1$ (IV)NC1 surface. The normal human lgG did not bind to either surface. Figure $1 \mathrm{~B}$ shows the binding of the anti- $\alpha 1$ antibodies to the $\alpha 1$ (IV)NC 1 -coupled sensor cell. The anti- $\alpha 1$ antibodies have a rapid dissociation rate, indicating that this reaction is less stable than that of anti-GBM patients with auto-antibodies to $\alpha 3$ (IV)NC1 collagen.

\section{Kinetic analysis of anti-GBM antibodies}

To further evaluate the kinetic constants of binding of the anti-GBM antibodies, dose-responses were further analyzed. Figures $2 \mathrm{~A}$ and $3 \mathrm{~A}$ show the raw data obtained from varying concentrations of affinity-purified auto-antibodies from a single patient (range 6.25 to $200 \mathrm{nmol} / \mathrm{L}$ ). Similar concentration curves were obtained from each patient and used to determine the kinetics of binding of the auto-antibodies for each individual. The kinetic parameters for each patient's auto-antibodies binding response were then further estimated from calculations of the linear transformations of the Langmuir equation, as described in the Methods section. Figures $2 \mathrm{~B}$ and $3 \mathrm{~B}$ show a family of linear plots of the first derivative of the binding signal (rate of signal change) versus the response at each time point. The secondary plots of the calculated slopes [kobs (s-1)] plotted versus the concentration of auto-antibody samples are linear with slopes equal to the kinetic on rate constant kon (Figs. $2 \mathrm{C}$ and $3 \mathrm{C}$ ). The exponential dissociation of auto-antibody described by the In RO/R 1 versus time of dissociation is shown by Figures 2D and 3D. 
A
Association
Dissociation

150

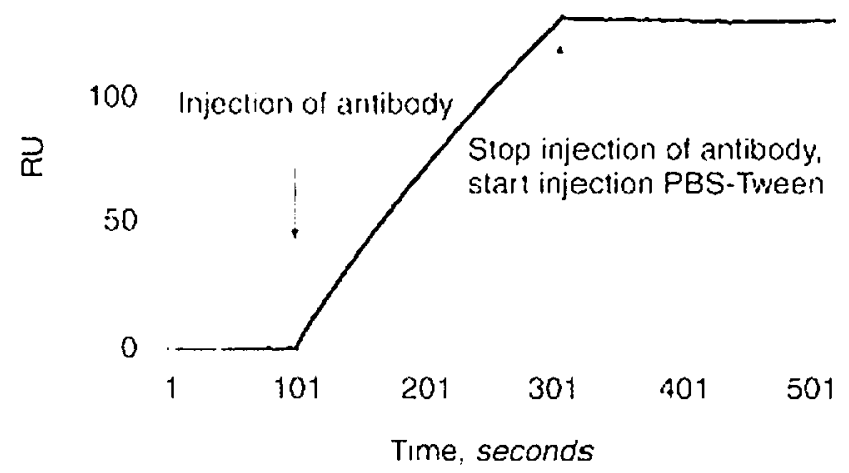

B

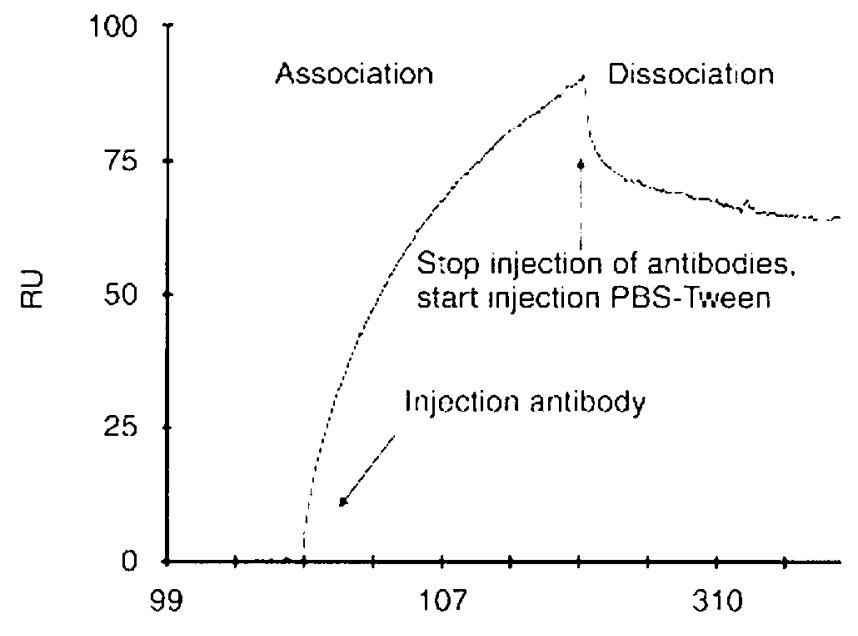

Time, seconds

Figure 1. (A) Sensorgram illustrating binding of purified anti-GBM auto-antibodies ( $200 \mathrm{nmol} / \mathrm{L})$ to the $\alpha 3$ (IV)NC1 surface (1000 RU density) at a flow of $30 \mathrm{uL} / \mathrm{min}$. Binding is characterized by a rapid association rate and very slow dissociation rate. (B) Binding of anti- $\alpha$.1 (IV)NC1 antibodies to immobilized $\alpha$. (IV)NC1. Note the faster dissociation of the anti- $\alpha$.1 (IV)NC1 antibodies when compared with the stable formation of the anti-GBM- $\alpha 3(\mathrm{IV}) \mathrm{NC} 1$ complex in $1 \mathrm{~A}$. 
A
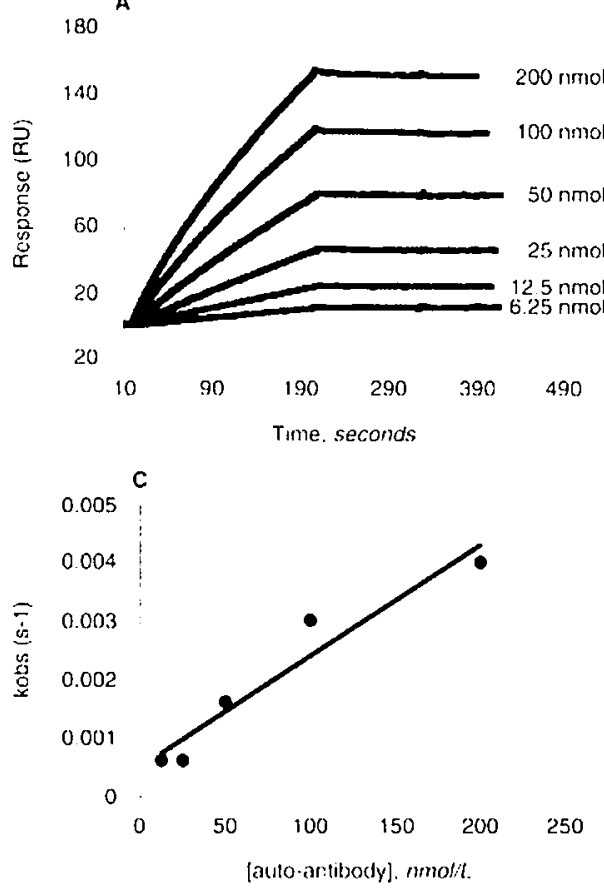
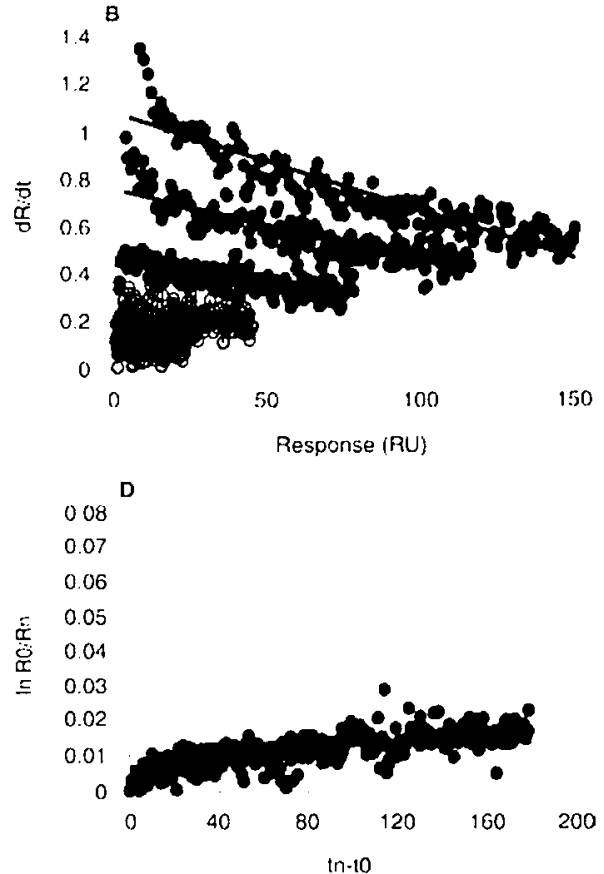

Figure 2. (A) Dose response sensorgrams showing increased binding of a typical patient's GBM antibodies to $\alpha .3$ (IV)NC 1 coupled to the dextran surface. The time of contact, 200 seconds, and the flow, $30 \mathrm{uL} / \mathrm{min}$, were constant throughout the experiment. (B) Linear transformation of the association portion of the binding data in which the derivatives of the binding signal are plotted as a function of the signal at each time point (Methods section), $r^{2}$ for the linear fits $\geq 0.975$. (C) Secondary plots of the association data in which the calculated slopes are plotted as a function of concentration of antibody give straight lines in the Langmuir model of binding at a surface with slope equal to the kon $(\mathrm{M}-1 \mathrm{~s}-1)$. (D) Linear transformation of the dissociation data from $A$ as plots of In (R1/R0) versus time. The calculated slopes are a measure of the koff for the interaction. Koff for the highest binding signal reported was used in the estimate of the dissociation rate constant for each patient.

Table 1. Affinity kinetic values for Goodpasture syndrome (GS) and Alport syndrome (AL) anti-GBM auto-antibodies (at a uniform $50 \mathrm{nmol} / \mathrm{L}$ concentration of autoantibody)

\begin{tabular}{llll}
\hline Patients & $K_{d}(s-1)$ & $K_{a}(M-1 s-1)$ & $K_{D}\left(K_{D} / K_{a}\right)$ \\
\hline$G S(n=7)$ & $1.39 E-4 \pm 7.3 E-5$ & $2.67 E+4 \pm 1.8 E+4$ & $5.2 n m o l / L \pm 4.1 E-9$ \\
AL $(n=4)$ & $8.90 E-5 \pm 2.8 E-5$ & $2.76 E+4 \pm 1.7 E+4$ & $3.2 \mathrm{nmol} / \mathrm{L} \pm 1.7 \mathrm{E}-9$ \\
Combined $(n=11)$ & $1.21 E-4 \pm 6.37 \mathrm{E}-5$ & $2.70 \mathrm{E}+4 \pm 1.67 \mathrm{E}+4$ & $4.5 \mathrm{nmol} / \mathrm{L} \pm 3.81 \mathrm{E}-9$ \\
\hline
\end{tabular}



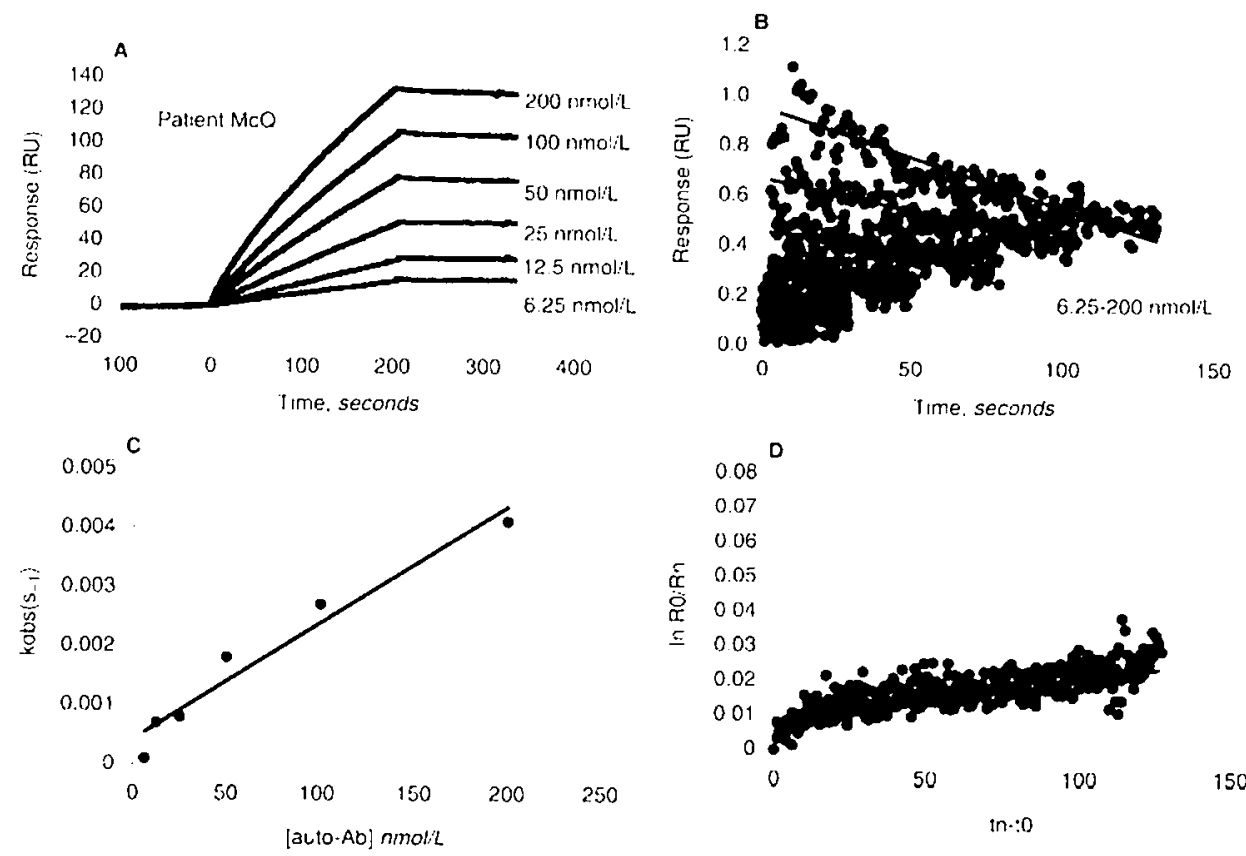

Figure 3. (A) Dose response sensorgrams showing increased binding of Alport patient 5 's antibodies to $\alpha .3$ (IV)NC 1 coupled to the dextran surface. The time of contact, 200 seconds, and the flow, $30 \mathrm{uL} / \mathrm{min}$, were constant throughout the experiment. (B) Linear transformation of the association portion of the binding data in which the derivatives of the binding signal are plotted as a function of the signal at each time point (Methods section). $r^{2}$ for the linear fits $\geq 0.975$. (C) Secondary plots of the association data in which the calculated slopes are plotted as a function of concentration of antibody give straight lines in the Langmuir model of binding at a surface with slope equal to the kon $(M-1 s-1)$. (D) Linear transformation of the dissociation data from $A$ as plots of In (R1/RO) versus time. The calculated slopes are a measure of the koff for the interaction. Koff for the highest binding signal reported was used in the estimate of the dissociation rate constant for each patient. Calculated parameters are reported in Table 1. BIAevaluation software was used to fit the dissociation curves from concentrations of 50 to $200 \mathrm{nmol} / \mathrm{L}$ in order to calculate the dissociation constants $\left[K_{d}(s-1)\right] . K_{d}$ values obtained from curves below the $50 \mathrm{nmol} / \mathrm{L}$ concentration show a wide variation and a high standard error and $X^{2}$ score. The signal to noise ratios in the more dilute samples were too low to obtain statistically significant results, and therefore, they were not used in the analysis. The calculated Kd values from every patient at a concentration of $50 \mathrm{nmol} / \mathrm{L}$ were very similar (Table 1). From these data, using the $K_{\mathrm{d}}(\mathrm{s}-1)$ and the antibody concentration from each sample, it was possible to derive the association constants, $K a(M-1 s-1)$, and calculate $K_{D}\left[K_{D}=\left(K_{d} / K_{a}\right)\right]$ values. The results are indicated in Table 1 . Particularly noteworthy, all of the anti-GBM auto-antibodies derived from patients with nephritis have high affinities. This was evident from the rapid association rates and low dissociation rates. 


\section{Discussion}

To our knowledge, this is the first report of the kinetic analysis of human pathogenic auto-antibodies derived from patients with autoimmune disease directed against their major antigenic target. The results indicate that spontaneously produced anti-GBM antibodies have a high affinity for $\alpha 3$ (IV)NC 1 collagen; these auto-antibodies bind rapidly to their target antigen, and they remain tightly bound, with slow dissociation rates. The high affinities observed in our analysis of anti-GBM antibodies are comparable to high affinity antibodies that develop during a secondary immune response to foreign antigen 25 . Affinity-purified anti-GBM antibodies are mono-specific but not monoclonal, and therefore, some diversity in the binding characteristics of purified anti-GBM antibodies from a single patient is expected, which explains the slight deviations from the $1: 1$ interaction model. Since the kinetic data give a linear transformation, the bivalent model of interaction in which each antibody binds two immobilized $\alpha 3$ (IV)NC1 molecules cannot describe the observed kinetics of binding. All patients sera contained various amounts of high affinity $\alpha 3$ (IV)NC1 auto-antibodies, which can be completely removed by our affinity purification ${ }^{26}$. These high affinity antibodies purified from circulation are the same as those deposited in the GBM and are associated with disease onset ${ }^{27}$.

Affinity purification with $\alpha 3$ (IV)NC 1 collagen removed all detectable auto-antibody activity from anti-GBM sera, confirming our previous report ${ }^{26}$. Therefore, antibody activities of all affinities are removed by the procedure. Nevertheless, elution, per se, may sometimes alter antibody activity, leading to a loss of affinity. Although we cannot absolutely exclude the possibility that there was a small population of low affinity auto-antibodies that were completely destroyed during elution and lost all antibody activity, the results support the conclusion that the major fraction of antibodies were of high affinity. In this regard, a population of antibodies with low and intermediate affinities was not observed in any serum, as would be expected if some high and intermediate affinity antibodies were influenced by elution, further supporting the conclusion that the majority of auto-antibodies were of high affinity.

The rapid association rate may contribute to the abrupt clinical presentation often observed in patients with these auto-antibodies; RPGN is a relatively common presentation. If appropriate epitopes were exposed, high affinity circulating auto-antibodies passing through the glomerulus would, therefore, be expected to bind rapidly to $\alpha 3$ (IV)NC1 collagen. In this regard, the glomerular milieu is a particularly favorable environment, since the auto-antibody concentration rises as filtration occurs throughout the glomerular capillary. Rapid accumulation of deposited antibodies would then lead to the efficient recruitment of inflammatory mediators and severe inflammation, typical of patients with anti-GBM diseases. This phenomenon of rapid association may also explain the failure to detect circulating auto-antibodies in some patients with less sensitive assays, such as indirect immunofluorescence, since many of the auto-antibodies may be removed from the circulation after only a brief encounter with the GBM in vivo. 
The slow dissociation rates are also particularly striking. Although the bivalent binding capacity of intactlgG may contribute, if this were the only factor, at high concentrations, a faster dissociation rate would have been detected because of the unavailability of spare sites for second binding. This was not observed. Although it is not known whether divalent or monovalent binding of the antibodies to the sensor surface is a paradigm of the in vivo situation in which dissociation and rebinding to the GBM are likely to occur, it is of particular interest that the sensor cell surface consists of a $100 \mathrm{nmol} / \mathrm{L}$ thick layer of $\alpha .3(\mathrm{VI}) \mathrm{NC} 1$ coupled to dextran.

Of potential relevance, rapid association/slow dissociation of the auto-antibodies to the GBM in vivo may contribute to both the rapid onset of disease and resistance to treatment. Rapid and persistent antibody binding would favor a fulminant course, often found in patients with anti-GBM disease. Persistence of deposited auto-antibodies would lower the threshold for auto-antibody production required for disease expression since accumulation of deposited antibodies would be expected. Furthermore, once sufficient antibodies were bound to the GBM, their persistence would continue to incite inflammation despite the removal of circulating immunoglobulins. Although disease progression is influenced by multiple factors, including the individual's local and systemic inflammatory responses and the capacity of conventional therapies to alter them, the continuous pro-inflammatory and fibrogenic effects of deposited antibody could prevail. Of further interest, patients with AL and GS had similar populations of high affinity auto-antibodies. This finding is in agreement with Kalluri et al's conclusions that auto-antibodies in these patients have similar antigenic specificities and binding profiles (Kalluri, manuscript in press). Although further analysis is required for more accurate comparisons, the high affinity auto-antibodies from both groups are also consistent with the notion that this property is disease relevant. Further analysis of transplanted Alport's patients with auto-antibodies with and without nephritis should be especially informative. Nevertheless, the present results are consistent with the notion that high affinity auto-antibodies may be required for full-blown disease expression. The high affinity of these pathogenic immunoglobulins is consistent with an antigen-driven response ${ }^{25}$.

Whether exposures of neo-antigens or molecular mimicry mechanisms are operative, in this situation, the events lead to production of specific, high affinity antibodies. In this regard, we (R.K.) and others have suggested that glomerular injury (for example, with oxidants) leads to exposure of neo-antigens that incite the autoimmune process ${ }^{9}$. Kidney transplantation provides the ideal milieu for these events, with neo-antigen exposure, in the setting of inflammatory and immunogenic stimuli. Transient minor injury to kidney (for example, as observed with viral infections) could also be operative in otherwise normal individuals with the spontaneous form of the disease. Further molecular analysis of both the pathogenic auto-antibodies and potential immunogens should help to address this hypothesis ${ }^{24}$.

As previously alluded to, slow dissociation of the auto-antibodies is especially intriguing when considered in the context of the fulminant course disease course often observed among these patients $17,28,29$. Recovery diminishes significantly once the glomerular filtration rate is significantly impaired $17,28,29$. Although many factors likely contribute to this phenomenon, high affinity auto-antibody-GBM interactions would lead to persistent antibody deposition. These 
deposited auto-antibodies would, therefore, continue to incite inflammation, leading to more severe disease. Thus, once sufficient antibodies accumulate within the glomerulus, disease progression would be predictable, despite the removal of circulating auto-antibodies and/or administration of immunosuppressive agents. Therefore, therapies that are directed at either removal of glomerular bound anti-GBM antibodies or/and alteration of the pro-inflammatory properties of deposited immunoglobulins should be considered in future strategies to alter the course of this disease in patients with significant renal dysfunction at the time of diagnosis.

\section{Acknowledgements}

This work was supported by a George M. O'Brien Kidney and Urological Research Center Grant (DK45191); PHS Awards DK 33694, Al 27915, DK-51711 (R.K.), the DCI RED FUND; the Philadelphia Chapter of the American Heart Association; and the Carl Gottschalk Research Award (R.K.). Dr. Meyers is the recipient of a Research Fellowship Award from the National Kidney Foundation of North America.

\section{References}

1. Jones DA, Jennette JC, Falk RJ: Goodpasture's syndrome revis- ited: A new perspective on glomerulonephritis and alveolar hemorrhage. NC Med J 51:411-415, 1990

2. Harrity $P$, Gilbert-Barness $E$, Cabalka A, Hong R, Zimmerman J: Isolated pulmonary Goodpasture syndrome. Pediatr Pathol 11: 635-646, 1991

3. Merkel F, Pullig O, Marx M, Netzer KO, Weber M: Course and prognosis of anti-basement membrane antibody (anti-BM-Ab)-mediated disease: Report of 35 cases. Nephrol Dial Transplant 9:372-376, 1994

4. Stanton MC, Tange JD: Goodpasture's syndrome: Pulmonary hemorrhage associated with glomerulonephritis. Aust Ann Med 7:132-144, 1958

5. Savage CO, Pusey CD, Bowman C, Rees AJ, Lockwood CM: Anti-glomerular basement membrane antibody mediated disease in the British Isles 1980-4. Br Med J 292:301-304, 1986

6. Herody M, Bobrie G, Gouarin C, Grunfeld JP, Noel LH: Anti-GBM disease: Predictive value of clinical, histological and serological data. Clin Nephrol 40:249-255, 1993

7. Kalluri RM, Weber M, Netzer KO, Sun MJ, Neilson EG, Hudson- BG: COL4A5 gene deletion and production of post-transplant anti-alpha 3 (IV) collagen alloantibodies in Alport syndrome. Kidney Int 45:721-726, 1994

8. Turner AN, Rees AJ: Goodpasture's disease and Alport's syndromes Annu Rev Med 47:377-386, 1996

9. Kalluri R, Gattone VH, Noelken ME, Hudson BG: The alpha 3 chain of type IV collagen induces autoimmune Goodpasture syndrome. Proc Natl Acad Sci USA 91:6201-6205, 1994

10. Neilson EG, Kalluri R, Sun MJ, Gunwar S, Danoff T, Mariyama M. Myers JC, Reeders ST, Hudson BG: Specificity of Good- pasture auto-antibodies for the recombinant noncollagenous domains of human type IV collagen. J Biol Chem 268:8402-8405, 1993

11. Hudson BG, Kalluri R, Gunwar S, Noelken ME, Mariyama M, Reeders ST: Molecular characteristics of the Goodpasture auto-antigen. Kidney Int 43:135-139, 1993

12. Turner N, Mason PJ, Brown R, Fox M, Povey S, Rees A, Pusey CD: Molecular cloning of the human Goodpasture antigen demonstrates it to be the alpha 3 chain of type IV collagen. J Clin Invest 89:592-601. 1992

13. Hudson BG, Kalluri R, Gunwar S, Weber M, Ballester F, Hudson JK, Noelken ME, Sarras M, Richardson WR, Saus J: The pathogenesis of Alport syndrome involves type IV collagen molecules containing the alpha 3 (IV) Chain: Evidence from anti-GBM nephritis after renal transplantation. Kidney Int 42:179-187, 1992 
14. Dehan P, Van den Heuvel LP, Smeets HJ, Tryggvason K, Foid- art JM: Identification of post-transplant anti-alpha 5 (IV) collagen alio-antibodies in X-linked Alport syndrome. Nephrol Dial Trans- plant 11:1983-1988, 1996

15. Couser WG: Rapidly progressive glomerulonephritis: Classification, pathogenetic mechanisms, and therapy. Am J Kidney Dis 11:449-464, 1988

16. Kelly PT, Haponik EF: Goodpasture syndrome: Molecular and clinical advances. Medicine (Baltimore) 73:171-185, 1994

17. Kalluri R, Petrides S, Wilson CB, Tomaszewski JE, Palevsky HI, Grippi MA, Madaio MP, Neilson EG: Anti-alpha1 (IV) collagen auto-antibodies associated with lung adenocarcinoma presenting as the Goodpasture syndrome. Ann Intern Med 124:651-653, 1996

18. Meyers KE, Kinniry PA, Kalluri R, Neilson EG, Madaio MP: Human Goodpasture anti-alpha3 (IV) NC1 auto-antibodies share structural determinants. Kidney Int 53:402-407, 1998

19. Kalluri R, Danoff TM, Okada H, Neilson EG: Susceptibility to anti-glomerular basement membrane disease and Goodpasture syndrome is linked to MHC class $I$ genes and the emergence of T cell-mediated immunity in mice. J Clin Invest 100:2263-2275, 1997

20. Jonsson U, Fagerstam L, Ivarsson B, Johnsson B, Karlsson R, Lundh K, Lofas S, Persson B, Roos H, Ronnberg I: Real-time biospecific interaction analysis using surface plasmon resonance and sensor chip technology. Biotechniques 11:620-627, 1991

21. Van Cott TC, Loomis LD, Redfield RR, Birx DL: Real-time biospecific interaction analysis of antibody reactivity to peptides from the envelope glycoprotein, gp 160, of HIV-1. J Immunol Methods 146:163-176, 1992

22. Garland P: Optical evanescent wave methods for the study of biomolecular interactions. Q Rev Biophys 29:91-117, 1996

23. Johnsson B, Lofas $S$, Lindquist $G$ : Immobilization of proteins to a carboxymethyldextran-modified gold surface for biospecific interaction analysis in surface plasmon resonance sensors. Anal Biochem 198:268-277, 1991

24. Karlsson R, Michaelsson A, Mattsson L: Kinetic analysis of monoclonal antibody-antigen interactions with a new biosensor based analytical system. J Immunol Methods 145:229-240, 1991

25. Feldman RG, Breukels MA. David S. Rijkers GT: Properties of human anti-group B streptococcal type III capsular IgG antibody. Clin Immunol Immunopathol 86:161-169, 1998

26. Boutaud AA, Kalluri R, Kahsai TZ, Noelken ME, Hudson BG: Goodpasture syndrome: Selective removal of anti-alpha 3 (IV) collagen auto-antibodies: A potential therapeutic alternative to plasmapheresis. Exp Nephrol 4:205-212, 1996

27. Kalluri R, Melendez E, Rumpf KW. Sattler K, Muller GA, Strutz F, Neilson EG: Specificity of circulating and tissue-bound auto-antibodies in Goodpasture syndrome. Proc Assoc Am Physicians 108:134-139, 1996

28. Meyers CM, Kalluri R, Neilson EG: Anti-glomerular basement membrane disease, in Immunologic Renal Diseases, edited by Neilson EG, Couser WG, Philadelphia, Lippincott-Raven, 1997, pp 959-972

29. Bolton WK: Goodpasture's syndrome. Kidney Int 50:1753-1766, 1996 

CHAPTER 5

\section{Coexistence of anti-GBM antibodies and MPO-ANCA in crescentic glomerulonephritis}

A. Rutgers, M.C. Slot, P. van Paassen, P.J.C. van Breda Vriesman, P.Heeringa, and J.W. Cohen Tervaert

Clinical and experimental Immunology, University Hospital Maastricht, The Netherlands

Presented as an abstract at the ASN 2003, San Diego, USA 


\section{ABSTRACT}

Backgrond Crescentic glomerulonephritis (CGN) is characterized in most cases by the presence of specific pathogenic auto-antibodies, such as anti-glomerular basement membrane (GBM) antibodies or anti-neutrophil cytoplasmic antibodies (ANCA). In a substantial proportion of patients both anti-GBM and ANCA with a specificity for myeloperoxidase (MPO-ANCA) are detected. These patients might display characteristics of both diseases and it has been suggested that the presence of MPO-ANCA in patients with anti-GBM CGN points to a better clinical outcome compared to patients with anti-GBM CGN, but without MPO-ANCA. Whether outcome in these patients differs from patients with MPO-ANCA only has, however, not been studied. In the present study, we questioned whether histological and clinical features of patients with both ANCA and anti-GBM antibodies, differ from those in patients with either ANCA or anti-GBM alone.

Methods We reviewed the Limburg renal biopsy registry (1978-2003; $n=1373$ ) for cases of CGN. The presence of linear fluorescence on renal biopsy and the presence of ANCA and/or anti-GBM antibodies was measured. Subsequently, we assessed patient characteristics and follow-up and compared histological findings between the different groups.

Results We identified 46 MPO-ANCA, 10 double-positives, and 13 anti-GBM positive patients. The respective average age was 63,64 and $52(p=0.043)$, serum creatinine was 445,910 , and $850 \mu \mathrm{mol} / \mathrm{l}(p=0.01)$. Granulomatous periglomerular inflammation was found in either MPO-ANCA or double positive patients, but not in anti-GBM antibody positive CGN without MPO-ANCA. In both anti-GBM and double positives anuria or oliguria occurred more often compared with MPO-ANCA positive patients $(p<0.05)$. Patient survival over the three groups was different, although this difference did not reach statistical significance (log rank $p=0.09$ with $67 \%, 79 \%$ and $100 \%$ alive at one year, respectively). However, renal survival analysis revealed significant differences between the three groups (log rank $p=0.009$ with $49 \%$, $10 \%$ and $10 \%$ off-dialysis at one year, respectively).

Conclusions In patients with both anti-GBM antibodies and MPO-ANCA histological findings differ from patients with anti-GBM antibodies only. Renal survival in these patients, however, is not better than in anti-GBM antibody positive patients and is worse compared to patients with MPO-ANCA only. 


\section{Introduction}

Crescentic glomerulonephritis (CGN) is a renal biopsy finding clinically characterized by the presence of auto-antibodies or antibody complexes, such as anti-glomerular basement membrane (GBM) antibodies (type I CGN), immune complexes (type II CGN), or anti-neutrophil cytoplasmic antibodies (ANCA; type III CGN) ${ }^{1}$. Histologically, these antibody mediated forms of CGN are characterized by a vasculitis of the glomerular capillaries resulting in the formation of cellular crescents within most glomeruli ${ }^{2}$. In anti-GBM mediated CGN immunofluorescence typically demonstrates linear immunoglobulin deposition along the GBM with or without complement deposition, in immune complex associated CGN immunofluorescence shows widespread immunecomplex deposition with complement activation, whereas immunofluorescence in ANCA associated CGN shows absent or scanty (i.e. pauci-immune) immune deposits 1,3. Anti-GBM antibodies are associated with Goodpasture's disease (anti-GBM antibody disease with pulmonary hemorrhage) and with renal limited anti-GBM nephritis, whereas ANCA are associated with Wegener's granulomatosis, Churg-Strauss syndrome, microscopic polyangiitis, or idiopathic necrotizing crescentic glomerulonephritis ${ }^{4}$.

The pathogenic effect of anti-GBM antibodies has been demonstrated by Lerner et al in their 1967 paper where they showed that human anti-GBM immunoglobulins could induce CGN in squirrel monkeys ${ }^{5}$. No such data exists for ANCA and pathogenecity has been questioned. However, for one of two types of ANCA that is associated with CGN (i.e. myeloperoxidase (MPO)-ANCA) Xiao et al have shown that, in mice, MPO-ANCA can induce CGN6.

Interestingly, a substantial proportion of patients with anti-GBM mediated CGN are also positive for ANCA (predominantly MPO-ANCA) ${ }^{7}$. It is unclear whether ANCA associated CGN predisposes to the development of anti-GBM disease or that ANCA positivity occurs in the course of anti-GBM CGN ${ }^{8}$. In addition, the respective pathophysiological role of ANCA and anti-GBM antibodies in double positive CGN patients has not been clarified. It has been suggested, however, that double-positive patients have a better prognosis than patients with anti-GBM nephritis 9.10 . In contrast, Heeringa et a/ have shown that MPO-ANCA increases the severity of anti-GBM mediated glomerulonephritis as demonstrated in a rat model of anti-GBM nephritis ${ }^{11}$.

In the present study, we questioned whether histological and clinical features of CGN in patients with both ANCA and anti-GBM antibodies, differ from those in patients with either ANCA or anti-GBM alone.

\section{Methods}

Study population

In this study we reviewed all entries (1978-2003; $n=1373$ ) in our regional renal biopsy registry (Limburg, The Netherlands) ${ }^{12}$ for the presence of either pauci-immune CGN or CGN with linear fluorescence. CGN was defined as the presence of any crescentic glomerulus in which $25 \%$ or more of Bowman's space was occupied by extracapillary cellular proliferation in the 
renal biopsy specimen ${ }^{13}$. Biopsies that showed CGN with immune-complex deposits were excluded from further study. We then analyzed retrospectively the presence of anti-GBM antibodies and ANCA in stored serum samples that were obtained at the time of renal biopsy. Based on the Dutch central bureau for statistics ( $W w w . s t a t l i n e . n l)$ the population served by the registry was estimated to be 720,000 on average during the study period $(750,000$ in 2000 and 690,000 in 1980). For the purpose of this paper, we restricted subsequent analysis to MPO-ANCA and/or anti-GBM positive patients, since the number of PR3-ANCA and anti-GBM double positive patients is too little to draw any conclusions.

\section{Histological scoring}

Renal biopsies were processed for light microscopy and immunofluorescence as described elsewhere ${ }^{12}$. Biopsies had to contain four or more glomeruli per section to qualify for evaluation. To assess the activity and chronicity of the lesions serial $1 \mu \mathrm{m}$ sections were stained with silver methenamin and counter stained with hematoxylin eosin. Numbers of normal glomeruli and numbers of glomeruli with global sclerosis were counted. Each glomerulus was separately assessed for the presence of fibrinoid necrosis and cellular and fibrous crescents (the latter two had to cover at least 25 percent of the glomerular surface area). Percentages of affected glomeruli were calculated by dividing the number of glomeruli with lesions by the total number of glomeruli. Interstitial lesions, such as interstitial inflammation, interstitial fibrosis and tubular atrophy, were graded semiquantitatively on a scale of 0 to 3 (absent, mild, moderate, and severe, respectively). The presence of periglomerular granulomatous inflammation was noted. Periglomerular granuloma were defined as described by Wegener in $1939^{14}$ and Former in $1950^{15}$ and included a periglomerular round cell infiltrate (lymphocellular/ plasmacellular) with locally epitheloid like cells, partial (>50\%) to total destruction of Bowman's capsule and (remnants) of glomerular capillairies in the centre, see also figure 1a) and b). Giant cells were sometimes detected as well. For calculation of activity scores (modified from $\left.{ }^{16}\right)$, the presence of fibrinoid necrosis and cellular crescents was scored in a range of 0 to 3, where 0 stands for absence, 1 for less than $25 \%$ of glomeruli involved, 2 for 25 to $50 \%$ of glomeruli involved, and 3 for more than $50 \%$ of glomeruli involved. Additionally, the grade of interstitial inflammation was included in the activity score, resulting in a maximum score of 9 . The chronicity score (modified from ${ }^{16}$ ) included the percentage of glomeruli with fibrous crescents and the grade of interstitial fibrosis and tubular atrophy, resulting in a maximum chronicity score of 9 . The presence of granuloma was not included in activity or chronicity score. Immunofluorescence findings were categorized into four groups, 1) no immunodeposits, 2) scanty, not linear immunodeposits, 3) linear immunofluorescence as found in anti-GBM nephritis, and 4) a final group in which not sufficient material was present for immunofluorescent evaluation. All biopsies were scored by one nephropathologist blinded to clinical diagnosis (PVBV).

\section{ANCA and anti-GBM testing}

ANCA were evaluated using indirect immunofluorescence on ethanol-fixed neutrophil granulocytes (INOVA diagnostics, San Diego, USA) and MPO-ANCA and PR3-ANCA specific ELISAs (Euro-diagnostica B.V. Arnhem, The Netherlands) ${ }^{17}$. The presence of ANCA was confirmed by 


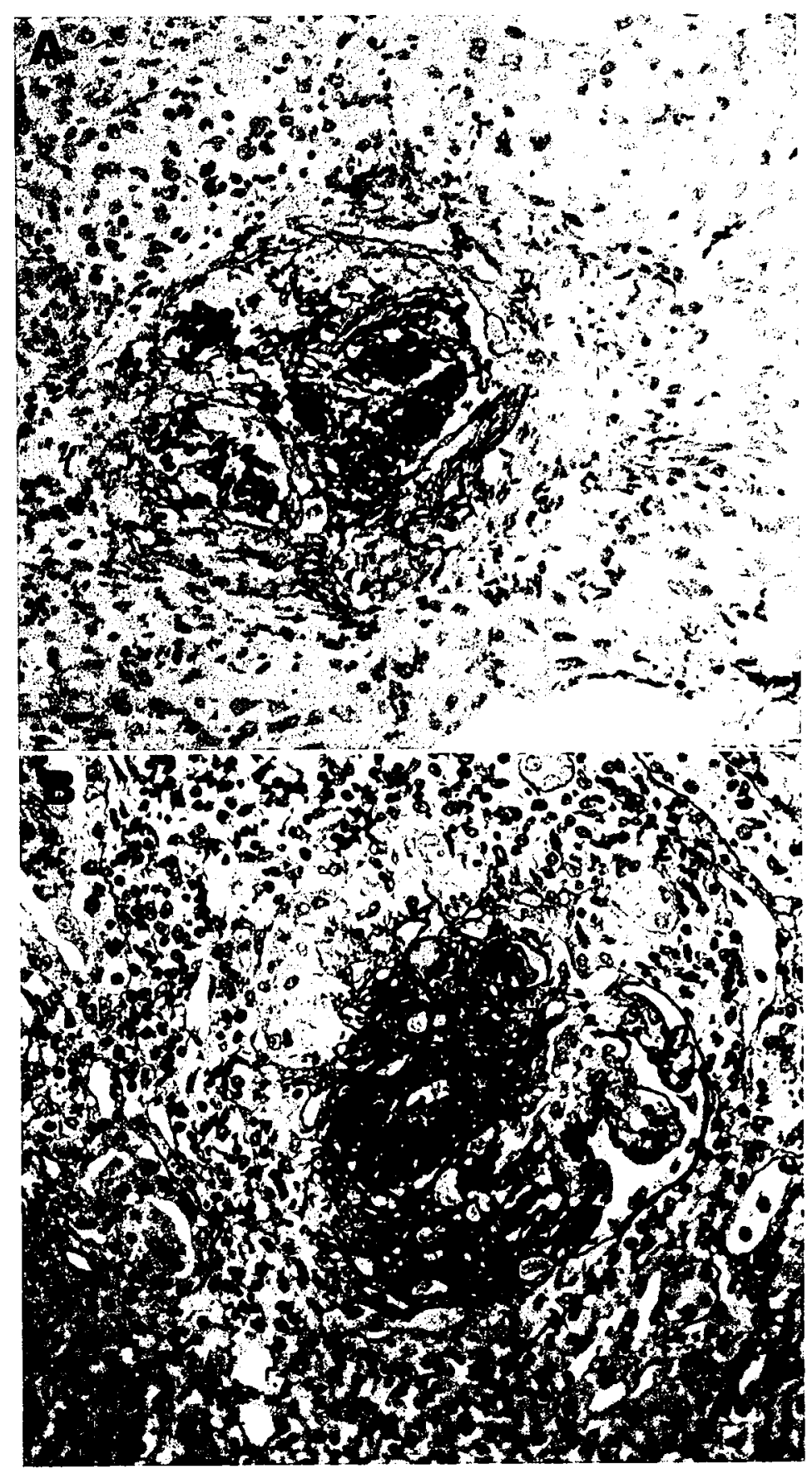

Figure 1. Figure A) showing periglomerular granuloma surrounding a sclerotic and crescentic glomerulus, with complete destruction of Bowman's capsule. B) shows a similar process, with an incomplete destruction of Bowman's capsule. 
a capture ELISA specific for PR3-ANCA ${ }^{17}$ or MPO-ANCA ${ }^{18}$. Anti-GBM antibodies were tested by commercial ELISA (Euro-diagnostica).

\section{Diagnostic criteria and clinical characteristics}

At the time of renal biopsy patient gender, age and blood pressure was obtained, 24-hour urine was collected and analyzed for volume and total protein content, and serum samples were obtained for determination of creatinine and antibody titers. Anuria and oliguria was defined as an urinary output of less than 50 or $400 \mathrm{ml}$ per 24 hours, respectively.

Anti-GBM mediated GN was diagnosed based on evidence of anti-GBM antibody formation. This could be demonstrated by the presence of linear fluorescence of $\lg G$ along the GBM in the renal biopsy and/or by the presence of specific circulating anti-GBM antibodies ${ }^{1}$. MPO-ANCA associated GN was diagnosed based on the presence of pauci-immune CGN in combination with the presence of MPO-ANCA as detected by ELISA. Patients with anti-GBM mediated CGN that tested positive for MPO-ANCA by ELISA are referred to as double positives.

\section{Statistical analysis}

Data represent mean \pm standard deviation unless stated otherwise. Analysis of variance (ANOVA) was used to test significant differences between groups, Bonferroni corrected post-testing was performed were indicated. Cross-tabulated data were tested using $\mathrm{Chi}^{2}$ analysis. Survival curves for patient and renal survival were calculated using Kaplan-Meier estimates for survival distribution. End point for renal survival analysis was the start of renal replacement therapy or death due to renal failure. Differences between groups in survival were analyzed with log-rank test with survival time as dependent variable. Renal survival rates (survival without end-stage renal disease) are calculated with subjects dying with independent renal function censored. Variables included in survival analyses were disease groups and the presence of periglomerular granulomatous inflammation. Correlations were tested with Pearson's analysis and all analyses were performed with the statistical programme SPSS 10.1 (Chicago, Illinois, USA).

\section{Results}

From 1978 to 2003,127 of $1373(9.2 \%$ ) biopsies showed pauci-immune or anti-GBM mediated CGN. 47 were PR3-ANCA positive, 46 MPO-ANCA positive, 5 were both MPO-ANCA and PR3-ANCA positive, 10 were double positive (i.e. anti-GBM and MPO-ANCA positive) and 13 were anti-GBM positive (see also table 1). One case identified positive for both PR3-ANCA and anti-GBM antibodies was excluded as we restricted the analysis to MPO-ANCA and anti-GBM patients.

The overall annual incidence of MPO-ANCA, double positives, and anti-GBM single positive CGN was calculated to be $2.6,0.6$ and 0.7 per million per year (based on an average popula- 
Table 1. Patients characteristics at time of biopsy

\begin{tabular}{lllll}
\hline & MPO-ANCA & Double positive & Anti-GBM & p \\
\hline & $(n=46)$ & $(n=10)$ & $(n=13)$ & \\
Age (SD) & $63(12.7)$ & $64(8.7)$ & $52(20.6)$ & 0.043 \\
Male gender & $67 \%$ & $80 \%$ & $39 \%$ & 0.082 \\
Bloodpressure, syst/diast & $150 / 83$ & $158 / 84$ & $145 / 85$ & $n .5$ \\
Proteinuria, g/24hrs median (range) & $2.0(0.0-1.1)$ & $1.3(0.0-2.6)$ & $2.3(0.6-5.4)$ & 0.315 \\
An-/oliguria \% & $12 \%$ & $63 \%$ & $50 \%$ & $<0.01$ \\
Serum creatinine (SD) & $445(258)$ & $910(499)$ & $850(718)$ & $=0.01$ \\
\hline
\end{tabular}

MPO-ANCA = Myeloperoxidase-Anti-neutrophil cytoplasmic antibodies; anti-GBM = anti-Glomerular Basement Membrane antibodies; Double positives = patients positive for both MPO-ANCA and anti-GBM antibodies; $\mathrm{SD}=$ standard deviation; syst = systolic bloodpressure; diast = diastolic bloodpressure; $\mathrm{g} / 24 \mathrm{hrs}=$ grams of proteinuria per 24 hours. P indicates significance level calculated with ANOVA statistics over the three groups.

tion of 720,000), respectively. When analyzing cases from 1978 to 1991 and from 1991 to 2003 a doubling in number of crescentic GN positive biopsies was observed ( 24 to 45 ).

Patient characteristics at the time of biopsy differed between groups (table 1). Mean age was higher in the MPO-ANCA positive and the double positive group as compared to the anti-GBM group ( 63 and 64 versus 52 , respectively, $p=0.04$ ), as was the percentage of males $(67 \%, 80 \%$ and $39 \%$, respectively, $p=0.08$ ). However, serum creatinine and percentage of patients presenting with oligo- or anuria was lower in the MPO-ANCA single positive group ( $258 \mu \mathrm{mol} / \mathrm{l}$ and $12 \%$, respectively) compared with the double positive $(910 \mu \mathrm{mol} / \mathrm{l}$ and $63 \%$, respectively) and the GBM positive group ( $850 \mu \mathrm{mol} / \mathrm{l}$ and $50 \%$, respectively, $p<0.01$ and $p=0.01$, respectively, see also table 1).

Histopathological findings also differed between the three groups (table 2). Activity scores tended to be higher for the anti-GBM antibody and double positives, whereas chronicity scores tended to be lower in these two groups compared to the MPO-ANCA positive group. The total number of glomeruli, the percentage of necrotic glomeruli, and the percentage of cellular and fibrous crescents did not differ between the three groups. The percentage of normal glomeruli correlated with serum creatinine at diagnosis $(p<0.01, r=0.5)$.

Periglomerular granulomatous inflammation was only observed in MPO-ANCA positive patients and double positive patients (11\% and $40 \%$ of patients), but not in anti-GBM mediated CGN. Patients with periglomerular granulomas $(n=9)$ had similar creatinine levels (673 \pm 602 versus $564 \pm 435)$ and the same chronicity index $(4.0 \pm 1.9$ versus $4.3 \pm 2.3)$ compared to patients without granuloma $(n=58)$, respectively. However, these patients had less proteinuria ( $781 \pm 573$ versus $2821 \pm 2478 \mathrm{mg} / 24$ hours, $p=0.02$ ) and a higher activity index $(4.4 \pm 1.2$ versus $2.8 \pm 1.5, p=0.03)$.

Immunofluorescence studies of the renal biopsies revealed that MPO-ANCA positive patients did not have linear immunofluorescence (by definition), but that in $33 \%$ of biopsies scanty 
Table 2. Table showing histopathological characteristics of the three groups. Note the absence of granulomatous inflammation in the GBM group. Numbers between brackets indicate the maximum and minimum values. *expressed as percentage of total glomeruli

\begin{tabular}{llllll}
\hline & & MPO-ANCA & Double positive & Anti-GBM & $\mathrm{p}$ \\
\hline \multirow{4}{*}{ Active } & Number of glomeruli & $16(5-65)$ & $12(4-21)$ & $10(5-17)$ & n.s. \\
& Normal glomeruli* & $30(0-89)$ & $16(0-44)$ & $20(0-75)$ & n.s. \\
& Necrotic glomeruli* & $4(0-20)$ & $9(0-33)$ & $9(0-60)$ & n.s. \\
& Cellular crescents* & $18(0-75)$ & $27(0-75)$ & $29(0-90)$ & n.s. \\
& Fibrous crescents* & $27(0-100)$ & $31(0-100)$ & $43(0-100)$ & n.s. \\
& Activity score & $2.8(0-5)$ & $3.7(2-7)$ & $3.5(1-6)$ & 0.18 \\
& & & & \\
Chronic & Interstitial inflammation* & $1.4(0-3)$ & $1.7(0-3)$ & $1.5(0-3)$ & n.s. \\
& Interstitial fibrosis* & $1.3(0-3)$ & $1.3(0-2)$ & $1.2(0-2)$ & n.s. \\
& Tubular atrophy* & $1.5(0-3)$ & $1.7(0-3)$ & $1.3(0-2)$ & n.s. \\
& Chronicity score & $4.3(0-8)$ & $4.3(0-8)$ & $4.4(0-7)$ & 0.99 \\
& & & & \\
& Peri-glomerular granuloma, \% & 11 & 40 & 0 & 0.02 \\
\hline
\end{tabular}

Table 3. Table showing the immunofluorescence findings

\begin{tabular}{llll}
\hline Immunofluorescence pattern & MPO-ANCA & Double positive & Anti-GBM \\
\hline No deposits (\% of group) & $27(59 \%)$ & $0(0 \%)$ & $0(0 \%)$ \\
Scanty, not linear deposits & $15(33 \%)$ & $5(50 \%)$ & $2(15 \%)$ \\
Linear deposits & $0(0 \%)$ & $4(40 \%)$ & $10(77 \%)$ \\
No material & $4(9 \%)$ & $1(10 \%)$ & $1(8 \%)$ \\
\hline
\end{tabular}

Table 4. Table showing the therapeutic regimens for the different patient

\begin{tabular}{llll}
\hline Therapy & MPO-ANCA & Double positive & Anti-G8M \\
\hline Other & $7(15 \%)$ & $2(20 \%)$ & $5(38 \%)$ \\
Cytostatic therapy & $23(50 \%)$ & $3(30 \%)$ & $0(0 \%)$ \\
Cytostatic therapy and plasmapheresis & $4(9 \%)$ & $4(40 \%)$ & $7(54 \%)$ \\
Unknown & $12(26 \%)$ & $1(10 \%)$ & $1(8 \%)$ \\
\hline
\end{tabular}

'Other' included patients who were treated with steroids alone. Cytostatic therapy included steroids and cyclophosphamide or in one case mycophenolate mofetil.

immunedeposits were noted. In the double positives, immunofluorescence in $50 \%$ of biopsies showed scanty immune deposits and in $40 \%$ a linear fluorescence. Within this double positive group, patients with linear fluorescence presented with a higher percentage of cellular crescentic glomeruli compared to patients with scanty immune deposits ( $55 \%$ versus $10 \%$, $p<0.05$, respectively). The serum creatinine levels were higher as well, although these did not reach significance $(1219 \pm 678$ versus $665 \pm 209, p=0.2)$. In $77 \%$ of the anti-GBM positive group a linear fluorescence could be observed (table 3 ). 


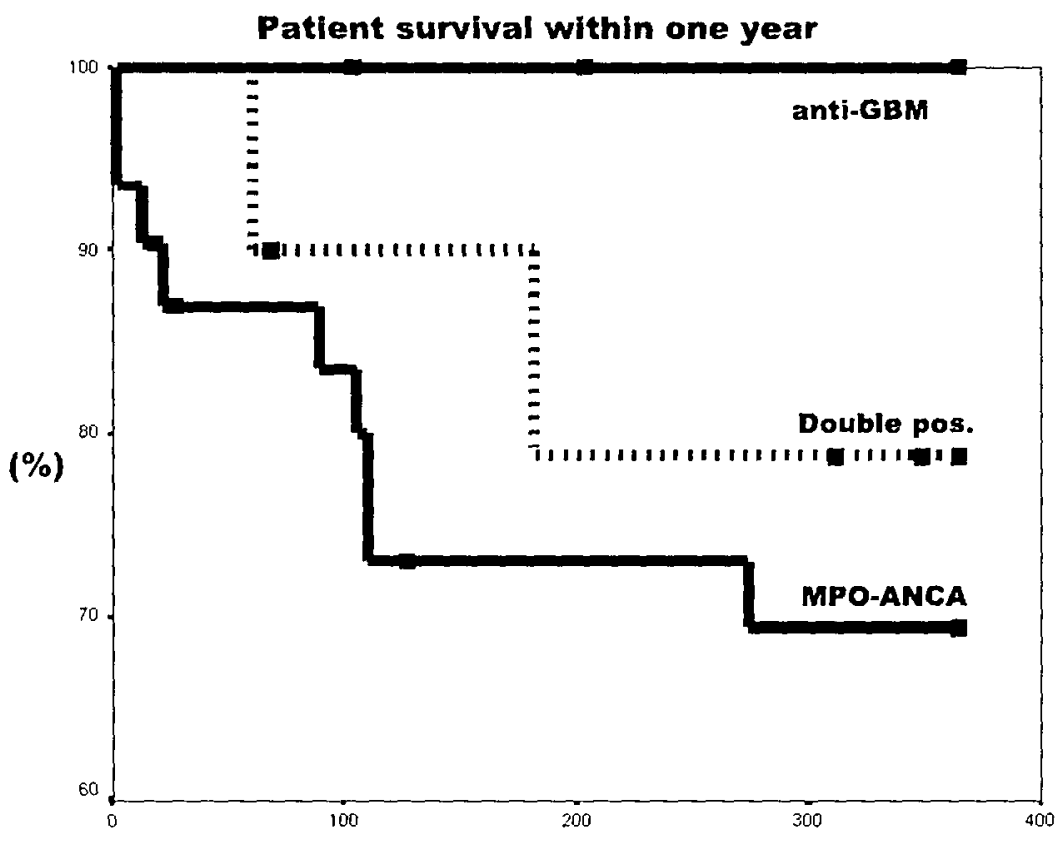

Figure 2. Kaplan-Meier curve of overall patient survival within one year. Combined Log Rank analysis revealed no significant differences between the three groups $(p=0.12)$. Cumulative patient survival at one year was $69.4 \%$ (SE 8.5)for the MPO-ANCA group, $78.8 \%$ (SE 13.4) for the double positives, and $100 \%$ for the anti-GBM group. Censored subjects are indicated by thick black squares. Patients still at risk at one year were 19,5 and 10 respectively.

Table 4 shows the therapeutic regimens and follow-up data of the patients. Data of 14 of 69 patients were not accessible for analysis (all MPO-ANCA single positives), and these patients were subsequently excluded for survival analysis. The MPO-ANCA patients were treated with cytostatic therapy in $50 \%$ of cases, in $9 \%$ of cases plasmapheresis was added to this regimen. In 15\% of cases therapy was withheld or consisted of merely steroids. In the double positive group, $30 \%$ of cases were treated with cytostatic therapy and in $40 \%$ of cases plasmapheresis was added. The anti-GBM group was treated with cytostatic therapy with plasmapheresis in $54 \%$ of cases. In $38 \%$ of cases treatment was clinically considered futile and thus not commenced (see table 4).

The average patient follow-up was 4.8 years (range 2 days to 22 years). Figure 2 shows the patient survival of the three different patient groups within one year. Patient survival over the three groups was different, with the anti-GBM group having the best patient cumulative survival (100\% at one year), followed by the double positives (79\% at one year), and the MPO-ANCA positive group ( $69 \%$ at one year), although the differences did not reach statistical significance $(p=0.12)$. 


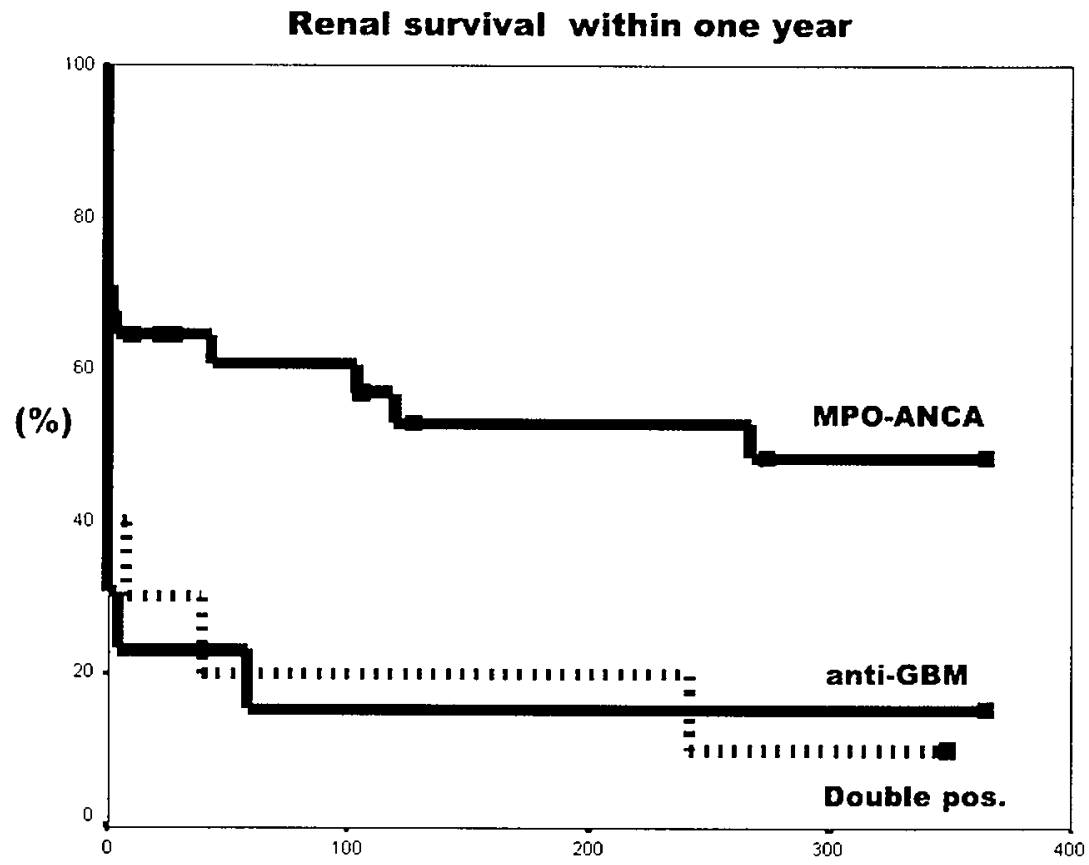

Figure 3. Kaplan-Meier curve of overall renal survival with patients dying with independent renal function within one year censored. Combined Log Rank analysis revealed significant differences between the three groups ( $p=0.009$ ). Pairwise comparison per group revealed a significant difference between the MPO-ANCA group and both the double positives and the anti-GBM patient group $(p=0.01$ and $p=0.01$, respectively). Cumulative renal survival at one year was 50.3\% (SE 9.3) for the MPO-ANCA group, 10.0\% (SE 9.5) for the double positives, and $15.4 \%$ (SE 10.0) for the anti-GBM group. Censored subjects are indicated by thick black squares. Patients still at risk at one year were 11,0 and 2 respectively.

Figure 3 shows the renal survival for the three groups within one year. Combined Log Rank analysis revealed significant differences between the three groups $(p=0.006)$. Pairwise comparison per group showed a significant difference between the MPO-ANCA group and both the double positives and the anti-GBM patient group $(p<0.01$ and $p<0.01$, respectively). At diagnosis $28 \%$ of MPO-ANCA positive patients were dialysis dependent, compared to $60 \%$ and $69 \%$ of the double positives and the anti-GBM positive patients, respectively $(p=0.02)$. MPO-ANCA positive patients had better cumulative renal survival ( $50 \%$ at one year), than both the double positives (10\% at one year) and the anti-GBM group (15\% at one year).

\section{Conclusions and discussion}

In our study, we found that double-positive CGN patients had severe renal involvement at diagnosis comparable with anti-GBM CGN and more severe than patients with MPO-ANCA 
Table 5. Table showing the percentage of MPO-ANCA and PR3-ANCA positive patients with in the group of anti-GBM positive patients as reported in the literature

\begin{tabular}{lllll}
\hline $\begin{array}{l}\text { Total number of } \\
\text { anti-GBM positive patients }\end{array}$ & MPO-ANCA $(n)$ & PR3-ANCA (n) & Year & Ref \\
\hline 136 & $31 \%(42)$ & $10 \%(14)$ & 2002 & 19 \\
100 & $25 \%(25)$ & $12 \%(12)$ & 1997 & 7 \\
13 & $54 \%(7)^{\star}$ & & 1996 & 20 \\
9 & $0 \%(0)$ & $0 \%(0)$ & 1995 & 21 \\
160 & $16 \%(25)$ & $2 \%(3)$ & 1995 & 22 \\
12 & $17 \%(2)$ & $17 \%(2)$ & 1992 & 23 \\
23 & $30 \%(7)$ & $0 \%(0)$ & 1992 & 24 \\
37 & $30 \%(11)^{\star *}$ & & 1991 & 9 \\
67 & $30 \%(20)^{\star \star *}$ & & 1990 & 25 \\
\hline
\end{tabular}

* These included only patients with pulmonary hemorrhage and nephritis, no division between PR3 or MPO ANCA was made. ** MPO-ANCA specificity was tested by testing IIF on MPO deficient neutrophils. *** Only $\| F-A N C A$ was performed in these samples. GBM $=$ glomerular basement membrane; $\mathrm{MPO}=$ myeloperoxidase; ANCA $=$ anti-neutrophil cytoplasmic antibodies; PR3 = proteinase 3; Anti-glomerular basement membrane antibodies $=$ anti-GBM

only. Histological findings, however, showed that periglomerular granulomatous inflammation was only found in MPO-ANCA and double positive patients. Finally, patient and renal survival analysis showed that double positives did not have a better prognosis than anti-GBM antibody positive patients, contrary to reports in the literature, but in line with our results obtained in our experimental animal model.

\section{Epidemiology}

We observed that $43 \%$ of patients with anti-GBM mediated CGN were positive for MPO-ANCA. These findings are somewhat higher as compared to other groups (see table $5)^{7,9,19-25}$

Since our renal biopsy registry functions as a primary regional centre for evaluating renal pathology, all patient samples (i.e. serum and histological material) were collected without referral bias. This enabled us to calculate the annual incidence for MPO-ANCA associated CGN of 2.6 per million in our region. The estimated annual incidence of MPO-ANCA associated CGN in another Dutch population (Groningen) for the years 1984 to 1988 was lower, i.e. 1 case per million ${ }^{26}$. Next to regional variation within the Netherlands, this difference could result from an increase in incidence over the study period. In our analysis we found that the incidence increased over the years 1978-1992 and 1992-2003. Others have reported similar observations ${ }^{27,28}$. Whether this is due to the increased availability of diagnostic tools such as ANCA, or due to an increased awareness of the existence of ANCA-associated glomerulonephritis as a potentially treatable form of renal insufficiency or due to a real increased incidence remains unclear. 
To the best of our knowledge, there is no literature on the incidence of anti-GBM or double positivity in a general population.

\section{Histological differences}

In our series, periglomerular granuloma were exclusively found in MPO-ANCA positive patients and not in anti-GBM single positive patients. Periglomerular granuloma were first described by Wegener in 1939 in three patients with systemic vasculitis, granulomatous upper respiratory tract disease and glomerulonephritis, later described as Wegener's Granulomatosis. Godman and Churg also found this type of granulomatous inflammation in 2 out of seven patients described, which they considered not to be specific for Wegener's disease 29 . Indeed, Former had described in 1950 already 5 patients with periglomerular granuloma, including two with bacterial endocarditis, showing that this type of lesion is not exclusively found in Wegener's granulomatosis ${ }^{15}$. At that time ANCA testing was not available and thus exclusion of (co-existing) ANCA in their patients with endocarditis and CGN was not possible 30,31 .

More recently, Bajema et a/ found periglomerular granulomas in about $10 \%$ of 157 renal biopsies from patients with ANCA associated systemic vasculitis ${ }^{32}$. Periglomerular granuloma are found in MPO- as well as in PR3-ANCA positive patients ${ }^{33}$. Bajema et a/ hypothesized that renal granulomas are not typical for WG and can be found in other disease as well, such as anti-GBM GN. However, as we have shown in this study, cases with anti-GBM nephritis and granulomas were MPO-ANCA positive as well. Bajema et al found that renal granulomas were not indicative for severe renal involvement, since renal functioning was not different from patients without granulomatous inflammation. We also found that creatinine levels were similar as was the percentage of normal glomeruli in our patients with and without periglomerular granulomatous inflammation. We found, however, that patients with periglomerular granulomatous inflammation presented with lower proteinuria $(781 \pm 573$ versus $2821 \pm 2478, p<0.001)$ and a higher activity index $(4.4 \pm 1.2$ versus $2.8 \pm 1.5, p=0.003)$, perhaps indicating a more aggressive and active disease process. Larger series are needed to provide a more definite answer whether periglomerular granulomatous inflammation in anti-GBM CGN is indeed restricted to patients that test also positive for ANCA.

\section{Clinical differences}

in $15 \%$ of our MPO-ANCA positive patients, in $20 \%$ of double positive patients, and in $38 \%$ of anti-GBM positive patients, therapy was withheld, or consisted merely of a short course of steroids. Nowadays, standard treatment for CGN includes steroids and cytostatic therapy. In patients with MPO-ANCA CGN with severe renal failure and in all cases of anti-GBM CGN, plasmapheresis is added to this regimen. In most of our patients in whom therapy was withheld renal function was considered lost and side-effects of therapy outweighed expected treatment benefit 34,35 . 
Patient survival in our groups was $69 \%, 79 \%$ and $100 \%$ alive at one year for the MPO-ANCA, double, and anti-GBM positive groups, respectively. These numbers are similar to the literature and are dependent on renal function at diagnosis 35 .

At diagnosis $28 \%$ of MPO-ANCA positive patients were dialysis dependent, compared to $60 \%$ and $69 \%$ of the double positives and the anti-GBM positive patients, respectively. Cumulative renal survival was $50 \%, 10 \%$ and $15 \%$ at one year for the MPO-ANCA, double, and anti-GBM positive groups, respectively. None of our patients on dialysis recovered renal function. This is contrary to data shown by Bosch et al were double positivity was linked to better renal prognosis 9 . They showed that none of their dialysis dependent anti-GBM CGN patients recovered independent renal function, whereas $45 \%$ of the double positive patients on dialysis recovered renal function. Major differences between our population and the one studied by Bosch et a/ include the percentage of anti-GBM patients presenting with oliguria and/or anuria (50\% versus $88 \%$, respectively), and the use of plasmapheresis next to immunosuppression in the double positive group ( $40 \%$ versus $100 \%$, respectively). The latter might suggest that the patients in our study group were not optimally treated and therapy should always include prompt plasmapheresis. However, in contrast with the findings of Bosch et al, Levy et al also suggest that double positive patients respond to therapy poorly and are thus associated with poor renal outcome, these patients did receive plasmapheresis in addition to immunosuppressive therapy ${ }^{35}$. Bonsib et al also demonstrate poor prognosis and treatment response in a small study ${ }^{23}$. Here, we show that renal survival in double positive patients is not better and maybe worse than in anti-GBM CGN patients.

\section{Pathophysiological considerations}

It is not clear whether ANCA associated CGN predisposes to the development of anti-GBM disease or that ANCA positivity occurs in the course of anti-GBM CGN ${ }^{8}$.

Our findings that patient characteristics of double positive patients are similar to the MPO-ANCA group (e.g. patient age and gender) suggests that MPO-ANCA disease occurs first. The finding that disease and histological characteristics in double positive patients contain elements of MPO-ANCA disease (i.e. granulomatous periglomerular inflammation) as well as of anti-GBM disease (i.e. serum creatinine, oliguria/anuria, and renal survival at one year), is suggestive of coexistent disease, thus MPO-ANCA disease first, followed by concomitant anti-GBM disease. In fact, we have observed one patient in our clinics that presented with a double positive disease, where, in retrospect, MPO-ANCA positivity could be demonstrated prior to the development of anti-GBM disease.

The pathophysiological explanation for the occurrence of anti-GBM antibody formation as a result of MPO-ANCA mediated glomerulonephritis and/or vasculitis is speculative, but could include the following. MPO-ANCA have been shown to activate (primed) neutrophils resulting in the production of reactive oxygen species and degranulation. MPO present outside inflammatory sites is normally cleared and inactivated by ceruloplasmin ${ }^{36}$. The presence of MPO-ANCA however, interferes with these mechanisms, leaving a circulating highly reactive enzyme ${ }^{37}$. This reactive enzyme produces MPO-derived oxidants which increases proteolysis 
of the $\mathrm{GBM}^{38}$. Moreover, Kalluri et a/ have shown that oxidants can alter the hexameric structure of the GBM therewith exposing immunologic epitopes (i.e. the Goodpasture epitope ${ }^{39}$ ) embedded in the basement membrane ${ }^{40}$. More specifically, it has been recently shown that the Goodpasture epitope can be cleaved from the $\alpha .3$ chain of type IV collagen by matrix metalloproteinase- -94 the latter can be activated by myeloperoxidase ${ }^{42}$. Indeed, in MPO-ANCA mediated CGNMPO-derived oxidants have been demonstrated in kidney biopsies ${ }^{43}$.

In conclusion, in patients with both anti-GBM antibodies and MPO-ANCA histological findings differ from patients with anti-GBM antibodies only. Renal survival in these patients, however, is not better than in anti-GBM antibody positive patients and is worse compared to patients with MPO-ANCA only.

\section{Acknowledgements}

We would like to thank $\mathrm{H}$. van Rie, Clinical and Experimental Immunology, University hospital Maastricht, for the excellent collection and technical preparation of biopsy material and all participating physicians and patients for their generous contributions to this paper (including the following physicians Dr. F. de Heer and Dr. G.H. Verseput, Maaslandziekenhuis, Sittard; Dr. W. Grave, Dr J. Wirtz, and Dr S. Boorsma, St.Laurentiusziekenhuis, Roermond; Dr. J. Wolters and Dr. L.A.M. Frenken, Atrium Medisch Centrum, Heerlen; Dr E. Zeppenfelt, Landgraaf; Prof. dr. K.M.L. Leunissen, University hospital Maastricht, Maastricht).

\section{References}

1. Glassock RJ, Adler SG, Cohen AH: Primary Glomerular Diseases, in The Kidney (vol 1), edited by Brenner BM, Rector FC, 4 ed, Philadelphia, W.B. Saunders Company, 1991, pp 1182-1279

2. Hricik DE, Chung-Park M, Sedor JR: Glomerulonephritis. N Engl J Med 339:888-899, 1998

3. Jennette $J C$, Wilkman AS, Falk RJ: Anti-neutrophil cytoplasmic autoantibody-associated glomerulonephritis and vasculitis. Am J Pathol 135:921-930, 1989

4. Jennette JC, Falk RJ, Andrassy K, Bacon PA, Churg J, Gross WL, Hagen EC, Hoffman GS, Hunder GG, Kallenberg CG, et al: Nomenclature of systemic vasculitides. Proposal of an international consensus conference. Arthritis Rheum 37:187-192, 1994

5. Lerner RA, Glassock RJ, Dixon FJ: The role of anti-glomerular basement membrane antibody in the pathogenesis of human glomerulonephritis. J Exp Med 126:989-1004, 1967

6. Xiao H, Heeringa P, Hu P, Liu Z, Zhao M, Aratani Y, Maeda N, Falk RJ, Jennette JC: Antineutrophil cytoplasmic autoantibodies specific for myeloperoxidase cause glomerulonephritis and vasculitis in mice. I Clin Invest 110:955-963, 2002

7. Hellmark T, Niles $J$, Collins AB, McCluskey RT, Brunmark C: Comparison of anti-GBM antibodies in sera with or without ANCA. J Am Soc Nephrol 8:376-385, 1997

8. Jennette JC: Rapidly progressive crescentic glomerulonephritis. Kidney Int 63:1164-1177, 2003

9. Bosch X, Mirapeix E, Font J, Borrellas X, Rodriguez R, Lopez-Soto A, Ingelmo M, Revert L: Prognostic implication of anti-neutrophil cytoplasmic autoantibodies with myeloperoxidase specificity in anti-glomerular basement membrane disease. Clin Nephrol 36:107-113, 1991

10. Hudson BG, Tryggvason K, Sundaramoorthy M, Neilson EG: Alport's syndrome, Goodpasture's syndrome, and type N collagen. N Engl I Med 348:2543-2556, 2003 
11. Heeringa P, Brouwer E, Klok PA, Huitema MG, van den Born J, Weening JJ, Kallenberg CG: Autoantibodies to myeloperoxidase aggravate mild anti-glomerular-basement-membrane-mediated glomerular injury in the rat. Am J Pathol 149:1695-1706, 1996

12. Tiebosch AT, Wolters J, Frederik PF, van der Wiel TW, Zeppenfeldt E, van Breda Vriesman PJ: Epidemiology of idiopathic glomerular disease: a prospective study. Kidney Int 32:112-116, 1987

13. Stilmant MM, Bolton WK, Sturgill BC, Schmitt GW, Couser WG: Crescentic glomerulonephritis without immune deposits: clinicopathologic features. Kidney Int 15:184-195, 1979

14. Wegener F: Uber die eigenartige rhinogene Granulomatose mit besonderer Beteiligung des Arteriensystems und der nieren. Beitrage zur Path Anat 102:36-68, 1939

15. Former F: Uber die granulomatose Periglomerulitis. Schweizerische Zeitschrift fur allgemeine Pathologie und Bakteriology 13:42-59, 1950

16. Franssen CF, Gans RO, Arends B, Hageluken C, ter Wee PM, Gerlag PG, Hoorntje SJ: Differences between anti-myeloperoxidase- and anti-proteinase 3-associated renal disease. Kidney Int 47:193-199, 1995

17. Boomsma MM, Damoiseaux JG, Stegeman CA, Kallenberg CG, Patnaik M, Peter JB, Cohen Tervaert JW: Image analysis: a novel approach for the quantification of antineutrophil cytoplasmic antibody levels in patients with Wegener's granulomatosis. J Immunol Methods 274:27-35, 2003

18. Boomsma MM, Stegeman CA, Oost-Kort WW, Kallenberg CG, Moguilevsky N, Limburg PC, Cohen Tervaert JW: Native and recombinant proteins to analyze auto-antibodies to myeloperoxidase in pauci-immune crescentic glomerulonephritis. I Immunol Methods 254:47-58, 2001

19. Denton M, Magee C, Niles J: Rapidly progressive glomerulonephritis. Ann Intern Med 137:W1, 2002

20. Niles JL, Bottinger EP, Saurina GR, Kelly KJ, Pan G, Collins AB, MCCluskey RT: The syndrome of lung hemorrhage and nephritis is usually an ANCA-associated condition. Arch Intern Med 156:440-445, 1996

21. Saxena R, Bygren P, Arvastson B. Wieslander J: Circulating autoantibodies as serological markers in the differential diagnosis of pulmonary renal syndrome. J Intern Med 238:143-152, 1995

22. Short AK, Esnault VL, Lockwood CM: Anti-neutrophil cytoplasm antibodies and anti-glomerular basement membrane antibodies: two coexisting distinct autoreactivities detectable in patients with rapidly progressive glomerulonephritis. Am J Kidney Dis 26:439-445, 1995

23. Bonsib SM, Goeken JA, Kemp JD, Chandran P, Shadur C. Wilson L: Coexistent anti-neutrophil cytoplasmic antibody and antiglomerular basement membrane antibody associated disease $=$ report of six cases. Mod Pathol 6:526-530, 1993

24. Weber MF, Andrassy K, Pullig O, Koderisch J, Netzer K: Antineutrophil-cytoplasmic antibodies and antiglomerular basement membrane antibodies in Goodpasture's syndrome and in Wegener's granulomatosis. J Am Soc Nephrol 2:1227-1234, 1992

25. Jayne DR, Marshall PD, Jones SJ, Lockwood CM: Autoantibodies to GBM and neutrophil cytoplasm in rapidly progressive glomerulonephritis. Kidney Int 37:965-970, 1990

26. Cohen Tervaert JW, Goldschmeding R, Elema JD, van der Giessen M, Huitema MG, van der Hem GK, The $T H$, von dem Borne AE, Kallenberg CG: Autoantibodies against myeloid lysosomal enzymes in crescentic glomerulonephritis. Kidney Int 37:799-806, 1990

27. Pettersson EE, Sundelin B, Heigl Z: Incidence and outcome of pauci-immune necrotizing and crescentic glomerulonephritis in adults. Clin Nephrol 43:141-149, 1995

28. Watts RA, Lane SE, Scott DG, Koldingsnes W, Nossent H, Gonzalez-Gay MA, Garcia-Porrua C, Bentham GA: Epidemiology of vasculitis in Europe. Ann Rheum Dis 60:1156-1157, 2001

29. Godman GC, Churg J: Wegener's granulomatosis. A.M.A. Archives of Pathology 58:533-553, 1954

30. Choi HK, Lamprecht P. Niles JL, Gross WL, Merkel PA: Subacute bacterial endocarditis with positive cytoplasmic antineutrophil cytoplasmic antibodies and anti-proteinase 3 antibodies. Arthritis Rheum 43:226-231, 2000

31. Hellmich B, Ehren M, Lindstaedt M, Meyer M, Pfohl M, Schatz H: Anti-MPO-ANCA-positive microscopic polyangiitis following subacute bacterial endocarditis. Clin Rheumatol 20:441-443, 2001

32. Bajema IM, Hagen EC. Ferrario F, Waldherr R, Noel LH, Hermans J, van der Woude FJ, Bruijn JA: Renal granulomas in systemic vasculitis. EC/BCR Project for ANCA-Assay Standardization. Clin Nephrol 48:16-21, 1997

33. Hauer HA, Bajema IM, van Houwelingen HC, Ferrario F, Noel LH, Waldherr R, Jayne DR, Rasmussen $N$, Bruijn JA, Hagen EC: Renal histology in ANCA-associated vasculitis: differences between diagnostic and serologic subgroups. Kidney Int 61:80-89, 2002 
34. Franssen CF, Stegeman CA, Oost-Kort WW, Kallenberg CG, Limburg PC, Tiebosch A, De Jong PE, Tervaert JW: Determinants of renal outcome in anti-myeloperoxidase-associated necrotizing crescentic glomerulonephritis. J Am Soc Nephrol 9:1915-1923, 1998

35. Levy JB, Turner AN, Rees AJ, Pusey CD: Long-term outcome of anti-glomerular basement membrane antibody disease treated with plasma exchange and immunosuppression. Ann Intern Med 134:1033-1042, 2001

36. Segelmark M, Persson B, Hellmark T, Wieslander J: Binding and inhibition of myeloperoxidase (MPO): a major function of ceruloplasmin? Clin Exp Immunol 108:167-174, 1997

37. Griffin SV, Chapman PT, Lianos EA, Lockwood CM: The inhibition of myeloperoxidase by ceruloplasmin can be reversed by anti-myeloperoxidase antibodies. Kidney Int 55:917-925, 1999

38. Vissers MC, Winterbourn CC: The effect of oxidants on neutrophil-mediated degradation of glomerular basement membrane collagen. Biochim Biophys Acta 889:277-286, 1986

39. Kalluri R, Gattone VH, 2nd, Noelken ME, Hudson BG: The alpha 3 chain of type IV collagen induces autoimmune Goodpasture syndrome. Proc Natl Acad Sci U S A 91:6201-6205, 1994

40. Kalluri R, Cantley LG, Kerjaschki D, Neilson EG: Reactive oxygen species expose cryptic epitopes associated with autoimmune goodpasture syndrome. J Biol Chem 275:20027-20032, 2000

41. Hamano Y, Zeisberg M, Sugimoto H, Lively JC, Maeshima Y, Yang C, Hynes RO, WerbZ, Sudhakar A, Kalluri $\mathrm{R}$ : Physiological levels of tumstatin, a fragment of collagen IV alpha 3 chain, are generated by MMP-9 proteolysis and suppress angiogenesis via alphaV beta3 integrin. Cancer Cell 3:589-601, 2003

42. Meli DN, Christen S, Leib SL: Matrix metalloproteinase-9 in pneumococcal meningitis: activation via an oxidative pathway. J Infect Dis 187:1411-1415, 2003

43. Heeringa P, van Goor H, Moshage H, Klok PA. Huitema MG, de Jager A, Schep AJ, Kallenberg CG: Expression of NOS, eNOS, and peroxynitrite-modified proteins in experimental anti-myeloperoxidase associated crescentic glomerulonephritis. Kidney Int 53:382-393, 1998 
CHAPTER 6

\section{Neutrophil myeloperoxidase activity and the influence of two single nucleotide promoter polymorphisms}

Abraham Rutgers, Peter Heeringa, Joyce E.H.M. Giesen, Ruud T. Theunissen, Heinz Jacobs, and Jan Willem Cohen Tervaert

Clinical and Experimental Immunology, University hospital Maastricht, The Netherlands

Published as a short publication in: Br J Haematol. 2003 Nov; 123(3): 536-8. 
82 Chapter 6

\section{ABSTRACT}

Myeloperoxidase (MPO) catalyzes the formation of hypochlorous acid and is involved in many physiologic and pathophysiological processes. Two single nucleotide polymorphisms (SNPS) have been described in the MPO promoter region: One at position $-463(463 \mathrm{G} / \mathrm{A})$ and one at $-129(129 \mathrm{G} / \mathrm{A})$. Only limited data are available on the functional consequences of these SNPS. The present study was designed to determine whether the $463 \mathrm{G} / \mathrm{A}$ and $129 \mathrm{G} / \mathrm{A}$ polymorphisms affect neutrophil MPO protein levels and activity. In 243 healthy controls MPO activity was measured on a single cell level using a hematologic analyzer and whole blood samples. Genotypes were determined using polymorphism specific restriction digestion reactions. In a subgroup MPO protein levels were measured as well. The $129 \mathrm{G} / \mathrm{A}$ affects the MPO activity in neutrophils, the A allele being associated with lower MPO activity. For the $463 \mathrm{G} / \mathrm{A}$ polymorphism only a gender dependent difference in MPO activity in older age groups could be found. Thus, the 129G/A MPO promoter polymorphism is a functional polymorphism and association studies are warranted to further elucidate the role of this SNP in diseases in which MPO has been suggested to play a pathophysiological role. 


\section{Introduction}

Myeloperoxidase (EC 1.11.1.7) is a heme containing peroxidase expressed and stored in monocyte and neutrophil granulocyte precursors. In mature resting neutrophils, MPO is the most abundant protein and upon neutrophil activation MPO is readily released into phagocytic vacuoles as well as in the extracellular space where it catalyses the formation of hypochlorous acid (bleach; $\mathrm{HOCl}$ ) out of chloride ions and hydrogen peroxide $\left(\mathrm{H}_{2} \mathrm{O}_{2}\right)$. $\mathrm{HOCl}$ can react with a variety of cellular substrates including thiols, nucleotides and amines and, as such, it contributes to innate immunity against bacteria and fungi by neutrophils ${ }^{1}$. In addition to this conventional view on the role for the MPO/HOCI system, recent evidence suggests that MPO can also act as a detoxicant for $\mathrm{H}_{2} \mathrm{O}_{2}$ thereby protecting proteolytic enzymes from inactivation $^{2,3}$. Furthermore, MPO can inactivate protease inhibitors ${ }^{4}$, thus increasing protease activity at inflammatory sites. Given the broad substrate range for MPO it is very critical to control the site of MPO activity.

Growing evidence indicates that the MPO-HOCI system is not only involved in the killing of microorganisms but may also play a potential pathophysiological role in various diseases such as atherosclerosis and cancer. In this respect, MPO-HOCI has been shown to oxidize LDL ${ }^{1}$, activate carcinogens ${ }^{5}$ and form DNA adducts ${ }^{5-9}$. MPO-HOCl is also directly cytotoxic in high concentrations, whereas in lower concentrations it is able to activate MAPK pathways and can cause growth arrest and apoptosis ${ }^{10}$.

Moreover, recent studies have shown that MPO can use nitric oxide (NO) as a substrate in the presence of $\mathrm{H}_{2} \mathrm{O}_{2}$ leading to reduced $\mathrm{NO}$ bioavailability ${ }^{11,12}$. Such an effect would be especially relevant at sites of inflammation where MPO, $\mathrm{NO}$ and $\mathrm{H}_{2} \mathrm{O}_{2}$ are present. Interestingly, catalytically active MPO has been detected in glomerular and atherosclerotic lesions in conjunction with $\mathrm{HOCl}$-modified proteins ${ }^{13,14}$. In addition, it has been demonstrated that coronary atherosclerosis is associated with an increased neutrophil MPO content suggesting a link between MPO protein levels and atherosclerosis 15 .

Recently two MPO promoter polymorphisms have been identified that can potentially influence the transcription of MPO and therefore the amount of active enzyme available. The first polymorphism is a $-463 \mathrm{G}$ to A nucleotide change within an Alu-encoded hormone response element. The GG genotype is the most common, at $61 \%$ of the Northern European population. The AA genotype occurs in $3-7 \%$ of Caucasians and the GA in $32-36 \% 16$.

The $G$ allele contains a SP1 binding site associated with a stronger promoter activity (see also figure 1). The A allele destroys this SP1 binding site, but creates an estrogen binding motif. In cellular transfection assays the $G$ allele increases the transcription of a reporter gene by 25 -fold whereas in the presence of the A allele transcription is increased following $\beta$-estradiol incubation ${ }^{16}$. Reynolds et al found that in 10 tested patients with myeloid leukemia MPO protein level expression was higher for the GG than the GA or AA genotypes ${ }^{17}$. In contrast, however, Hoy et a/ were not able to demonstrate an association between MPO protein levels and the $463 \mathrm{G} / \mathrm{A}$ polymorphism ${ }^{18}$. 
Association studies have demonstrated that the 463GG genotype frequency is increased in several diseases e.g. atherosclerosis, vasculitis, Alzheimer's disease, multiple sclerosis, and cancer ${ }^{17,19-28}$. However, for some diseases data are controversial and could not be confirmed by others $29-32$.

A second MPO promoter polymorphism (129G/A) has been described recently. This $G$ to $A$ single nucleotide polymorphism (SNP) at position-129 presumably also interferes with promoter activity since Hoy et a/ have associated this SNP with decreased levels of MPO in the serum of healthy controls. About $10 \%$ of people in a French population was heterozygous for this polymorphism ${ }^{18}$. To date the $129 \mathrm{G} / \mathrm{A}$ polymorphism has been evaluated for disease association in only one population with sarcoidosis patients ${ }^{33}$.

Thus, the MPO-HOCl system plays an important role in many diseases involving neutrophils and monocytes suggesting that MPO levels themselves can modulate the outcome of and/or susceptibility for these diseases. Two recently described SNP's (463G/A and $129 \mathrm{G} / \mathrm{A}$ ) in the promoter region of the MPO gene can potentially affect MPO gene transcription and protein levels but only limited data are available to support this contention. Therefore, the present study was designed to investigate the influence of these SNP's on the MPO activity in neutrophils in a large group of healthy subjects.

\section{Materials and methods}

\section{Subjects}

243 Caucasian individuals ( 132 males and 111 females; median age 35 ; age range 18 - 82 years) with no record of present health problems were included in this study. EDTA anti-coagulated blood was drawn and tested for neutrophil MPO activity at single cell level within 3 hours and buffy-coats were stored for subsequent DNA analysis. Of a subgroup of 62 subjects, neutrophils were purified and MPO per neutrophil was determined (see later in this article). The recruitment of volunteers, drawing and use of blood for DNA and MPO activity measurements was approved by our local medical ethics committee.

\section{Genotyping}

DNA was isolated from leukocytes by a high pure PCR template preparation kit (Roche, Basel, Switzerland). For determination of the $463 \mathrm{G} / \mathrm{A}$ polymorphism a previously described method was used ${ }^{16,24}$. In short a 350 bp DNA fragment was amplified using 1 unit of Taq polymerase (Amersham Pharmacia, Uppsala, Sweden), $10 \mu$ mol/liter of primers (Sigma-Genosys, Cambridge, United Kingdom) (MPO-forward (5'-CGGTATAGGCACACAATGGTGAG) and MPO-reverse (5'-GCAATGGTTCAAGCGATTC-TTC), 0.2 mmol/liter deoxynucleotide triphosphate (Roche), and 10X PCR buffer (Amersham Pharmacia) in a total volume of $25 \mu \mathrm{l}$. Cycling conditions were $95^{\circ} \mathrm{C}$ for $6 \mathrm{~min}$., followed by 35 cycles at $95^{\circ} \mathrm{C}$ for $30 \mathrm{sec} .62^{\circ} \mathrm{C}$ $\left(-0.3^{\circ} \mathrm{C}\right.$ per cycle), for $1 \mathrm{~min}$., and $72^{\circ} \mathrm{C}$ for $30 \mathrm{sec}$. $15 \mu \mathrm{l}$ of the PCR product were digested with 5 units of Acil (Westburg, Leusden, The Netherlands) for 2 hrs or overnight at $37^{\circ} \mathrm{C}$, 
which produced three fragments $(168,121$, and $61 \mathrm{bp}$ ) for the $G \mathrm{G}$ and two fragments (289 and $61 \mathrm{bp}$ ) for the AA genotype. Fragments were separated on a $3 \%$ agarose gel stained with ethidium bromide (see figure 1).

To determine the $129 \mathrm{G} / \mathrm{A}$ polymorphism a 279 bp DNA fragment was amplified by PCR as previously described by Hoy et al (MPO-forward primer 5'-CCTCCACAGCTCAC-CTGATAT-3', and MPO-reverse $5^{\prime}$-CGCTTGAACCATTGCAC-ATCA-3', Sigma-Genosys) ${ }^{18}$. Cycling conditions were 30 cycles of $94^{\circ} \mathrm{C}$ for $30 \mathrm{sec}, 55^{\circ} \mathrm{C}$ for $30 \mathrm{sec}$, and $30 \mathrm{sec}$. at $72^{\circ} \mathrm{C}$. We identified a 1296 to A specific Apa 1 restriction site within the 278 bp PCR product. PCR products were digested with 20 units of Apa 1 (Roche) for 2 hours or overnight at $30^{\circ} \mathrm{C}$. The undigested 278 and the digested 154 and 124 bp fragments produced by the GA and GG genotype respectively were separated on a $2 \%$ agarose gel stained with ethidium bromide (see figure 1).

MPO activity measurements: ADVIA 120

The relative MPO activity was measured on a single cell level by automated cytometry in flow (ADVIA 120, Bayer). This cytometer makes use of peroxidase activity to differentiate whole blood in neutrophil, monocyte, and other cell populations. In brief, the addition of $\mathrm{H}_{2} \mathrm{O}_{2}$ and 4-Chloor-1-naphthol to peroxidase containing cells (i.e. neutrophils, monocytes and eosinophils) results in a dark colored staining. Peroxidase activity is directly proportional to the intensity of staining, which is measured as an absorption of light. Of the neutrophil cluster a mean neutrophil myeloperoxidase activity index is calculate (MPXI) automatically, which is the distance of the mean peroxidase activity of the neutrophil cluster from the theoretical mean of a standard neutrophil cluster (see figure $2 a$ and b).

MPO activity measurements: Dihydrorhodamine (DHR) oxidation

The capacity of intracellular neutrophil MPO to oxidate the non-fluorescent DHR to the fluorescent rhodamine was compared to neutrophil MPO activity as measured by the ADVIA in a number of subjects. DHR oxidation was measured as described ${ }^{34}$. In short, isolated neutrophils (see below) were incubated with DHR (Molecular Probes, Leiden. The Netherlands) and stimulated with phorbolmyristate acetate (PMA; Sigma St. Louis, USA). Flow cytometric analysis of cell-associated fluorescence was performed on a FACScan (Becton Dickinson, Mountain View, USA). Appropriate gates were set to exclude small cell aggregates and the mean fluorescence intensity for total green fluorescence ( $F L 1$ ) was used to express the mean cellular rhodamine fluorescence.

\section{Peroxidase activity and protein levels}

Neutrophils were isolated by density centrifugation and MPO was released as described elsewhere ${ }^{15}$. Briefly, neutrophils were isolated from whole blood by a one step centrifugation procedure with a Histopaque $1077 / 1114$ (Sigma, St. Louis M.O., U.S.A.) gradient. After cell count, MPO was released by the addition of an ionic detergent (hexadecyltrimethylammonium bromide; CETAB, Sigma, final concentration $0.2 \%$ ) and samples were snap frozen in liquid $\mathrm{N}_{2}$ and stored at minus $70^{\circ} \mathrm{C}$ until analysis. Protein levels were measured by using the bicinchoninic acid (BCA) protein assay (Pierce, Rockford, Illinois, U.S.A.) and MPO 

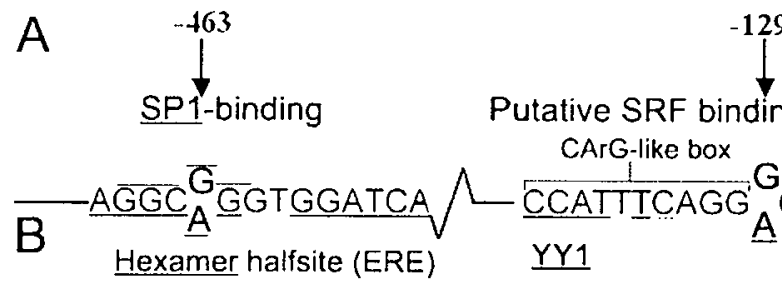

Putative SRF binding
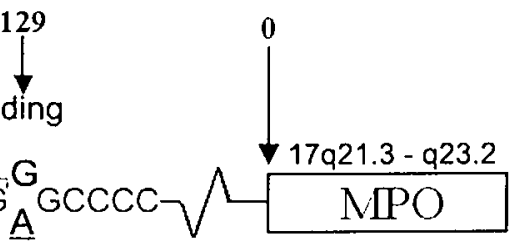

Hexamer halfsite (ERE)

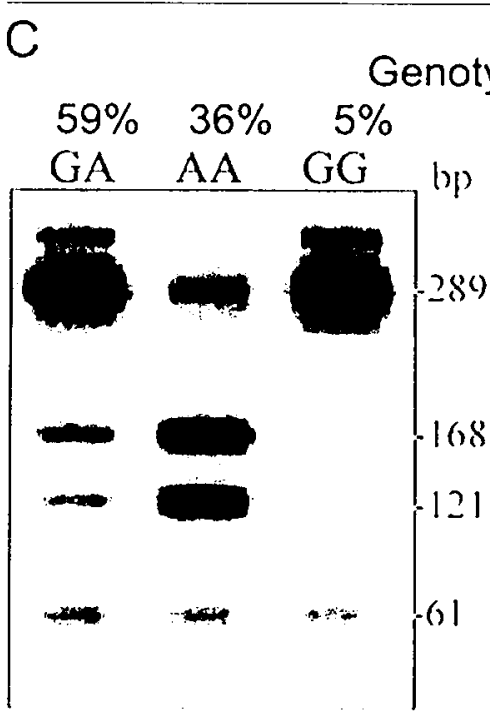

Aci 1

digestion enzyme

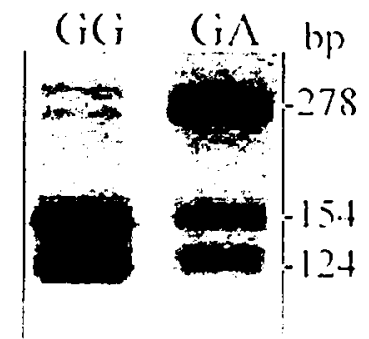

$89 \% 11 \%$

Figure 1. Figure showing the two single nucleotide polymorphisms (SNPs) in relation to the MPO gene. A) shows (putative) binding sites (black line on top of text) when both polymorphisms have their wild type genotype (i.e. G allele), B) shows the (putative) binding sites (underlined) when both sites are polymorphic (i.e. A allele). Note the single nucleotide mismatch with the consensus ${ }^{17}$ binding site of yin yang-1 (YY1) transcription factor (dotted underlined). ERE = Estrogen response element; SRF = serum response factor. C) Shows a picture of an agarose gel of the digested PCR product for both polymorphism. The $G$ to $A$ change results in the loss of a specific restriction site for the restriction enzymes Aci I and Apa I for the 463G/A and 129G/A polymorphism respectively.

levels were determined with a MPO capture enzyme linked immuno sorbent assay (ELISA). A Maxisorp (Nunc, Roskilde, Denmark) ELISA plate was coated with phosphate buffered saline (PBS) containing $7 \mu \mathrm{g} / \mathrm{ml} \mathrm{lg}$ fraction of a polyclonal anti-MPO antibody (Dako, Glostrup, Denmark) for 2 hours at room temperature washed 3 times with PBS alone and blocked with 150 $\mu$ of $1 \%$ bovine serum albumin in PBS (PBSA) for 1 hour at room temperature. Then a $100 \mu \mathrm{l}$ dilution in PBSA of the equivalent of $20,000,10,000$ and 5,000 neutrophils was incubated at $37^{\circ} \mathrm{C}$ for 1.5 hours in each well in triplicates, washed 3 times with washing buffer $(0.1 \%$ Tween-20 in tris buffered saline and subsequently PBSA containing $0.45 \mu \mathrm{g} / \mathrm{ml}$ mouse monoclonal antibody (MPO-7, Dako) was added for 1 hour at room temperature. Finally, this 


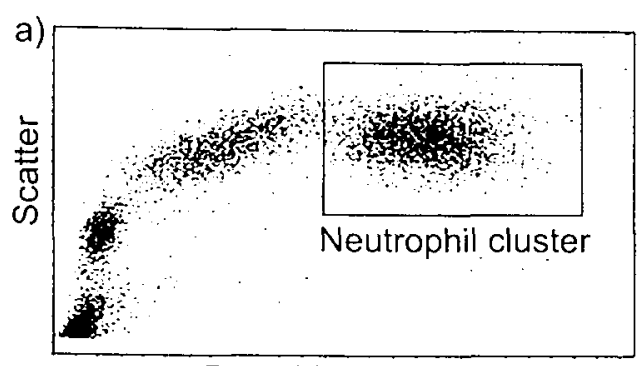

Peroxidase activity

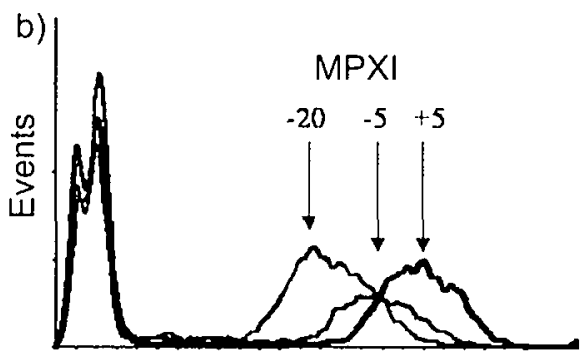

Peroxidase activity

Figure 2. MPXI measurement. Figure a) shows analysis of whole blood by the ADVIA 120. The X-axis shows the amount of absorption of light, i.e. the peroxidase activity. The $Y$-axis shows the scatter signal, i.e. the volume of the cells passing the laser beam. Different cell clusters can be identified (from left to right): lymphocytes, monocytes and neutrophils, the latter two containing MPO. The neutrophil cluster is indicated in the figure. This scatter plot can be transformed into a histogram plot showing the neutrophil peak relative to the peroxidase activity. In figure b) such a histogram plot is shown for three subjects with different neutrophil MPO activities (MPXI). Eosinophils do not fall inside the neutrophil cluster and are therefore not included in the MPXI measurement.

antibody-MPO-antibody sandwich was detected by a $0.6 \mu \mathrm{g} / \mathrm{ml}$ anti-mouse antibody coupled to alkaline phosphatase (Jackson, West Grove, PA, USA) in tris buffered saline (TBS). Subsequently, MPO in each sample was enzymatically measured upon addition of 4-nitrophenyl-phosphate by reading the microplate at $405 \mathrm{~nm}$. A triplet standard curve of known MPO (0 - 40 ng/well) (Calbiochem, San Diego, California, U.S.A.) concentration was used for determining sample MPO content. Pipetting volumes were always $100 \mu l$ unless mentioned otherwise. In between all steps plates were washed 3 times with washing buffer. MPO levels were expressed as percentage of total protein and of number of neutrophils.

\section{Statistical analysis}

Statistical analysis was performed with Graphpad Prism ${ }^{2}$ version 3.00. Analysis of variance (ANOVA) was used to compare multiple groups, for post testing bonferroni's multiple comparison test was used. Unpaired t testing was performed when data followed a Gaussian distribution, otherwise non-parametric testing was used (Mann Whitney). When evaluating correlation Pearson correlation testing was performed for Gaussian distributed values. Hardy-Weinberg equilibrium for each polymorphism was tested by a $\chi^{2}$ test. A $p$ value $<0.05$ was considered significant.

\section{Results}

MPO activity in healthy subjects

In our study population of 243 healthy subjects, the mean myeloperoxidase activity in neutrophils was $-2.3( \pm 5.46$ ) with a minimum of $-35,1$ and a maximum of $7.1 \mathrm{MPXI}$ units (see figure 3a). Furthermore, neutrophil myeloperoxidase activity in individual subjects was found to be 


\section{a) Myeloperoxidase activity of healthy} volunteers

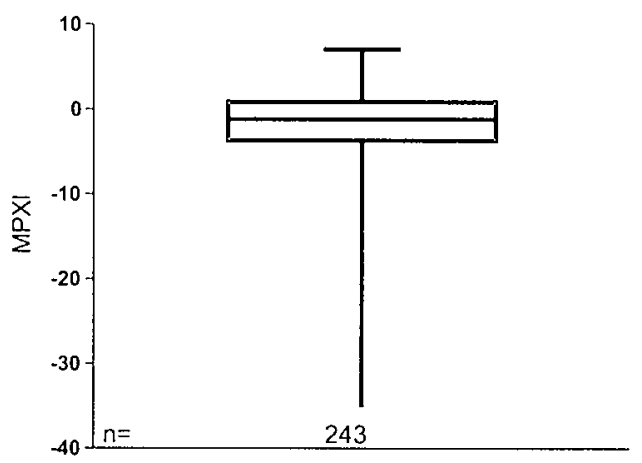

b)

\section{Sequential MPXI measurements}

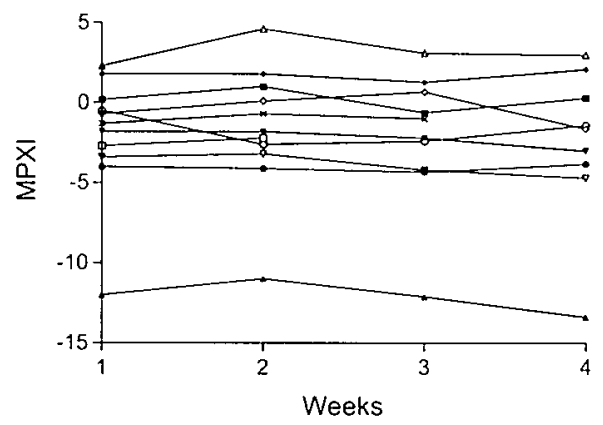

Figure 3. Myeloperoxidase in healthy controls. Figure a) showing the distribution of myeloperoxidase activity in a healthy population presented as a Box and Whisker plot*. Figure b) shows the stability of the MPXI measurement of 11 subjects over a 4 week time period. *Box and Whisker plots showing quartiles; The box extends from the 25 th percentile to the 75 th percentile, with a line at the median (i.e. 50th percentile). The whiskers extend above and below the box to show the highest and lowest values.

stable over time demonstrating only little variation upon sequential measurements indicating the sensitivity and reproducibility of this assay (standard deviation of 10 persons over 4 weeks of 0.7 , ANOVA $p=0,12 \mathrm{~F}=2.2$, figure $3 \mathrm{~b}$ ).

Upon further statistical analysis of neutrophil MPO activity in the whole population it was observed that MPXI values did not display a Gaussian distribution. This effect was found to be due to gender differences because separate analysis of male and female subjects revealed a significantly higher average MPXI value in women as compared to men $(-0.6$ versus -3.7 respectively, $p<0.0001$, see figure 4 ). 


\section{$M P()$ activity in men and women}

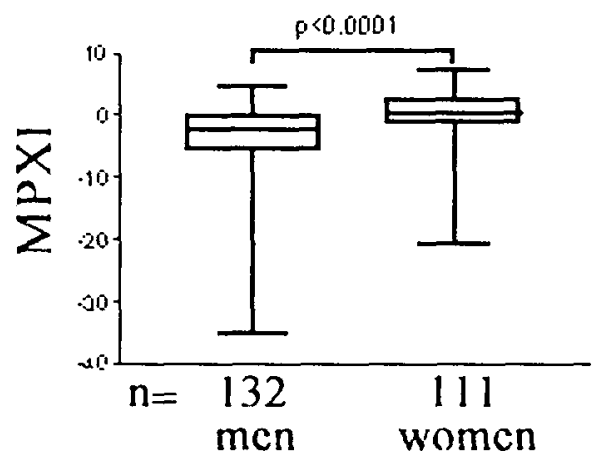

Figure 4. Box and Whisker plot of MPO activity in men and women. Women have a higher MPO activity than men $(-0.7$ versus $-3,8$, respectively; Mann Whitney test $p<0.0001)$

\section{Association of the 463G/A and 129G/A MPO gene polymorphisms and neutrophil MPO activity}

The genotypic analysis of the two SNP's, 463G/A and 129G/A in our population resulted in the detection of $59 \%$ GG, 36\% GA and 5\% AA genotypes for the $463 \mathrm{G} / \mathrm{A}$ and $89 \% \mathrm{GG}, 11 \% \mathrm{GA}$ and $0 \%$ AA genotypes for the 129G/A SNP (see table 1). Both polymorphisms were in Hardy-Weinberg equilibrium.

Next, we investigated whether there was an association between the respective MPO genotypes and neutrophil MPO activity. In our study population, no direct association was found between 463 G/A genotypes and MPO activity values (see figure 5).

Since the 463 A allele creates an estrogen binding motif, higher MPO activity values could be expected in female $463 \mathrm{GA}$ and AA subjects but no such relationship was observed when considering the whole study group. Interestingly, however, the $463 \mathrm{GA}$ genotype, but not the GG genotype, was associated with a higher MPO activity in women $<45$ years compared to women $>55$ years of age (MPXI-women: -0.9 to -5.7 respectively; $p=0.03$ ). In contrast, MPO activity values tended to be higher in men $>55$ compared to men $<45$ years of age although this did not reach statistical significance (MPXI-men under 45: -3.6, MPXI-men over 55: 0.6; $p=0.06$ ) (see also figure 6).

Analysis of the 129G/A SNP in relation with neutrophil MPO activity values revealed that the 129 A allele was significantly associated with lower MPO activity values. In subjects displaying a GG genotype an average activity of $-1.5 \mathrm{MPXI}$ units was observed, compared to -8.8 for the 
Men

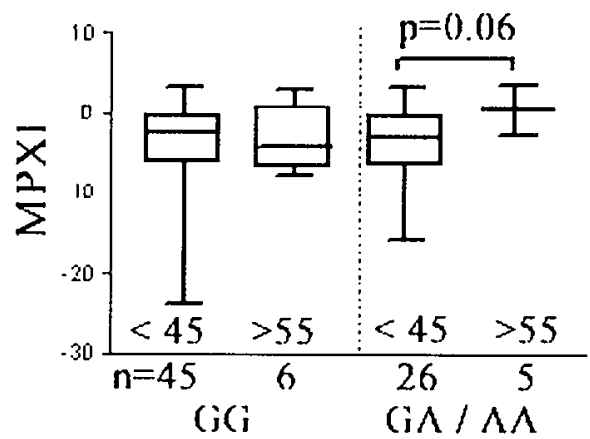

Women

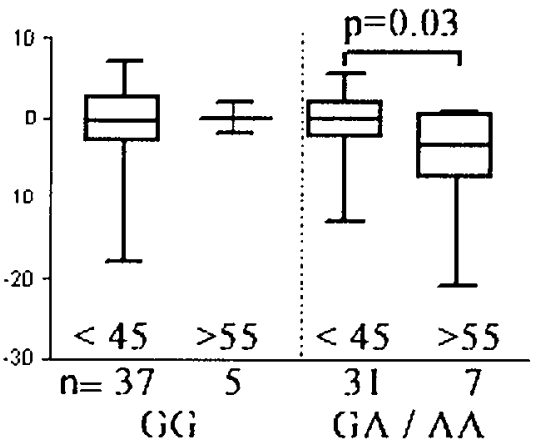

Figure 6. Figure showing MPO activity difference for the 463GA genotypes older than 55 compared to younger than 45 years (MPXI-men: -3.6 to 0.6; MPXI-women: -0.9 to -5.7 ; student's t-test $p=0.06$ and 0.03 respectively). Note the opposite effect of age on GA men compared to GA women.

a)

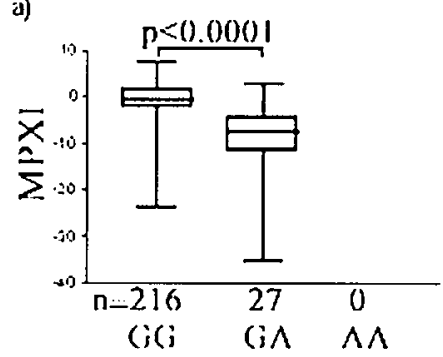

b)

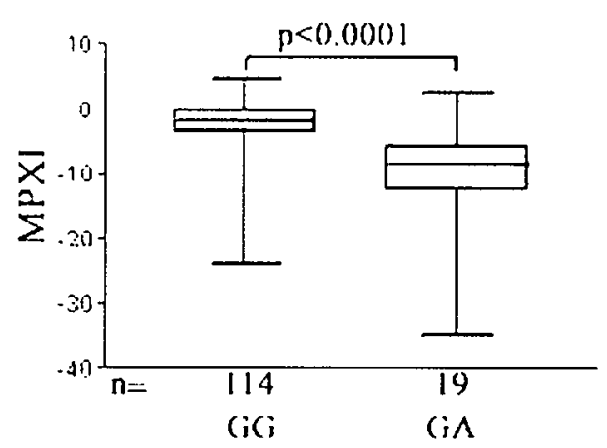

c)

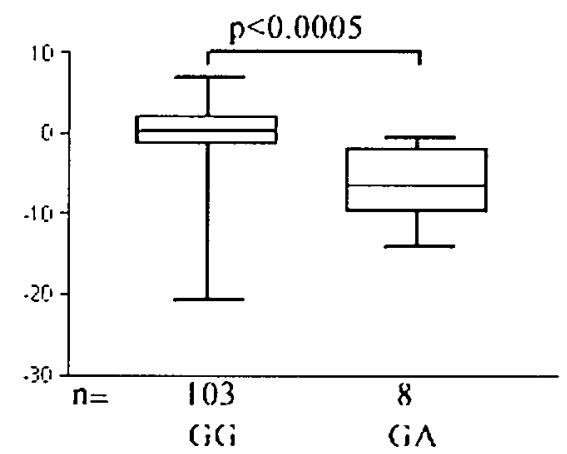

Figure 7. MPO activity related to $129 \mathrm{G} / \mathrm{A}$ polymorphism. Figure a) showing Box and Whisker plots of MPO activity related to the $129 \mathrm{G} / \mathrm{A}$ polymorphism. A significant difference between $129 \mathrm{GG}$ and $129 \mathrm{GA}$ genotypes was observed (average MPXI for GG and GA genotypes was -1.5 and -8.8 , respectively; Mann Whitney test $p<0.0001)$. No $A A$ genotypes in our group of healthy subjects could be identified. Figure $b$ ) and $c$ ) show Box and Whisker plots of MPO activity related to the $129 \mathrm{G} / \mathrm{A}$ polymorphism in males and females respectively. A significant difference between 129GG and 129GA genotypes was observed (Mann Whitney test $p<0.0001$ and $p=0.0005$, for men and women respectively). 


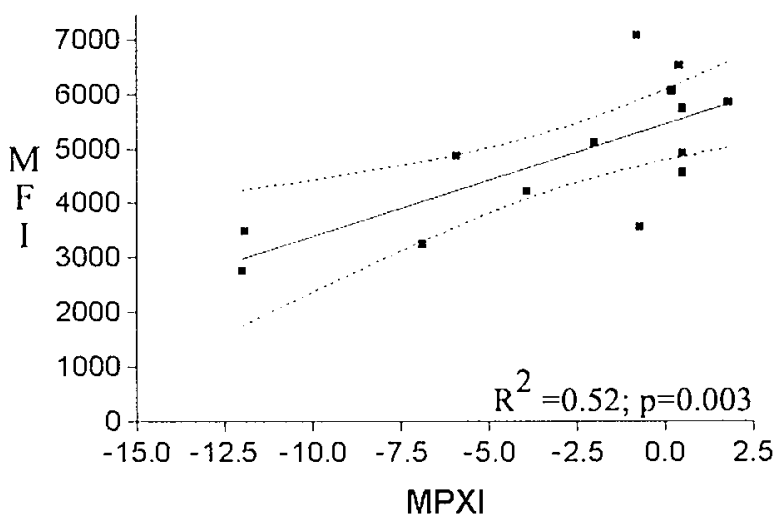

Figure 8. Figure showing correlation between the dihydrorhodamine oxidation by intracellular MPO and intracellular MPO activity (MPXI; $\left.R^{2}=0.52, p=0.003\right)$. MFI = Mean fluorescence intensity of FL1 channel.

Table 1. Polymorphisms frequency in healthy individuals

\begin{tabular}{llll}
\hline & $G G$ & $G A$ & $A A$ \\
& $n(\%)$ & $n(\%)$ & $n(\%)$ \\
\hline $463 G / A$ & $143(59 \%)$ & $88(36 \%)$ & $12(5 \%)$ \\
$129 \mathrm{G} / \mathrm{A}$ & $216(89 \%)$ & $27(11 \%)$ & $0(0 \%)$ \\
\hline
\end{tabular}

GA genotype $(p<0.0001)$ and the influence of the $129 \mathrm{G} / \mathrm{A}$ SNP on MPO activity was similar for each gender (see figure 7).

\section{Association of MPO activity and oxidation of rhodamine}

To demonstrate that MPO activity as measured by the MPXI corresponds to other measurements of intracellular MPO activity, we measured the oxidation of intracellular dihydrorhodamine to the fluorescent rhodamine by FACS analysis. A positive correlation between the MPXI values and the observed fluorescence of dihydrorhodamine could be observed $\left(r^{2}=0.52, n=14 ; p=0,003\right.$; see figure 8$)$.

\section{Association of MPO activity and protein levels.}

To demonstrate that MPO activity is related to MPO protein levels, the amount of MPO protein was measured by ELISA in neutrophil extracts of 62 individuals. A significant positive correlation ( $p=0.0031$ ) could be observed between MPO protein levels and MPO activity measurements, although $r$ square values were low $\left(r^{2}=0.13\right)$. The $r$ square value improved when analyzing only subjects with MPXI values below $-4,65$ (representing the lower $25 \%$ quartile of values, $n=16, p=0.0287 ; r^{2}=0.30$ ). To further investigate the relation between MPO protein and MPO activity data were divided into quartiles (see figure 9 a). Analysis of variance demonstrated significant differences between the 4 quartiles $(p=0.008)$ and post testing revealed 
a) $\mathrm{MPO}$ protcin levels per quartile

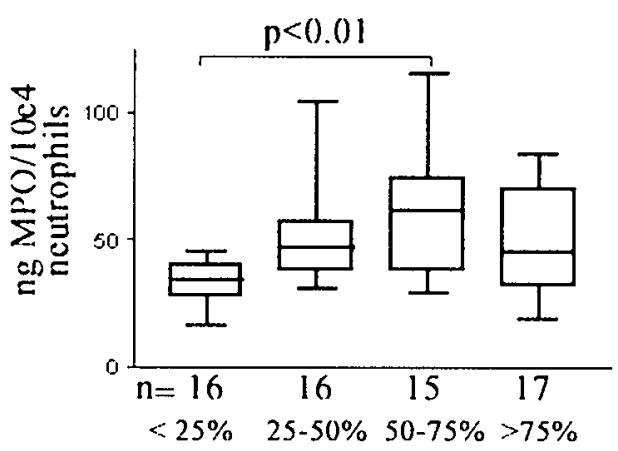

b) $\quad \mathrm{MP}()$ protcin levels and the $463(\mathrm{i} / \wedge$ polymorphisms

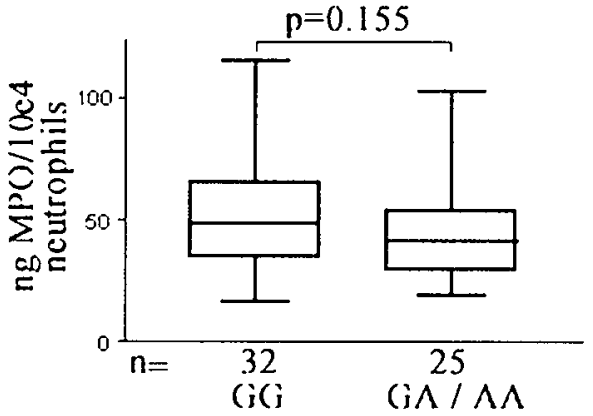

c) $\mathrm{MPO}$ protein levels and the 129 (j/A polymorphism

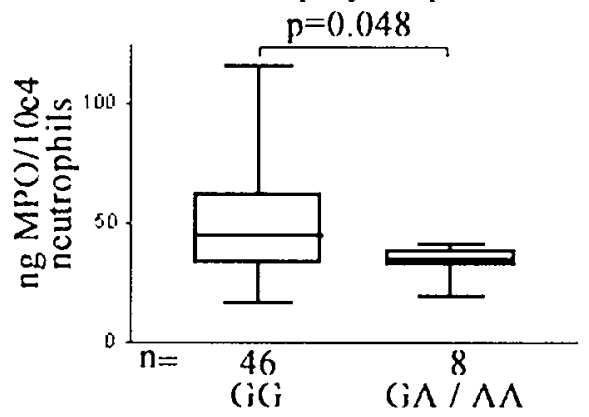

Figure 9. MPO protein levels. Figure a) showing MPO protein levels per quartile. Quartiles represent 4 equal groups of increasing MPO activity as measured by the ADVIA. Analysis of variance demonstrated significant differences between the 4 quartiles $(p=0.008$ ) and post testing revealed these differences between the lower $25 \%$ quartile and the $50-75 \%$ quartile $(p<0.01)$. Figure $b$ ) shows MPO protein levels for either the $463 \mathrm{GG}$ genotype or the 463GAVAA genotypes. No significant difference could be observed. Figure c) shows MPO protein levels for either the $129 \mathrm{GG}$ or the 129GA genotype, note the significant difference in protein levels between these two genotypes $(p=0.048)$ 
significant differences between the lower $25 \%$ quartile and the $50-75 \%$ quartile $(p<0.01)$ (see also figure 9 a).

Analysis of the two SNP's for MPO protein levels revealed that no difference in MPO protein content could be observed for the $463 G / A$ SNP $(p=0.155$, figure $9 b)$. However, for the 129 G/A SNP a significant difference could be observed, the GA genotype being associated with lower amount of MPO protein ( $p=0.048$, figure $9 c)$

\section{Conclusion and discussion}

In the present study, a cohort of healthy individuals was analyzed for neutrophil MPO activity in relation to the possible influence of two recently described SNPS in the promoter region of MPO that might affect MPO gene transcription. Overall results showed that neutrophil MPO activity is higher in women than in men and SNP analysis revealed that the 463G/A SNP is associated with gender dependent differences in MPO activity in older age groups. In contrast, the $129 \mathrm{G} / \mathrm{A}$ SNP was found to be associated with decreased MPO activity and protein levels compared to $129 \mathrm{GG}$ individuals in both males and females.

In the whole study population, a wide range in individual neutrophil MPO activities was observed varying from -35.1 to 7.1. These neutrophil MPO activities as measured by the MPXI correlated with the intracellular rhodamine oxidation by MPO as measured with the DHR assay. Although a positive correlation between MPO activity and MPO protein per neutrophil was found as well, the relation between these two was low. These results suggest that other factors can influence MPO activity. Possible factors are estrogens and changes in the coding sequence of the enzyme 35,36 . The latter can be important for MPO activity since MPO is a dimerized protein consisting of two monomers and the specific allelic contribution (with different promoters in the heterozygous situation) to the mature protein is not known. Thus, if one allele has high promoter activity, but encodes a less functional MPO monomer, the total (dimerized) MPO activity might not be elevated and vice versa. Also, the isolation procedure of neutrophils necessary for measurement of total neutrophil MPO content could result in partial degranulation leading to loss of MPO. Since our MPO activity measurements are performed on whole blood, this degranulation effect might explain differences in activity measurement and protein levels.

An interesting observation in our study was that women have a higher average MPO activity than men, an effect that was largely independent of genotype. Similar observations have been made by Kabutomori et a/ who suggested that female hormones may be the underlying cause for this difference ${ }^{37}$. In this respect, Bekesi et al found that treatment with estrogens increased neutrophil MPO activity in post-menopausal women ${ }^{35}$. Furthermore, MPO plasma levels are lower in women than men ${ }^{18}$. This contradiction can be explained by the fact that in vitro studies have shown that estrogens can inhibit MPO degranulation and as such may result in higher intracellular MPO activity and lower MPO plasma levels in women than men ${ }^{38}$. More- 
over, a recent clinical study has shown that the administration of estrogens to males prior to an elective coronary artery bypass operation lowers MPO release shortly after surgery ${ }^{39}$.

Overall no difference in MPO activity for the 463G/A polymorphism was found which contrasts with the findings of Reynolds et a ${ }^{17}$. These contradictory results can possibly be explained by the fact that Reynolds et a/ investigated a limited number of patients ( 5 GG, 2 GA and 3 AA genotypes) with myeloid leukemia for MPO mRNA and protein levels by Northern and Western blotting respectively ${ }^{17}$. These leukemic cells might not reflect normal peripheral blood neutrophils which are differentiated cells with MPO stored in granules and that have ceased MPO protein and mRNA synthesis ${ }^{40}$. Our data are, however, in line with the results of Hoy et a/ who studied MPO levels in serum of a large group of healthy individuals and were also not able to demonstrate an association between MPO protein levels and the $463 \mathrm{G} / \mathrm{A}$ polymorphism ${ }^{18}$.

Interestingly, in our cohort of healthy individuals subgroup analysis revealed that women over 55 years of age with the 463GA genotype have a lower MPO activity compared to women under 45 . The opposite effect, although not significant, was found in men. Since the $463 \mathrm{G}$ to A polymorphism creates an estrogen response element, cessation of ovarian estrogen production in post-menopausal women could explain this female MPO activity drop in GA or AA genotypes. Also, because conversion of androgenic precursors to estrogens increases as a function of obesity and aging, older men would be expected to have higher estrogen levels than young men ${ }^{41-43}$. This gender and age dependent effect on MPO activity for the 463GA genotype individuals might explain the necessity to look at age and gender specific differences when analyzing clinical association studies. In this respect it is interesting to note that older 463GA genotype males have an increased risk of lung cancer and that in a recent study of 1083 individuals a reduced risk for periodontal disease could be observed for females only $20-22,30,44$.

Finally, our study has been performed in a population of healthy individuals only. It cannot be excluded that local or systemic conditions in disease might augment the effect the $463 \mathrm{G} / \mathrm{A}$ polymorphism has on MPO expression. Moreover, recent reports indicate that monocyte derived tissue macrophages, often involved in disease, can also contain MPO but SNP effects on these cells have not been studied 45,46 .

With respect to the 129G/A polymorphism, a significant difference in MPO activity was found, the $A$ allele being associated with lower neutrophil MPO activity. Based on sequence comparison the 129A allele will bind yin yang-1 transcription factor (YY-1) better than the $129 \mathrm{G}$ allele (figure $1 \mathrm{~B}$ versus $1 \mathrm{~A}$ ). Preliminary data show that the $129 \mathrm{~A}$ allele has indeed an increased binding of $Y Y-1$ (data not shown). YY-1 is a multi-functional transcription factor and can activate, repress or initiate transcription ${ }^{47}$. We are currently investigating its role in promoter reporter assays. Interestingly, Erkeland et a/ showed that YY-1 can interfere with myeloid differentiation towards neutrophils ${ }^{48}$. 
Thus, the 129G/A MPO promoter polymorphism is a functional polymorphism and association studies are warranted to further elucidate the role of this SNP in diseases in which MPO has been suggested to play a pathophysiological role.

\section{Acknowledgements}

We would like to thank Maartje Boumans, Inge Jansen and Mia Vaessen (Clinical and Experimental Immunology, Maastricht, The Netherlands) for excellent technical assistance. Furthermore, we would like to thank all the volunteers for their blood donations.

\section{References}

1. Winterbourn CC, Vissers MC, Kettle AJ: Myeloperoxidase. Curr Opin Hematol 7:53-58., 2000

2. Roos D, Winterbourn CC: IMMUNOLOGY: Enhanced: Lethal Weapons. Science 296:669-671, 2002

3. Reeves EP, Lu H, Jacobs HL, Messina CG, Bolsover S, Gabella G, Potma EO, Warley A, Roes J, Segal AW: Killing activity of neutrophils is mediated through activation of proteases by K+ flux. Nature 416:291-297. 2002

4. Matheson NR, Wong PS, Travis J: Enzymatic inactivation of human alpha-1-proteinase inhibitor by neutrophil myeloperoxidase. Biochem Biophys Res Commun 88:402-409, 1979

5. Petruska JM, Mosebrook DR, Jakab GJ, Trush MA: Myeloperoxidase-enhanced formation of (+-)-trans-7,8-dihydroxy-7,8-dihydrobenzo[a]pyrene-DNA adducts in lung tissue in vitro: a role of pulmonary inflammation in the bioactivation of a procarcinogen. Carcinogenesis 13:1075-1081, 1992

6. Williams JA: Single nucleotide polymorphisms, metabolic activation and environmental carcinogenesis: why molecular epidemiologists should think about enzyme expression. Carcinogenesis 22:209-214, 2001

7. Rojas M, Godschalk R, Alexandrov K, Cascorbi I, Kriek E, Ostertag J, Van Schooten FJ, Bartsch H: Myeloperoxidase-463A variant reduces benzo[a]pyrene diol epoxide DNA adducts in skin of coal tar treated patients. Carcinogenesis 22:1015-1018, 2001

8. Van Rensburg CE, Van Staden AM, Anderson R, Van Rensburg EJ: Hypochlorous acid potentiates hydrogen peroxide-mediated DNA-strand breaks in human mononuclear leucocytes. Mutat Res 265:255-261, 1992

9. Brockstedt U, Krajinovic M, Richer C, Mathonnet G. Sinnett D, Pfau W, Labuda D: Analyses of bulky DNA adduct levels in human breast tissue and genetic polymorphisms of cytochromes P450 (CYPS), myeloperoxidase (MPO), quinone oxidoreductase (NQO1), and glutathione S-transferases (GSTs). Mutat Res 516:41-47, 2002

10. Winterbourn CC: Biological reactivity and biomarkers of the neutrophil oxidant, hypochlorous acid. Toxicology 181-182:223-227, 2002

11. Abu-Soud HM, Hazen SL: Nitric oxide is a physiological substrate for mammalian peroxidases. $\mathrm{J}$ Bio/ Chem 275:37524-37532, 2000

12. Eiserich JP, Hristova M, Cross CE, Jones AD, Freeman BA, Halliwell $B$, van der Vliet A: Formation of nitric oxide-derived inflammatory oxidants by myeloperoxidase in neutrophils. Nature 391:393-397, 1998

13. Grone HJ, Grone EF, Malle E: Immunohistochemical detection of hypochlorite-modified proteins in glomeruli of human membranous glomerulonephritis. Lab invest 82:5-14, 2002

14. Malle E, Waeg G, Schreiber R, Grone EF, Sattler W. Grone HJ: Immunohistochemical evidence for the myeloperoxidase $/ \mathrm{H}_{2} \mathrm{O}_{2}$ /halide system in human atheroscleroticlesions: colocalization of myeloperoxidase and hypochlorite-modified proteins. Eur J Biochem 267:4495-4503, 2000

15. Zhang R, Brennan ML, Fu X, Aviles RJ, Pearce GL, Penn MS, Topol EJ, Sprecher DL, Hazen SL: Association between myeloperoxidase levels and risk of coronary artery disease. Jama 286:2136-2142, 2001

16. Reynolds WF, Hiltunen M, Pirskanen M, Mannermaa A, Helisalmi S, Lehtovirta M, Alafuzoff I, Soininen H: MPO and APOEepsilon4 polymorphisms interact to increase risk for AD in Finnish males. Neurology 55:1284-1290., 2000 
17. Reynolds WF, Chang E, Douer D, Ball ED, Kanda V: An allelic association implicates myeloperoxidase in the etiology of acute promyelocytic leukemia. Blood 90:2730-2737., 1997

18. Hoy $A$, Tregouet $D$, Leininger-Muller $B$, Poirier $O$, Maurice $M$, Sass $C$, Siest $G$, Tiret $L$, Visvikis S: Serum myeloperoxidase concentration in a healthy population: biological variations, familial resemblance and new genetic polymorphisms. Eur I Hum Genet 9:780-786, 2001

19. Nikpoor B, Turecki G. Fournier C. Theroux P, Rouleau GA: A functional myeloperoxidase polymorphic variant is associated with coronary artery disease in French-Canadians. Am Heart J142:336-339., 2001

20. Reynolds WF, Stegeman CA, Cohen Tervaert JW: -463 G/A Myeloperoxidase Promoter Polymorphism Is Associated with Clinical Manifestations and the Course of Disease in MPO-ANCA-Associated Vasculitis. Clin Immun 103:154-160, 2002

21. Reynolds WF, Rhees J, Maciejewski D, Paladino T, Sieburg H, Maki RA, Masliah E: Myeloperoxidase polymorphism is associated with gender specific risk for Alzheimer's disease. Exp Neurol 155:31-41, 1999

22. Nagra RM, Becher B, Tourtellotte WW, Antel JP, Gold D, Paladino T, Smith RA, Nelson JR, Reynolds WF: Immunohistochemical and genetic evidence of myeloperoxidase involvement in multiple sclerosis. I Neurommunol 78:97-107, 1997

23. Schabath MB, Spitz MR, Zhang X, Delclos GL, Wu X: Genetic variants of myeloperoxidase and lung cancer risk. Carcinogenesis 21:1163-1166, 2000

24. Cascorbi I, Henning S, Brockmoller J, Gephart J, Meisel C, Muller JM, Loddenkemper R, Roots I: Substantially reduced risk of cancer of the aerodigestive tract in subjects with variant-463A of the myeloperoxidase gene. Cancer Res 60:644-649., 2000

25. Kantarci $O H$, Lesnick TG, Yang P, Meyer RL, Hebrink DD, McMurray $C T$, Weinshenker BG: Myeloperoxidase -463 (G->A) polymorphism associated with lower risk of lung cancer. Mayo Clin Proc 77:17-22, 2002

26. London SJ, Lehman TA, Taylor JA: Myeloperoxidase genetic polymorphism and lung cancer risk. Cancer Res 57:5001-5003., 1997

27. Matsuo K, Hamajima N, Suzuki R, NakamuraS, Seto M, Morishima Y, Tajima K: No substantial difference in genotype frequencies of interleukin and myeloperoxidase polymorphisms between malignant lymphoma patients and non-cancer controls. Haematologica 86:602-608, 2001

28. Pecoits-Filho R, Stenvinkel P. Marchlewska A, Heimburger O, Barany P, Hoff CM, Holmes CJ, Suliman M, Lindholm B, Schalling M. Nordfors L: A functional variant of the myeloperoxidase gene is associated with cardiovascular disease in end-stage renal disease patients. Kidney int Suppl:172-176, 2003

29. Le Marchand L, Seifried A, Lum A, Wilkens LR: Association of the myeloperoxidase $-463 G \rightarrow$ a polymorphism with lung cancer risk. Cancer Epidemiol Biomarkers Prev 9:181-184., 2000

30. Misra RR, Tangrea JA, Virtamo J, Ratnasinghe D, Andersen MR, Barrett M, Taylor PR, Albanes D: Variation in the promoter region of the myeloperoxidase gene is not directly related to lung cancer risk among male smokers in Finland. Cancer Lett 164:161-167., 2001

31. Nelissen I, Fiten P, Vandenbroeck K, Hillert J, Olsson T, Marrosu MG, Opdenakker G: PECAM1, MPO and PRKAR1A at chromosome 17q21-q24 and susceptibility for multiple sclerosis in Sweden and Sardinia. J Neuroimmunol 108:153-159., 2000

32. Kantarci OH, Atkinson EJ, Hebrink DD, MCMurray CT, Weinshenker BG: Association of a myeloperoxidase promoter polymorphism with multiple sclerosis. J Neuroimmunol 105:189-194., 2000

33. Rothkrantz-Kos S, Drent M, Rutgers A, Heeringa A, De Vries J, van Dieijen-Visser MP, Cohen Tervaert JW: Influence of myeloperoxidase promoter polymorphism on the severity of sarcoidosis? Eur I Intern Med accepted, 2003

34. van Pelt $L$, van Zwieten R, Weening RS, Roos D, Verhoeven AJ, Bolscher BG: Limitations on the use of dihydrorhodamine 123 for flow cytometric analysis of the neutrophil respiratory burst. J/mmunol Methods 191:187-196, 1996

35. Bekesi G, Kakucs R, Varbiro S, Feher J, Pazmany T, Magyar Z, Sprintz D. Szekacs B: Induced myeloperoxidase activity and related superoxide inhibition during hormone replacement therapy. Bjog 108:474-481., 2001

36. Nauseef WM, Brigham S, Cogley M: Hereditary myeloperoxidase deficiency due to a missense mutation of arginine 569 to tryptophan. J Biol Chem 269:1212-1216, 1994

37. Kabutomori O, Yanagihara T, Iwatani Y, Kawarazaki A, Kabutomori M: Sex difference in myeloperoxidase activity of neutrophils. Am J Hematol 60:312-313., 1999

38. Buyon JP, Korchak HM, Rutherford LE, Ganguly M, Weissmann G: Female hormones reduce neutrophil responsiveness in vitro. Arthritis Rheum 27:623-630, 1984 
39. Wei M, Kuukasjarvi P, Kaukinen S, Laurikka J, Pehkonen E, Laine S, Moilanen E, Metsanoja R, Tarkka M: Anti-inflammatory effects of 17 beta-estradiol pretreatment in men after coronary artery surgery. $J$ Cardiothorac Vasc Anesth 15:455-459, 2001

40. Borregaard N, Theilgaard-Monch K, Sorensen OE, Cowland JB: Regulation of human neutrophil granule protein expression. Curr Opin Hematol 8:23-27, 2001

41. Edman CD. MacDonald PC: Effect of obesity on conversion of plasma androstenedione to estrone in ovulatory and anovulator young women. Am J Obstet Gynecol 130:456-461, 1978

42. Grodin JM. Siiteri PK, MacDonald PC: Source of estrogen production in postmenopausal women. $J$ Clin Endocrinol Metab 36:207-214, 1973

43. Hemsell DL, Grodin IM, Brenner PF, Siiteri PK, MacDonald PC: Plasma precursors of estrogen. II. Correlation of the extent of conversion of plasma androstenedione to estrone with age. J Clin Endocrinol Metab 38:476-479, 1974

44. Meisel P, Krause T, Cascorbi I, Schroeder W, Herrmann F, John U, Kocher T: Gender and smoking-related risk reduction of periodontal disease with variant myeloperoxidase alleles. Genes/mmun 3:102-106, 2002

45. Brennan M, Gaur A, Pahuja A, Lusis AJ, Reynolds WF: Mice lacking myeloperoxidase are more susceptible to experimental autoimmune encephalomyelitis. J Neuroimmunol 112:97-105, 2001

46. Brown KE, Brunt EM, Heinecke JW: Immunohistochemical detection of myeloperoxidase and its oxidation products in Kupffer cells of human liver. Am J Pathol 159:2081-2088, 2001

47. Shrivastava $A$, Calame $K$ : An analysis of genes regulated by the multi-functional transcriptional regulator Yin Yang-1. Nucleic Acids Res 22:5151-5155, 1994

48. Erkeland SJ, Valkhof M, Heijmans-Antonissen C, Delwel R, Valk PJ, Hermans MH, Touw IP: The gene encoding the transcriptional regulator Yin Yang $1(Y Y 1)$ is a myeloid transforming gene interfering with neutrophilic differentiation. Blood 101:1111-1117, 2003 
CHAPTER 7

\section{The myeloperoxidase 463 promoter polymorphism is related to the pulse wave velocity in subjects with hypertension}

A. Rutgers* , P. Heeringa*, A.J.H.M. Houben**, A.A. Kroon** , P.W. de LeeuW**, and J.W. Cohen Tervaert*

${ }^{\star}$ Clinical and Experimental Immunology,

** Vascular Medicine, University Hospital Maastricht, The Netherlands

Manuscript in preparation 


\section{ABSTRACT}

Background: Large artery stiffness is an important predictor of cardiovascular disease in hypertensive patients. Nitric oxide (NO), a smooth muscle relaxant, has been shown to regulate this process. Interestingly, myeloperoxidase (MPO) has recently been shown to function as a leukocyte derived nitric oxide (NO) oxidase, consuming NO at sites of inflammation and two MPO promoter polymorphisms, MPO463 and MPO129, influence MPO levels. In the present study, we evaluated the influence of these polymorphisms on large artery stiffness as measured by pulse wave velocity in a group of hypertensive patients. We hypothesized that a 'high MPO' genotype results in an increased NO consumption with subsequent increase in pulse wave velocity.

Methods: The pulse wave velocity of 109 patients diagnosed with primary hypertension was measured and their genetic polymorphisms were determined.

Results: The average PWV $(\mathrm{m} / \mathrm{s})$ for the whole group was $13.2( \pm 3.4)$. Males had an average PWV of $14.3( \pm 3.6)$, whereas females had a PWV of 11.7 ( \pm $2.4, \mathrm{p}<0.001$ ). For the MPO129 polymorphism no significant differences were observed. However, for the MPO463GG versus GAVAA genotype significant differences were observed in women but not in men (men $14.5 \pm 3.4$ versus $14.1 \pm 3.7, p=0.6$ and women $12.4 \pm 2.2$ versus $10.3 \pm 2.2, p=0.003$ ).

Conclusions: These results suggest that the MPO463 polymorphism, linked to higher MPO transcription, is associated with an increased pulse wave velocity in women. The latter could be due to the observed gender dependent differences for this polymorphism. 


\section{Introduction}

Large artery stiffness is an important predictor of cardiovascular disease in hypertensive patients ${ }^{1}$. Determinants of large artery stiffness include structural components of the arterial wall, age and systolic blood pressure'. However, stiffness also depends on smooth muscle tone and nitric oxide (NO), a smooth muscle relaxant, has been shown to regulate this pro$\operatorname{cess}^{2}, 3$

Myeloperoxidase (MPO; EC 1.11.1.7) is a heme derived peroxidase and is increasingly recognized as a central participant in the link between inflammation and cardiovascular diseases ${ }^{4}$. MPO produces hypochlorous acid $(\mathrm{HOCl})$ in the presence of hydrogen peroxide and chloride ions $^{5}$. In addition to bactericidal and viricidal activity, MPO has been found to function as a leukocyte derived nitric oxide (NO) oxidase, consuming NO at sites of inflammation ${ }^{6}$. Another pathway by which MPO could influence NO availability and atherosclerotic disease development is by the oxidative modification of $L^{2} L^{7,8}$. Also, higher MPO levels have been linked to the presence of coronary atherosclerosis ${ }^{9}$. Recently, it has been shown that circulating neutrophils release MPO while passing over an atherosclerotic vasculature ${ }^{10}$ and MPO and MPO-modified proteins and LDL have been detected in atherosclerotic plaques ${ }^{\prime 1}$. Moreover, a MPO promoter polymorphism affecting MPO transcription (MPO463) has been associated with a decreased presence of atherosclerosis in two independent studies ${ }^{12,13}$. For this MP0463 polymorphism age and gender dependent influences have been observed ${ }^{14-16}$. Recently, we and others have shown that another MPO promoter polymorphism (MPO129) is associated with decreased MPO levels in serum ${ }^{17}$ and neutrophils ${ }^{15}$. Furthermore, this MPO129 polymorphism has been shown to influence brain infarct size in stroke patients ${ }^{18}$.

In the present study, we evaluated the influence of these two MPO promoter polymorphisms on large artery stiffness as measured by pulse wave velocity (PWV) in a group of hypertensive patients. We hypothesized that a 'high' MPO genotype results in an increased NO consumption with subsequent increase in pulse wave velocity, therewith increasing cardiovascular disease risk.

\section{Materials and methods}

\section{Subjects}

109 patients were included ( 62 males and 47 females). All patients were diagnosed with primary hypertension and evaluated for the presence of renal artery stenosis ${ }^{19}$. PWV was calculated from measurements of pulse transit time and the distance traveled by the pulse between the carotid artery and the femoral artery. Pulses were measured by a pressure-sensitive tranducer (Complior SP(k) , Berkshire, UK). The pressure waveforms were digitized and automatically processed to calculate the pulse wave velocity (PWV) as described ${ }^{1}$. Other patient characteristics were described previously ${ }^{19}$. 


\section{Genotyping}

For determination of the 463 G/A-SNP a previously described method was used 20 .

To determine the 129G/A-SNP a 278 bp DNA fragment was amplified by PCR as previously described ${ }^{17}$. We recently identified a $129 \mathrm{G}$ to A specific Apa1 restriction site within this PCR product facilitating SNP analysis ${ }^{15}$. The undigested 278 and the digested 154 and 124 bp fragments produced by the GA and GG genotype respectively were separated on an agarose gel stained with ethidium bromide.

Statistical analysis

Hardy-Weinberg equilibrium for each polymorphism was tested by a $\chi^{2}$ test.

For the statistical analysis of the influence of the MPO polymorphisms on PWV MPO463 and MPO129 GA and AA polymorphisms were combined. Also, males and females were analyzed separately based on previously established gender differences in MPO genotype association with disease states and the large difference in PWV between men and women ${ }^{14,15,21}$. Student's T-test were performed on the Gaussian distributed groups. P-values below 0.05 were considered statistically significant.

\section{Results}

109 patients were analyzed for their MPO genotypes. For the MPO463 promoter polymorphism, 7 (6\%) were AA, $42(39 \%) \mathrm{GA}$, and 60 (55\%) were of the GG genotype. For the MPO129 promoter polymorphism $14(13 \%)$ were found to be of the GA genotype and 95 (87\%) of the GG genotype, no AA genotypes were identified. Both polymorphisms were in Hardy-Weinberg equillibrium. Table 1 shows the patient characteristics.

The average PWV for the whole group was 13.15 ( \pm 3.4 ). Males had an average PWV of 14.3 ( \pm 3.6), whereas females had a PWV of $11.7( \pm 2.4, p<0.001)$. For the MPO129GG versus GA genotype no significant differences were observed (men $14.2 \pm 3.8$ versus $15.2 \pm 2.0, p=0.50$ and women $11.4 \pm 2.3$ versus $13.2 \pm 1.7, p=0.11$ ). For the MPO463GG versus GAVAA genotype significant differences were observed only in women (men $14.5 \pm 3.4$ versus 14.1 \pm 3.7 . $p=0.6$ and women $12.4 \pm 2.2$ versus $10.3 \pm 2.2, p=0.003$ ).

No significant differences in age distribution were observed over the groups (see also table 2). Table 2 also shows the patients cholesterol levels and body mass index (BMI). MPO464 GG males had higher cholesterol levels, compared to males with the MPO463 GAVAA polymorphism $(6.0$ versus 5.4 , respectively, $p=0.04$ ). For females the difference was not statistically significant ( 5.8 versus 5.2 , respectively, $p=0.30$ ). 
Table 1. Table showing patient characteristics. $\pm=$ Standard deviation; BMI Body mass index. Patient characteristics

\begin{tabular}{ll}
\hline Males & $57 \%$ \\
Age $( \pm)$ & $52.4(12.3)$ \\
Bloodpressure systolic/diastolic $( \pm)$ & $179.4(23.9) / 106.4(14.1)$ \\
Pulse pressure $( \pm)$ & $73.0(19.3)$ \\
BMl $( \pm)$ & $27.4(5.2)$ \\
Cholesterol $( \pm)$ & $5.7(1.0)$ \\
Smokers & $36 \%$ \\
\hline
\end{tabular}

Table 2. Table showing the different patient characteristics differentiated to gender and MPO polymorphism. Note the higher cholesterol level for MPO463GG males versus GAVAA males. The PWV is not different in males, but very different in females patients when comparing MPO463GG with GAAA genotypes $(p=0.003)$

\begin{tabular}{llll}
\hline & MPO463 polymorphism & p-value \\
\cline { 2 - 3 } Males & GAAA & $G G$ & 0.28 \\
Age & 58 & 55 & $0.63 / 0.90$ \\
Blood pressure & $179 / 107$ & $176 / 179$ & 0.63 \\
Pulse pressure & 72.4 & 69.8 & 0.04 \\
Cholesterol & 5.4 & 6.0 & 0.06 \\
BMl & 26.8 & 29.4 & 0.59 \\
PWV & 14.1 & 14.5 & \\
Females & & & 0.16 \\
Age & 44.1 & 49.3 & $0.22 / 0.21$ \\
Blood pressure & $176 / 103$ & $185 / 108$ & 0.47 \\
Pulse pressure & 72.8 & 77.0 & 0.30 \\
Cholesterol & 5.2 & 5.8 & 0.23 \\
BMI & 25.4 & 27.2 & 0.003 \\
PWV & 10.3 & 12.4 & \\
& & & \\
Males & MPO129 polymorphism & & \\
Age & GAAA & $G G$ & 0.97 \\
Blood pressure & 56.4 & 56.3 & $0.60 / 0.98$ \\
Pulse pressure & $174 / 106$ & $179 / 106$ & 0.54 \\
Cholesterol & 67.6 & 72.8 & 0.47 \\
BMl & 5.4 & 5.8 & 0.74 \\
PWV & 28.8 & 28.2 & 0.50 \\
Females & 15.2 & 14.2 & 0.93 \\
Age & & & $0.31 / 0.42$ \\
Blood pressure & 48.2 & 47.6 & 0.26 \\
Pulse pressure & $201 / 113$ & $179 / 104$ & 0.11 \\
Cholesterol & 88.0 & 74.8 & \\
BMl & 6.0 & 27.4 & \\
PWV & 25.1 & 11.4 & \\
\hline
\end{tabular}

BMI body mass index; PWW pulse wave velocity; Blood pressure systole / diastole 


\section{Discussion}

These results suggest that the MPO463GG genotype, linked to higher MPO transcription, is associated with an increased pulse wave velocity. However, this effect is only present in women. Others have also found the GG-genotype to be a female-specific risk factor $20-25$.

MPO is increasingly recognized as an important player in the link between inflammation and atherosclerosis. Atherosclerotic lesions contain MPO and hypochlorite modified proteins ${ }^{11}$. In addition, recent evidence suggests that the MPO system has an important role in the oxidative conversion of LDL into a high-uptake form for macrophages, leading to foam cell formation and thus contributing to the atherosclerotic plaque formation 9,26 . This oxidatively modified LDL is also capable of inhibiting NO synthesis in endothelial cells ${ }^{8}$. More importantly, it was recently shown that MPO can use nitric oxide (NO) directly as a substrate in the presence of hydrogen peroxide leading to reduced NO bioavailability 5,27 . Such an effect is especially relevant at sites of inflammation where MPO, $\mathrm{NO}$ and $\mathrm{H}_{2} \mathrm{O}_{2}$ are present. The in vivo inhibition of NO results in a more stiff arterial vasculature resulting in a increased PWV 2,3 .

Interestingly, it has been demonstrated that coronary atherosclerosis is associated with an increased neutrophil MPO content suggesting a link between MPO protein levels and atherosclerotic processes ${ }^{28}$. Also, mice genetically modified to over-express human MPO in their monocytes displayed increased atherosclerosis compared to wild type mice ${ }^{29}$. On the other hand, MPO deficient mice develop more severe atherosclerosis compared to their MPO sufficient counterparts ${ }^{30}$. These differences may reflect differences between human and mouse atherosclerotic disease, MPO, and/or phagocytes ${ }^{31}$.

Recently, additional data have been published on gender dependent differences between the MPO463 genotypes. An autopsy study among males suggests that in younger individuals atherosclerotic fibrotic and calcified lesions are larger in $G G$ than in patients with the MPO463 GAVA genotypes ${ }^{16}$. Furthermore, a 5-year follow-up study among post-menopausal females demonstrated that patients with the $463 \mathrm{GG}$ genotype had a lower increase in atherosclerosis when treated with hormone replacement therapy compared to controls, whereas no benefit for hormone replacement therapy could be demonstrated in patients with the MPO GAAA genotype over the 5 -year period 25 . This study, although not randomized and blinded, could help to understand the pro- and anti-atherogenic effects of hormone replacement therapy. The MPO463 GAVAA polymorphism creates an estrogen responsive element ${ }^{20}$, exposure to estrogens during hormone replacement therapy could result in increased (pro-atherogenic) MPO expression ${ }^{32}$, therewith outweighing the anti-atherosclerotic effects of hormone replacement therapy. Furthermore, this created estrogen responsiveness could perhaps help to explain the differences observed between men, women and age groups ${ }^{15}$ and could provide a genetic basis for the identification of women who are most likely to benefit from hormone replacement therapy ${ }^{33}$.

The increased cholesterol levels found in males with the MPO463 GG genotype, is contrary to results found by Hoy et $a^{17}$, although the two populations might not be comparable, since we 
report much higher basal total cholesterol levels than reported in their paper (5.7 versus 2.0. respectively).

Finally, it has recently been suggested that MPO deficient individuals possibly have a decreased risk of atherosclerosis 4,34 .

For the MPO129 polymorphism no significant differences could be observed. The analysis of these data is hampered by the relative low numbers of heterozygous patients. The observed frequency for the MPO129GA polymorphism is in concurrence with published data 15,17,18. However, since only about $10 \%$ of the general population carry the 129 A allele, much larger study groups are needed to firmly establish the influence of the MPO 129 polymorphism on PWV, but is of interest, since recent publications suggest that the effect of this polymorphism on MPO expression is even greater than for the MPO463 polymorphism ${ }^{15,17}$.

These results suggest that the MPO463 polymorphism, linked to higher MPO transcription, is associated with an increased pulse wave velocity in women. The latter could be due to the observed gender dependent differences for this polymorphism.

\section{References}

1. Blacher J, Asmar R, Djane S, London GM, Safar ME: Aortic pulse wave velocity as a marker of cardiovascular risk in hypertensive patients. Hypertension 33:1111-1117, 1999

2. Kinlay S, Creager MA, Fukumoto M, Hikita H, Fang JC, Selwyn AP, Ganz P: Endothelium-derived nitric oxide regulates arterial elasticity in human arteries in vivo. Hypertension 38:1049-1053, 2001

3. Wilkinson IB, MacCallum H, Cockcroft JR, Webb DJ: Inhibition of basal nitric oxide synthesis increases aortic augmentation index and pulse wave velocity in vivo. Br J Clin Pharmacol 53:189-192, 2002

4. Brennan ML, Hazen SL: Emerging role of myeloperoxidase and oxidant stress markers in cardiovascular risk assessment. Curr Opin Lipidol 14:353-359, 2003

5. Winterbourn CC, Vissers MC, Kettle AJ: Myeloperoxidase. Curr Opin Hematol 7:53-58, 2000

6. Eiserich JP, Baldus S, Brennan ML, MaW, Zhang C. Tousson A, Castro L, Lusis AJ, Nauseef WM, White CR, Freeman BA: Myeloperoxidase, a leukocyte-derived vascular NO oxidase. Science 296:2391-2394, 2002

7. PodrezEA, Abu-Soud HM, Hazen SL: Myeloperoxidase-generated oxidants and atherosclerosis. Free Radic Biol Med 28:1717-1725, 2000

8. Nuszkowski A, Grabner R, Marsche G, Unbehaun A, Malle E, Heller R: Hypochlorite-modified low density lipoprotein inhibits nitric oxide synthesis in endothelial cells via an intracellular dislocalization of endothelial nitric-oxide synthase. J Biol Chem 276:14212-14221, 2001

9. Zhang R, Brennan ML, Shen Z, MacPherson JC, Schmitt D, Molenda CE, Hazen SL: Myeloperoxidase functions as a major enzymatic catalyst for initiation of lipid peroxidation at sites of inflammation. J Biol Chem 277:46116-46122, 2002

10. Buffon A, Biasucci LM, Liuzzo G, D'Onofrio G, Crea F, Maseri A: Widespread coronary inflammation in unstable angina. N Engl/ Med 347:5-12, 2002

11. Malle E, Waeg G, Schreiber R, Grone EF, Sattler W, Grone HJ: Immunohistochemical evidence for the myeloperoxidase $/ \mathrm{H}_{2} \mathrm{O}_{2}$ /halide system in human atherosclerotic lesions: colocalization of myeloperoxidase and hypochlorite-modified proteins. Eur I Biochem 267:4495-4503, 2000

12. Nikpoor B, Turecki G, Fournier C, Theroux P, Rouleau GA: A functional myeloperoxidase polymorphic variant is associated with coronary artery disease in French-Canadians. Am Heart J 142:336-339, 2001

13. Pecoits-Filho R, Stenvinkel P, Marchlewska A, Heimburger O, Barany P. Hoff CM, Holmes CI, Suliman M, Lindholm B, Schalling M, Nordfors L:: A functional variant of the myeloperoxidase gene is associated with cardiovascular disease in end-stage renal disease patients. Kidney int Suppl:\$172-176, 2003 
14. Schabath MB, Spitz MR, Zhang X, Delclos GL, WuX: Genetic variants of myeloperoxidase and lung cancer risk. Carcinogenesis 21:1163-1166, 2000

15. Rutgers A, Heeringa P, Giesen JE, Theunissen RT, Jacobs $H$, Cohen Tervaert JW: Neutrophil myeloperoxidase activity and the influence of two single nucleotide promoter polymorphisms. British journal of haematology accepted, 2003

16. Makela R, Karhunen PJ, Kunnas TA, Ilveskoski E, Kajander OA, Mikkelsson J, Perola M, Penttila A, Lehtimaki $\mathrm{T}$ : Myeloperoxidase gene variation as a determinant of atherosclerosis progression in the abdominal and thoracic aorta: an autopsy study. Lab invest 83:919-925, 2003

17. Hoy $A$, Tregouet $D$, Leininger-Muller $B$, Poirier $O$, Maurice $M$, Sass $C$, Siest $G$, Tiret $L$, Visvikis $S$ : Serum myeloperoxidase concentration in a healthy population: biological variations, familial resemblance and new genetic polymorphisms. Eur J Hum Genet 9:780-786, 2001

18. Hoy A, Leininger-Muller B, Poirier O, Siest G, Gautier M, Elbaz A, Amarenco P, Visvikis S: Myeloperoxidase polymorphisms in brain infarction. Association with infarct size and functional outcome. Atherosclerosis $167: 223-230,2003$

19. van der Ven AJ, Hommels MJ, Kroon AA, Kessels A, Flobbe K, van Engelshoven J, Bruggeman CA, de Leeuw PW: Chlamydia pneumoniae seropositivity and systemic and renovascular atherosclerotic disease. Arch Intern Med 162:786-790, 2002

20. Reynolds WF, Hiltunen M, Pirskanen M, Mannermaa A, Helisalmi S, Lehtovirta M, Alafuzoff I, Soininen H: MPO and APOEepsilon4 polymorphisms interact to increase risk for $A D$ in Finnish males. Neurology 55:1284-1290., 2000

21. Meisel P, Krause T, Cascorbi I, Schroeder W, Herrmann F, John U, Kocher T: Gender and smoking-related risk reduction of periodontal disease with variant myeloperoxidase alleles. Genes/mmun 3:102-106, 2002

22. Reynolds WF, Stegeman CA, Cohen Tervaert JW: -463 G/A Myeloperoxidase Promoter Polymorphism Is Associated with Clinical Manifestations and the Course of Disease in MPO-ANCA-Associated Vasculitis. Clin Immun 103:154-160, 2002

23. Nagra RM, Becher B, Tourtellotte WW. Antel JP, Gold D, Paladino T, Smith RA, Nelson JR, Reynolds WF: Immunohistochemical and genetic evidence of myeloperoxidase involvement in multiple sclerosis. $J$ Neuroimmunol 78:97-107, 1997

24. Reynolds WF, Rhees J, Maciejewski D, Paladino T, Sieburg H, Maki RA, Masliah E: Myeloperoxidase polymorphism is associated with gender specific risk for Alzheimer's disease. Exp Neurol 155:31-41, 1999

25. Makela R, Dastidar P, Jokela H, Saarela M, Punnonen R, Lehtimaki T: Effect of long-term hormone replacement therapy on atherosclerosis progression in postmenopausal women relates to myeloperoxidase promoter polymorphism. I Clin Endocrinol Metab 88:3823-3828, 2003

26. Podrez EA, Schmitt D, Hoff HF, Hazen SL: Myeloperoxidase-generated reactive nitrogen species convert $\mathrm{LDL}$ into an atherogenic form in vitro. J Clin Invest 103:1547-1560, 1999

27. Abu-Soud HM, Hazen SL: Nitric oxide is a physiological substrate for mammalian peroxidases. $J$ Biol Chem 275:37524-37532, 2000

28. Zhang R, Brennan ML, Fu X, Aviles RJ, Pearce GL, Penn MS, Topol EJ, Sprecher DL, Hazen SL: Association between myeloperoxidase levels and risk of coronary artery disease. Jama 286:2136-2142, 2001

29. MCMillen MS, Heinecke JW, LeBoeuf RC: Accelerated atherosclerosis in myeloperoxidase transgenic mice, in, 2003

30. Brennan ML, Anderson MM, Shih DM, Qu XD. Wang X, Mehta AC, Lim LL, Shi W, Hazen SL, Jacob JS, Crowley JR, Heinecke JW, Lusis AJ: Increased atherosclerosis in myeloperoxidase-deficient mice. I Clin Invest 107:419-430, 2001

31. Nauseef WM: The proper study of mankind. I Clin Invest 107:401-403, 2001

32. Bekesi G, Kakucs R, Varbiro S, Feher J, Pazmany T, Magyar Z, Sprintz D, Szekacs B: Induced myeloperoxidase activity and related superoxide inhibition during hormone replacement therapy. Bjog 108:474-481., 2001

33. Herrington DM, Howard TD: From presumed benefit to potential harm--hormone therapy and heart disease. N Eng/ J Med 349:519-521, 2003

34. Kutter $D$, Devaquet $P$, Vanderstocken $G$, Paulus IM, Marchal V. Gothot A: Consequences of total and subtotal myeloperoxidase deficiency: risk or benefit ? Acta Haematol 104:10-15, 2000 


\section{CHAPTER 8}

\section{Intra-neutrophil myeloperoxidase activity in ANCA associated vasculitis}

A. Rutgers, M.C. Slot, I. Jansen, J.E. Giesen, P. Heeringa, and J.W. Cohen Tervaert Clinical and Experimental Immunology, University hospital Maastricht, The Netherlands 


\section{ABSTRACT}

Introduction: Wegener's granulomatosis, Churg-Strauss syndrome, microscopic polyangiitis and idiopathic crescentic glomerulonephritis are vasculitides strongly associated with the presence of anti-neutrophil cytoplasmic antibodies (ANCA) directed against either the neutrophil granule protein proteinase 3 (PR3) or myeloperoxidase (MPO). Since ANCA are capable of inducing neutrophil degranulation and since levels of circulating MPO are correlated with disease activity in patients with Wegener's granulomatosis, we hypothesized that, intra-neutrophil MPO activity levels are decreased in ANCA associated vasculitis during active disease.

Methods: We included 22 patients with ANCA associated vasculitis and 42 age and sex matched controls and measured neutrophil MPO activity (MPXI) at a single cell level using automated cytometry in flow (ADVIA 120). In 5 patients data could be obtained before and during disease relapse. In addition, sequential measurements were performed in 13 patients and 10 controls.

Results: The average MPXI was -2.7 (SD 3.4) and -2.4 (SD 4.0) for male patients and controls, respectively $(p=0.85)$. For females the average MPXI was -3.3 (SD 4.8) and -0.9 (SD 2.8) for patients and controls, respectively $(p=0.08)$. In 4 of 5 patients with a relapse MPXI decreased. Sequential measurements revealed that the standard deviation of the MPXI in patients was greater than that of controls (2.2 versus 0.67, respectively, $p<0.01$, figure 5).

Conclusion: Active disease in patients with vasculitis is associated with a decrease in MPO activity. Patients with vasculitis, however, have a larger variation in intra-neutrophil MPO activity than controls. We hypothesize that this wider dispersal could be the result of increased neutrophil degranulation due to either activating ANCA or (recurrent) infectious events. 


\section{Introduction}

Wegener's granulomatosis, Churg-Strauss syndrome, microscopic polyangiitis and idiopathic crescentic glomerulonephritis are vasculitides strongly associated with the presence of anti-neutrophil cytoplasmic antibodies (ANCAs) either directed against the neutrophil granule constituent proteinase 3 (PR3) or myeloperoxidase (MPO). Recent in vivo data show a direct pathogenic role for MPO-ANCA in vasculitic disease ${ }^{1}$.

For both PR3-ANCA as well as for MPO-ANCA there is compelling in vitro evidence of their contribution to disease development (reviewed $\mathrm{in}^{2}$ ). In short, priming of neutrophils by cytokines such as TNF $\alpha$ results in mitogen-activated protein kinase dependent translocation of MPO and PR3 to the cell surface ${ }^{3}$. Stimulation of these primed neutrophils with ANCA results in neutrophil activation, with reactive oxygen species generation (including $\mathrm{O}_{2}^{-}$and $\mathrm{H}_{2} \mathrm{O}_{2}$ ), degranulation, adhesion to and killing of endothelial cells ${ }^{2}$. Also, degranulated MPO can bind to unprimed neutrophils making them directly vulnerable to activation by MPO-ANCA 4 . Most of these processes are thought to be FC and FCy-receptor dependent ${ }^{2}$.

Thus, binding of both MPO- and PR3-ANCA to neutrophils results in neutrophil activation and degranulation. These neutrophils therewith generate products crucial in the inflammatory response against the vessel wall (i.e. vasculitis) observed in these patients.

Circulating MPO and PR3 have been detected in higher concentrations in patients with ANCA associated vasculitis than in healthy controls 5,6 .

Recently, it has been shown that levels of circulating MPO are correlated with disease activity in patients with Wegener's granulomatosis? ${ }^{7}$. We hypothesized that, since serum MPO levels originate mostly from neutrophil MPO, intra-neutrophil MPO levels are decreased in ANCA associated vasculitis when the disease is active.

\section{Materials and methods}

Subjects

22 patients with ANCA associated vasculitis (11 males, 11 females) and 42 healthy age-matched controls (20 males, 22 females) were included. All included patients had a clinical diagnosis of Wegener's granulomatosis, microscopic polyangiitis, Churg-Strauss syndrome, or idiopathic crescentic glomerulonephritis ${ }^{8}$. Four patients were ANCA negative, but had clinical and histopathological (e.g. granulomatous inflammation) evidence for ANCA associated vasculitis. For every patient two healthy controls were included of the same gender and age ( \pm 5 years). For one 75 year old male patient no age matched controls could be included. In 5 vasculitis patients data could be obtained before and during disease relapse. In 13 of the ANCA associated vasculitis patients three or more serial measurements were obtained during sequential outpatient clinic visits. Controls consisted of 10 healthy subjects in whom four weekly sequential measurements were performed as well. 
Table 1. Patient characteristics

\begin{tabular}{lll}
\hline Characteristics & Patients & Controls \\
\hline$\%$ Male & 50 & 48 \\
Age (SD) & 56 & 54 \\
ANCA (MPO/PR3/both/none) & $6 / 10 / 2 / 4$ & 0 \\
\hline
\end{tabular}

A relapse was defined as the recurrence of clinical, laboratory and/or histopathological signs of vasculitis resulting in the decision to increase immunosuppressive therapy during follow-up of patients in remission?.

\section{MPO activity measurements: ADVIA 120}

EDTA anti-coagulated blood was drawn and tested for neutrophil MPO activity at single cell level within 3 hours ${ }^{10}$. The relative MPO activity was measured on a single cell level by automated cytometry in flow (ADVIA 120, Bayer). This cytometer makes use of peroxidase activity to differentiate whole blood in neutrophil, monocyte, and other cell populations. In brief, the addition of $\mathrm{H}_{2} \mathrm{O}_{2}$ and 4-Chloor-1-naphthol to peroxidase containing cells (i.e. neutrophils, monocytes and eosinophils) results in a dark colored staining. Peroxidase activity is directly proportional to the intensity of staining, which is measured as an absorption of light. Of the neutrophil cluster a mean neutrophil myeloperoxidase activity index is calculated (MPXI) automatically, which is the distance of the mean peroxidase activity of the neutrophil cluster from the theoretical mean of a standard neutrophil cluster (see figure $1 \mathrm{a}$ and $\mathrm{b}$ ).

\section{Statistical analysis}

Statistical analysis was performed with SPSS version 10.0 (SPSS Inc. Headquarters, Chicago, Illinois, USA). Analysis of variance (ANOVA) was used to compare multiple groups, for post testing bonferroni's multiple comparison test was used. Unpaired t testing was performed when data followed a Gaussian distribution, otherwise non-parametric testing was used (Mann Whitney). When evaluating correlation Pearson correlation testing was performed for Gaussian distributed values. A p value $<0.05$ was considered significant.

\section{Results}

Patient characteristics are shown in table 1 . The average age was 56 and 54 for patients and controls respectively $(p=0.51)$.

The average MPXI was -3.0 (SD 4.1) and -1.6 (SD 3.5) for patients and controls, respectively $(p=0.16$; figure $2 a)$. Since we have previously shown that the average MPXI is lower in males compared to females ${ }^{10}$, we performed separate analysis for males and females as well (see figure $2 \mathrm{~b}$ and $2 \mathrm{C}$ ). The average MPXI was -2.7 (SD 3.4) and -2.4 (SD 4.0) for male patients and controls, respectively $(p=0.85)$. For females the average MPXI was -3.3 (SD 4.8) and -0.9 (SD 2.8) for patients and controls, respectively ( $p=0.08)$. 


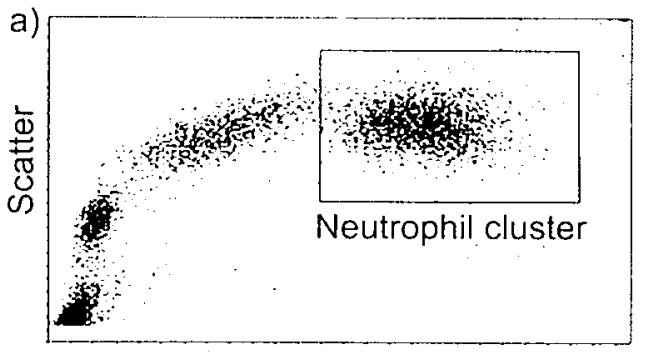

Peroxidase activity

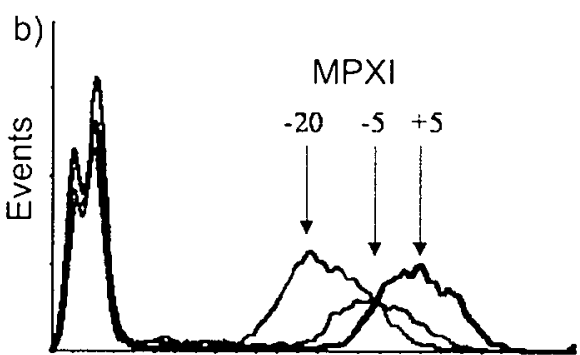

Peroxidase activity

Figure 1. MPO activity measurement. Figure a) shows analysis of whole blood with the ADVIA 120 . The X-axis shows the amount of absorption of light, i.e. the peroxidase activity. The $Y$-axis shows the scatter signal, i.e. the volume of the cells. Different cell clusters can be identified (from left to right): lymphocytes, monocytes and neutrophils, the latter two containing MPO. The neutrophil cluster is indicated in the figure. This scatter plot can be transformed into a histogram plot showing the neutrophil peak relative to the peroxidase activity. In figure b) such a histogram plot is shown for three subjects with different neutrophil MPO activities (MPXI).

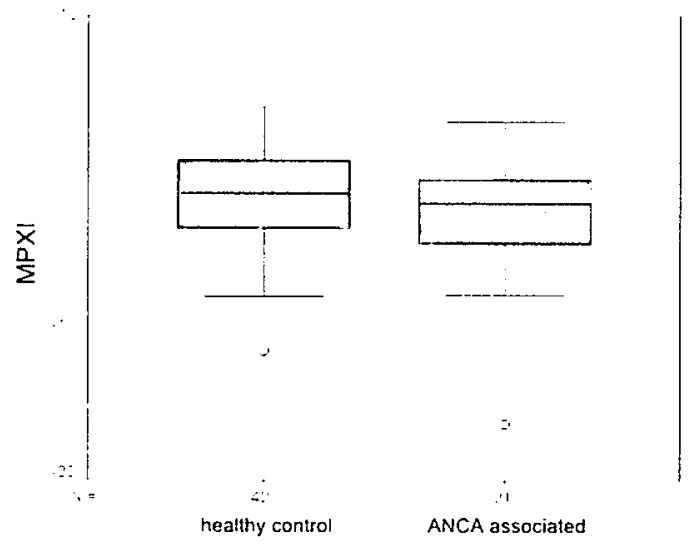

Figure 2a. Figure showing box whisker plots of the mean neutrophil myeloperoxidase activity index (MPXI) of healthy controls compared to patients with ANCA associated vasculitis. Patients has an average MPXI of -3.0 (SD 4.1), whereas controls had a MPXI of $-1,6(S D 3,5), p=0.15$.

Sequential measurements revealed that the standard deviation of the MPXI in patients was greater than that of controls ( 2.2 versus 0.67 , respectively, $p<0.01$, figure 3 ). We hypothesized that the cause for this wider dispersal could be the result of increased neutrophil degranulation due to either activating ANCA or (recurrent) infectious events. In 4 of the 13 patients a relapse occurred during follow-up measurements and when these 4 patients were excluded dispersal was still different from controls. 


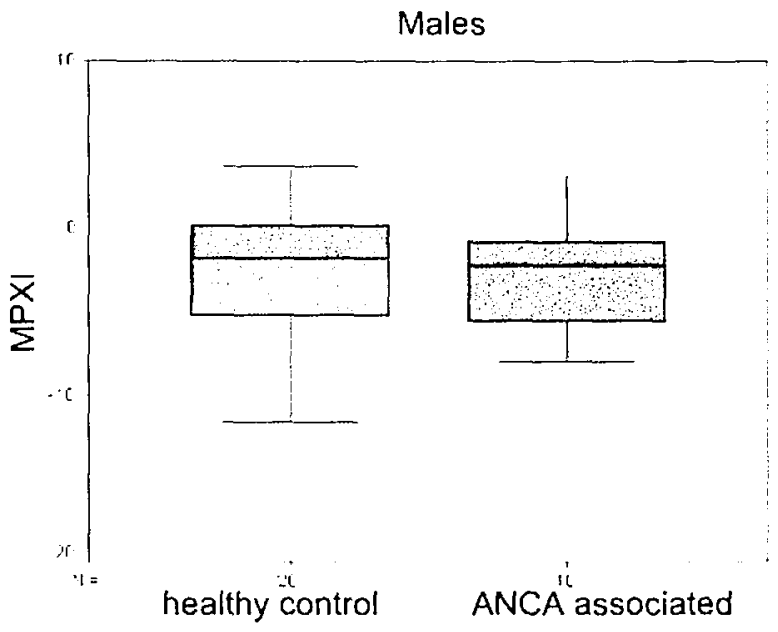

Figure 2b. Figure showing box whisker plots of the mean neutrophil myeloperoxidase activity index (MPXI) of the male healthy controls compared to male patients with ANCA associated vasculitis. Male patients has an average MPXI of -2.7 (SD 3.4), whereas male controls had a MPXI of -2.4 (SD 4.0), $p=0.85$

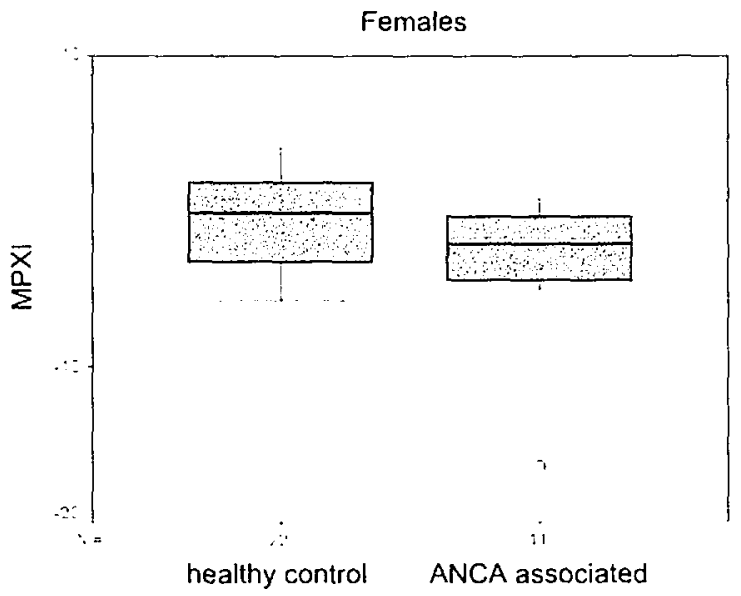

Figure 2c. Figure showing box whisker plots of the mean neutrophil myeloperoxidase activity index (MPXI) of the female healthy controls compared to female patients with ANCA associated vasculitis. Female patients had an average MPXI of -3.3 (SD 4.8), whereas female controls had a MPXI of -0.9 (SD 2.8), $p=0.08$.

4 of 5 of the observed relapses were associated with a decrease in MPXI. One patient with a relapse, of which we obtained only two sequential measurements, the MPXI rose after detection of clinical relapse. These data are summarized in figure 4. 


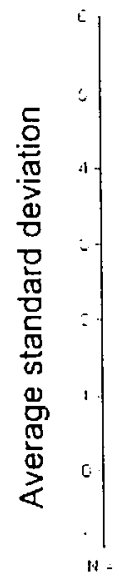

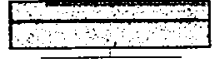

iiv

Controls

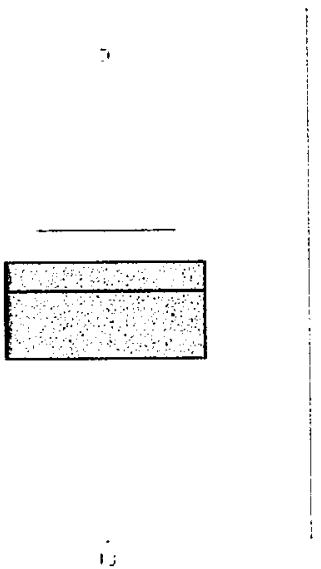

ANCA associated

Figure 3. Figure showing box whisker plots of the standard deviation of the three or more sequential measurements in patients versus controls. The average 'standard deviation' was 0.67 (SD 0.31) and 2.2 (SD 1.23) for the healthy controls and patients respectively (Mann Whitney $p<0.01$ ).

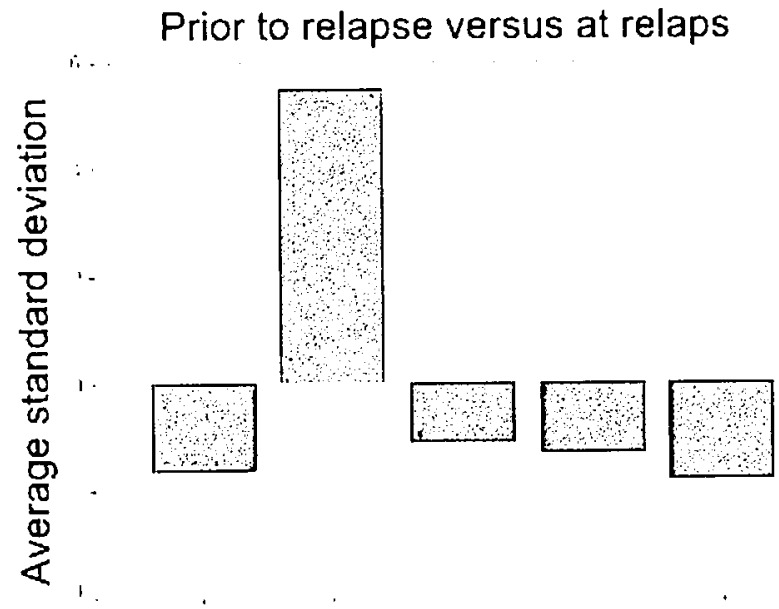

\section{Patients}

Figure 4. Figure showing the MPXI change after detection of an disease relapse. 4 out of 5 patients show a decrease in MPXI when comparing the MPXI before relapse with MPXI values during relapse. 


\section{Discussion}

We have shown that the mean neutrophil MPO activity overall is not different between patients in remission and control subjects. Female patients however, demonstrate a trend towards lower neutrophil MPO activity compared to female control subjects. In 4 out of 5 patients with a disease relapse, we have demonstrated a decrease in neutrophil MPO activity. However, during follow-up of patients in remission we have demonstrated a larger dispersal compared to controls, suggesting that also other factors, like intercurrent infections or sub-clinical relapses can influence intra-neutrophil MPO activity.

Circulating MPO, originating mostly from neutrophil MPO, has been detected in patients with ANCA associated vasculitis in higher concentrations than in healthy controls ${ }^{6}$. Endothelial cells can bind and take up this degranulated MPO resulting in an increased intracellular oxidant radical formation ${ }^{11}$. MPO can also form complexes with circulating MPO-ANCA that bind and dimerize $\mathrm{Fc} \gamma$-receptors on neutrophils resulting in activation ${ }^{2}$. MPO present outside inflammatory sites is normally cleared and inactivated by ceruloplasmin ${ }^{12}$. The presence of MPO-ANCA however, interferes with these mechanisms, leaving a circulating highly reactive enzyme $^{13}$. Active MPO can produce hypochlorous acid (bleach) from hydrogen peroxide and chloride ions. This oxidant species not only kills bacteria and fungi, but can also damage host tissue. Moreover, MPO can increase protease activity at inflammatory sites by inactivating protease inhibitors and by acting as a detoxicant for $\mathrm{H}_{2} \mathrm{O}_{2}$ thereby protecting proteolytic enzymes from inactivation ${ }^{14-16}$. In ANCA associated vasculitis protease/anti-protease imbalance has been proposed to play a role in vasculitic lesion development ${ }^{17}$. Recently, it has been shown that MPO can consume nitric oxide $(\mathrm{NO})^{18-20}$, therewith adding to the endothelial dysfunction observed in vasculitis patients ${ }^{21}$. NO also functions as an anti-inflammatory agent and decreases endothelial cell adhesion molecule expression. These properties make circulating or deposited MPO not only important as an antigenic target, but also as a functional enzyme with potentially pathogenic properties (for review ${ }^{22}$ ).

Our data shows that intracellular MPO activity has a larger standard deviation in patients in remission than in controls. As described above, ANCA are capable of inducing neutrophil degranulation and could therefore be responsible for the observed increased standard deviation in patients. However, other factors could influence neutrophil MPO contents as well. Band form neutrophils with high MPO content during acute inflammation (i.e. a left shift) can result in increased intracellular MPO levels ${ }^{23}$, whereas infections themselves can activate and degranulate neutrophils. Moreover, recent evidence shows that neutrophils can be partially depleted of MPO while traversing over an atherosclerotic vasculature ${ }^{24}$. Also, we have recently shown that two genetic polymorphisms in the promoter region of MPO, namely MPO129 and MPO463, influence intracellular MPO levels in healthy controls ${ }^{10}$. The MPO463 polymorphism has been investigated in MPO-ANCA associated disease ${ }^{25,26}$. Reynolds established that the MPO GG genotype was overrepresented in female, but not male, patients with MPO-ANCA associated vasculitis. Furthermore, we found that GAVA genotypes were diagnosed at an earlier age compared to the GG genotype ( 41 versus 56 years, respectively). Interestingly, relapse-free survival was significantly different between patients with the $463 \mathrm{GG}$ 
compared to those with the 463GA or AA genotype. A recent study by Adu et al could not confirm these observations ${ }^{26}$. Taken together, these data suggest that the high MPO expression genotype $(G G)$ is a risk factor for development of disease, but once disease is present it is possibly associated with a lower relapse rate ${ }^{25}$. Thus, next to environmental factors, genetic factors can influence intracellular MPO activity as well.

In conclusion, neutrophil MPO activity measurements in patients with ANCA associated vasculitis decrease during active disease. Variation in neutrophil MPO activity measurements in these patients is larger than in healthy controls. Next to disease activity, possible other factors that influence MPO activity measurements include infections and genetic polymorphisms. Future studies in patients with vasculitis should give further inside whether neutrophil MPO activity measurements or MPO serum levels are useful monitors to evaluate patients for disease relapses.

\section{Acknowledgements}

Supported by the Friedrich Wegener Foundation, the Netherlands.

\section{References}

1. Xiao H, Heeringa P. Hu P, Liu Z, Zhao M. Aratani Y, Maeda N, Falk RJ, Jennette JC: Antineutrophil cytoplasmic autoantibodies specific for myeloperoxidase cause glomerulonephritis and vascultis in mice. J Clin invest 110:955-963, 2002

2. Hewins P. Savage C: Anti-neutrophil cytoplasm antibody associated vasculitis. Int I Biochem Cell Biol 35:277-282, 2003

3. Kettritz R, Schreiber A, Luft FC, Haller H: Role of mitogen-activated protein kinases in activation of human neutrophils by antineutrophil cytoplasmic antibodies. J Am Soc Nephrol 12:37-46, 2001

4. Hess C, Sadallah S, Schifferli JA: Induction of neutrophil responsiveness to myeloperoxidase antibodies by their exposure to supernatant of degranulated autologous neutrophils. Blood 96:2822-2827, 2000

5. Henshaw TJ, Malone CC. Gabay JE, Williams RC, Jr.: Elevations of neutrophil proteinase 3 in serum of patients with Wegener's granulomatosis and polyarteritis nodosa. Arthritis Rheum 37:104-112. 1994

6. Minota S, Horie S, Yamada A, Iwamoto M, Yoshio T, Mimori A, Masuyama J, Kano S: Circulating myeloperoxidase and anti-myeloperoxidase antibody in patients with vasculitis. Scand I Rheumatol 28:94-99, 1999

7. Gota C, Hazen S, Brennan ML, Goffman GS: Association between plasma myeloperoxidase levels and disease activity in Wegeners granulomatosis. Kidney Blood Press 11 th International Vasculitis and ANCA Workshop, 2003

8. Jennette JC. Falk RJ, Andrassy K, Bacon PA, Churg J, Gross WL, Hagen EC. Hoffman GS, Hunder GG, Kallenberg $C G$, et al: Nomenciature of systemic vasculitides. Proposal of an international consensus conference. Arthritis Rheum 37:187-192, 1994

9. Stegeman CA, Cohen Tervaert JW, de Jong PE, Kallenberg CG: Trimethoprim-sulfamethoxazole (co-trimoxazole) for the prevention of relapses of Wegener's granulomatosis. Dutch Co-Trimoxazole Wegener Study Group. N Engl J Med 335:16-20, 1996

10. Rutgers A, Heeringa P, Giesen J, Theunissen R, Jacobs H, Cohen Tervaert JW: Neutrophil myeloperoxidase activity and the influence of two single-nucleotide promoter polymorphisms. Br J Haematol 123:1-3, 2003

11. Yang JJ, Preston GA, PendergraftWF, Segelmark M, Heeringa P, Hogan SL, Jennette JC, Falk RJ: Internalization of proteinase 3 is concomitant with endothelial cell apoptosis and internalization of myeloperoxidase with generation of intracellular oxidants. Am J Pathol 158:581-592, 2001 
12. Segelmark $M$, Persson $B$, Hellmark T, Wieslander J: Binding and inhibition of myeloperoxidase (MPO): a major function of ceruloplasmin? Clin Exp Immunol 108:167-174, 1997

13. Griffin SV, Chapman PT, Lianos EA, Lockwood CM: The inhibition of myeloperoxidase by ceruloplasmin can be reversed by anti-myeloperoxidase antibodies. Kidney int 55:917-925, 1999

14. Roos D. Winterbourn CC: IMMUNOLOGY: Enhanced: Lethal Weapons. Science 296:669-671, 2002

15. Reeves EP, Lu H, Jacobs HL, Messina CG, Bolsover S, Gabella G, Potma EO, Warley A, Roes J, Segal AW: Killing activity of neutrophils is mediated through activation of proteases by $\mathrm{K}+$ flux. Nature 416:291-297, 2002

16. Matheson NR, Wong PS, Travis J: Enzymatic inactivation of human alpha-1-proteinase inhibitor by neutrophil myeloperoxidase. Biochem Biophys Res Commun 88:402-409, 1979

17. Esnault VL, Audrain MA, Sesboue R: Alpha-1-antitrypsin phenotyping in ANCA-associated diseases: one of several arguments for protease/antiprotease imbalance in systemic vasculitis. Exp Clin Immunogenet 14:206-213, 1997

18. Eiserich JP, Baldus S, Brennan ML, Ma W, Zhang C, Tousson A, Castro L, Lusis AJ, Nauseef WM, White CR, Freeman BA: Myeloperoxidase, a leukocyte-derived vascular NO oxidase. Science 296:2391-2394, 2002

19. Zhang R, Brennan ML, Fu X, Aviles RJ, Pearce GL, Penn MS, Topol EJ, Sprecher DL, Hazen SL: Association between myeloperoxidase levels and risk of coronary artery disease. Jama 286:2136-2142, 2001

20. Abu-Soud HM. Hazen SL: Nitric oxide is a physiological substrate for mammalian peroxidases. $J$ Biol Chem 275:37524-37532, 2000

21. Raza K, Thambyrajah J, Townend JN, Exley AR, Hortas C, Filer A, Carruthers DM, Bacon PA: Suppression of inflammation in primary systemic vasculitis restores vascular endothelial function: lessons for atherosclerotic disease? Circulation 102:1470-1472., 2000

22. Rutgers A, Heeringa $P$. Cohen Tervaert JW: The role of myeloperoxidase in the pathogenesis of systemic vasculitis. Clin Exp Rheumatol in press, 2003

23. Charuruks $N$, Voravud N, Sriuranpong V: MPXI and early neutrophilia: new potential therapeutic biomarkers for recombinant human granulocyte colony-stimulating factor. J Clin Lab Anal 12:41-46, 1998

24. Buffon A, Biasucci LM, Liuzzo G, D'Onofrio G, Crea F, Maseri A: Widespread coronary inflammation in unstable angina. N Eng/ J Med 347:5-12, 2002

25. Reynolds WF, Stegeman CA, Cohen Tervaert JW: $-463 \mathrm{G} / \mathrm{A}$ myeloperoxidase promoter polymorphism is associated with clinical manifestations and the course of disease in MPO-ANCA-associated vasculitis. Clin Immunol 103: 154-160, 2002

26. Adu D, Rajp A, Savage C: Myeloperoxidase-463G/A polymorphism in ANCA associated vasculitis. Nephrol Dial Transplant 18:347، 2003 


\section{CHAPTER 9}

\section{Review}

The role of myeloperoxidase in the pathogenesis of systemic vasculitis

Abraham Rutgers, MD, Peter Heeringa, PhD, and Jan Willem Cohen Tervaert, MD, $\mathrm{PhD}$

Clinical and Experimental Immunology, University hospital Maastricht, The Netherlands

Clin Exp Rheumatol, 21 (6): S55-S63 Suppl. 32 Nov-Dec 2003 


\section{ABSTRACT}

Wegener's granulomatosis, microscopic polyangiitis, Churg-Strauss syndrome and idiopathic pauci-immune necrotizing crescentic glomerulonephritis are strongly associated with the presence of anti-neutrophil cytoplasmic antibodies (ANCA). These ANCA-associated vasculitides can serologically be separated into myeloperoxidase (MPO)-ANCA and proteinase 3 (PR3)-ANCA positive patients. The unique properties of the antigen targeted by the anti-MPO antibodies could help to explain the specific characteristics of MPO-ANCA associated disease. Recently, an animal model has been developed that proofs that anti-mouse MPO immunoglobulins alone are capable of causing disease similar to that in humans. Also, the in vitro pathologic effects of binding of MPO-ANCA to MPO are better understood. MPO-ANCA can activate (primed) neutrophils directly causing extensive reactive oxygen species formation and degranulation of neutrophil constituents, including MPO, resulting in a destructive inflammatory response towards the vessel wall. MPO-ANCA can prevent the clearing and inactivation of MPO by ceruloplasmin as well, resulting in increased myeloperoxidase activity. Myeloperoxidase produces not only the strong oxidant bleach (hypochlorous acid) out of hydrogen peroxide and chloride ions but also oxidizes LDL into a macrophage high-uptake form, inactivates protease inhibitors, and consumes nitric oxide. These may contribute to endothelial dysfunction and add to the chronic renal lesions observed in patients with MPO-ANCA. MPO levels are influenced by genetic factors including two, MPO463 and MPO129, single nucleotide polymorphisms. The MPO 463 polymorphism has been associated with an increased risk of development of MPO-ANCA associated disease. 


\section{Introduction}

Vasculitis is an inflammatory process of blood vessels resulting in damage and eventually destruction and occlusion of vessels. Vasculitis may be primary or secondary to underlying connective tissue disease, infection, malignancy, or drugs. Clinical presentation largely depends on the type and size of vessels involved. Primary vasculitides can be subdivided according to the 1993 Chapel Hill Consensus Conference definitions in large vessel vasculitides, medium-sized vessel vasculitides, small vessel vasculitides not associated with anti-neutrophil cytoplasmic antibodies (ANCA), and small vessel vasculitides associated with ANCA ${ }^{1,2}$.

The ANCA associated small vessel vasculitides can be separated into Wegener's granulomatosis (WG), microscopic polyangiitis (MPA), Churg-Strauss syndrome (CSS) and idiopathic pauci-immune necrotizing crescentic glomerulonephritis (iNCGN) (table 1).

Generally, ANCA detected in patients with these small vessel vasculitides are either directed against the myeloid lysosomal enzymes proteinase 3 (PR3) or myeloperoxidase (MPO) ${ }^{3}$. There is increasing awareness that MPO-ANCA and PR3-ANCA positive patients represent separate diseases within the spectrum of the ANCA associated vasculitides ${ }^{4}$. The reason why MPO-ANCA positive patients develop a different type of disease is largely unknown. The unique properties of the enzyme targeted by anti-MPO antibodies could perhaps help to explain the specific characteristics of MPO-ANCA associated disease.

This review will focus on the clinical characteristics of MPO-ANCA associated vasculitis and will discuss recently developed animal models. Also, the role and function of the enzyme will be discussed as well as promoter polymorphisms that influence MPO expression levels and disease risk.

\section{Clinical characteristics of MPO-ANCA associated vasculitis}

The ANCA associated vasculitides are characterized by a necrotizing vasculitis of the smaller vessels and as such can give rise to arteriolitis, capillaritis, venulitis and glomerulonephritis. However, larger vessels can sometimes participate in the disease process as well. According to the 1993 Chapel Hill Consensus Conference, the types of tissue affected, the presence or absence of granulomatous inflammation and the presence or absence of asthma and eosinophilia distinguishes between the different ANCA associated vasculitides (table 1). The commonly used generalized term 'ANCA-associated vasculitides' for these diseases fails to distinguish the differences between patients with PR3-ANCA positivity and those with MPO-ANCA (table 2).

Studies looking at disease associations between patients with PR3-ANCA and MPO-ANCA have shown that most patients with WG have PR3-ANCA and most iNCGN as well as CSS patients have MPO-ANCA. However, in MPA positivity is more evenly distributed (table 1) $6,9,10,13,19-23$. 
Table 1. The ANCA associated vasculitides. PR3-ANCA = anti proteinase 3 neutrophil cytoplasmic antibodies; $\mathrm{MPO}-\mathrm{ANCA}=$ anti myeloperoxidase neutrophil cytoplasmic antibodies; $\mathrm{GBM}=$ glomerular basement membrane

\begin{tabular}{|c|c|c|c|c|c|}
\hline Disease & Pathologic definition & $\begin{array}{l}\text { Clinical } \\
\text { hallmarks }\end{array}$ & $\begin{array}{l}\text { MPO- } \\
\text { ANCA }\end{array}$ & $\begin{array}{l}\text { PR3- } \\
\text { ANCA }\end{array}$ & Ref. \\
\hline $\begin{array}{l}\text {-Idiopathic } \\
\text { pauci-immune } \\
\text { necrotizingcrescentic } \\
\text { glomerulonephritis } \\
\text { (iNCGN) }\end{array}$ & $\begin{array}{l}\text { Necrotizing crescentic } \\
\text { glomerulonephritis, with } \\
\text { few or no immune deposits. } \\
\text { Absence of small vessel } \\
\text { vasculitis in other organs. }\end{array}$ & $\begin{array}{l}\text { Nephritis, } \\
\text { malaise }\end{array}$ & $70-80 \%$ & $10-30 \%$ & 5,6 \\
\hline $\begin{array}{l}\text {-Microscopic } \\
\text { polyangiitis (MPA)* }\end{array}$ & $\begin{array}{l}\text { Necrotizing vasculitis } \\
\text { affecting small vessels with } \\
\text { absence of granulomatous } \\
\text { inflammation of the } \\
\text { respiratory tract. }\end{array}$ & $\begin{array}{l}\text { Nephritis, } \\
\text { purpura, } \\
\text { hemoptysis }\end{array}$ & $50-80 \%$ & $20-50 \%$ & $7-11$ \\
\hline $\begin{array}{l}\text {-Churg-Strauss } \\
\text { syndrome (CSS)* }\end{array}$ & $\begin{array}{l}\text { Eosinophil-rich and } \\
\text { granulomatous } \\
\text { inflammation involving the } \\
\text { respiratory tract. Necrotizing } \\
\text { vasculitis affecting small to } \\
\text { medium-sized vessels. }\end{array}$ & $\begin{array}{l}\text { Asthma, } \\
\text { eosinophilia, } \\
\text { neuropathy }\end{array}$ & $50-80 \%$ & $3-10 \%$ & $\begin{array}{l}3.12-1 \\
4\end{array}$ \\
\hline $\begin{array}{l}\text {-Wegener's } \\
\text { granulomatosis (WG)* }\end{array}$ & $\begin{array}{l}\text { Granulomatous } \\
\text { inflammation involving the } \\
\text { respiratory tract. Necrotizing } \\
\text { vasculitis affecting small to } \\
\text { medium-sized vessels. }\end{array}$ & $\begin{array}{l}\text { Nose bleeds, } \\
\text { nephritis, lung } \\
\text { infiltrates, } \\
\text { hemoptysis }\end{array}$ & $10-30 \%$ & $70-90 \%$ & $15-18$ \\
\hline
\end{tabular}

Table 2. Differences between MPO-ANCA associated disease and PR3-ANCA

\begin{tabular}{|c|c|c|}
\hline & MPO-ANCA & PR3-ANCA \\
\hline Disease association & iNCGN, CSS, MPA and WG & WG, MPA, iNCGN and CSS \\
\hline (in order of prevalence) & \multicolumn{2}{|c|}{ For relative frequency of encountered ANCA see table I } \\
\hline Age & Older age (57-63) & Younger age (45-56) \\
\hline $\begin{array}{l}\text { Extrarenal organ } \\
\text { involvement }\end{array}$ & Less involved (average 2.2) & More involvement (average 3.9) \\
\hline $\begin{array}{l}\text { Upper respiratory tract } \\
\text { disease }\end{array}$ & $\begin{array}{l}\text { Less frequent, if present mild, } \\
\text { characterized by rhinitis and polyps }\end{array}$ & $\begin{array}{l}\text { Frequently present characterized by } \\
\text { destructive and granulomatous } \\
\text { inflammation }\end{array}$ \\
\hline Granuloma & With the exception of CSS rare & Granulomas hallmark of disease \\
\hline Renal characteristics & $\begin{array}{l}\text { Pre-treatment renal deterioration rate } \\
\text { lower } \\
\text { More chronic lesions in kidney biopsy } \\
\text { Renal outcome depends on persistent } \\
\text { high MPO-ANCA titres and proteinuria } \\
\text { at diagnosis and during follow-up }\end{array}$ & $\begin{array}{l}\text { Pre-treatment renal deterioration rate } \\
\text { higher } \\
\text { More acute lesions in kidney biopsy } \\
\text { Renal outcome associated with renal } \\
\text { relapses }\end{array}$ \\
\hline Relapse & Lower relapse rate & Higher relapse rate \\
\hline
\end{tabular}


Renal disease is a hallmark of ANCA associated disease, most studies report renal involvement between $75-90 \%$ of patients $9,10,20,24$. For CSS reported percentages are somewhat lower, between 26 and $68 \%$ of patients ${ }^{14,25}$. The prevalence of renal disease generally does not differ between MPO- and PR3-ANCA positive patients ${ }^{4}$. Also, the type of histopathological lesions is essentially the same and consist of fibrinoid necrosis of the capillary wall with extracapillary proliferation and crescent formation. However, Franssen et al found that at the time of diagnosis, anti-MPO positive patients have less acute renal lesions and more chronic lesions $^{26}$. Recently, these findings were confirmed by Hauer et al in a large cohort of 173 patients with ANCA associated renal disease. MPO-ANCA compared to PR3-ANCA positive patients had the same occurrence of fibrinoid necrosis and crescents, but more glomerulosclerosis ( $25 \%$ versus $15 \%$, respectively), more interstitial fibrosis, more tubular atrophy, and more arteriosclerosis 27 . These findings suggest a different pathogenesis of renal disease in MPO-ANCA positive patients compared to PR3-ANCA patients. In line with these histopathological differences in renal lesions, pre-treatment deterioration of renal function is slower in MPO-ANCA patients compared to PR3-ANCA positive patients ${ }^{26}$. Since at the time of diagnosis serum creatinine levels are the same in patients with MPO-ANCA associated glomerulonephritis 26,28 , we think that renal lesions in MPO-ANCA patients develop more slowly, and could therefore result in delayed diagnosis of MPO-versus PR3-ANCA positive patients. This, in turn, results in increased chronic lesions in MPO-ANCA patients.

Also, despite good initial response to treatment progressive deterioration of renal function leading to end-stage renal disease has been observed in a substantial proportion of patients with MPO-ANCA positivity, but is extremely infrequent in patients with PR3-ANCA ${ }^{10.29}$. Risk factors for decrease of renal function in patients with MPO-ANCA are proteinuria at diagnosis and during follow-up as well as persistent high levels of MPO-ANCA ${ }^{30}$. This is contrary to risk factors found in PR3-ANCA patients, where long term renal survival was determined by renal relapses during follow-up ${ }^{29}$. The presence of hypertension was not found to be an independent risk factor for renal function deterioration in both MPO and PR3-ANCA positive patients 29,30 . Progressive deterioration of renal function without relapses, as found in the MPO-ANCA patients, is rarely observed in PR3-ANCA associated glomerulonephritis ${ }^{29}$. Moreover, relapses are more frequently observed in patients with PR3-ANCA as compared to MPO-ANCA (Figure 1) 31 .

In most PR3-ANCA positive patients the upper respiratory tract is characterized by an aggressive, destructive inflammatory process, whilst in MPO-ANCA positive patients upper respiratory tract involvement is usually much milder and characterized by nasal polyps, rhinitis and/or sinusitis. Except for patients with MPO-ANCA and CSS, granuloma are almost exclusively found in PR3-ANCA patients $5,20,21,32$.

Next to these differences, MPO-ANCA positive patients are older at the time of diagnosis 26,33 and generally have fewer extrarenal organs involved in the disease process than PR3-ANCA patients $10,20,21,33$. The frequency of pulmonary disease on the other hand, is equal in both patient groups. However, MPO-ANCA patients less frequently have nodular and/or pneumonia-like lesions typical for PR3-ANCA patients on their chest $x$-rays and will have more patchy 


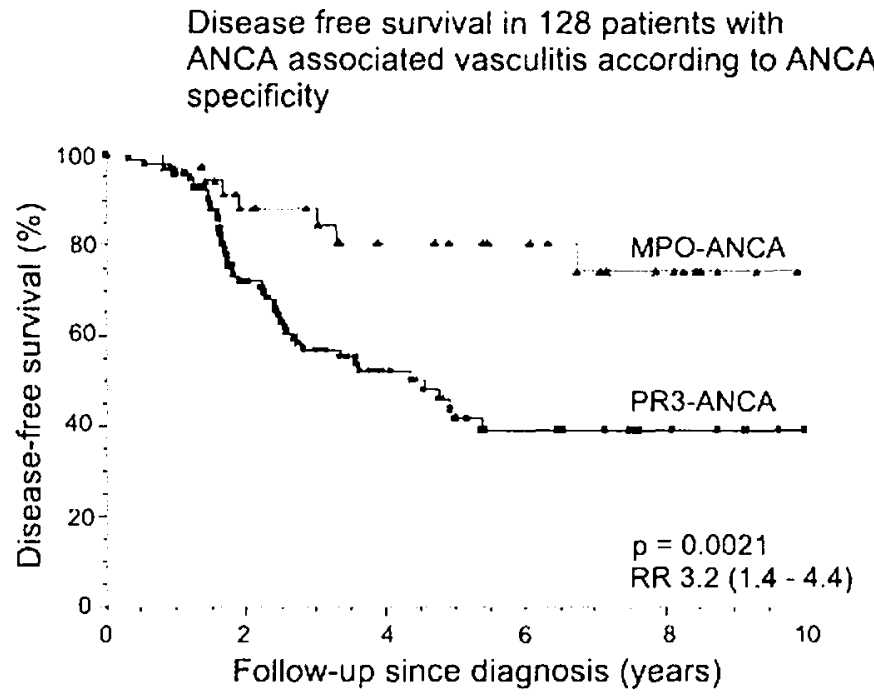

Figure 1. Disease-free survival (\%) in 128 patients with ANCA positive vasculitis according to ANCA specificity (PR3-ANCA $n=93$; MPO-ANCA $n=35$ ).

lesions consistent with pulmonary hemorrhage ${ }^{6,9,22}$. The absence of nodular lesions is probably due to the absence of granulomatous inflammation in most of the MPO-ANCA patients.

This review will further discuss the evidence for the pathogenecity of MPO-ANCA focusing on a recently developed animal model. For a pathogenetic comparison between MPO-ANCA and PR3-ANCA associated vasculitis we would like to refer to another review article ${ }^{4}$. We will also discuss the functions of the enzyme-antigen MPO, as well as promoter polymorphisms that influence MPO expression and disease risk.

MPO-ANCA: animal models

Animal models for MPO-ANCA associated vasculitis have been developed to prove that MPO-ANCA are pathogenic in vivo as well as to address specific questions about pathogenic mechanisms and to study the effects of novel therapies in vivo. Existing animal models are summarized in table 3. The two recent models are one developed by Smyth et al and one by Xiao et al. In preliminary studies, Smyth et al reported that in Wistar Kyoto rats immunized with human MPO, cross-reacting rat anti-rat MPO antibodies develop accompanied by pauci-immune crescentic glomerulonephritis and alveolar hemorrhage ${ }^{34}$. The investigators suggested that the rat strain used is most likely to be very important since other groups have failed to induce disease after immunization with human MPO in different strains of rat. It will be interesting to genetically compare these different rat strains to investigate disease specific genes. 


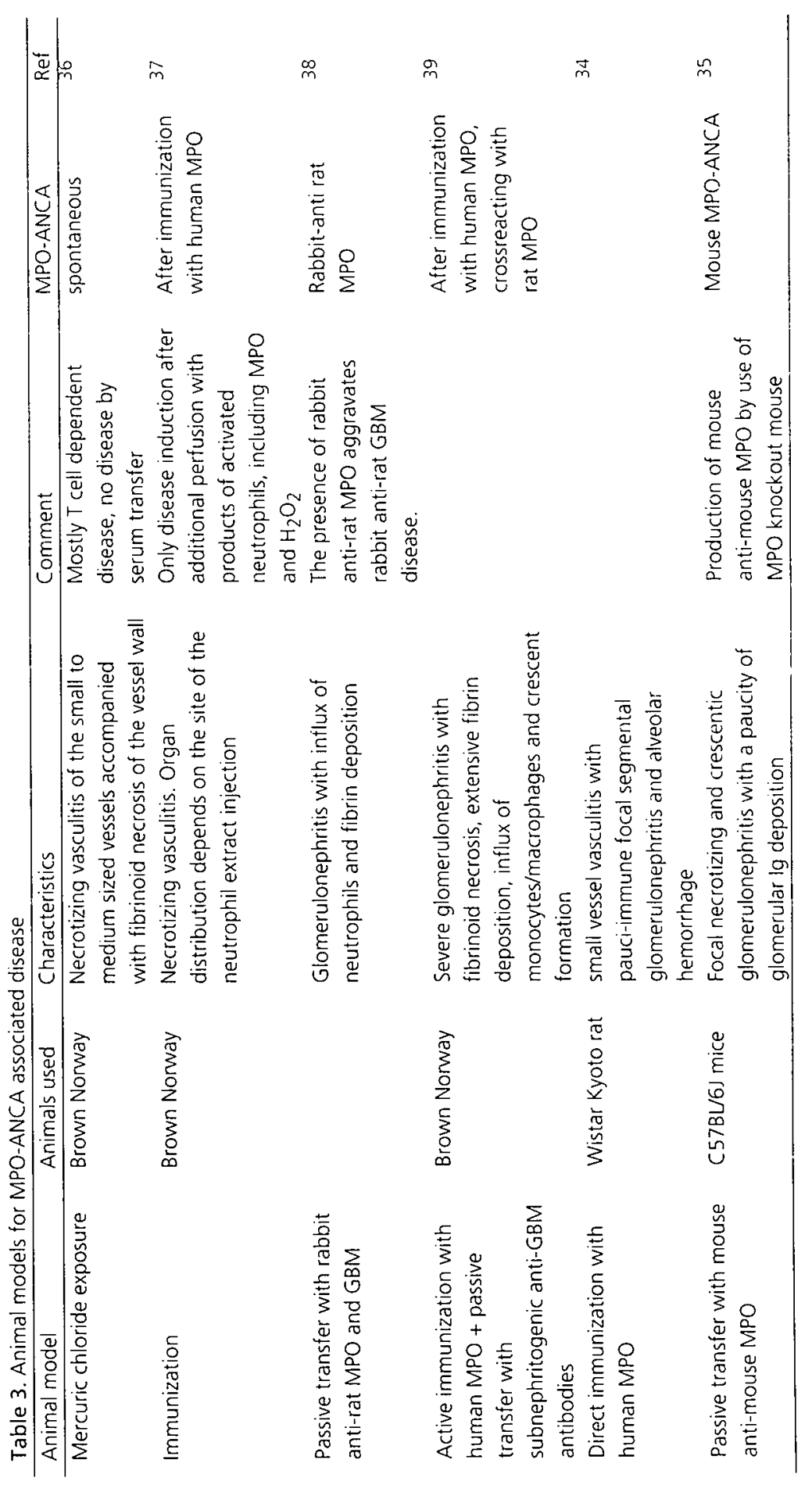


Xiao et al made use of the recently generated MPO knockout mouse. Since these mice lack MPO, no immunological tolerance for this enzyme has developed. After immunization in this otherwise immunocompetent mouse a strong humoral and cellular response will develop. Xiao et a/ showed that Rag2\% (T, B cell deficient) mice injected with anti-MPO splenocytes developed circulating MPO-ANCA and a dose-dependent deterioration of renal function, histologically characterized by severe necrotizing and crescentic glomerulonephritis ${ }^{35}$. Interestingly, 7 of 16 injected animals developed extrarenal vasculitis, including pulmonary alveolar capillaritis and granulomatous inflammation was present in only 1 of 16 mice.

Also, passive transfer of MPO-ANCA IgG was capable of transferring disease. Within 6 days after injection of the antibodies into MPO sufficient mice, focal necrotizing glomerulonephritis developed in all injected mice, although the number of glomeruli effected was much lower than in the splenocytes transfer. The histopathological similarities to the human form of MPO-ANCA disease is striking. In collaboration with Xiao et al, we could reproduce this model of murine anti-MPO associated glomerulonephritis as well (figure 2). This disease model offers unique opportunities to study pathogenic mechanisms and to test novel therapies. Whether it will be possible to mimic aspects of the chronic disease like in humans, remains to be seen.

\section{MPO-ANCA pathologic mechanisms}

Although it still remains to be determined what the exact pathological mechanisms are, the experimental animal models described above strongly support the hypothesis that MPO-ANCA directly cause disease. Many in vitro studies have tried to unravel the pathologic mechanisms involved in MPO-ANCA associated disease (reviewed $\mathrm{in}^{40}$ ). In short, priming of neutrophils by TNF $\alpha$ (e.g. as a result of an upper respiratory tract infection) results in mitogen-activated protein kinase (MAPK) dependent translocation of MPO to the cell surface $^{41}$. Stimulation of these primed neutrophils with MPO-ANCA results in neutrophil activation, with reactive oxygen species generation (including $\mathrm{O}_{2}^{-}$and $\mathrm{H}_{2} \mathrm{O}_{2}$ ), degranulation, adhesion to and killing of endothelial cells $5^{40}$. Also, degranulated MPO can bind to unprimed neutrophils making them directly vulnerable to activation by MPO-ANCA ${ }^{42}$. Monocytes can be activated as well, resulting in enhanced cytokine and chemokine production (e.g. IL-8, II-6, TNF and $M(P-1)^{40}$. Most of these processes are thought to be $F c$ and $F(\gamma$-receptor dependent 40 .

Circulating MPO has been detected in patients with MPO-ANCA associated vasculitis in higher concentrations than in healthy controls ${ }^{43}$. Endothelial cells can bind and take up this degranulated MPO resulting in an increased intracellular oxidant radical formation ${ }^{44}$. MPO can also form complexes with circulating MPO-ANCA that bind and dimerize Fc $\gamma$-receptors on neutrophils resulting in activation ${ }^{40}$. MPO present outside inflammatory sites is normally cleared and inactivated by ceruloplasmin ${ }^{45}$. The presence of MPO-ANCA however, interferes with these mechanisms, leaving a circulating highly reactive enzyme ${ }^{46}$. The potential pathologic significance of this circulating functional enzyme will be discussed in the next paragraph. 


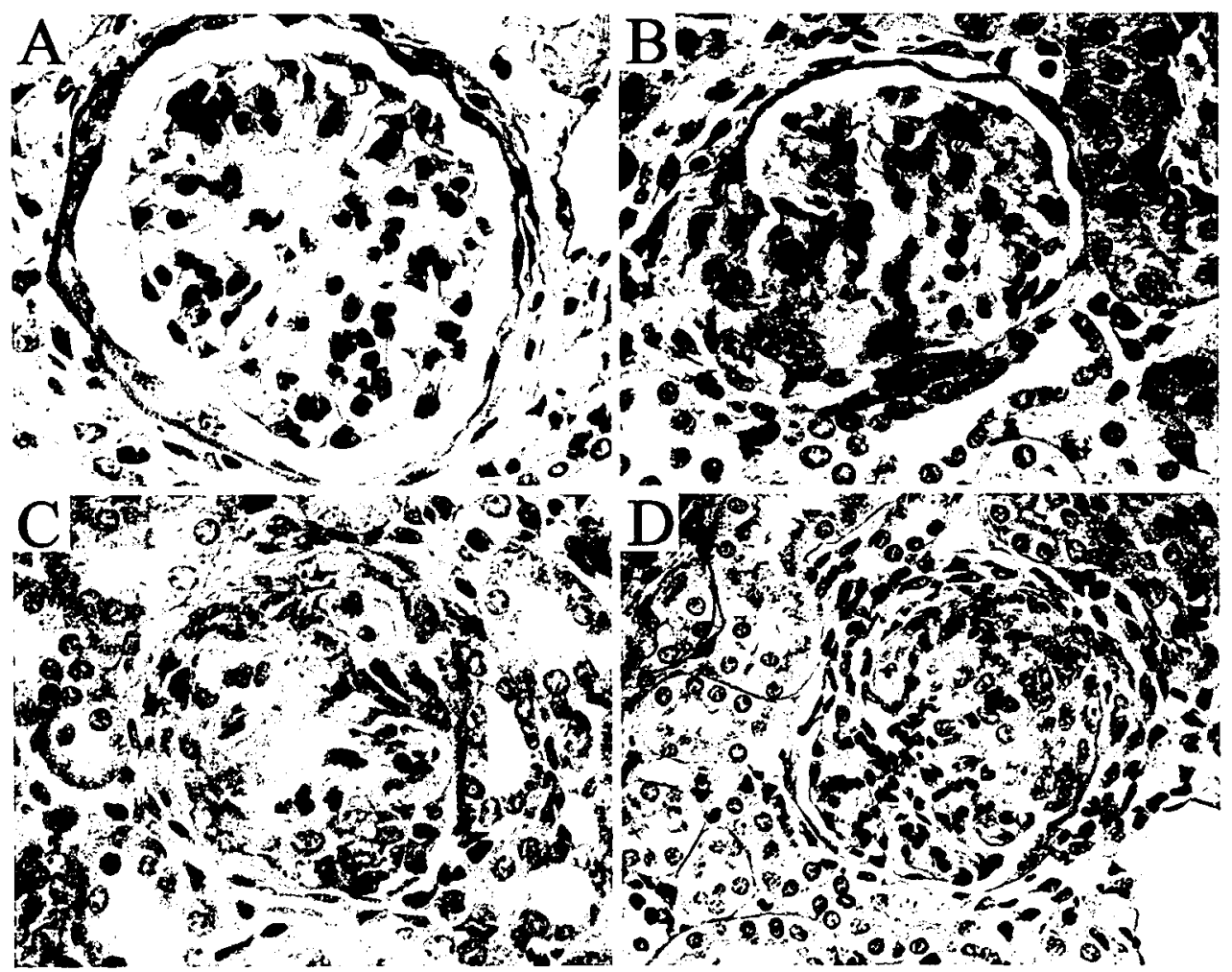

Figure 2. The development of necrotizing crescentic glomerulonephritis in a wildtype C57BU6j mouse by passive transfer with MPO-ANCA. MPO-ANCA were produced by immunization of a MPO knock-out mouse with mouse MPO. This figure shows 4 glomeruli cut from the same kidney of a mouse 6 days after injection with MPO-ANCA. A) shows a normal glomerulus, B) shows fibrinoid necrosis $\left({ }^{*}\right)$ and extracapillary proliferation, C) shows fibrinoid necrosis and crescent formation, D) shows fibrinoid necrosis $\left(^{*}\right)$ surrounded by a large crescent with inflammatory involvement of bowman's capsule. A), B), and D) are PAS stained sections, C) is a Martius Scarlet Blue stained section.

Functions of MPO and pathophysiological implications for MPO-ANCA associated vasculitis

Myeloperoxidase (MPO; EC 1.11.1.7) is a heme containing peroxidase expressed and stored in monocyte and neutrophil granulocyte precursors. In mature resting neutrophils, MPO is the most abundant protein and upon neutrophil activation MPO is readily released into phagocytic vacuoles as well in the extracellular space where it catalyzes the formation of bleach (hypochlorous acid; $\mathrm{HOCl}$ ) out of chloride ions and hydrogen peroxide $\left(\mathrm{H}_{2} \mathrm{O}_{2}\right)$. As summarized in table 4 and figure 3 the effects and pathological consequences of MPO are multiple. Firstly, $\mathrm{HOCl}$ can react with a variety of cellular substrates including thiols, nucleotides and amines and, as such, it contributes to innate immunity against bacteria and fungi by neutrophils $^{47}$. HOCl can however, also damage host tissue and catalytically active MPO has been 
Table 4. Effects and pathological consequences of MPO

\begin{tabular}{|c|c|c|}
\hline function & Effect & Pathologic significance \\
\hline \multirow{6}{*}{$\begin{array}{l}\text { Procluction of } \mathrm{HOCl} \\
\text { (bleach) }\end{array}$} & Bactericidal $^{47}$ & Aids in clearing bacteria \\
\hline & Activate pro-MMP ${ }^{68}$ & Contributes to matrix degradation \\
\hline & MAPK activation 50 & $\begin{array}{l}\text { Contributes to neutrophil membrane } \\
\text { expression of } \mathrm{MPO}^{4 i}\end{array}$ \\
\hline & Inhibition of $T$ cell proliferation 69 & - \\
\hline & Depending on concentration & Apoptotic overload may cause antigen \\
\hline & pro-apoptotic or cytotoxic & $\begin{array}{l}\text { presentation and auto-antibody production } 52 \\
\text { Apoptosis of endothelial cells } 70\end{array}$ \\
\hline Corisumption of $\mathrm{H}_{2} \mathrm{O}_{2}$ & Prevent protease inactivation 55,56 & $\begin{array}{l}\text { Contributes in protease mediated vascular } \\
\text { damage }\end{array}$ \\
\hline $\begin{array}{l}\text { macuvate protease } \\
\text { mhibitors }\end{array}$ & Prevent protease inactivation 57,71 & $\begin{array}{l}\text { Contributes in protease mediated vascular } \\
\text { damage }\end{array}$ \\
\hline Oxidation & $\begin{array}{l}\text { Oxidize } L D L^{53}, \text { MPO-ANCA } \\
\text { patients have high anti-oxLDL } \\
\text { titers }^{54}\end{array}$ & $\begin{array}{l}\text { Pro-apoptotic, stimulates } \\
\text { monocyte-endothelial cell interactions, and } \\
\text { stimulates proliferation of smooth muscle cells } \\
\text { and monocytes/ macrophages } 72\end{array}$ \\
\hline Consume $\mathrm{NO}^{59}$ & $\begin{array}{l}\text { Lower NO bioavailability at } \\
\text { inflammatory sites }\end{array}$ & $\begin{array}{l}\text { Contributes to endothelial dysfunction } 62,63 \text {. } \\
\text { Promotes renal injury e.g. through pathogenic } \\
\text { properties of unopposed normal angiotensin } 11 \\
\text { levels } 65\end{array}$ \\
\hline
\end{tabular}

PR3-ANCA = anti proteinase 3 neutrophil cytoplasmic antibodies; MPO-ANCA = anti myeloperoxidase neutrophil cytoplasmic antibodies; GBM = glomerular basement membrane

detected in glomerular and atherosclerotic lesions in conjunction with $\mathrm{HOCL}$-modified proteins ${ }^{48,49}$. HOCl is directly cytotoxic in high concentrations, whereas in lower concentrations it is able to activate MAPK pathways and can cause growth arrest and apoptosis ${ }^{50}$. Apoptosis of neutrophils could contribute to the presentation of the normally concealed MPO to the immune system ${ }^{51}$. Moreover, exposure to large numbers of apoptotic cells, exceeding the phagocytic capacity of the reticuloendothelial system to clear apoptotic material, is able to elicit an auto-antibody response ${ }^{52}$.

Secondly, in addition to the conventional view on the role of the MPO/HOCI system recent evidence suggests that MPO has an important role in the oxidative conversion of LDL into a high-uptake form for macrophages, leading to foam cell formation ${ }^{53}$. In this respect, Swets et al observed that patients with ANCA associated vasculitis had increased levels of auto-antibodies against oxidized LDL, suggesting that patients were more susceptible to oxidation of $\mathrm{LDL}^{54}$.

Thirdly, MPO can increase protease activity at inflammatory sites by inactivating protease inhibitors and by acting as a detoxicant for $\mathrm{H}_{2} \mathrm{O}_{2}$ thereby protecting proteolytic enzymes from inactivation 55.57 . In ANCA associated vasculitis protease/anti-protease imbalance has been proposed to play a role in vasculitic lesion development ${ }^{58}$. 


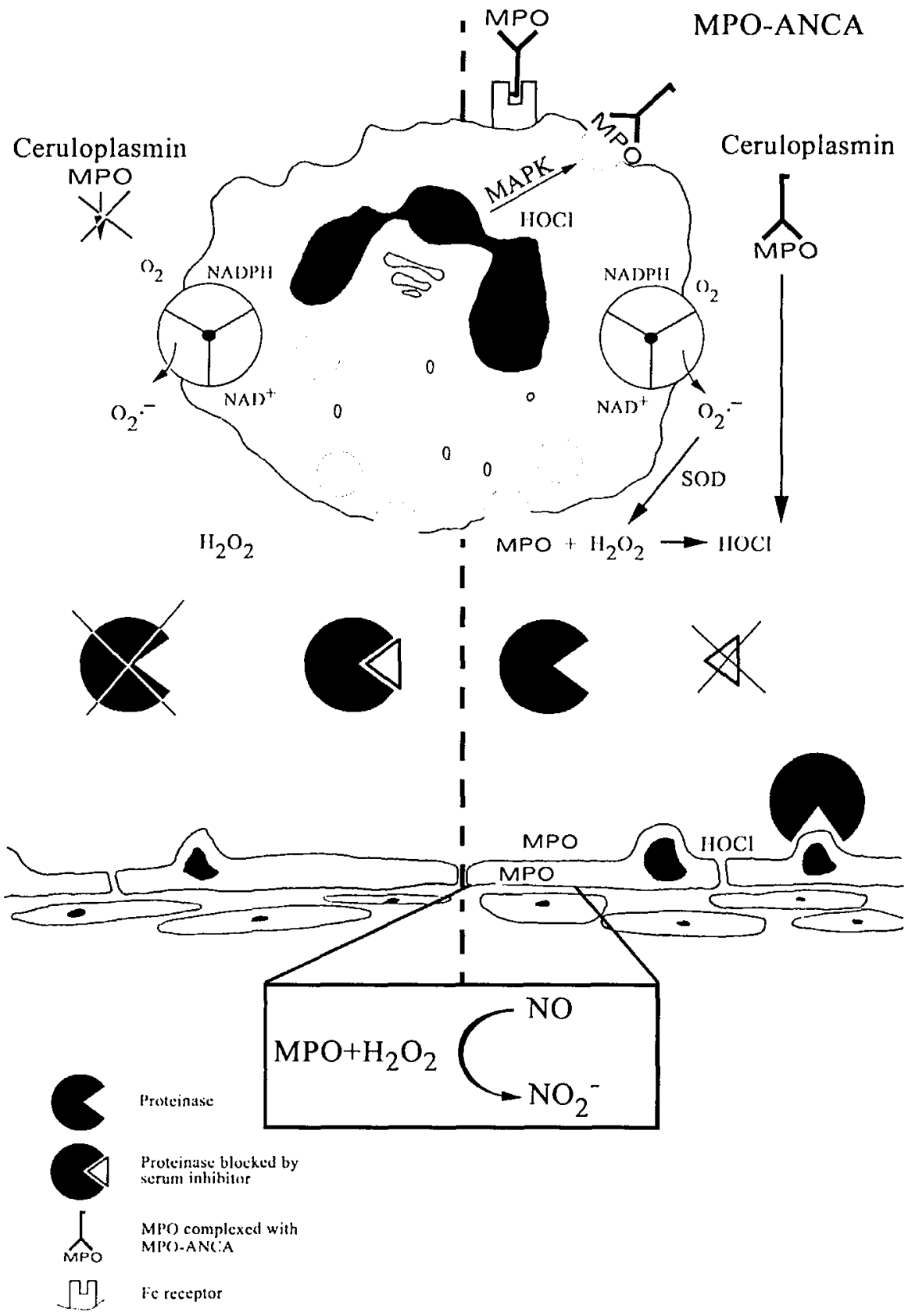

Figure 3. Schematic presentation of the functions of MPO in vascular damage. Left-side of the figure represents the situation without ANCA, right-side figure represents the situation where MPO-ANCA can activate primed neutrophils directly or via the Fcg receptor and prevent inhibition of MPO by ceruloplasmin. See also table 4. 
Finally, MPO can act as a leukocyte-derived vascular nitric oxide (NO) oxidase, thereby reducing NO bioavailability and contributing to endothelial dysfunction ${ }^{59-61}$. Endothelial dysfunction has been shown to be an important characteristic of ANCA associated disease, especially during active disease ${ }^{62,63}$. Interestingly, chronic blockade of NO synthesis in rats results in hypertension, proteinuria, glomerular sclerotic injury, tubulointersitial damage and infiltration of the interstitium by mononuclear cells 64,65 . Moreover, in glomerulonephritis it has been shown that NO synthase is reduced and that mice lacking a functional gene for endothelial NO synthase (eNOS) develop more severe glomerulonephritis than wildtypes ${ }^{66,67}$.

\section{Levels of MPO expression}

Increased neutrophil MPO content has been linked to coronary atherosclerosis suggesting a link between MPO protein levels and atherosclerosis ${ }^{60}$. Also, in patients with MPO-ANCA associated vasculitis higher circulating levels of serum MPO have been found compared to control subjects ${ }^{43}$. Higher levels of MPO could result in more antigen present for binding by MPO-ANCA and more active enzyme circulating uninhibited by ceruloplasmin due to binding of MPO-ANCA. In this respect two MPO promoter polymorphisms influencing MPO levels are of particular interest.

Expression of MPO during myelopoiesis is tightly regulated and multiple transcription factors are involved in transcription of $\mathrm{MPO}^{73}$. Two genetic promoter polymorphisms have been shown to influence MPO expression levels, the MPO463 and MPO129 single nucleotide polymorphisms (figure 4).

The most studied polymorphism is the $-463 \mathrm{G} / \mathrm{A}$ nucleotide change within an Alu-encoded hormone response element. The GG genotype is the most common, at $61 \%$ of the Northern European population. The AA genotype occurs $3-7 \%$ in Caucasians and thus the GA in $32-36 \% 74$.

The $G$ allele contains a SP1 binding site associated with a stronger promoter activity. The A allele destroys this SP1 binding site, but creates an estrogen binding motif making the promoter responsive to estrogens ${ }^{74}$. Reynolds et a/ found that in 10 tested patients MPO protein level expression was higher for the GG than the GA or AA genotypes ${ }^{75}$. In contrast, however, Hoy et al were not able to demonstrate an association between MPO protein levels and the $463 \mathrm{G} / \mathrm{A}$ polymorphism ${ }^{76}$.

Interesting is the association of the MPO463 SNP with an impaired vasodilatative response to the administration of nitroglycerine, a direct NO donor, in females ${ }^{77}$. This implies that higher levels of MPO (i.e. GG genotype) correlate with impaired vasodilatation. The MPO463 polymorphism has been investigated in MPO-ANCA associated disease as well. Reynolds established that the MPO GG genotype was overrepresented in female, but not male, patients with MPO-ANCA associated vasculitis. Furthermore, we found that GAVAA genotypes were diagnosed at an earlier age compared to the GG genotype (41 versus 56 years, respectively). Interestingly, relapse-free survival is significantly different between patients with the $463 \mathrm{GG}$ compared to those with the $463 \mathrm{GA}$ or AA genotype (figure 5). 


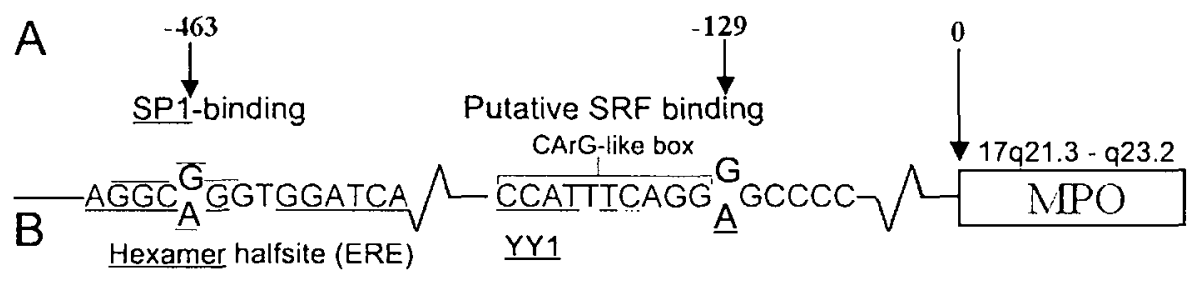

\begin{tabular}{cccc}
\hline C & \multicolumn{3}{c}{ Genotype frequencies } \\
& 61 & GG & 89 \\
$32-36$ & GA & 10 \\
$3-7$ & AA & $0-1$
\end{tabular}

Figure 4. Figure showing two important single nucleotide polymorphisms in the promoter of myeloperoxidase at position -463 and -129 . A) shows (putative) binding sites (black line on top of text) when both polymorphisms have their wild type genotype (i.e. $G$ allele), B) shows the (putative) binding sites (underlined) when both sites are polymorphic (i.e. A allele). Note the single nucleotide mismatch with the consensus binding site of yin yang-1 (YY 1) transcription factor (dotted underlined) 86 . ERE = Estrogen response element; $\mathrm{SRF}=$ serum response factor $\mathrm{C}$ ) shows the genotypic frequencies of the respective polymorphisms.

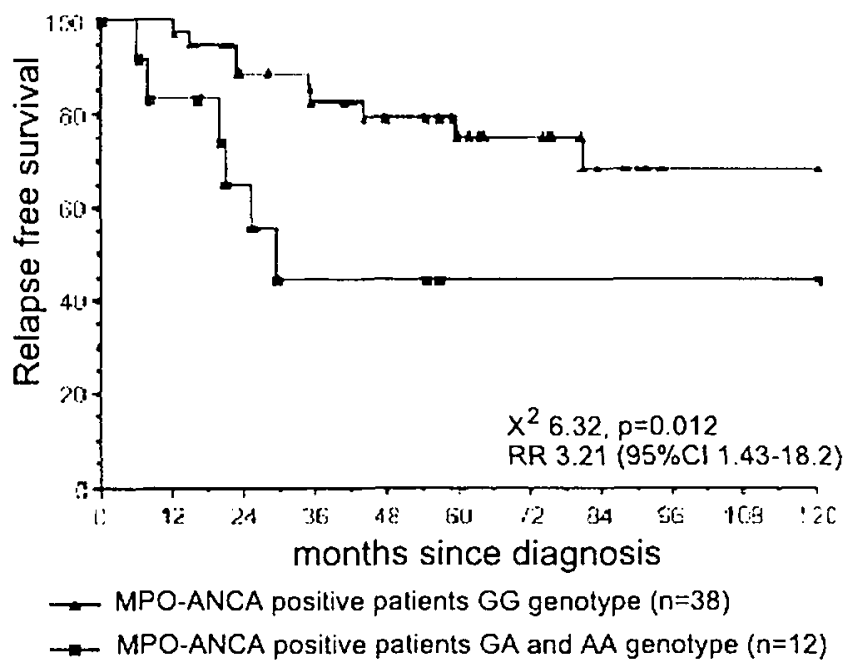

Figure 5. Relapse-free survival is significantly different between patients with the $463 G G(n=38)$ genotype compared to $463 \mathrm{GA}$ or AA genotypes $(n=12)(p=0.012)$. Reproduced from ${ }^{79}$ with permission. 
However, the latter finding was not confirmed in a recent abstract ${ }^{78}$. Taken together, these data suggest that the high MPO expression genotype (GG) is a risk factor for development of disease, but once disease is present it is possibly associated with a lower relapse rate ${ }^{79}$.

A second MPO promoter polymorphism (129G/A) has been described recently. This G to A single nucleotide polymorphism at position -129 has been associated with decreased levels of MPO in the serum of healthy controls. About $10 \%$ of people in a French population was heterozygous for this polymorphism ${ }^{76}$. To date the $129 \mathrm{GA}$ polymorphism has been evaluated for disease in only one population of sarcoidosis patients ${ }^{80}$ and it will be interesting to learn its role in vasculitic disease.

Thus, genetic factors influence MPO activity by controlling MPO expression. However, MPO activity can also be changed directly by other factors. Estrogens for instance, can have a stimulatory effect on the enzymatic activity of $\mathrm{MPO}^{81-83}$, whereas, for example non-steroidal anti inflammatory drugs can inhibit MPO activity in vitro ${ }^{84}$. Whether the latter has relevance in vivo is doubted 85 .

\section{Conclusions}

MPO-ANCA induces vasculitis and glomerulonephritis in mice. In vitro, MPO-ANCA can activate (primed) neutrophils directly causing extensive reactive oxygen species formation and degranulation of neutrophil constituents, including MPO, resulting in an aggravated immune response towards the vessel wall. MPO-ANCA can prevent the clearing and inactivation of MPO by ceruloplasmin as well, resulting in increased myeloperoxidase activity. Myeloperoxidase produces not only the strong oxidant bleach (hypochlorous acid) out of hydrogen peroxide and chloride ions but also inactivates protease inhibitors, oxidizes LDL into a macrophage high-uptake form, and consumes nitric oxide. These may contribute to endothelial dysfunction and add to the chronic renal lesions observed in patients with MPO-ANCA. MPO levels are further influenced by hormonal and genetic factors including two, MPO463 and MPO129, single nucleotide polymorphisms. The MPO 463 polymorphism has been associated with an increased risk of development of MPO-ANCA associated disease.

\section{Acknowledgements}

We would like to thank Marjan Slot (Clinical and Experimental Immunology, Maastricht, The Netherlands) for providing figure 1 and Dennis Huugen and Anita van Esch (Clinical and Experimental Immunology, Maastricht, The Netherlands) for providing figure 2. 


\section{References}

1. Jennette JC, Falk RJ, Andrassy K, Bacon PA, Churg J, Gross WL, Hagen EC, Hoffman GS, Hunder GG, Kallenberg CG, et al: Nomenclature of systemic vasculitides. Proposal of an international consensus conference. Arthritis Rheum 37:187-192، 1994

2. MCLaren JS, MCRorie ER, Luqmani RA: Diagnosis and assessment of systemic vasculitis. Clin Exp Rheumatol 20:854-862, 2002

3. Cohen Tervaert JW, Limburg PC, Elema ID, Huitema MG, Horst G, The TH, Kallenberg CG: Detection of autoantibodies against myeloid lysosomal enzymes: a useful adjunct to classification of patients with biopsy-proven necrotizing arteritis. Am J Med 91:59-66, 1991

4. Franssen CF, Stegeman CA, Kallenberg CG, Gans RO, De Jong PE, Hoorntje SJ, Tervaert JW: Antiproteinase 3- and antimyeloperoxidase-associated vasculitis. Kidney Int 57:2195-2206, 2000

5. Falk RJ, Jennette JC: Anti-neutrophil cytoplasmic autoantibodies with specificity for myeloperoxidase in patients with systemic vasculitis and idiopathic necrotizing and crescentic glomerulonephritis. N Eng/ J Med 318:1651-1657, 1988

6. Cohen Tervaert JW, Goldschmeding R, Elema JD, van der Giessen M, Huitema MG, van der Hem GK, The $T H$, von dem Borne $A E$, Kallenberg $C G$ : Autoantibodies against myeloid lysosomal enzymes in crescentic glomerulonephritis. Kidney Int 37:799-806, 1990

7. Lhote F, Cohen P, Genereau T, Gayraud M, Guillevin L: Microscopic polyangiitis: clinical aspects and treatment. Ann Med Interne (Paris) 147:165-177, 1996

8. Gaskin G, Savage CO, Ryan JJ, Jones S, Rees AJ, Lockwood CM, Pusey CD: Anti-neutrophil cytoplasmic antibodies and disease activity during long-term follow-up of 70 patients with systemic vasculitis. Nephrol Dial Transplant 6:689-694, 1991

9. Geffriaud-Ricouard C, Noel LH, Chauveau D, Houhou S, Grunfeld JP, Lesavre P: Clinical spectrum associated with ANCA of defined antigen specificities in 98 selected patients. Clin Nephro/ 39:125-136, 1993

10. Franssen C, Gans R, Kallenberg C. Hageluken C, Hoorntje S: Disease spectrum of patients with antineutrophil cytoplasmic autoantibodies of defined specificity: distinct differences between patients with anti-proteinase 3 and anti-myeloperoxidase autoantibodies. J Intern Med 244:209-216, 1998

11. Guillevin L, Durand-Gasselin B, Cevallos R, Gayraud M, Lhote F, Callard P, Amouroux J, Casassus P, Jarrousse B: Microscopic polyangiitis: clinical and laboratory findings in eighty-five patients. Arthritis Rheum 42:421-430, 1999

12. Cohen Tervaert JW, Goldschmeding R, Elema JD, von dem Borne AE, Kallenberg CG: Antimyeloperoxidase antibodies in the Churg-Strauss syndrome. Thorax 46:70-71, 1991

13. Guillevin L, Visser H, Noel LH, Pourrat J, Vernier I, Gayraud M, Oksman F, Lesavre P: Antineutrophil cytoplasm antibodies in systemic polyarteritis nodosa with and without hepatitis $B$ virus infection and Churg-Strauss syndrome-62 patients. I Rheumatol 20:1345-1349, 1993

14. Guillevin L, Cohen P, Gayraud M, Lhote F, Jarrousse B, Casassus P: Churg-Strauss syndrome. Clinical study and long-term follow-up of 96 patients. Medicine (Baltimore) 78:26-37, 1999

15. Weber MF, Andrassy K, Pullig O, Koderisch J, Netzer K: Antineutrophil-cytoplasmic antibodies and antiglomerular basement membrane antibodies in Goodpasture's syndrome and in Wegener's granulomatosis. J Am Soc Nephrol 2:1227-1234, 1992

16. Hagen EC, Daha MR, Hermans J, Andrassy K, Csernok E, Gaskin G, Lesavre P, Ludemann J, Rasmussen N, Sinico RA, Wiik A, van der Woude FJ: Diagnostic value of standardized assays for anti-neutrophil cytoplasmic antibodies in idiopathic systemic vasculitis. EC/BCR Project for ANCA Assay Standardization. Kidney int 53:743-753, 1998

17. Cohen Tervaert JW, van der Woude FJ, Fauci AS, Ambrus JL, Velosa J, Keane WF, Meijer S, van der Giessen $M$, van der Hem GK, The TH, et al.: Association between active Wegener's granulomatosis and anticytoplasmic antibodies. Arch Intern Med 149:2461-2465, 1989

18. Nolle B, Specks U, Ludemann J, Rohrbach MS, DeRemee RA, Gross WL: Anticytoplasmic autoantibodies: their immunodiagnostic value in Wegener granulomatosis. Ann Intern Med 111:28-40, 1989

19. Falk RJ, Hogan S, Carey TS, Jennette JC: Clinical course of anti-neutrophil cytoplasmic autoantibody-associated glomerulonephritis and systemic vasculitis. The Glomerular Disease Collaborative Network. Ann Intern Med 113:656-663, 1990 
20. Goldschmeding R, Cohen Tervaert JW, Gans RO, Dolman KM, van den Ende ME, Kuizinga MC, Kallenberg $C G$, von dem Borne AE: Different immunological specificities and disease associations of C-ANCA and p-ANCA. Neth I Med 36:114-116, 1990

21. Jennette JC, Wilkman AS, Falk RJ: Anti-neutrophil cytoplasmic autoantibody-associated glomerulonephritis and vasculitis. Am J Pathol 135:921-930, 1989

22. Sinico RA, Gregorini G, Radice A, Campanini M, Pozzi C, Quarenghi M, Napodano P, Giordano A, Ferrario F: Clinical significance of autoantibodies to myeloperoxidase in vasculitic syndromes. Contrib Nephrol 94:31-37, 1991

23. Conron M, Beynon HL: Churg-Strauss syndrome. Thorax 55:870-877, 2000

24. Cohen Tervaert JW, Goldschmeding R, Elema JD, Limburg PC, van der Giessen M, Huitema MG, Koolen MI, Hene RJ, The TH, van der Hem GK, et al.: Association of autoantibodies to myeloperoxidase with different forms of vasculitis. Arthritis Rheum 33:1264-1272, 1990

25. Clutterbuck EJ, Evans DJ, Pusey CD: Renal involvement in Churg-Strauss syndrome. Nephrol Dial Transplant 5:161-167, 1990

26. Franssen CF, Gans RO, Arends B, Hageluken C, ter Wee PM, Gerlag PG, Hoorntje SJ: Differences between anti-myeloperoxidase- and anti-proteinase 3-associated renal disease. Kidney int 47:193-199, 1995

27. Hauer HA, Bajema IM, van Houwelingen HC, Ferrario F, Noel LH, Waldherr R, Jayne DR, Rasmussen N, Bruijn JA, Hagen EC: Renal histology in ANCA-associated vasculitis: differences between diagnostic and serologic subgroups. Kidney int 61:80-89, 2002

28. Slot MC, van Paassen P, Van Breda Vriesman PJ, Cohen Tervaert JW: Do biopsy scores at diagnosis explain differences in outcome in ANCA-associated vasculitis?, in 11th international vasculitis and ANCA workshop, Prague, 2003

29. Slot MC, Cohen Tervaert JW. Franssen CF, Stegeman CA: Renal survival and prognostic factors in patients with PR3-ANCA associated vasculitis with renal involvement. Kidney int 63:670-677, 2003

30. Franssen CF, Stegeman CA, Oost-Kort WW, Kallenberg CG, Limburg PC, Tiebosch A, De Jong PE, Tervaert JW: Determinants of renal outcome in anti-myeloperoxidase-associated necrotizing crescentic glomerulonephritis. J Am Soc Nephrol 9:1915-1923, 1998

31. Slot MC, Cohen Tervaert JW, Boomsma MM, Stegeman CA: A positive C-anca titer at switch to azathioprine therapy is associated with a disquieting relapse rate in pr3-anca-related vasculitis. Arthritis Care Res In press, 2003

32. Jennette JC, Falk RJ: Antineutrophil cytoplasmic autoantibodies and associated diseases: a review. Am J Kidney Dis 15:517-529, 1990

33. Gencik M, Borgmann S, Zahn R, Albert E, Sitter T, Epplen JT, Fricke H: Immunogenetic risk factors for anti-neutrophil cytoplasmic antibody (ANCA)-associated systemic vasculitis. Clin Exp Immunol 117:412-417, 1999

34. Smyth CL, Smith H, Cook T, Haskard DO, Pusey CD: Immunisation with MPO directly induces small vessel vasculitis with pauci-immune focal segmental glomerulonephritis and alveolar haemorrhage in WKY rats, in American Society of Nephrology, Philadelphia, 2002

35. Xiao H, Heeringa P, Hu P, Liu Z, Zhao M, Aratani Y, Maeda N, Falk RJ, Jennette JC: Antineutrophil cytoplasmic autoantibodies specific for myeloperoxidase cause glomerulonephritis and vasculitis in mice. $J$ Clin Invest 110:955-963, 2002

36. Esnault VL, Mathieson PW, Thiru S, Oliveira DB, Martin-Lockwood C: Autoantibodies to myeloperoxidase in brown Norway rats treated with mercuric chloride. Lab Invest 67:114-120, 1992

37. Brouwer E, Huitema MG, Klok PA, de Weerd H, Tervaert JW, Weening JJ, Kallenberg CG: Antimyeloperoxidase-associated proliferative glomerulonephritis: an animal model. J Exp Med 177:905-914, 1993

38. Kobayashi K, Shibata $T$, Sugisaki $T$ : Aggravation of rat nephrotoxic serum nephritis by anti-myeloperoxidase antibodies. Kidney int 47:454-463, 1995

39. Heeringa P, Brouwer E, Klok PA, Huitema MG, van den Born J, Weening JJ, Kallenberg CG: Autoantibodies to myeloperoxidase aggravate mild anti-glomerular-basement-membrane-mediated glomerular injury in the rat. Am J Pathol 149:1695-1706, 1996

40. Hewins P, Savage C: Anti-neutrophil cytoplasm antibody associated vasculitis. Int I Biochem Cell Biol $35: 277-282,2003$

41. Kettritz $R$, Schreiber $A$, Luft FC, Haller $H$ : Role of mitogen-activated protein kinases in activation of human neutrophils by antineutrophil cytoplasmic antibodies. J Am Soc Nephrol 12:37-46, 2001 
42. Hess C, Sadallah S, Schifferli JA: Induction of neutrophil responsiveness to myeloperoxidase antibodies by their exposure to supernatant of degranulated autologous neutrophils. Blood 96:2822-2827, 2000

43. Minota S, Horie 5, Yamada A, Iwamoto M, Yoshio T. Mimori A, Masuyama J, Kano S: Circulating myeloperoxidase and anti-myeloperoxidase antibody in patients with vasculitis. Scand $J$ Rheumatol 28:94-99, 1999

44. Yang JJ, Preston GA, PendergraftWF, SegelmarkM, Heeringa P, Hogan SL, Jennette JC, Falk RJ: Internalization of proteinase 3 is concomitant with endothelial cell apoptosis and internalization of myeloperoxidase with generation of intracellular oxidants. Am J Pathol 158:581-592, 2001

45. Segelmark M, Persson B, Hellmark T, Wieslander J: Binding and inhibition of myeloperoxidase (MPO): a major function of ceruloplasmin? Clin Exp Immunol 108:167-174, 1997

46. Griffin SV, Chapman PT, Lianos EA, Lockwood CM: The inhibition of myeloperoxidase by ceruloplasmin can be reversed by anti-myeloperoxidase antibodies. Kidney int 55:917-925, 1999

47. Winterbourn CC, Vissers MC, Kettle AJ: Myeloperoxidase. Curr Opin Hematol 7:53-58., 2000

48. Malle E, Waeg G, Schreiber R, Grone EF, Sattler W, Grone HJ: Immunohistochemical evidence for the myeloperoxidase $/ \mathrm{H}_{2} \mathrm{O}_{2}$ /halide system in human atherosclerotic lesions: colocalization of myeloperoxidase and hypochlorite-modified proteins. Eur J Biochem 267:4495-4503, 2000

49. Grone HJ, Grone EF, Malle E: Immunohistochemical detection of hypochlorite-modified proteins in glomeruli of human membranous glomerulonephritis. Lab Invest 82:5-14, 2002

50. Winterbourn CC: Biological reactivity and biomarkers of the neutrophil oxidant, hypochlorous acid. Toxicology 181-182:223-227, 2002

51. Esnault VL: Apoptosis: the central actor in the three hits that trigger anti-neutrophil cytoplasmic antibody-related systemic vasculitis. Nephrol Dial Transplant 17:1725-1728, 2002

52. Stuart L, Hughes J: Apoptosis and autoimmunity. Nephrol Dial Transplant 17:697-700, 2002

53. Zhang R, Brennan ML, Shen Z, MacPherson JC, Schmitt D, Molenda CE, Hazen SL: Myeloperoxidase functions as a major enzymatic catalyst for initiation of lipid peroxidation at sites of inflammation. J Bio/ Chem 277:46116-46122, 2002

54. Swets BP, Brouwer DA, Cohen Tervaert JW: Patients with systemic vasculitis have increased levels of autoantibodies against oxidized LDL. Clin Exp Immunol 124:163-167, 2001

55. Roos D, Winterbourn CC: IMMUNOLOGY: Enhanced: Lethal Weapons. Science 296:669-671, 2002

56. Reeves EP, Lu H, Jacobs HL, Messina CG, Bolsover S, Gabella G, Potma EO, Warley A, Roes J, Segal AW: Killing activity of neutrophils is mediated through activation of proteases by $K+$ flux. Nature 416:291-297, 2002

57. Matheson NR, Wong PS, Travis J: Enzymatic inactivation of human alpha-1-proteinase inhibitor by neutrophil myeloperoxidase. Biochem Biophys Res Commun 88:402-409, 1979

58. Esnault VL, Audrain MA, Sesboue R: Alpha-1-antitrypsin phenotyping in ANCA-associated diseases: one of several arguments for protease/antiprotease imbalance in systemic vasculitis. Exp Clin Immunogenet $14: 206-213,1997$

59. Eiserich JP, Baldus S, Brennan ML, Ma W, Zhang C, Tousson A, Castro L, Lusis AJ, Nauseef WM, White CR, Freeman BA: Myeloperoxidase, a leukocyte-derived vascular NO oxidase. Science 296:2391-2394, 2002

60. Zhang R, Brennan ML, Fu X, Aviles RJ. Pearce GL, Penn MS, Topol EJ, Sprecher DL، Hazen SL: Association between myeloperoxidase levels and risk of coronary artery disease. JAMA 286:2136-2142, 2001

61. Abu-Soud HM, Hazen SL: Nitric oxide is a physiological substrate for mammalian peroxidases. $\mathrm{J}$ Bio/ Chem 275:37524-37532, 2000

62. Filer AD, Gardner-Medwin JM, Thambyrajah J, Raza K, Carruthers DM, Stevens RJ, Liu L, Lowe SE, Townend IN, Bacon PA: Diffuse endothelial dysfunction is common to ANCA associated systemic vasculitis and polyarteritis nodosa. Ann Rheum Dis 62:162-167, 2003

63. Raza K, Thambyrajah J, Townend IN, Exley AR, Hortas C, Filer A, Carruthers DM, Bacon PA: Suppression of inflammation in primary systemic vasculitis restores vascular endothelial function: lessons for atherosclerotic disease? Circulation 102:1470-1472., 2000

64. Baylis C. Mitruka B, Deng A: Chronic blockade of nitric oxide synthesis in the rat produces systemic hypertension and glomerular damage. J Clin Invest 90:278-281, 1992

65. Verhagen AM, Braam B, Boer P, Grone HJ, Koomans HA, Joles JA: Losartan-sensitive renal damage caused by chronic NOS inhibition does not involve increased renal angiotensin II concentrations. Kidney Int $56: 222-231,1999$

66. Heeringa $P$, Steenbergen $E$, van Goor $H$ : A protective role for endothelial nitric oxide synthase in glomerulonephritis. Kidney Int 61:822-825, 2002 
67. Heeringa $P$, Bijl $M$, de Jager-Krikken A, Zandvoort A, Dijkstra $G$, Moshage $H$, Tervaert JW, Tiebosch AT, Kallenberg CG, van Goor $\mathrm{H}$ : Renal expression of endothelial and inducible nitric oxide synthase, and formation of peroxynitrite-modified proteins and reactive oxygen species in Wegener's granulomatosis. J Pathol 193:224-232, 2001

68. Fu X, Kassim SY, Parks WC, Heinecke JW: Hypochlorous acid oxygenates the cysteine switch domain of pro-matrilysin (MMP-7). A mechanism for matrix metalloproteinase activation and atherosclerotic plaque rupture by myeloperoxidase. / Biol Chem 276:41279-41287, 2001

69. el-Hag A, Clark RA: Immunosuppression by activated human neutrophils. Dependence on the myeloperoxidase system. J Immunol 139:2406-2413, 1987

70. Vissers MC, Pullar JM, Hampton MB: Hypochlorous acid causes caspase activation and apoptosis or growth arrest in human endothelial cells. Biochem J 344 Pt 2:443-449, 1999

71. Gressier B, Lebegue S, Gosset P, Brunet C, Luyckx M, Dine T, Cazin M, Cazin JC, Wallaert B: Protective role of glutathione on alpha 1 proteinase inhibitor inactivation by the myeloperoxidase system. Hypothetic study for therapeutic strategy in the management of smokers' emphysema. Fundam Clin Pharmacol 8:518-524, 1994

72. Mertens A, Holvoet P: Oxidized LDL and HDL: antagonists in atherothrombosis. Faseb / 15:2073-2084, 2001

73. Borregaard N, Theilgaard-Monch K, Sorensen OE, Cowland J8: Regulation of human neutrophil granule protein expression. Curr Opin Hematol 8:23-27, 2001

74. Reynolds WF, Hiltunen M, Pirskanen M, Mannermaa A, Helisalmi S, Lehtovirta M, Alafuzoff I, Soininen H: $M P O$ and APOEepsilon4 polymorphisms interact to increase risk for $A D$ in Finnish males. Neurology 55:1284-1290., 2000

75. Reynolds WF, Chang E, Douer D, Ball ED, Kanda V: An allelic association implicates myeloperoxidase in the etiology of acute promyelocytic leukemia. Blood 90:2730-2737., 1997

76. Hoy $A$, Tregouet $D$, Leininger-Muller B, Poirier $O$, Maurice M, Sass C, Siest G, Tiret L, Visvikis S: Serum myeloperoxidase concentration in a healthy population: biological variations, familial resemblance and new genetic polymorphisms. Eur J Hum Genet 9:780-786, 2001

77. Reynolds WF, Monnink SH, Tio RA, Sieburg HB, Veeger NJ, van Boven AJ, Cohen Tervaert JW: Gender dependent association of the $-463 \mathrm{G} / \mathrm{A}$ myeloperoxidase polymorphism with impaired vasodilation in $C A D$ patients. In: PhD-Thesis S.H. Monnink

78. Adu D, Rajp A, Savage C: Myeloperoxidase $-463 \mathrm{G} / \mathrm{A}$ polymorphism in ANCA associated vasculitis. Nephrol Dial Transplant 18:347, 2003

79. Reynolds WF, Stegeman CA, Cohen Tervaert JW: $-463 \mathrm{G} / \mathrm{A}$ myeloperoxidase promoter polymorphism is associated with clinical manifestations and the course of disease in MPO-ANCA-associated vasculitis. Clin Immunol 103:154-160, 2002

80. Rothkrantz-Kos S, Drent M, Rutgers A, Heeringa A, De Vries J, van Dieijen-Visser MP. Cohen Tervaert JW: Influence of myeloperoxidase promoter polymorphism on the severity of sarcoidosis? Eur J intern Med accepted, 2003

81. Jansson G: Oestrogen-induced enhancement of myeloperoxidase activity in human polymorphonuclear leukocytes-a possible cause of oxidative stress in inflammatory cells. Free Radic Res Commun $14: 195-208,1991$

82. Kabutomori O, Yanagihara T, Iwatani Y, Kawarazaki A, Kabutomori M: Sex difference in myeloperoxidase activity of neutrophils. Am J Hematol 60:312-313., 1999

83. Bekesi G, Kakucs R, Varbiro S, Feher J, Pazmany T, Magyar Z, Sprintz D, Szekacs B: Induced myeloperoxidase activity and related superoxide inhibition during hormone replacement therapy. Bjog 108:474-481., 2001

84. Neve J, Parij N, Moguilevsky N: Inhibition of the myeloperoxidase chlorinating activity by non-steroidal anti-inflammatory drugs investigated with a human recombinant enzyme. Eur J Pharmaco/ 417:37-43, 2001

85. Kettle AJ, Gedye CA, Winterbourn CC: Superoxide is an antagonist of antiinflammatory drugs that inhibit hypochlorous acid production by myeloperoxidase. Biochem Pharmacol 45:2003-2010, 1993 
CHAPTER 10

\section{Summary, conclusions and general discussion}




\title{
Summary and conclusions
}

\author{
Myeloperoxidase (MPO)
}

Myeloperoxidase is a heme containing peroxidase present in neutrophils and monocytes. It is able to catalyze hypochlorous acid (bleach) from hydrogen peroxide and chloride ions and is therewith an important enzyme in the host defense against bacteria, viruses and fungi ${ }^{1}$. MPO can, however, also damage host tissue by its production of reactive oxidants and can be involved in the oxidative modification of low-density lipoproteins $(L D L)^{2,3}$, the consumption of nitric oxide (NO) $)^{4,5}$, and the activation of proteolytic enzymes ${ }^{6-8}$. MPO and MPO-derived oxidants therefore also play a significant (patho)physiological role in other non-infectious diseases including immune mediated vascular disorders, such as the primary small vessel vasculitides and atherosclerosis.

\section{Vasculitis}

The primary small vessel vasculitides comprise a group of diseases (table 1), separate from the medium and large sized vessel vasculitides. They are characterized by inflammation of the vessel wall of the smallest arteries, veins, and/or capillaries resulting in for instance glomerulonephritis and alveolitis, and also (epi)scleritis, mononeuritis multiplex, purpura and petechiae ${ }^{9}$. In most cases specific auto-antibodies like anti-neutrophil cytoplasmic antibodies (ANCA), anti-glomerular basement membrane (anti-GBM) antibodies, cryoglobulins, or IgA are found. ANCA are specifically associated with Wegener's granulomatosis, microscopic polyangiitis, Churg-Strauss syndrome and idiopathic pauci-immune necrotizing glomerulonephritis. In these diseases, ANCA are mostly directed against either proteinase 3 (PR3) or MPO 10,11. Anti-GBM antibodies are associated with anti-GBM crescentic nephritis, anti-GBM alveolitis, or pulmonary hemorrhage combined with crescentic glomerulonephritis (i.e. Goodpasture disease) ${ }^{12}$. Interestingly, about $30 \%$ of patients with anti-GBM mediated disease are positive for (MPO-)ANCA as well.

\section{Atherosclerosis}

Atherosclerosis is the underlying cause for heart attacks, strokes, and peripheral vascular disease and is the major cause of death in western society. It is a vascular disease involving primarily the large and medium sized vessels ( $>3 \mathrm{~mm}$ external diameter) ${ }^{13}$. Central in one of the major theories trying to explain the pathogenesis of atherosclerosis, the so-called response to injury theory by Ross, is the oxidative modification of LDL and endothelial cell dysfunction ${ }^{14}$.

The first part of this thesis (chapter 2 to 5) has focused on the role of MPO as an antigenic target. In chapter 2 we reviewed the role of ANCA and anti-GBM antibodies in the diagnosis and follow-up of patients with vasculitic disease. ANCA and anti-GBM antibodies have proven to be important specific and sensitive diagnostic markers in vasculitic disease.

In contrast to anti-GBM mediated disease, ANCA-associated vasculitides are chronic diseases with a high relapse rate and since morbidity is dictated by the frequency and severity of these relapses, much health benefit can be achieved when a relapse is detected as early as possible. 
Table 1. The primary small vessel* vasculitides?

\begin{tabular}{|c|c|c|}
\hline Disease & Characteristics & $\begin{array}{l}\text { (Auto-)antibody } \\
\text { associated }\end{array}$ \\
\hline -Henoch-Schönlein purpura & $\begin{array}{l}\text { Vasculitis predominantly of the skin, joints, } \\
\text { gastrointestinal tract, and kidneys. } \\
\text { Mostly occurring in childhood with an average age of } \\
\text { onset of } 4 \text { years. } \\
\text { Characterized by palpabel purpura, colicky abdominal } \\
\text { pain, vomiting, bloody diarrhea, melaena, } \\
\text { macroscopic haematuria, and arthralgias. }\end{array}$ & $\lg A$ \\
\hline $\begin{array}{l}\text {-Mixed essential } \\
\text { cryoglobulinemic vasculitis }\end{array}$ & $\begin{array}{l}\text { Vasculitis secondary to mixed essential } \\
\text { cryoglobulinaemia. Can be a primary disorder, or } \\
\text { associated with haematological malignancies, } \\
\text { infections, and/or autoimmune rheumatic diseases } \\
\text { such as Sjögren's syndrome. In the last decade, a } \\
\text { strong association of mixed essential } \\
\text { cryoglobulinaemia with the presence of hepatitis } C \\
\text { virus infections is recognized. } \\
\text { Characterized by purpura, arthalgias, and nephritis. }\end{array}$ & Cryoglobulins \\
\hline $\begin{array}{l}\text {-Wegener's granulomatosis } \\
(\text { WG })^{*}\end{array}$ & $\begin{array}{l}\text { Granulomatous inflammation involving the respiratory } \\
\text { tract and necrotizing vasculitis affecting small to } \\
\text { medium-sized vessels in other organs. } \\
\text { Characterized by nose bleeds, nephritis, lung } \\
\text { infiltrates, and hemoptysis. }\end{array}$ & ANCA \\
\hline $\begin{array}{l}\text {-Churg-Strauss syndrome } \\
(\mathrm{CSS})^{*}\end{array}$ & $\begin{array}{l}\text { Eosinophil-rich and granulomatous inflammation } \\
\text { involving the respiratory tract and necrotizing } \\
\text { vasculitis affecting small to medium-sized vessels. } \\
\text { Characterized by nephritis, lung infiltrates and } \\
\text { neuropathy. Associated with asthma, and } \\
\text { eosinophilia. }\end{array}$ & ANCA \\
\hline $\begin{array}{l}\text {-Microscopic polyangiitis } \\
\text { (MPA)* }^{*}\end{array}$ & $\begin{array}{l}\text { Necrotizing vasculitis affecting small vessels with } \\
\text { absence of granulomatous inflammation of the } \\
\text { respiratory tract. Pulmonary capillaritis often occurs. } \\
\text { Characterized by nephritis, purpura, and hemoptysis }\end{array}$ & ANCA \\
\hline $\begin{array}{l}\text {-Idiopathic pauci-immune } \\
\text { necrotizingcrescentic } \\
\text { glomerulonephritis (iNCGN) }\end{array}$ & $\begin{array}{l}\text { Crescentic glomerulonephritis, with few or no } \\
\text { immune deposits. Absence of small vessel vasculitis in } \\
\text { other organs. } \\
\text { Characterized by nephritis, and malaise. }\end{array}$ & ANCA \\
\hline $\begin{array}{l}\text {-Goodpasture disease-Isolated } \\
\text { anti-GBM nephritis-Isolated } \\
\text { anti-GBM alveolitis }\end{array}$ & $\begin{array}{l}\text { Crescentic glomerulonephritis and/or alveolitis. } \\
\text { Characterized by hemoptysis, nephritis, and malaise. }\end{array}$ & $\begin{array}{l}\text { Anti-GBM } \\
\text { antibodies (and in } \\
30 \% \text { of cases } \\
\text { ANCA) }\end{array}$ \\
\hline
\end{tabular}

*small vessels include capillaries, venules, or arterioles 
The literature showed that increases in ANCA titers and persistently high ANCA levels indicate a high risk of relapse and warrant clinical evaluation of the patient for signs of relapse.

In chapter 3 we evaluated the use of a rapid ANCA-GBM dot-blot screening assay in terms of sensitivity, specificity, and inter-observer effect for the differential diagnosis of rapidly progressive glomerulonephritis (RPGN). RPGN may be caused by ANCA-associated crescentic glomerulonephritis (CGN), immune-complex induced glomerulonephritis, or anti-GBM CGN and is characterized by rapid and progressive loss of renal function and the presence of CGN. Prompt diagnosis is thus crucial in preventing extensive organ damage or even death. We concluded that the ANCA-GBM dot-blot is a useful screening tool in situations where conventional ANCA testing is not readily available with excellent performance for PR3-ANCA detection, but less optimal sensitivity for MPO-ANCA and specificity for anti-GBM detection.

In chapter 4 we measured the affinity of anti-GBM antibodies of patients with anti-GBM mediated vasculitis for their purified antigenic target within the GBM, i.e. the $\alpha 3$ chain of the non-collageneous part of type IV collagen $[\alpha 3 \mathrm{IV}(\mathrm{NC} 1)]$. We postulated that the binding kinetics of the anti-GBM antibodies contributed to the clinically observed fulminant nature and treatment resistance of this disease. By comparison with other antibody interactions, these anti-GBM antibodies demonstrated high affinity $(4.5 \mathrm{nmol} / \mathrm{L})$, with relatively high on (binding) rates and slow off (dissociation) rates. The results suggested that anti-GBM antibodies bind rapidly and remain tightly bound to the GBM in vivo. This property likely contributes to both the fulminant nature of the disease and its resistance to therapy, because persistent glomerular antibody deposition has the potential to produce continuous inflammation, despite removal of circulating antibodies by plasmapheresis and adequate immunosuppression.

A substantial proportion ( $\pm 30 \%$ ) of patients with anti-GBM antibody mediated CGN are positive for MPO-ANCA as well (i.e. double positive). In Chapter 5 we reviewed the occurrence of double positivity for our Limburg renal biopsy registry and evaluated the influence of the respective auto-antibodies on renal biopsy features. We found double positivity in $43 \%$ of our patients with anti-GBM mediated CGN. In their renal biopsies, double-positive CGN patients showed features of both MPO-ANCA associated CGN and anti-GBM nephritis. Renal and patient survival analysis revealed that, contrary to the literature, double positives had a worse prognosis than anti-GBM antibody positive patients, whereas renal survival in double positives was similar to anti-GBM CGN patients and worse compared to MPO-ANCA positive patients. We postulated that MPO-ANCA positivity predisposes to the development of anti-GBMCGN.

Chapter 6 to 8 focus on functional intra-neutrophil MPO levels in health and disease. MPO levels in neutrophils are influenced by the amount of MPO protein synthesized in the cell as well as by the amount that is released. In Chapter $\mathbf{6}$ we studied the influence of two MPO promoter polymorphisms, MPO463 and MPO129, on the intra-neutrophil MPO activity and protein content in a large group of healthy individuals. We found that the 129GA polymorphism affects the MPO activity in neutrophils, the A allele being associated with lower MPO activity. For the $463 \mathrm{GA}$ polymorphism only a gender dependent difference in MPO activity in older age groups could be observed. 
In Chapter 7 we evaluated the influence of these two polymorphisms on large artery stiffness as measured by pulse wave velocity in a group of hypertensive patients. We hypothesized that an 'increased MPO' genotype results in an increased NO consumption with subsequent increase in pulse wave velocity. For the MPO129 polymorphism we found no differences, possibly due to the low number of heterozygous patients available. However, for the MPO463GG versus GAVAA genotype significant differences were observed in women, but not in men.

Patients with small vessel vasculitis often have evidence of neutrophil activation with release of MPO and recently, plasma levels of circulating MPO have been associated with disease activity $^{15}$. In Chapter $\mathbf{8}$ we investigated the intra-neutrophil MPO activity in a group of patients with small vessel vasculitis in remission compared to healthy controls. We also monitored the intra-neutrophil MPO activity during relapse of these patients. Although hampered due to the limited availability of patients, we observed a trend towards a lower MPO activity in women in remission, but not in men. Sequential measurements revealed that the standard deviation in patients in remission was greater than that of controls. In most patients with a relapse MPO activity decreased.

Finally, in Chapter 9 we reviewed the current knowledge on the role of MPO in the pathogenesis of systemic vasculitis. MPO-ANCA can activate (primed) neutrophils directly causing extensive reactive oxygen species formation and degranulation of neutrophil constituents, including MPO, resulting in an aggravated immune response towards the vessel wall. MPO-ANCA can prevent the clearing and inactivation of MPO by ceruloplasmin as well, resulting in increased myeloperoxidase activity. Active myeloperoxidase may contribute to endothelial dysfunction and add to the chronic renal lesions observed in patients with MPO-ANCA. MPO levels are further influenced by hormonal and genetic factors including the MPO463 and MPO129 promoter polymorphisms. The 463 polymorphism has been associated with an increased risk of development of MPO-ANCA associated disease.

\section{General discussion}

Both vasculitis and atherosclerosis are characterized by an immune mediated vessel directed inflammatory process with an influx of MPO containing myeloid cells, and in both diseases the effects of MPO and its oxidative products are relevant to pathogenesis.

\section{MPO as antigenic target}

For long, no definitive proof was available that auto-immunity to MPO causes the pathogenic effects observed in MPO-ANCA associated vasculitis. The presented evidence was merely circumstantial. MPO-ANCA were found to be closely related to the presence of vasculitic disease. Relapses were often, but not always, associated with a rise in ANCA titer (reviewed in chapter 2). Also, in vitro evidence showed that MPO-ANCA were capable of activating primed neutrophils and promote neutrophil mediated endothelial cell injury (for review ${ }^{16}$ ). Moreover, in rats injection of anti-MPO antibodies to rats with sub-clinical nephritis caused marked disease aggravation, but MPO-ANCA could not by themselves cause disease ${ }^{17}$. However, during the 
completion of this thesis, for the first time direct in vivo pathogenic proof has emerged. With the availability of the MPO knockout mouse it was possible to bypass tolerance and develop a full-blown species specific anti-MPO response in previously healthy animals. Transfer of anti-MPO antibodies to wild-type animals resulted in vasculitic disease similar to that observed in humans ${ }^{18}$.

This animal model creates the opportunity to further decipher the pathogenic events important in the development of disease. Recently, our laboratory has shown that lipopolysaccharide (LPS), a bacterial component capable of priming neutrophils and promoting endothelial cell adhesion molecule expression ${ }^{19}$, aggravates disease ${ }^{20}$. It will be interesting to test new therapeutic agents aimed at reducing disease severity. Agents that can prevent neutrophil activation and degranulation would be interesting candidates. In this respect, the administration of for instance relaxin, a peptide hormone, could result in a new therapy. Relaxin has been shown to inhibit both the LPS-induced adhesion of neutrophils to coronary endothelial cells as well as the activation of neutrophils by a NO mediated mechanism 21,22 .

\section{MPO levels}

MPO levels in neutrophils are influenced by the amount of MPO protein synthesized in the cell as well as by the amount that is released. Increased MPO levels can promote MPO-mediated pathogenic processes, it has for instance been demonstrated that coronary atherosclerosis is associated with an increased neutrophil MPO content ${ }^{23}$. Also, mice genetically modified to over-express human MPO in their monocytes displayed increased atherosclerosis compared to wild type mice 24 .

As we demonstrated (chapter 6), two MPO promoter polymorphisms influence intra-neutrophil MPO activity. Both polymorphisms have been linked to an increased risk for atherosclerosis and/or vasculitic disease $25-30$. However, for the MPO463 polymorphism data are often difficult to interpret since effects of this polymorphism on neutrophil MPO levels depend on age and gender. Moreover, both polymorphisms explain only a limited proportion of the observed variation in intra-neutrophil MPO activity, when measured in healthy individuals. Since MPO activity in these individuals was stable over time, other (un)identified (genetic) factors determine intra-neutrophil MPO contents as well, like gender (chapter 6). We found that intra-neutrophil MPO levels are higher in women than in men, whereas Hoy et al found the contrary in plasma MPO levels ${ }^{31}$. This apparent contradiction can be explained by the fact that in vitro studies have shown that estrogens can inhibit MPO degranulation and as such may result in higher intracellular MPO activity and lower MPO plasma levels in women than men ${ }^{32}$. Moreover, a clinical study has shown that the administration of estrogens to males prior to an elective coronary artery bypass operation lowers MPO release shortly after surgery $^{33}$.

In addition to genetic factors, intra-neutrophil MPO levels are also influenced by neutrophil age. Young neutrophils or band forms, recruited from the bone marrow contain more MPO than senescent neutrophils ${ }^{34}$. This suggests that neutrophils release or degrade MPO while ageing. 
Finally, intra-neutrophil MPO content reflects neutrophil activation as well. Buffon et al showed that neutrophils, while passing through an atherosclerotic vasculature, were partially depleted of their MPO content ${ }^{35}$.

Thus, intra-cellular MPO levels have been useful for evaluating the effect of two promoter polymorphisms, but in disease intra-neutrophil MPO leveis not only reflect genetic differences, but also neutrophil recruitment and activation. When using MPO as a biomarker for neutrophil activation, it may be interesting to measure MPO serum levels since MPO serum levels originate mostly from neutrophil MPO. Recent data support the use of serum MPO as a biomarker of neutrophil activation. It has been shown that levels of circulating MPO correlate with disease activity in patients with Wegener's granulomatosis ${ }^{15}$. Also in atherosclerosis MPO levels have been associated with disease activity ${ }^{23,36}$. Baldus et al showed that, in patients with acute coronary syndromes, MPO serum levels could help predict the chance of death and myocardial infarction during 6 months of follow-up. Importantly, MPO serum level was a risk factor independent from previously established risk factors such as C-reactive protein, vascular endothelial growth factor, soluble CD40 ligand and troponin T. Patients with an elevated MPO serum level (above $350 \mathrm{ug} / \mathrm{l}$ ) had twice the risk at death or non-fatal myocardial infarction at 6 months after inclusion ${ }^{36}$. These results were confirmed by Brennan et $a^{37}$.

However, MPO is more than an indicator of a neutrophil mediated inflammatory response, MPO itself is an active participant of pathogenic processes in various diseases. Clinically, it will be interesting to evaluate the effect of reducing MPO activity on disease severity and outcome.

\section{Reducing MPO activity}

Theoretically, there are several ways to reduce MPO activity. One could reduce the amount of bio-available MPO by reducing the amount of neutrophils and monocytes. This can be accomplished by removal of circulating neutrophils or by decreasing the production of neutrophils. Case reports have shown that the removal of circulating neutrophils might be of benefit in patients with MPO-ANCA associated vasculitis ${ }^{38}$. The inhibition of neutrophil production (with for instance cyclophosphamide) is part of the standard treatment of MPO-ANCA associated vasculitis. The main disadvantages of these therapies are the numerous side-effects, which reduces long term applicability and the clinical usage in atherosclerotic disease.

Another way to reduce MPO activity is by preventing neutrophil degranulation. Since degranulation is preceded by neutrophil priming and activation, agents preventing these events also prevent MPO release. Examples include general anti-inflammatory agents (e.g. steroids), TNF $\alpha$ inhibitors (etanercept, infliximab), estrogens, and other cytokine mediating agents. Steroids are routinely and successfully used to treat MPO-ANCA associated vasculitis, but not atherosclerotic disease. The use of TNFoinhibitors is experimental, but they may be additionally effective in ANCA associated vasculitis disease 39 . Strikingly, they may also help to reduce endothelial dysfunction in patients with ANCA associated vasculitis, thus linking anti-vasculitic therapy to anti-atherosclerotic therapy ${ }^{40}$. Interestingly, a small clinical study has shown that the administration of estrogens to males prior to an elective coronary artery 
bypass operation lowers MPO release shortly after surgery 33 , indicating that estrogens inhibit MPO release as well.

A totally different approach to reduce MPO activity is to decrease MPO expression at a gene level. Oligonucleotide based therapies (e.g. small interfering RNAs and anti-sense oligonucleotides) aimed at specifically inhibiting MPO production are exciting potential therapeutic options ${ }^{41}$. Also, recently Reynolds et al have demonstrated that peroxisome proliferator-activated receptor- $\alpha$ gamma (PPAR- $\alpha$ ) agonists (e.g. thiazolinediones clinically used as antidiabetic agents) strongly regulate MPO gene expression likely due to interference with the MPO promoter at the site of the MPO463 promoter polymorphism ${ }^{42}$. In this study in vitro gene expression was either strongly upregulated or downregulated depending on GMor M-CSF co-incubation. In vivo studies should be performed to clarify the effect on MPO expression in disease.

Finally, MPO activity can be reduced by inhibitors of MPO. The most potent inhibitor of MPO is 4-aminobenzoic acid hydrazide 43 . It binds to the enzyme and irreversibly inactivates MPO. However, relative high concentrations of hydrogen peroxide are necessary to initiate this process, this likely limits the usefuiness in vivo. A more specific and potent inhibitor is desirable to investigate the involvement of myeloperoxidase in inflammatory processes ${ }^{1}$. Methimazole, already clinically used to inhibit thyroid peroxidase in thyroid disease, also inhibits MPO. Commonly described 'side effects' include agranulocytosis. These side effects appear to be dose-related ${ }^{44}$. Unfortunately, no information is available about the in vivo concentrations necessary to inhibit MPO functions.

In conclusion, MPO is an important marker of and active participant in vasculitis and atherosclerotic disease. Measuring MPO in both diseases will be useful in establishing disease risk. MPO levels can identify and determine disease severity and disease activity during patient follow-up. In the future, it will be interesting to evaluate the use of MPO inhibiting agents as part of the treatment of both atherosclerosis and ANCA associated vasculitis.

Treatment of vasculitic disease consists of rapid intervention with heavy drugs, suppressing the acute inflammatory reactions. Treatment of atherosclerotic disease, however, is mostly directed towards chronic management of disease. Since many pathologic events overlap, therapeutic interventions used in atherosclerosis are potentially useful in vasculitic disease, and vice versa.

\section{References}

1. Winterbourn CC, Vissers MC, Kettle AJ: Myeloperoxidase. Curr Opin Hematol 7:53-58., 2000

2. Zhang R, Brennan ML, Shen Z, MacPherson JC, Schmitt D, Molenda CE, Hazen SL: Myeloperoxidase functions as a major enzymatic catalyst for initiation of lipid peroxidation at sites of inflammation. $J$ Biol Chem 277:46116-46122, 2002

3. Podrez EA, Schmitt D, Hoff HF, Hazen SL: Myeloperoxidase-generated reactive nitrogen species convert LDL into an atherogenic form in vitro. J Clin invest 103:1547-1560, 1999 
4. Eiserich JP, Baldus S, Brennan ML, MaW, Zhang C, Tousson A, Castro L, Lusis AJ, Nauseef WM, White CR, Freeman BA: Myeloperoxidase, a leukocyte-derived vascular NO oxidase. Science 296:2391-2394, 2002

5. Abu-Soud HM. Hazen SL: Nitric oxide is a physiological substrate for mammalian peroxidases. $J$ Biol Chem 275:37524-37532, 2000

6. Reeves EP, Lu H, Jacobs HL, Messina CG, Bolsover S, Gabella G, Potma EO, Warley A, Roes J, Segal AW: Killing activity of neutrophils is mediated through activation of proteases by K+ flux. Nature 416:291-297, 2002

7. Roos D, Winterbourn CC: IMMUNOLOGY: Enhanced: Lethal Weapons. Science 296:669-671, 2002

8. Matheson NR, Wong PS, Travis J: Enzymatic inactivation of human alpha-1-proteinase inhibitor by neutrophil myeloperoxidase. Biochem Biophys Res Commun 88:402-409, 1979

9. Jennette JC, Falk RJ, Andrassy K, Bacon PA, Churg J, Gross WL, Hagen EC, Hoffman GS, Hunder GG, Kallenberg CG, et al: Nomenclature of systemic vasculitides. Proposal of an international consensus conference. Arthritis Rheum 37:187-192, 1994

10. Jennette JC, Falk RJ: Small-vessel vasculitis. N Engi J Med 337:1512-1523, 1997

11. Cohen Tervaert IW, Limburg PC, Elema JD, Huitema MG, Horst G, The TH, Kallenberg CG: Detection of autoantibodies against myeloid lysosomal enzymes: a useful adjunct to classification of patients with biopsy-proven necrotizing arteritis. Am J Med 91:59-66, 1991

12. Lerner RA, Glassock RJ, Dixon FJ: The role of anti-glomerular basement membrane antibody in the pathogenesis of human glomerulonephritis. J Exp Med 126:989-1004, 1967

13. Naoumova RP, Scott J: The pathogenesis of atherosclerosis, in Oxford textbook of medicine (vol 2), edited by Warell DA, Cox TM. Firth JD, Benz Jr EJ, 4 ed, Oxford university press, 2003

14. Ross R: The pathogenesis of atherosclerosis: a perspective for the 1990s. Nature 362:801-809, 1993

15. Gota C, Hazen S, Brennan ML, Hoffman GS: Association between plasma myeloperoxidase leveis and disease activity in Wegeners granulomatosis, in 11 th international Vasculitis and ANCA Workshop, Prague, 2003

16. Hess C, Sadallah S, Schifferli JA: Induction of neutrophil responsiveness to myeloperoxidase antibodies by their exposure to supernatant of degranulated autologous neutrophils. Blood 96:2822-2827, 2000

17. Heeringa P, BrouwerE, Klok PA. Huitema MG, van den Born J, Weening JJ, Kallenberg CG: Autoantibodies to myeloperoxidase aggravate mild anti-glomerular-basement-membrane-mediated glomerular injury in the rat. Am J Pathol 149:1695-1706, 1996

18. Xiao H. Heeringa P, Hu P, Liu Z, Zhao M, Aratani Y, Maeda N, Falk RJ, Jennette JC: Antineutrophil cytoplasmic autoantibodies specific for myeloperoxidase cause glomerulonephritis and vasculitis in mice. $J$ Clin Invest 110:955-963, 2002

19. Bachschmid $M$. Thurau S, Zou MH, Ullrich $V$ : Endothelial cell activation by endotoxin involves superoxide/NO-mediated nitration of prostacyclin synthase and thromboxane receptor stimulation. Faseb J17:914-916, 2003

20. Huugen D, Xiao H, Esch Van A, Peutz-Kootstra CJ, Jennette JC, Cohen Tervaert JW, Heeringa P: Lipopolysacharide augments anti-myeloperoxidase antibody induced glomerulonephritis in mice. abstract ANCA workshop 2003, 2003

21. Masini E, Nistri S, Vannacci A, Bani Sacchi T, Novelli A, Bani D: Relaxin inhibits the activation of human neutrophils: involvement of the nitric oxide pathway. Endocrinology 145:1106-1112, 2004

22. Nistri S. Chiappini L, Sassoli C, Bani D: Relaxin inhibits lipopolysaccharide-induced adhesion of neutrophils to coronary endothelial cells by a nitric oxide-mediated mechanism. Faseb J 17:2109-2111, 2003

23. Zhang R, Brennan ML, Fu X, Aviles RJ, Pearce GL, Penn MS, Topol EJ, Sprecher DL, Hazen SL: Association between myeloperoxidase levels and risk of coronary artery disease. JAMA 286:2136-2142, 2001

24. McMillen TS, Heinecke JW, LeBoeuf RC: Abstract: Accelerated atherosclerosis in myeloperoxidase transgenic mice. 4th Conference on Arteriosclerosis, Thrombosis and Vascular Biology, 2003

25. Reynolds WF, Stegeman CA, Cohen Tervaert JW: -463 G/A Myeloperoxidase Promoter Polymorphism Is Associated with Clinical Manifestations and the Course of Disease in MPO-ANCA-Associated Vasculitis. Clin Immun 103:154-160, 2002

26. Hoy A, Leininger-Muller B, Poirier O, Siest G, Gautier M, Elbaz A, Amarenco P, Visvikis S: Myeloperoxidase polymorphisms in brain infarction. Association with infarct size and functional outcome. Atherosclerosis $167: 223-230,2003$

27. Makela R, Dastidar P, Jokela H, Saarela M, Punnonen R, Lehtimaki T: Effect of long-term hormone replacement therapy on atherosclerosis progression in postmenopausal women relates to myeloperoxidase promoter polymorphism. J Clin Endocrinol Metab 88:3823-3828, 2003 
28. Makela R, Karhunen PJ, Kunnas TA, IlveskoskiE, Kajander OA, Mikkelsson J, Perola M, Penttila A, Lehtimaki $T$ : Myeloperoxidase gene variation as a determinant of atherosclerosis progression in the abdominal and thoracic aorta: an autopsy study. Lab Invest 83:919-925, 2003

29. Nikpoor B, Turecki G, Fournier C. Theroux P, Rouleau GA: A functional myeloperoxidase polymorphic variant is associated with coronary artery disease in French-Canadians. Am Heart/142:336-339., 2001

30. Pecoits-Filho R, Stenvinkel P, Marchlewska A, Heimburger O, Barany P, Hoff CM, Holmes CJ, Suliman M, Lindholm B, Schalling M, Nordfors L: A functional variant of the myeloperoxidase gene is associated with cardiovascular disease in end-stage renal disease patients. Kidney Int Suppl:172-176, 2003

31. Hoy $A$, Tregouet $D$, Leininger-Muller $B$, Poirier $O$, Maurice $M$, Sass $C$, Siest $G$, Tiret $L$, Visvikis $S$ : Serum myeloperoxidase concentration in a healthy population: biological variations, familial resemblance and new genetic polymorphisms. Eur I Hum Genet 9:780-786, 2001

32. Buyon JP, Korchak HM, Rutherford LE, Ganguly M, Weissmann G: Female hormones reduce neutrophil responsiveness in vitro. Arthritis Rheum 27:623-630, 1984

33. Wei M, Kuukasjarvi P, Kaukinen S, Laurikka J, Pehkonen E, Laine S, Moilanen E, Metsanoja R, Tarkka M: Anti-inflammatory effects of 17 beta-estradiol pretreatment in men after coronary artery surgery. $J$ Cardiothorac Vase Anesth 15:455-459, 2001

34. Borregaard N, Theilgaard-Monch K, Sorensen OE, Cowland JB: Regulation of human neutrophil granule protein expression. Curr Opin Hemato/ 8:23-27, 2001

35. Buffon A, Biasucci $L M$, Liuzzo G, D'Onofrio G. Crea F, Maseri A: Widespread coronary inflammation in unstable angina. N Engl / Med 347:5-12, 2002

36. Baldus $S$, Heeschen C, Meinertz T, Zeiher AM, Eiserich JP, Munzel T, Simoons ML, Hamm CW: Myeloperoxidase serum levels predict risk in patients with acute coronary syndromes. Circulation 108:1440-1445, 2003

37. Brennan ML, Penn MS, Van Lente F, Nambi V, Shishehbor MH, Aviles RJ, Goormastic M, Pepoy ML, McErlean ES, Topol EJ, Nissen SE, Hazen SL: Prognostic value of myeloperoxidase in patients with chest pain. N Eng/ J Med 349:1595-1604, 2003

38. Hasegawa M, Kawamura N, Kasugai M, Koide S, Murase M, Asano S, Toba T, Kushimoto H, Murakami K, Tomita M, Shikano M, Sugiyama S: Cytapheresis for the treatment of myeloperoxidase antineutrophil cytoplasmic antibody-associated vasculitis: report of five cases. Ther Apher 6:443-449, 2002

39. Booth A, Harper L, Hammad T, Bacon P, Griffith M, Levy J, Savage C, Pusey C, Jayne D: Prospective study of TNFalpha blockade with infliximab in anti-neutrophil cytoplasmic antibody-associated systemic vasculitis. J Am Soc Nephrol 15:717-721, 2004

40. Booth AD, Jayne DR, Kharbanda RK, MCEniery CM, Mackenzie IS, Brown J, Wilkinson IB: Infliximab Improves Endothelial Dysfunction in Systemic Vasculitis. A Model of Vascular Inflammation. Circulation, 2004

41. Milhavet O, Gary DS, Mattson MP: RNA interference in biology and medicine. Pharmaco/ Rev 55:629-648, 2003

42. Kumar AP, Piedrafita FJ, Reynolds WF: Peroxisome proliferator-activated receptor gamma ligands regulate myeloperoxidase expression in macrophages by an estrogen-dependent mechanism involving the $-463 \mathrm{GA}$ promoter polymorphism. J Biol Chem 279:8300-8315, 2004

43. Kettle AJ, Gedye CA, Hampton MB, Winterbourn CC: Inhibition of myeloperoxidase by benzoic acid hydrazides. Biochem / 308 ( Pt 2):559-563, 1995

44. Wiberg JJ, Nuttall FQ: Methimazole toxicity from high doses. Ann Intern Med 77:414-416, 1972 


\section{Nederlandse samenvatting}

\section{Myeloperoxidase}

Myeloperoxidase (MPO) is een enzym aanwezig in twee soorten witte bloedcellen, de neutrofielen en monocyten. MPO kan bleekwater genereren uit waterstofperoxide en chloride ionen. Hiermee is het een belangrijk enzym in de verdediging van het menselijk lichaam tegen bacteriën, virussen en schimmels. De door MPO gemaakte stoffen zijn echter zeer reactief en beschadigen soms ook het lichaam zelf. Zo kan MPO bijvoorbeeld het LDL cholesterol oxideren, stikstof monoxide verbruiken en proteolytische enzymen activeren.

Deze eigenschappen maakt dat MPO niet alleen belangrijk is bij de afweer tegen infecties, maar ook een belangrijke pathofysiologische rol speelt in immuungemedieerde vaataandoeningen, zoals de vasculitiden en arteriosclerose.

\section{Vasculitiden}

Vasculitis is een ontstekingsproces van bloedvaten resulterend in beschadiging en uiteindelijk destructie en afsluiting van deze vaten. Een vasculitis kan secundair aan een andere ziekte zijn (bijvoorbeeld reumatoïde artritis), maar komt ook primair voor. De verschillende vormen van primaire vasculitis worden meestal onderverdeeld in de grote, middelgrote en kleine vaten vasculitiden. De kleine vaten vasculitiden zijn een groep van ziektes gekenmerkt door ontsteking van de kleinste arteriën, venen en/of capillairen. Dit kan resulteren in bijvoorbeeld ontsteking van de nieren, longen, zenuwen, ogen, huid of andere organen. In de meeste gevallen van kleine vaten vasculitis worden in het bloed van de patiënt specifieke antistoffen zoals anti-neutrofiel cytoplasmatische antistoffen (ANCA), anti-glomerulaire basaal membraan antistoffen (anti-GBM), koude antistoffen, of IgA antistoffen gevonden.

ANCA zijn geassocieerd met de ziekte van Wegener, microscopische polyangiitis, het syndroom van Churg-Strauss en idiopathische pauci-immuun necrotizerende glomerulonefritis. In deze ziekten blijken ANCA meestal gericht te zijn tegen proteïnase 3 of MPO.

Anti-GBM antistoffen zijn geassocieerd met anti-GBM crescentische nefritis, anti-GBM alveolitis, of longbloedingen met crescentische glomerulonefritis (oftewel, de ziekte van Goodpasture). Interessant is dat er in ongeveer $30 \%$ van de patiënten met een anti-GBM gemedieerde ziekte ook antistoffen tegen MPO gevonden worden. 


\section{Arteriosclerose}

Arteriosclerose is de onderliggende oorzaak voor hartaanvallen, herseninfarcten en perifere vaatziekten (bijvoorbeeld etalagebenen). Arteriosclerose is doodsoorzaak nummer 1 in de westerse samenleving. Het is een vaataandoening van met name de middelgrote en grote vaten ( $>3 \mathrm{~mm}$ in diameter). De op dit moment belangrijkste theorie die het ontstaan van arteriosclerose probeert te verklaren is de 'response to injury' theorie van Ross. Centraal in deze theorie is de continue beschadiging van de vaatwand door bijvoorbeeld roken, suikerziekte of hoge bloeddruk, het disfunctioneren van de vaatwandbekleding ('endothelial cell dysfunction') en de oxidatieve veranderingen van cholesterol partikels. MPO kan in deze processen een belangrijke rol spelen.

Het eerste gedeelte van dit proefschrift (hoofdstuk 2 tot 5) richt zich op de rol van MPO als antigeen voor ANCA. In hoofdstuk 2 beschouwen we de rol van ANCA en anti-GBM antistoffen in de diagnose en 'follow-up' van patiënten met vasculitis. ANCA en anti-GBM antistoffen zijn specifieke en sensitieve hulpmiddelen in diagnostiek naar vasculitiden. De literatuur laat zien dat een stijging in ANCA titer en persisterend verhoogde ANCA titers een vergroot risico op een recidief met zich meebrengt.

In hoofdstuk 3 hebben we de ANCA-GBM dot-blot test geëvalueerd wat betreft sensitiviteit, specificiteit en inter-waarnemer effect in de differentiaal diagnose van snel progressieve glomerulonefritis. Deze snel progressieve glomerulonefritis kan worden veroorzaakt door een ANCA-, immuuncomplex-, of anti-GBM gemedieerde ziekte. Onze conclusie was dat de ANCA-GBM dot-blot een bruikbare screeningsmethode is voor de detectie van deze antilichamen. Dit met name in situaties waar conventionele ANCA en anti-GBM testen niet beschikbaar zijn.

In hoofdstuk 4 hebben we de bindingssterkte (affiniteit) tussen anti-GBM antilichamen en de specifieke bindingsplaats voor deze antilichamen op de GBM bepaald. De binding was van een zeer hoge affiniteit, met snelle associatie en langzame dissociatie ratio's. Deze resultaten suggereren dat anti-GBM antilichamen snel en stevig binden aan de GBM in vivo. Deze eigenschappen dragen bij aan het ernstige en moeilijk te behandelen beloop van deze ziekte.

Een belangrijk deel $( \pm 30 \%)$ van patiënten met anti-GBM antistof gemedieerde glomerulonefritis hebben ook MPO antistoffen in het bloed, dat wil zeggen zijn dubbel positief. In hoofdstuk 5 hebben we gekeken naar het voorkomen van deze dubbel positiviteit in het regionale nierbiopten archief van Zuid-Limburg. Ook hebben we gekeken naar het effect van de verschillende auto-antistoffen op de nierbiopt karakteristieken. Wij vonden dat in Zuid-Limburg 43\% van de patiënten met anti-GBM antistoffen ook positief waren voor anti-MPO antistoffen. Dubbel positieve patiënten hadden een slechtere overleving vergeleken met enkel positieve patiënten. De 'overleving' van de nier was in beide groepen echter gelijk. We postuleerden dat anti-MPO antistoffen predisponeren voor het ontwikkelen van anti-GBM gemedieerde glomerulonefritis. 
Hoofdstuk 6 tot en met 8 gaan over de intra-neutrofiel MPO activiteit in zowel gezonde personen als in patiënten. De MPO hoeveetheid per neutrofiel wordt bepaald door de productie, afbraak en uitscheiding van MPO.

In hoofdstuk 6 bestudeerden we het effect van twee MPO promotor polymorfismen, MPO463 en MPO129, op de intra-neutrofiel MPO activiteit in een grote groep gezonde proefpersonen. We vonden dat in proefpersonen met het MPO129GA genotype de MPO activiteit significant lager was vergeleken met de MPO129GG genotypes. Voor het MPO463 polymorfisme vonden we leeftijd en geslachtsafhankelijke effecten. Dit maakt het noodzakelijk om in vergelijkende studies geslacht en leeftijd als variabelen mee te nemen.

In hoofdstuk 7 hebben we gekeken naar het effect van deze twee polymorfismes op de stijfheid van de grotere arteriën, gemeten middels de 'pulse wave velocity' in een groep van hypertensieve patiënten. Onze hypothese was dat een hoog MPO-gehalte genotype leidt tot een verhoogde stikstofmonoxide consumptie, resulterend in een stijver vaatbed. Voor het MPO129 polymorfisme vonden we geen verschillen, mogelijk als gevolg van het lage aantal beschikbare heterozygote patiënten. Voor het MPO464 polymorfisme daarentegen vonden we significante verschillen in vrouwen, maar niet in mannen.

In patiënten met een kleine vaten vasculitis wordt vaak bewijs gevonden van neutrofiel activatie met daarmee vrijkomen van MPO. In hoofdstuk 8 beschrijven we de intra-neutrofiel MPO activiteit in een groep van patiënten met een kleine vaten vasculitis, zowel tijdens actieve ziekte als gedurende remissie. Ondanks de relatief kleine groep van patiënten, vonden we een trend voor een lagere MPO activiteit in vrouwen met een vasculitis in remissie vergeleken met leeftijd en geslacht gematchte controles. Dit gold niet voor mannen. Opeenvolgende metingen lieten zien dat in vasculitis patiënten de activiteit vaak wisselde, dit in tegenstelling tot gezonde controles. In de meeste patiënten met een recidief van de ziekte, daalde de intracellulaire MPO activiteit.

Als laatste hebben we in hoofdstuk 9 de hedendaagse kennis over de rol van MPO in de pathogenese van systeemvasculitis uiteengezet. MPO-ANCA kunnen neutrofielen activeren en laten degranuleren. Hierdoor ontstaat uitgebreide reactieve zuurstof metaboliet formatie en worden actieve enzymen vrijgemaakt, dit leidt tot een versterkte immuunreactie tegen de vaatwand. MPO-ANCA kunnen het verwijderen en inactiveren van MPO door ceruloplasmine tegengaan, wat een verhoogde MPO activiveit veroorzaakt. Actief MPO kan bijdragen aan endotheel dysfunctie en aan de chronische nierafwijkingen van patiënten met MPO-ANCA glomerulonefritis. Verder worden MPO spiegels beïnvloed door hormonale en genetische factoren, zoals het MPO463 en MPO129 promotor polymorfisme. Het MPO463 polymorfisme is geassocieerd met een verhoogd risico op het ontwikkelen van MPO-ANCA geassocieerde ziekte.

Samenvattend speelt MPO een belangrijke rol in vasculitis en arteriosclerose, zowel als maat voor ziekteactiviteit, als onderdeel van het pathogenetisch proces. In de toekomst is het interessant om MPO remmende medicamenten uit te testen als onderdeel van de therapie bij 
zowel arteriosclerose als vasculitis. De behandeling van vasculitis bestaat uit de snelle en agressieve immuun modulerende therapie. In arteriosclerose daarentegen, is de meeste therapie gericht op het chronisch management van het ziekteproces. Omdat een gedeelte van de immuunreactie in vasculitis en arteriosclerose overlapt, kan het zeer zinvol zijn om de therapie van deze twee ziekten uit te wisselen. 


\section{DANKWOORD}

Als laatste mijn dankwoord. Opeens is het dan klaar. Weg het continue gevoel van 'nog eventjes aan mijn proefschrift werken'. Misschien ga ik het nog wel missen ook. Achteraf had ik dingen graag anders gedaan, maar achteraf is makkelijk praten. Al met al is mijn promotietijd omgevlogen en kijk ik terug met een gevoel van voldoening en trots op een prettige en leerzame periode.

Bij deze wil ik iedereen, maar een aantal mensen in het bijzonder, bedanken die heeft bijgedragen aan het tot stand komen van mijn proefschrift. Allereerst alle proefpersonen en patiënten die bloed en tijd hebben afgestaan voor dit onderzoek, zonder hen was, is en zal er geen onderzoek mogelijk zijn.

Jan Willem, mijn promotor, ik wil je hartelijk danken voor de enthousiaste en altijd positieve begeleiding. Mijn enigszins calvinistische aard kan dit soms wel gebruiken. Peter, mijn co-promotor, ook jou wil ik hartelijk danken voor de samenwerking van de afgelopen jaren. Met Jan Willem zorgde je voor een goede balans in de begeleiding en je kon soms Jan Willem's enthousiasme omvormen tot een 'haalbare kaart'. Ik hoop dat ik je mening over medici in het lab een beetje heb kunnen nuanceren! Mijn collega onderzoekers, Marjan (Sm), Marjan (SI), Silvie, Ellen, Ariane en last but not least Dennis, ik wil jullie bedanken voor de gezellige tijd en collegiale sfeer.

Zonder analytische steun was ik niet ver gekomen. Joyce ik wil je hartelijk danken voor je inzet en ijver, zonder jou hadden we de beginstudies zeker niet kunnen uitvoeren. Maar met alleen Joyce ben ik er niet. Hulp kwam ervan allerlei kanten. Van Inge en Maartje, van het lab van de algemene immunologie (niet te verwarren met de speciële immunologie en zeker niet met het universitaire lab immunologie) was er altijd Mia om bloed te prikken en dankzij Jos en de anderen kon ik altijd terecht voor bepalingen en vriezerruimte. Bedankt voor het dulden van de ADVIA! Vanuit de speciële immunologie kreeg ik les in de eiwitelectroferese van de altijd te bescheiden Ruud. Bedankt voor je geduld en bereidheid om te helpen. Ik wens je veel succes met je eigen promotieonderzoek! Lucienne, niet alleen bedankt voor de celkweken en andere labondersteuning, maar vooral ook voor de georganiseerde etentjes, wijntjes en achtergrondinformatie omtrent menigeen. Henk, naast de biopten zorgde je altijd voor voldoende geld. Op de een of andere manier was er toch altijd wel genoeg, ook al was het budget al tijden op. Heeft het te maken met je zeeuwse wortels? Met de huidige AZM bezuinigingen weet ik niet of je het nog steeds klaarspeelt. Ik hoop dat je samen met Petra nog lang de zuid-limburgse ziekenhuizen af zult reizen op zoek naar nog meer crescentische glomeruli. Heinz Jacobs, een echte hard-core onderzoeker, wars van bureaucratie en regelzucht, ik wil je danken voor je uitleg en kennis van de moleculaire technieken. Samen met Kim bouwden we 
een mooi promotor construct. Eerst met licht van de vuurvlieg, maar zelfs het licht van de sea pansy mocht niet baten. Ons promotor construct heeft nooit licht gegeven, maar het was leuk om te maken. Peter Heijmans bedankt voor de verlevendiging van de discussies. Ad bedankt voor je lange discussies en voor het aannemen van Marieke als stagestudente. Jan bedankt voor je oprechte en duidelijke mening en natuurlijk voor de uitleg over FACS en menig lab-test.

Met Anita heb ik niet veel praktisch werk gedaan, ik denk wel dat je samen met Dennis het MPO diermodel tot een mooi onderzoeksresultaat zal gaan brengen! Maria en José, ik heb weinig laboratoriumonderzoek met jullie mogen verrichten, maar ik wil jullie bedanken voor jullie positieve aanwezigheid op de achtergrond.

Pieter, ik wil je hartelijk danken voor de morele ondersteuning op het werk en de gezellige tijd in Berlijn. Je bent voor mij een voorbeeld hoe je als clinicus ook kunt functioneren (en soms hoe ook niet). En je weet het, je hebt mijn mobiele nummer in geval van computer nood! Professor van Breda Vriesman ik wil u bedanken voor uw bevlogen verhalen en fantastisch medisch en maatschappelijk (in)zicht. De volgende verkiezingen zullen leren of u mijn stemgedrag heeft beïnvloed. Chris ik wil je graag bedanken voor je collegialiteit en ik wil je veel succes wensen met het opzetten van de allergologie in Maastricht.

Verder wil ik de dames van het secretariaat (Francy, Petra, Anita en Desiree) hartelijk danken voor jullie (meestal) vrolijke aanwezigheid, koffie en hulp.

Tevens wil ik de leescommissieleden prof.dr. K.M.L. Leunissen, prof.dr. M.J.A.P. Daemen, prof.dr. C.Kallenberg, dr. N. Moguilevsky en prof.dr. E.F.M. Wouters hartelijk danken voor het doorlezen van mijn manuscript, maar bovenal voor het unaniem goedkeuren hiervan. Nicole, thanks for the lab experience with the CHO cells in Brussels. I also like to thank Mike Madaio and Kevin Meyers for giving me the opportunity to develop my laboratory skills and for a wonderful time in 'Philly' (USA).

Coen van Rooijen en Jan van de Boogaart wil ik bedanken voor het ter beschikking stelling van de ADVIA 120. De Friedrich Wegener stichting en dan met name Elisabeth Venselaar en Geert ter Weeme wil ik bedanken voor de veelvuldige steun die ik van hen heb mogen ontvangen

Ik wil mijn huidige collega's in Sittard danken voor de gezellige en stimulerende werksfeer. Ook de 'bazen' aldaar, ik wil jullie bedanken voor de beginselen van de interne geneeskunde, maar ook voor een openhartig kijkje binnen het functioneren van een maatschap met type $A$, $B$, maar ook $A+$ en $B+$ persoonlijkheden. Met name bedankt voor de steun met betrekking tot mijn wens om de resterende opleiding in Groningen af te maken.

Liffert, ik bedank je voor de veelal nachtelijke discussies over wetenschap en gelukkig ook andere zaken. Robert, paranymf, ik wil je bedanken voor de veelal meta-wetenschappelijke discussies. Mogelijk krijg ik nu tijd om je in je Gombrowicziaanse manie te volgen. Met jou Dennis, paranymf, deel ik het MPO project en geregeld een biertje. Je zal de komende jaren 
moeten zorgen voor verdere ontdekkingen aan de pathogenese van de MPO-ANCA gemedieerde ziekten!

En als laatste Marieke, het belangrijkste wat het maken van dit proefschrift me heeft gebracht. Drie maanden mocht ik wennen aan het laboratorium, jij had je stage onderbroken voor een buitenlands co-schap en vakantie, maar toen was je er toch. Reeds vanaf het eerste moment wist jij dat ik wat voor je was, niet veel later had je mij daar ook van overtuigd. Nog 6 weken, dan zijn we 4 jaar bij elkaar! Bedankt voor je onverminderde steun, aanwezigheid en stimulans tot werken en soms ook niet (en zoals altijd heb je natuurlijk gelijk) LB. 



\section{Curriculum vitae}

Bram (Abraham) Rutgers is geboren in Nijverdal op 29 augustus 1975. Reeds na 1 jaar besloten zijn ouders zich te settelen in Groningen. Eerst in de wijk Lewenborg, waar zijn vader nog altijd huisarts is, later naar het buitengelegen Garmerwolde. Na de voltooiing van de eerste twee jaar op het Willem Lodewijk Gymnasium, besloot hij dat een talenknobbel niet een van de overgeërfde kwaliteiten was en vervolgde het VWO op het Wessel Gansfoort College te Groningen. De studie geneeskunde leek de enige logische studiekeuze en in 1993 kon hieraan in Groningen worden begonnen. Zijn wetenschappelijke carrière begon met een stage van een jaar bij het laboratorium van professor M.P. Madaio en doctor K.E.C. Meyers aan de University of Pennsylvania (Upenn) in Philadelphia, VS. Daar leerde hij de beginselen van het laboratoriumonderzoek en publiceerde hij zijn eerste artikel. Na de co-schappen wilde hij zich graag in de wetenschappelijke kant van de geneeskunde verder ontwikkelen. Prof.dr. J.W. Cohen Tervaert had hem vanuit Nederland ondersteund in Philadelphia en zag mogelijkheden voor een promotieonderzoek in Maastricht. Tijdens zijn promotieonderzoek is hij bestuurslid geweest van het Platform AIO's in de Nefrologie (PLAN), een junior commissie van de Nederlandse Federatie voor Nefrologie. In aansluiting op zijn promotieonderzoek is hij in oktober 2003 gestart met de opleiding interne geneeskunde in de regio Maastricht. Per oktober 2004 zal hij deze opleiding in de regio Groningen vervolgen. 



\title{
Lijst met publicaties
}

\author{
Publicaties
}

2004 ANCA-GBM Dot-Blot: Evaluation of an Assay in the Differential Diagnosis of Patients Presenting with Rapidly Progressive Glomerulonephritis. Rutgers A, Damoiseaux JG, Roozendaal C, Limburg PC, Stegeman CA, Cohen Tervaert JW. J Clin Immunol in press (July 2004 issue)

2003 The role of myeloperoxidase in the pathogenesis of systemic vasculitis. Rutgers A, Heeringa P, Tervaert JW. Clin Exp Rheumatol. 2003 Nov-Dec;21 (6 Supp/32):555-63

2003 Neutrophil myeloperoxidase activity and the influence of two single nucleotide promoter polymorphisms. Rutgers A, Heeringa $\mathrm{P}$, Giesen JE, Theunissen RT, Jacobs $H$, Cohen Tervaert JW. Br J Haematol 2003 Nov; 123(3):536-8

2003 Peripheral blood myeloperoxidase activity increases during hemodialysis. Rutgers A, Heeringa $P$, Kooman JP, van der Sande FM, Cohen Tervaert, JW. Kidney Int 2003; $64(2) ; 760$, letter

2003 Relationship between myeloperoxidase promotor polymorphism and disease severity in sarcoidosis. Rothkrantz-Kos S, Drent M, Rutgers A, et al. Eur J intern Med. 2003 Aug: 14(5):296-301

2003 ANCA and anti-GBM antibodies in diagnosis and follow-up of vasculitic disease. Rutgers A, Heeringa P, Damoiseaux JG, Cohen Tervaert JW. Eur J Intern Med 2003; 2003 Aug; 14(5):287-295

2003 Imaging in systemic vasculitides. Rutgers A, van der Werf TS, Boeve WJ, Kallenberg CGM, Cohen Tervaert JW. In: Isenberg D, Renton P, eds. Imaging in Rheumatology: Oxford university press 2003

2001 Hoe groot is de kans op een vasculitis bij een normale BSE en CRP? Rutgers A, Cohen Tervaert JW. Internisten Vademecum nr 20, 27 december 2001.

2000 High affinity of anti-GBM antibodies from Goodpasture and transplanted Alport patients to alpha3(IV)NC1 collagen. Rutgers A, Meyers KE, Canziani G, Kalluri R, Lin J, Madaio MP. Kidney Int 2000; 58:115-22.

1999 Selection of specific phage from display libraries: monoclonal antibody against VCS M13 helper phage coat protein III (gIllp). Lin J, Yanase K, Rutgers A, Madaio MP, Meyers KE. Hybridoma 1999; 18:257-61.

\section{Abstracts}

2003 Coexistence of anti-GBM antibodies in MPO-ANCA crescentic glomerulonephritis. Rutgers A, van Paassen P. Slot MC, et al. JASN 14: 279A-279A Suppl. S NOV 2003. ASN, San Diego

2003 Polymorphisms formyeloperoxidase and glutathione S-transferase and gender related COPD risk. Dentener $M$, Rutgers $A$, Heeringa $P$, van Schooten FJ, Maas $L$, Cohen Tervaert JW, Wouters EF. ERS, Vienna 
2003 ANCA-GBM Dot-Blot: Evaluation of a Screening Assay for the Early Diagnosis of Rapidly Progressive Glomerulonephritis. Damoiseaux J, Rutgers A, Roozendaal C. Limburg PC, Stegeman CA, Cohen Tervaert JW., ISN, Berlin (NDT 2003; 18 (S4):347)

2002 Peripheral blood myeloperoxidase activity increases during hemodialysis. Rutgers A, Heeringa A, Kooman JP, van der Sander FM, Cohen Tervaert JW. Nederlandse Nefrologiedagen, Noordwijkerhout

2001 Myeloperoxidase activity differences between men and women and mouse and rat strains: relation with disease susceptibility? Rutgers A, Heeringa A, Giesen J, Damoiseaux J, Cohen Tervaert JW. NVVI, Noordwijkerhout

1998 High affinity of anti-GBM antibodies from Goodpasture and transplanted Alport patients to alpha3(IV)NC1 collagen. Rutgers A, Meyers KE, Kalluri R, Madaio MP, ASN, Philadelphia 